Portland State University

PDXScholar

Summer 8-27-2013

\title{
The Retention Puzzle Reconsidered: Second Year Student Attitudes and Experiences with Advising
}

Michael Edward Walsh

Portland State University

Follow this and additional works at: https://pdxscholar.library.pdx.edu/open_access_etds

Part of the Educational Leadership Commons, Higher Education Commons, and the Student Counseling and Personnel Services Commons

Let us know how access to this document benefits you.

\section{Recommended Citation}

Walsh, Michael Edward, "The Retention Puzzle Reconsidered: Second Year Student Attitudes and Experiences with Advising" (2013). Dissertations and Theses. Paper 993.

https://doi.org/10.15760/etd.993

This Dissertation is brought to you for free and open access. It has been accepted for inclusion in Dissertations and Theses by an authorized administrator of PDXScholar. Please contact us if we can make this document more accessible: pdxscholar@pdx.edu. 
The Retention Puzzle Reconsidered: Second Year Student Attitudes and Experiences with Advising

by

Michael Edward Walsh

A dissertation submitted in partial fulfillment of the requirements for the degree of

Doctor of Education in

Educational Leadership: Postsecondary Education

\author{
Dissertation Committee: \\ Janine Allen, Chair \\ Tom Chenoweth \\ Moti Hara \\ Yves Labissiere
}

Portland State University

2013 
(C) 2013 Michael Edward Walsh 
Abstract

College student retention has been described as a puzzle because retention rates have stagnated, and in some cases declined, despite over seventy years of research into the problem. The magnitude of the problem is that 50 percent of college students will leave their institution before obtaining a degree (Braxton, Hirschy, \& McClendon, 2011). In an effort to improve retention rates, colleges and universities have concentrated their attention on first year students. But this concentrated strategy may have simply transferred the retention problem into the second year where retention rates for many schools are as low as first year rates (Amaury, Barlow, \& Crisp, 2005). While advising practices have been identified as one of the three top contributors to increasing retention, major gaps exist about the role academic advising might play in the retention of second year students.

The present correlational study was undertaken to fill gaps in the mostly conceptual second year literature base which implies second year students differ from first year and upper division students. Advising formed the focus of the study because advising has been identified as one of the most important methods for putting students into a mentoring relationship with college staff and faculty, a practice with strong ties to retention (Habley \&McClanahan, 2004; Kuh, 2008). Six research questions were posed in the study which asked whether second year students differed from first year and upper division students and whether retained second year students differed from not retained second year students in their attitudes toward and experiences with advising. 
Using simultaneous and logistic regression models, and controlling for confounding variables, statistically significant differences were found between second year students and their first year and upper division peers as well as between retained second year students and not retained second year students.

The findings of difference between second year and other students provide the growing second year retention literature with an empirical basis to support previously held assumptions about difference between class years which had also formed the basis for presumptions about practice for second year success and retention. Many of the findings in this study also support present retention and second year research and prescriptions for practice provided by that research. 


\section{Dedication}

I dedicate this dissertation to my mother and father who taught me through their example to steadfastly pursue creativity, knowledge, and understanding.

Doctrina urbi serviat 


\section{Acknowledgments}

It takes a village to raise a child and to complete a dissertation. My village consisted of many patient, bright, and hopeful people, some of whom I would like to acknowledge here. First, Dr. Janine Allen, the hardest working advisor I know, shepherded me with great patience throughout this entire process, shaking her head all the time at my persistent anthropomorphisms (studies do not "pose" questions, you pose questions!), plural pronouns for singular subjects, and of course my dreaded and consistent lapse into that voice which is passive (into that passive voice!). Thank you for your wisdom, your immense knowledge on the topic, and for your care for the product and the producer.

I am also very grateful to my dissertation committee, the members of which provided patient guidance and wisdom. Their involvement and interest in my education and professional development paved the way for me to consider my study in novel ways that led to a much more refined and valuable finished product.

Dr. John Goldrick, my supervisor in my professional work for ten years, supported my desire to pursue this doctorate while I also served full time for him as his Director of Residence Life. Without his personal and professional support, I would not have been able to start doctoral studies, much less complete them. Thank you John for helping me to see through the mist enough to realize I could do it.

For many years my children had no idea what I was doing. As they have grown up in the last six years, they have come to understand their father is a student, just like 
them; but my papers are a lot longer. They have had to grow up with a father who often spent weekends and late nights in what we call "The Green Study Cave" meaning less time for fun and games with them. Thank you, Bryn and Elinor, for playing your part in my completing this dissertation.

My wife knew what was going on and courageously supported the family and me nonetheless. I would never be where I am without you, Jenny, thank you.

And finally, I believe we humans participate in something greater than ourselves in all that we do. I am grateful to be participating. 
TABLE OF CONTENTS

PAGE

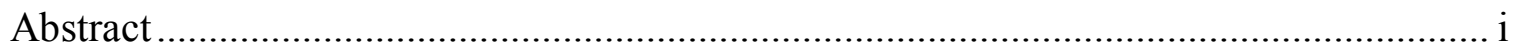

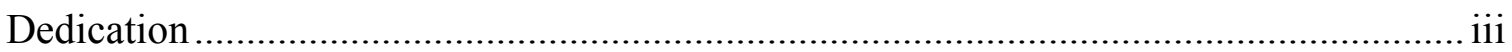

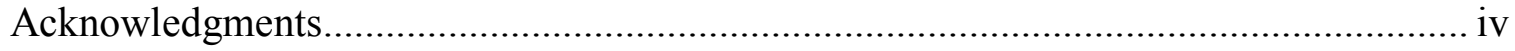

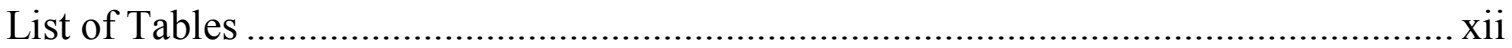

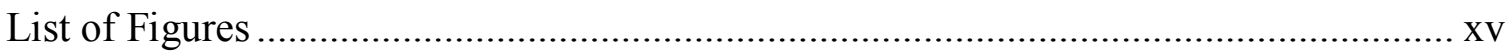

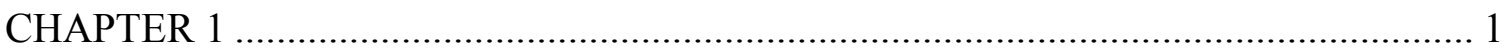

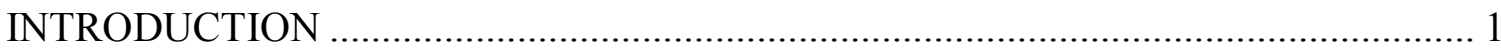

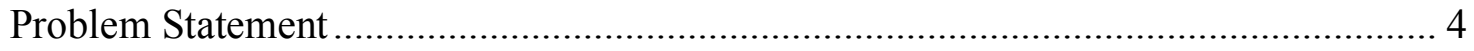

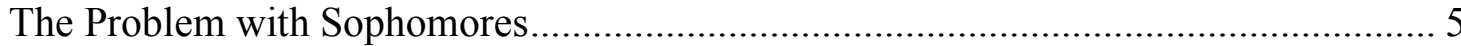

Developmental Framework for Understanding the Second Year .............................. 9

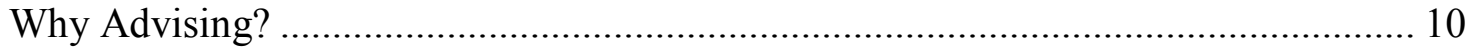

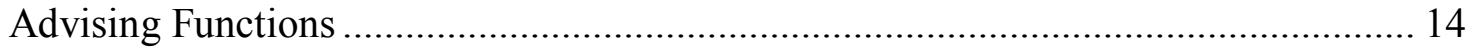

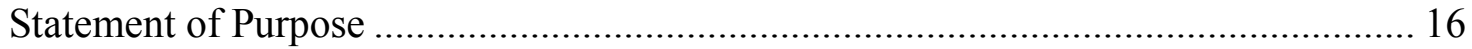

Significance of the Research................................................................................ 16

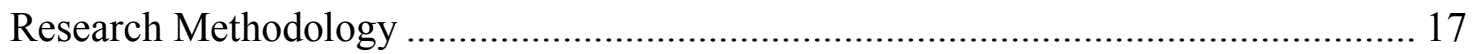

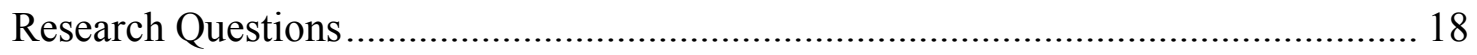

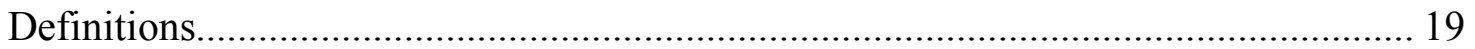

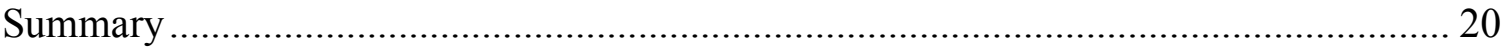




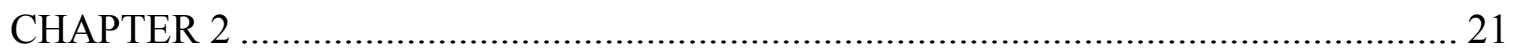

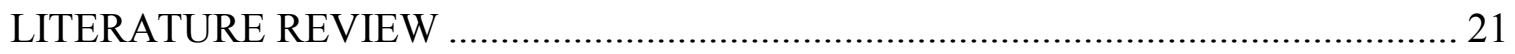

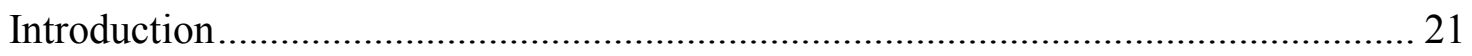

A Metaphor for the College Journey ......................................................................... 21

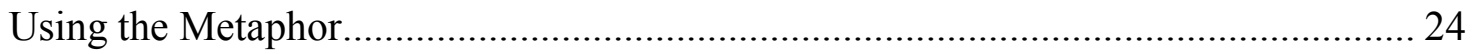

The Longitudinal Nature of College Student Retention ........................................... 25

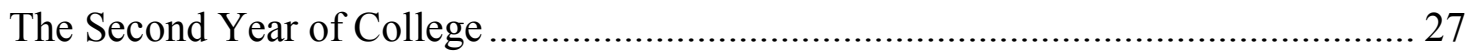

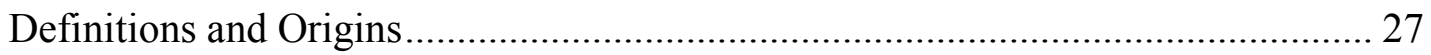

History of the Second Year and Current State of the Research ................................ 28

Contemporary Understanding of the Second Year ....................................................... 32

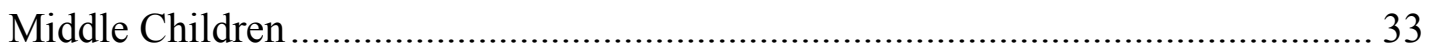

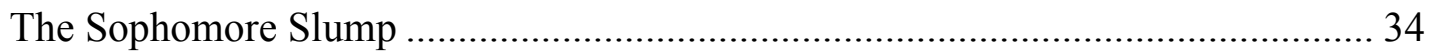

Sophomore Year as a Transition............................................................................. 36

Developmental Literature Regarding the Second Year of College ............................... 39

King and Kitchener's Reflective Judgment Model................................................. 41

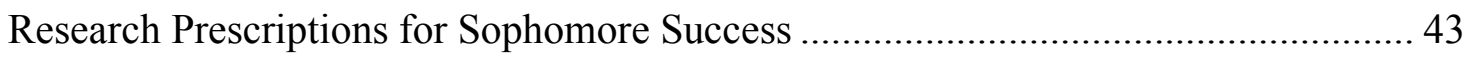

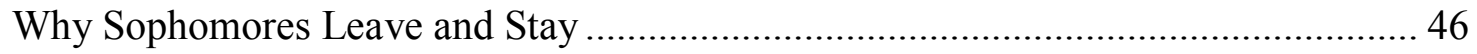

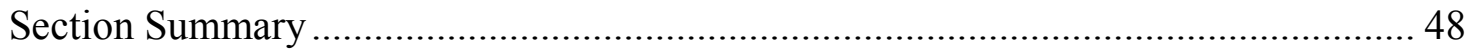

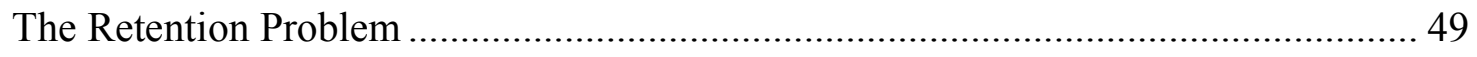


Retention and Attrition Statistics .................................................................... 49

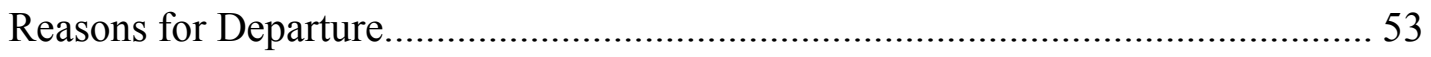

The Role of Advising Towards Retention for the Second Year Student ..................... 54

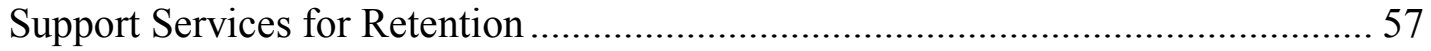

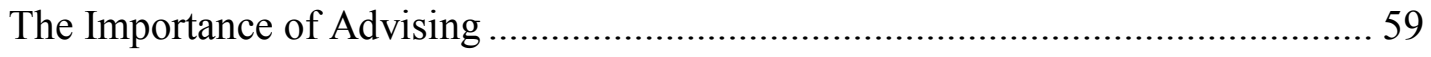

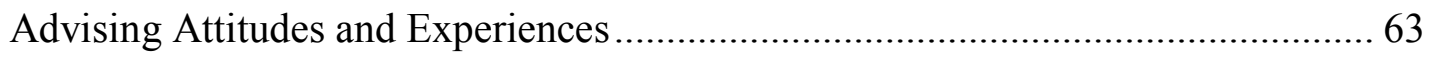

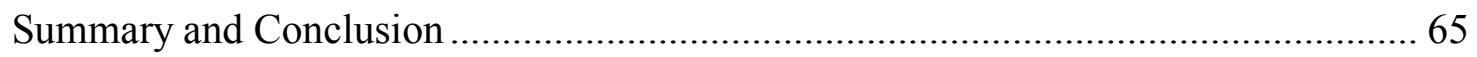

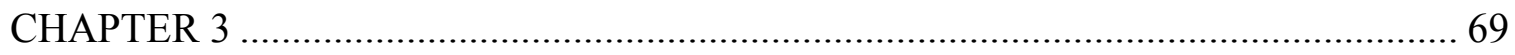

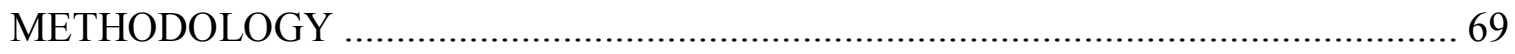

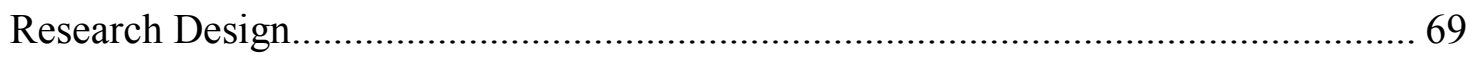

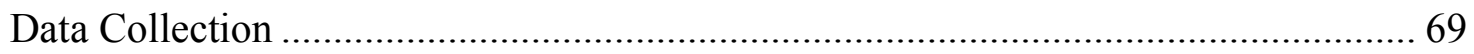

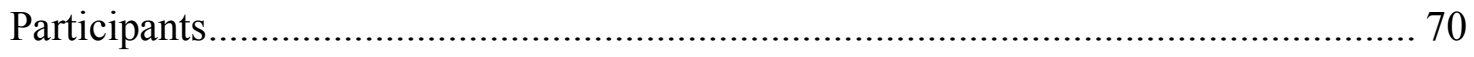

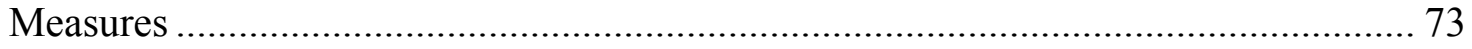

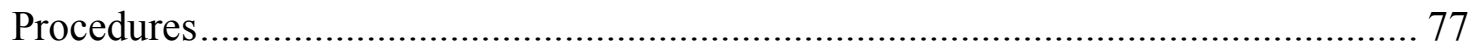

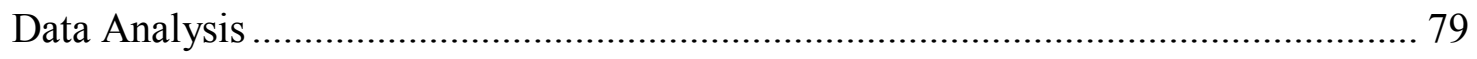

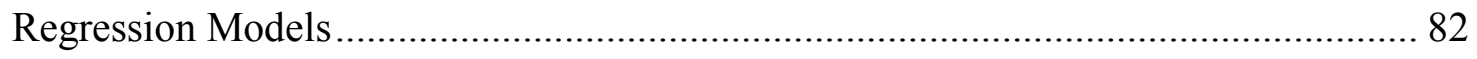

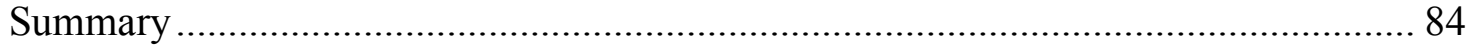

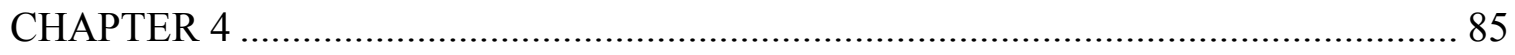

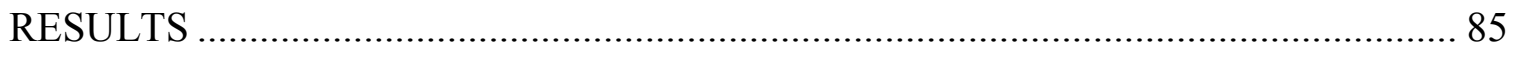


Differences between Second Year Students and First Year Students and Upper

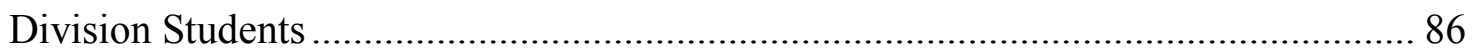

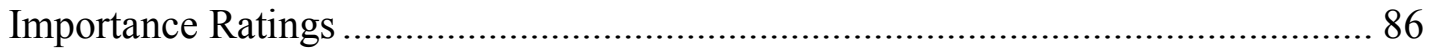

Satisfaction Ratings ................................................................................. 90

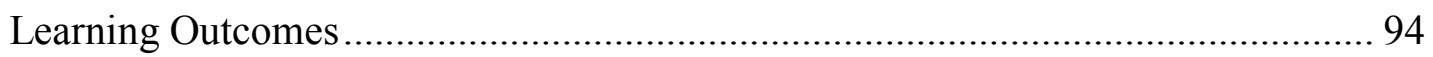

Differences between Retained Second Year Students and Not Retained Second Year

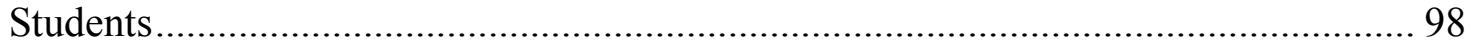

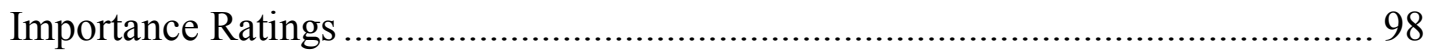

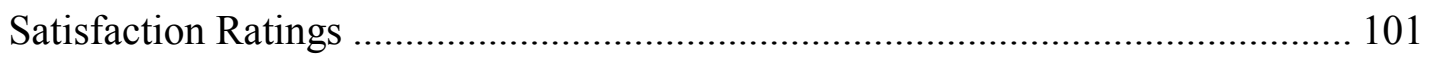

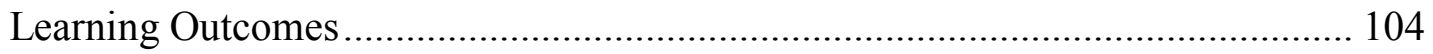

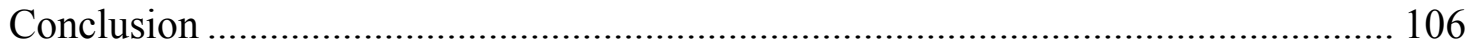

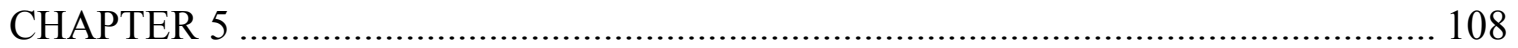

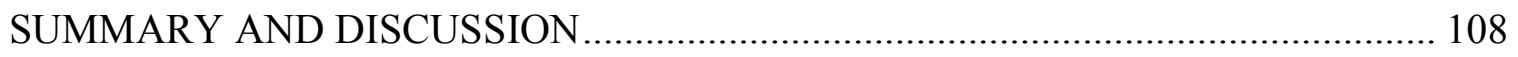

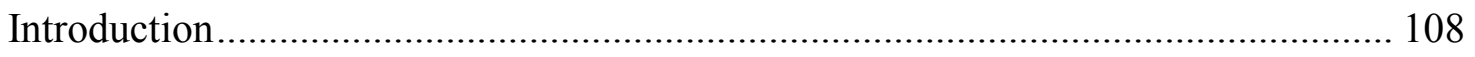

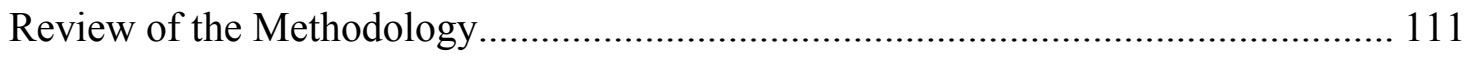

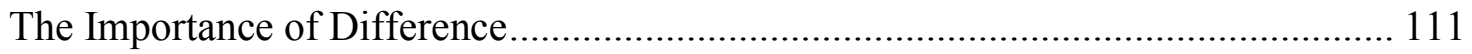

Differences Exist between Second Year and First Year and Upper Division Students

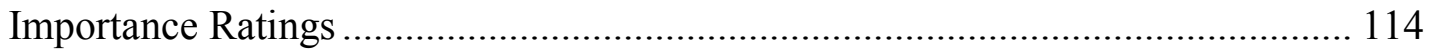

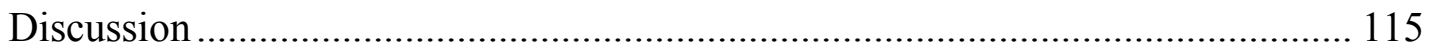




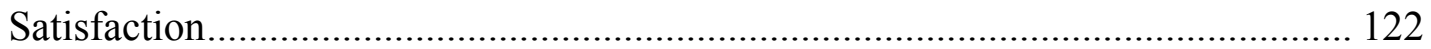

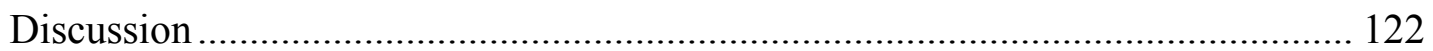

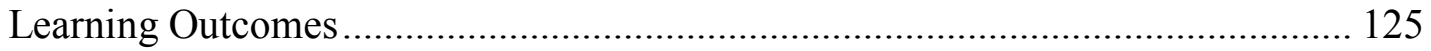

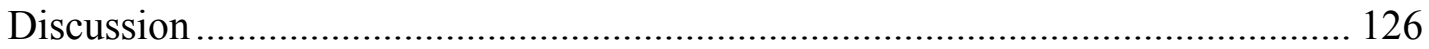

Differences Exist between Retained and Not Retained Second Year Students .......... 127

Importance Ratings and Discussion.............................................................. 128

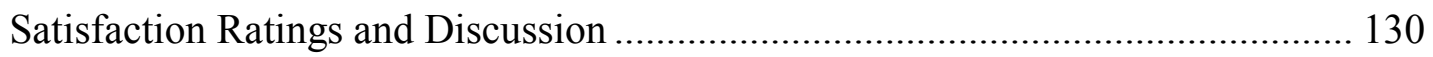

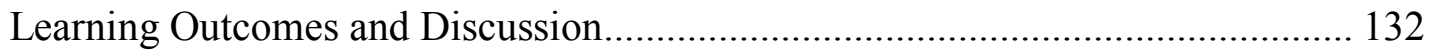

Relationship of the Current Study to Previous Research...................................... 134

The Longitudinal Nature of Retention ........................................................ 134

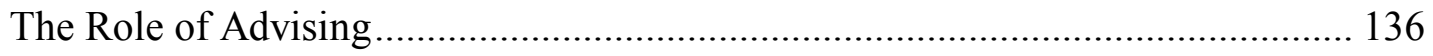

Prescriptive or Developmental Advising .................................................... 137

Schaller's Stages of Second Year Development................................................ 138

Second Year Specific Learning Outcomes ...................................................... 138

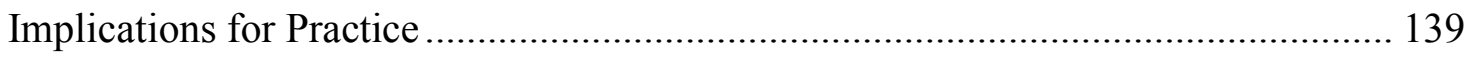

Advising Learning Outcomes for Second Year Students .................................. 140

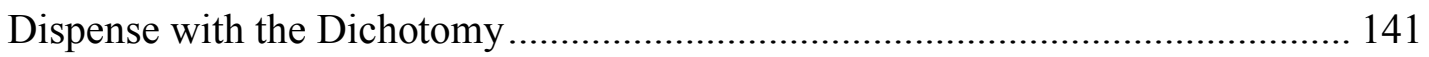

Consider a Dual Advisor Structure .................................................................. 142

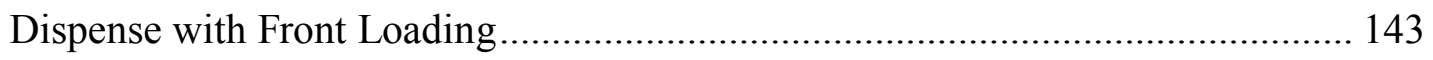




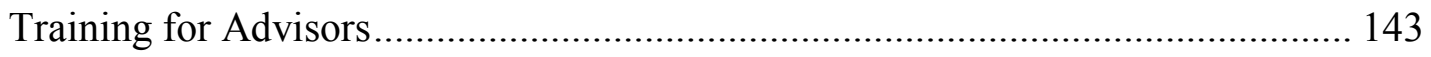

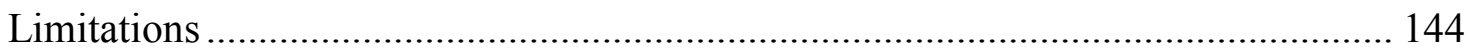

Suggestions for Additional Research........................................................ 145

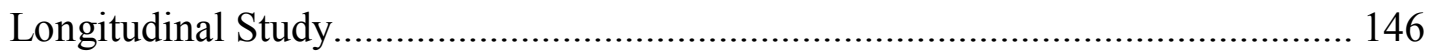

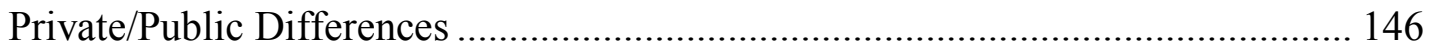

Identify At-Risk Second Year Students ........................................................ 147

Differences within the Second Year ................................................................. 147

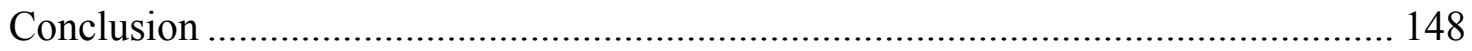

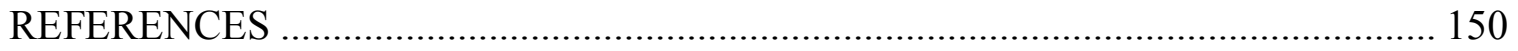

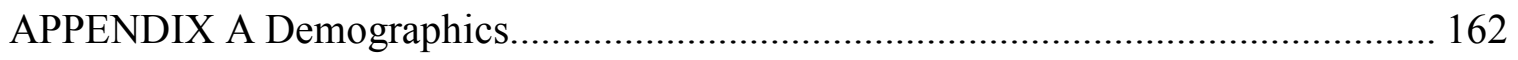

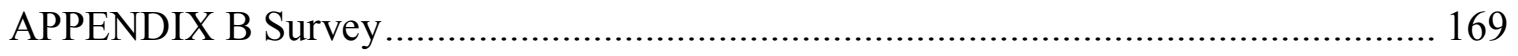

APPENDIX C Sample Student Invitation Email ................................................... 192

APPENDIX D Summary of Significant Results for Each Research Question............... 194 
List of Tables

Table 1 Carnegie Classification and Fulltime Equivalent (fte) Enrollment of

Study Institutions, Number of Participants from each Study

Institution............................................ 71

Table 2 Comparison of Sample Demographics with Population

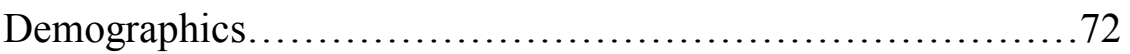

Table 3 Academic Advising Functions and Survey Items.................75

Table $4 \quad$ Academic Learning Outcomes...................................... 77

Table 5 Numbers, Means, and Standard Deviations of Importance Ratings

of First Year, Second Year, and Upper Division Students and

Summary of Results of Simultaneous Regression Analyses

Comparing Importance Ratings of Second Year Students with First Year Students and Upper Division

Students.............................................87

Table 6 Significant Results of Regression Analyses Comparing Importance Ratings of Second Year Students with those of First Year Students and Upper Division

Students............................................... 88

Table 7 Numbers, Means and Standard Deviations of Satisfaction Ratings

of First Year, Second Year, and Upper Division Students and

Summary of Results of Simultaneous Regression Analyses

Comparing Satisfaction Ratings of Second Year Students with 
First Year Students and Upper Division Students................91

Table 8 Significant Results of Regression Analyses Comparing Satisfaction Ratings of Second Year Students with those of First Year Students and Upper Division Students.............................92

Table 9 Numbers, Means and Standard Deviations of Satisfaction Ratings of First Year, Second Year, and Upper Division Students and Summary of Results of Simultaneous Regression Analyses Comparing Learning Outcome Ratings of Second Year Students with First Year Students and Upper Division Students..........96

Table 10 Significant Results of Regression Analyses Comparing Learning Outcome Ratings of Second Year Students with those of First Year Students and Upper Division Students........................97

Table 11 Results of Logistic Regressions with Results for n, Means, Standard Deviations, and Significance of Importance Ratings of Retained and Not Retained Second Year Students and Comparison of Both Groups .99

Table 12 Summary of Significant Values for Importance Ratings. 100

Table 13 Model Tests for Variables with Significant Values for Importance Ratings Comparing Retained Second Year Students with Not Retained Second Year Students 100

Table 14 Results of Logistic Regressions with Results for n, Means, Standard Deviations, and Significance of Satisfaction Ratings of 
Retained and Not Retained Second Year Students and Comparison of Both

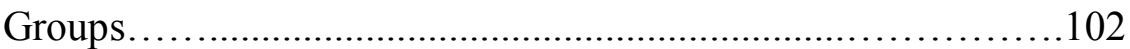

Table 15 Summary of Significant Values for Satisfaction Ratings...........103

Table16 Model Tests for Variables with Significant Values for Satisfaction

Ratings................................................. 103

Table 17 Results of Logistic Regressions with Results for n, Means, Standard Deviations, and Significance of Learning Outcomes of Retained and Not Retained Second Year Students and Comparison of Both Groups...........................................105

Table 18 Summary of Significant Values for Learning Outcomes.........105

Table 19 Model Tests for Variables with Significant Values for Learning Outcomes..................................................106 


\section{List of Figures}

\section{Figure 1 Dummy Coded}

Variables............................................84 


\section{CHAPTER 1 \\ INTRODUCTION}

Low and stagnant retention rates continue to plague U.S. institutions of higher education presenting a lingering problem that affects students, institutions, and society as a whole (ACT, 2009; Braxton \& Lee, 2005; Seidman, 2005; Tinto \& Pusser, 2006). The magnitude of this retention problem is that at least half of all college students will leave college at some point in their careers despite a growing college student population (Braxton et al., 2011). The problem is further complicated by the fact that universities continue to tackle retention problems with interventions that have not changed much in 30 years and which focus on students as they enter the university and when they leave the university (Amaury et al., 2005; Schaller \& Tetley, in press; Seidman, 2005).

This student departure puzzle (Braxton et al., 2011) can have a significant negative effect on a person's ability to achieve a higher standard of living, greater health and life expectancy, and a better life for his or her children (Institute for Higher Education Policy, 1998). Low graduation rates in higher education present significant problems for our democratic and technologically based society as well. More college educated citizens help a society through higher tax revenues from higher incomes and allow for an enlightened electorate to support a stable democracy (Baum, Ma, \& Payea, 2010; Tinto, 1993). Conversely, low graduation rates consume immense institutional and individual resources with no return on those resources for society and families, while additionally failing to meet societal accountability expectations (Pullins, 2011). 
Institutions of higher education benefit from high retention rates as well. Tuitiondependent institutions, for instance, cannot afford to lose students whom they otherwise could keep. It costs too much to recruit students to let them slip away; indeed, the tuition money from even a few students can mean the difference between keeping an important program or retaining a quality faculty member (Schuh, 2005; Siegel, 2011). Schuh (2005) lists numerous other costs to universities associated with low retention. For example, institutional financial aid is a form of investment that universities lose when a student drops out. Other direct costs include the loss of residence hall fees and payments made to universities from auxiliary programs, such as dining services and book store sales, based on student population. Additionally, many schools rely on retention data to increase their standing among competitor schools in ranking systems such as those offered by U.S. News and World Report. Still other universities that reach out to disadvantaged and historically underrepresented students look to retention as vital to their mission to provide a higher education to those whose families have not historically had that opportunity.

Despite the importance of higher education retention to society, schools, and students, universities remain mired in a retention rut such that research and efforts to increase retention over the last 30 years have yielded no changes in retention rates and even decreases in retention for certain disadvantaged and at-risk groups (Tinto \& Pusser, 2006). Though the scholarly work of the last three decades has produced a great deal of research related to retention, the problem still remains intractable. Despite this scholarship and our knowledge of the significance of the retention problem in American 
higher education, there is little agreement among the various theoretical perspectives to help retention specialists and faculty increase retention rates (Seidman, 2005).

As the retention problem persists and too many students do not, much fingerpointing occurs. Some, such as Adrianna Kezar (2004), define the problem as a moral one in which the responsibility for low retention lies with institutions who fail to reduce harm by using ineffective retention strategies or not trying new strategies. Others point to the self-efficacy, attitudes, and enthusiasm of the individual students as the source of the problem (Dewitz, Woolsey, \& Walsh, 2009). According to this point of view, students simply need to be more engaged, seek out faculty who can help them, and take control of their own educational destiny.

While scholars may not agree on who is to blame for student departure, practitioners have managed to find some agreement on interventions across the United States by attacking the retention problem mostly with a focus on programs directed at the student's first year of college when attrition is highest (Amaury et al., 2005; Seidman, 2005). This focus on the first year, known as "front-loading," produced results for many colleges beginning in the early 80 s and through the 90 s (Seidman, 2005). But this concentrated first year strategy may have simply moved the retention problem into the second year (Amaury et al., 2005). And so, despite a focus on the first year that brought early results, universities are now stuck in a rut, doing the same things over and over and expecting retention to improve. In the middle of these academic arguments though, lies the dogged persistence of the persistence problem and an answer that probably consists of wisdom that reaches outside of familiar and narrowly tailored practices to include 
interventions informed by a longitudinal understanding of the retention problem (Tinto, 1988, 1993).

This reconsideration should include interventions specific to the second year of college, which is the second most at-risk year for attrition with rates sometimes equaling those of the first year (Flanagan, 1991; Ho Yu, DiGangi, Jannash-Pennell, \& Kaprolet, 2010; Pattengale, 2000). In other words, practitioners and educational researchers may need to reconsider 1) how to address the retention problem in higher education by learning more about what students need for success beyond their first year in college, 2) how those success needs differ for second year students compared to first year and upper division students, and 3) how to construct student success programs, for instance through advising programs, for students in their second year of college based on data about how those students differ from students at other developmental points on the college journey.

\section{Problem Statement}

For over three decades, professionals in higher education have mostly overlooked the longitudinal nature of college student persistence to graduation by front-loading retention efforts into the first year, thereby contributing to stagnating or dropping retention rates. This situation suggests institutions need to apply interventions through the second year of college in order to break out of the retention rut in which the same percentage of students drop out today as did thirty years ago. Because academic advising is often touted as important to student retention (Habley et al., 2004), interventions that strengthen advising for second year students might well be a key to breaking out of the 
retention rut. Tailoring advising encounters according to student circumstances has long been considered good practice in academic advising (Smith \& Allen, 2008); thus it is important that interventions to strengthen advising be informed by knowledge about second year students and how their needs and experiences differ from first year students and upper division students. However, the second year of college remains largely unexamined by educational researchers leaving practitioners few theoretical or empirical foundations upon which to base their interventions.

\section{The Problem with Sophomores}

To understand why the second year of college has been mostly left out of the retention research, it is important to consider that the second year of college has been referred to as the "middle child" year of college (Gahagan \& Hunter, 2006). We pay special attention to the oldest "children" (juniors and seniors) while we take special care of the "newborns" (the freshmen). Meanwhile we leave the "middle children" (sophomores or second years) to fend for themselves without the special support and nurturing they came to expect as the once "youngest child." With the "middle-child" metaphor in mind, researchers and practitioners have understandably failed to notice the second year student as needing a different kind of attention. This lack of attention to the middle child of higher education in the transition from second year to junior year can be costly, however, if the lack of attention brings on difficulties great enough to lead to high losses of second year students - losses which often approach those of the first year (Flanagan, 1991; Ho Yu et al., 2010; Pattengale, 2000). 
General research into the second year experience has been a relatively recent development with a group of unrelated studies occurring in the 1990s (Boivin, Beuthin, \& Hauger, 1993; Flanagan, 1991) and two important and related works (Schreiner \& Pattengale, Eds., 2000; Tobolowski \& Cox, Eds., 2007). Dissertation research has picked up only very recently with a few dissertations indentified since 2009 (Harris, 2012; Kawczynski, 2009; Pullins, 2011). Overall, though, major gaps exist in the literature relative to the second year (Ho Yu et al., 2010). Simply stated, the second year as a special transitional population has not been considered in retention research until very recently with researchers such as Ho Yu, DiGangi, Jannasch-Pennell, and Kaprolet (2010).

Perhaps due to the lack of research on the student experience during the second year, practitioners have understandably followed the lead of educational researchers by inadvertently ignoring the second year student while providing broad academic and social support to traditional-aged first year students in order to increase retention rates. This common and effective university practice, known as front-loading, may come at the expense of second year students, though, possibly leading to a higher than necessary attrition rate from the second to third year (Pattengale, 2000; Sanchez-Leguelinel, 2008). Indeed, while institutions devote enormous resources to the first year experience in the name of retention, "nearly all of these support systems are curtailed during the second year leaving sophomores feeling ignored and abandoned by the university" (SanchezLenguelinel, 2008, p. 2). The scarcity of second year support and advising programs specifically targeting second year students suggests that universities do not yet realize 
that traditional-aged second year students experience a transition different from but equally as difficult as the transition from high school to college (Gahagan \& Hunter, 2006; Schaller, 2005).

The premature withdrawal of resources may leave second year students adrift. For instance, in a study that compared freshmen, sophomores, juniors and seniors on measures of engagement, Gardner (2000) concluded that second year students are generally “drifting”(p. 68). He described this drift as "a lack of meaningful relationships with faculty, staff, or mentors... and poorly defined purposes for being in college" (p. 68). Gardner (2000) suggests that practitioners start new initiatives for second year students that increase opportunities for students to have meaningful interactions with faculty and staff at the institution.

Additionally, student perceptions of how supportive and engaged their university is toward their academic success seem to have an effect on student success. When the university withdraws support, such as during the second year, perceptions of support (and therefore actual student success) will slump along with retention (Kuh, Kinzie, Cruce, Shoup, \& Gonyea, 2006). Coll and Draves (2009) further suggest in their study that academic advising is the best intervention to put students in a relationship with faculty and staff. This kind of relationship is important because student persistence is linked to student perception of supportive adult relationships on campus (Coll \& Draves, 2009; Kuh et al., 2006).

Faculty and staff may, therefore, inadvertently perceive the second year student differently from the first year student and the upper division student. Inadvertent or not, 
however, differences in perception by faculty and staff can shape student confidence in how much the university will attend to their academic and social needs (Pascarella \& Terenzini, 2005). Student perceptions of university support can also be important to increases in retention (Kuh, 2008). Questions about second year student's perceptions about their experience, satisfaction, and attitudes are gradually now being explored in the growing (and yet still quite small) body of research investigating the second year experience.

\section{Slumping Sophomores}

The slowly growing knowledge base on second year students supports a decades old conventional wisdom that second year students experience something different which leads to unnecessarily high rates of student departure (Furr \& Gannaway, 1982; Lemons \& Richmond, 1987). Early research described that something as a "sophomore slump" characterized by confusion, anxiety, and uncertainty indicating a significant transitional and developmental journey for second year students which they often traverse without the support they received during their first year (Furr \& Gannaway, 1982; Lemons \& Richmond, 1987). Later conceptual works have come to support this understanding of the traditionally aged second year student as negotiating a very real and distinct developmental journey - an understanding which should inform university interventions and interactions (Gahagan \& Hunter, 2006; Schaller, 2005).

While there is growing evidence to support the long-held sentiment among educators that the second year of college may represent a developmental phase, we know 
little about its unique challenges and supports needed to assist students with these challenges. Understanding the second year of college through a developmental framework may well be a key to devising interventions to foster the retention and success of second year students.

\section{Developmental Framework for Understanding the Second Year}

King and Kitchener $(1994,2002)$ provide a developmental theory that proves appropriate and beneficial as a framework for understanding the distinct developmental needs of the second year student. The stages of the model are sequential and "correlate highly with age, and they are linked to educational attainment" (Tennant \& Pogson, 1995, p. 129) which means the stages can be applied accurately to the time in life that corresponds with the age of the typical traditional-aged second year student. King and Kitchener's seven stage longitudinally-tested model chronicles how the learner moves from childhood in stage one to maturity and the potential for reaching stage seven. King and Kitchener used the model to test how learners managed "ill-structured" problems problems typical second year students make such as choice of major and career for which there is not one, concrete solution.

King and Kitchener $(1994,2002)$ found that students at stage three - prereflective judgment - occupy the last two years of high school and the first year of college. This stage is characterized by a recognition that a truth may exist but that it may not always be accessible. Those using pre-reflective judgment look for fully concrete 
evidence, and in its absence look solely to "what feels right at the moment," which is a typical behavior found in the first year (Schaller, 2000).

After their first year of college, students generally move into stage four - quasireflective judgment -- of King and Kitchener's $(1994,2002)$ model and continue in that stage until the end of college. Students using quasi-reflective judgment acknowledge an uncertainty in knowing the "truth," a certain skepticism about how one should relate to authorities (such as professors and advisors) and a "growing distinction between wellstructured problems, which can be solved with certainty, and ill-structured problems" (Tennant \& Pogson 1995, p. 128).

King and Kitchener $(1994,2002)$ have over the last 20 years successfully tested their theory that includes a consistent, predictable "Reflective Judgment" which corresponds also with the "moral and personal" problems college students typically work through. With this Reflective Judgment Model as my conceptual framework, I can position the second year of college as a gateway transitional year from late adolescence (junior, senior high school years and first college year) into a more advanced learning/problem solving stage (second, third, and fourth year of college), the problems of which may best be approached through advising (Habley et al., 2004).

\section{Why Advising?}

Gardner's (2000) proposal towards greater engagement by second year students with faculty and staff is consistent with previous research which has consistently found that student engagement in meaningful interactions with faculty and staff has a positive 
impact on a number of student outcomes, including retention (Pascarella \& Terenzini, 2005). Furthermore it is through academic advising encounters that students have opportunities to engage with faculty and staff. Indeed, Kuh (2008) asserts that "every advising contact is a precious opportunity for meaningful interaction” (p. 79). Yet, struggling second year students often lack opportunities for engagement, especially in the arena of advising and mentoring relationships (Schaller \& Tetley, in press). Advising for second year students should be an area of focus towards understanding how to retain second year students because the interactions within advising encounters are often considered an important strategy for increasing retention - so important that advising is cited as one of the three retention practices responsible for the greatest contribution to retention for both four year public and four year private universities (Habley et al., 2004).

Given the typical front-loading support paradigm in place, practitioners understandably focus institutional resources on offering advising interventions designed specifically for first year students in a way that the new student will find satisfying. But the practice in most colleges is to leave the second year out of these advising programs (Schaller, 2005). Furthermore, even when universities offer specialized advising to second year students, many of those students express dissatisfaction with the advising relationship, especially in private colleges (Juillerat, 2000). Confusion may exist among practitioners due to the vast amount of information about advising, most of which focuses on the first year.

Uncertainty about how to offer advising that attends to second year students differently than first year students may exist also because of the confusing and 
contradictory nature of educational research on advising as it relates to retaining students. For instance, Tinto (2005), one of the most widely cited retention researchers, acknowledges that "research on retention is voluminous" (ix). Much of the research is also inconclusive, contradictory, or poorly designed, especially with respect to advising and retention (Gordon \& Habley, 2000). Despite these realities, however, work over time between differing theories has given researchers "hold points" upon which to frame retention practice. Tinto (2005) asserts that these hold points broadly understood include academic preparation, commitments, and involvement. Gordan and Habley (2000) and Tinto and Pusser (2006) use slightly more specific language by suggesting that theories of student retention commonly point to student preparation, advising, and relationships with faculty and staff as institutionally vital components for retention.

Flanagan (2006) posits a Student Life and Retention Model based on Tinto's (1993) academic and social integration model. Flanagan uses his model to demonstrate, like Tinto, that students who feel connected to the institution both academically and socially are more likely to graduate. His model advances Tinto's, however, by including the concept that second year students have developmentally different needs from important academic integration programs such as advising and faculty mentoring from the first year students. His model carries the student departure theory of Tinto (1988, 1993) through the second year, implying that successful second year programs in advising will increase second year retention and bring more students to the upper divisions of college. Flanagan's model therefore builds conceptually on Tinto's and 
other's work which focus mainly on first year strategies to increase student success to graduation.

Confusion may also occur among advising and retention practitioners because research about retention beyond the first year describes a problem (low second year retention) but does not necessarily provide prescriptions for improvement. For instance, retention data from the last twenty years shows that attrition during the second year is equal to or a close second to the attrition found during the first year (Brainard \& Carlin, 1998; Gahagan \& Hunter, 2006), meaning the retention problem does not end when a student makes it past the first year. Additionally, institutions routinely withdraw support during the second year of college when students need it most, leading to needlessly high attrition during the second year (Gahagan \& Hunter, 2006).

Moreover, second year students have been found to be differently satisfied, generally, compared to other students and satisfaction has implications for retention (Juillerat, 2000; Pullins, 2011). Finally, Habley and McLanahan's (2004) survey research identified advising as one of the top three greatest contributors to retention while noting as well that almost none of the institutional survey respondents used one of the top three approaches to increasing retention suggesting that "business as usual" will not increase retention (p. 18).

Juillerat (2000) provides the only empirical evidence thus far that some differences may exist between class years. The research, based on a survey with over 100 items related to satisfaction in all areas of the university, cast a wide net on the problem of student satisfaction. This research is promising and, along with ample conceptual work 
about the second year, is enough to reasonably consider the second year of college as potentially distinct from the first year and upper divisions. Providing the support to help students traverse their second year of college may very well be the key for colleges and universities to break out of the retention rut they find themselves in. Indeed, Pattengale and Schreiner's (2007) assertion that "if sophomores are not successful, institutions are not successful" (p. vi) speaks directly to the promise for retention contained in helping second year students succeed. Furthermore, given the importance advising is purported to play in retention, it seems improving academic advising for second year students would be a critical step toward ultimately increasing retention rates. However, in order for educators to design effective interventions for second year students, it is important to understand their attitudes about and experiences with academic advising.

\section{Advising Functions}

To understand attitudes and experiences with academic advising, researchers must have a way of measuring them. To this end, Smith and Allen (2006 ) identify five constructs of academic advising which the literature suggests constitute quality advising. Within those constructs, Smith and Allen operationalize these five functions with 12 advising functions (see Table 3) which describe how advisors and students function together in the advising process. The constructs include integration of the student's academic, career, and life goals; referral to resources for academic and non-academic issues; information delivery about degree requirements, policies, and procedures; 
individuation, or care towards the unique student; and shared responsibility, or teaching students to grow in responsibility for their education (Smith \& Allen, 2006).

Identifying learning outcomes is another important method for providing the framework for assessing advising. Schaller and Tetley (in press), suggest that second year students will benefit when advisors use learning outcomes to guide their practice. Learning outcomes are those "statements that articulate what students are expected to know, do, and value as a result of involvement" in advising interactions (Robbins, 2009, p.268). Smith and Allen (2006) identified seven learning outcome statements (see Table 4) which correspond with the research over the last 30 years regarding what students should be expected to learn as a result of receiving quality advising. Along with the 12 advising functions, the learning outcome statements developed by Smith and Allen (2006) form the basis of the Inventory of Advising Functions (Smith \& Allen, 2006) which served as the instrument for data collection for this study. The survey was chosen for several reasons. First, the survey has been used successfully in previous research to measure student attitudes and experiences with advising in general. Second, the survey was used because the data collected from it could be used for the correlational design of this study. The correlational design was chosen so as to compare different class levels to determine unique associations among variables between the classes. The survey was also chosen because students using it could identify not only what is important to them in advising but also what satisfied them. Satisfaction is a key component to retention, especially with respect to advising (Juillerat, 2000; Pullins, 2011). And finally, the survey was used because student learning from advising could be measured allowing for 
a comparison regarding how students learned differently between class years through the advising experience.

\section{Statement of Purpose}

The purpose of this study was to contribute empirically to our understanding of the second year of college. Specifically, the purpose of this study was to provide an empirical basis for considering past propositions suggested in the literature on second year students that:

1. Second year students' attitudes toward and experiences with advising are distinct from those of first year students or upper division students.

2. The attitudes toward and experiences with advising of second year students who are retained differ from those who do not continue at their institution.

\section{Significance of the Research}

Successful college second year students navigate a transition nearly as difficult as the transition to college while the support services they had become accustomed to disappear leading to needlessly high attrition rates to the junior year (Gahagan \& Hunter, 2006). Additionally, while much is known about retention related to the first year, and despite our knowledge that the second year to junior year transition is often as difficult as the transition to college from high school, major gaps exists in the literature on retaining students beyond their first year (Amaury et al., 2005). 
Though the importance of quality advising to the academic enterprise and to student success has been explored to some degree over the past several years, little attention has been given to how attitudes about and experiences with advising may differ among first year students, second year students, and upper division students. And so we know much more about how advising attitudes affect first year student success than we do about second year student success. This is significant because the second year is the second most at risk period for a college student and attrition rates drop significantly after a college student's second year (Brainard \& Carlin, 1998; Gahagan \& Hunter, 2006).

Considering the comparative lack of empirical information about second year students, this research should be significant because it will fill a gap in our knowledge of the second year experience with respect to advising. The research should be significant, as well, because its findings may help inform advising practices that address the specific needs of the college student's second year. Finally the research may be significant by helping colleges increase retention overall, reduce time to graduation, and graduate more students.

\section{Research Methodology}

One purpose of this study was to provide an empirical basis for understanding differences between second year students and their first year and upper division peers. This study, therefore, sought to explain the relationship between and among variables (importance ratings, for instance) to consider how they co-vary with respect to class year. To appropriately adhere to the study's purpose therefore, this study uses a correlational design including simultaneous and logistic regression analyses to examine secondary data 
collected at seven public and private four-year institutions of higher education in the Pacific Northwest of the United States of America. The data were gathered from approximately 15,000 college students enrolled at one of the study institutions during the spring of 2010 or 2011 using the Inventory of Advising Functions - Student Version (C) 2006 By Cathleen L. Smith and Janine M. Allen). Demographic information and retention data on the participants were provided by each participating institution.

\section{Research Questions}

The following research questions were posed for this study:

1. Do second year students differ from first year and upper division students in the importance they ascribe to any of the twelve advising functions?

2. Do second year students differ from first year and upper division students in their satisfaction with any of the twelve advising functions?

3. Do second year students differ from first year and upper division students in their level of agreement with statements that reflect what students know, do, or value as a result of receiving academic advising (Learning Outcomes)?

4. Do retained second year students differ from not retained second year students in the importance they ascribe to any of the twelve advising functions?

5. Do retained second year students differ from not retained second year students in their satisfaction with any of the twelve advising functions? 
6. Do retained second year students differ from not retained second year students in their level of agreement with statements that reflect what students know, do, or value as a result of receiving academic advising (Learning Outcomes)?

\section{Definitions}

For the purpose of this study, the following definitions apply:

Traditional-Age Student - Student who matriculated into college directly from high school and remains in continuous enrollment through the senior year. The age range for the traditional age college student is 17-22 (Pascarella \& Terenzini, 2005).

First Year or Freshman - Traditional-age first-time, full-time college student matriculating in college in the fall semester after high school graduation.

Second Year or Sophomore - Traditional-age first-time, full-time college student who has persisted into the second year of academic work.

Upper Division - Traditional-age first-time full-time college student who has persisted into the third, fourth, or more year of academic work 


\section{Summary}

Research into the second year of college in general has increased over the last ten years providing practitioners with new ideas and proposals for approaching the second year student. The research to date, however, has included very little empirical analysis regarding how second year students might or might not differ from first year and upper division students. Advising for the second year student has not been addressed empirically at all even as advising has been identified as a key method to increase retention. This study attempts to fill this empirical research gap and provide evidence for past proposals made in the second year literature. The following chapter provides a review of the literature on second year students through the lens of advising towards greater retention. 


\section{CHAPTER 2}

\section{LITERATURE REVIEW}

\section{Introduction}

The purpose of this literature review is to expand the understanding of the retention problem from a longitudinal perspective to include persistence to the third year of college, which has been recently identified as a "more meaningful proxy for degree attainment" than persistence to the second year (Allen, Robbins, Casillas, \& Oh, 2008, p. 648). The chapter begins with a discussion of a metaphor to assist in the understanding of the longitudinal nature of retention (Tinto, 1988, 1993, 2005) which is used as the theoretical framework of retention for this study. Following this discussion, information is provided related to the developmental framework that informs this study's focus on the second year as well as an exploration of the literature about the second year of college. Finally, I provide in this review research regarding retention statistics and regarding the role that advising plays in the retention of college students from their second to third year.

\section{A Metaphor for the College Journey}

One way to reconsider complex social and organizational problems, such as retention in higher education, is to apply the use of metaphor to gain insights and ideas for new ways of approaching the problem. Morgan (2006) explains the power of using metaphor by asserting that "metaphor encourages us to think and act in new ways. It extends horizons of insight and creates new possibilities” (Morgan 2006, p. 341). 
Metaphors we use to understand our organizational problems lead to more metaphors of understanding, and push managers to "recognize [our] limitations and find ways of going beyond them" (p. 343). By expanding our understanding of the retention problem in ways that lead institutions to new ways of approaching the problem, metaphor can assist educators concerned with low retention rates in breaking out of the well-worn ruts in the road they have used over 30 years.

A helpful metaphor for framing the problem of low retention in colleges as longitudinal is that of a salmon migration from the river to the sea. The image is particularly appropriate for this study because the issue of salmon protection is prevalent and important to the Northwest, the location of the colleges included in this study. To understand college student retention through the metaphor of migrating salmon we can see the student, like the salmon, as migrating from their "birth" in a small stream. Salmon travel from their home river on a quest to "graduate" into the ocean, whereupon they commence their adult lives, applying all they learned, in order to travel back through the same rivers to eventually meet their ultimate goal of reproduction and death. The rivers they swim through, like the passage through college, present numerous and difficult obstacles that can keep them from making it to the ocean - to their graduation into adulthood. Some of these dangers are naturally found in their habitat. Some of them are human-made.

As salmon populations have declined due to departure conditions increasingly created by people, wildlife managers have employed techniques to assist them on their journey. Much like institutional faculty and staff, wildlife managers study the problem 
and apply solutions so the salmon will be less likely to drop out. Unlike university faculty and staff, though, salmon habitat managers have learned to employ their techniques over the entire life span of the salmon because they know that the salmon retention problem, like the college retention problem, is longitudinal in nature (Tinto, $1975,1988,1993)$. Obstacles come up for salmon not just when they are infant salmon but along the entire stretch of the river and into the ocean. And so it is with students as well that they experience departure issues after they make the transition to college in the first year.

The retention problem for universities resembles the retention problem for salmon on their journey to the sea in that universities lose more students than expected during the second year. But most of what is known of the nature of retention and practices to increase retention over the last 30 years has focused almost entirely on the time during the college life span when the young student has just begun the journey. Specifically, retention efforts have almost exclusively focused on the first year of college in what is known as "front loading" support services and advising into that crucial first year (Flanagan, 1991; Pattengale \& Schreiner, 2007; Tinto, 1988, 1993; Tinto \& Pusser, 2006). Educators know relatively little about later years in college (Pattengale, 2000) and it is assumed that first year students who persist to their second year will graduate (Tinto, 2006). But as with salmon travelling through treacherous rivers towards their own form of graduation, the obstacles to success for second year students do not disappear simply by making it past their first year. After receiving much support, a student may make it through the first year - the home stream - only to have migrated 
into a new river with even greater challenges. The human managers of salmon life know not to withdraw support for their charges at that point. Institutions of higher education, however, do tend to withdraw support just when students are making that transition into a more difficult academic environment after the first year, expecting the students will succeed simply because they made it past their first year (Pattengale \& Schreiner, 2007).

Students may consider leaving college at any time during their collegiate careers; problems associated with attrition during the first year may continue into subsequent years, or new problems may arise (Amaury et al., 2005). While first year attrition problems have improved over the last 30 years, Amaury, Barlow, and Crisp (2005) suggest in their review of retention data spanning all college years at a large and diverse research institution that due to the intense scrutiny paid to the first year, "problems with student attrition have shifted from the first year to subsequent years even when students successfully engage their initial collegiate experience" (p. 130). Twenty years prior to Amaury, Barlow, and Crisps' (2005) study, Tinto (1988) was calling for research to "ascertain whether the process of leaving which characterizes departure during the first semester is similar to that which describes departure after the first year and whether the widely studied process of departure at the end of the first year looks like that which marks departure afterward" (p. 450).

\section{Using the Metaphor}

Retention practitioners who use the metaphor of migrating salmon can expand their view of the college retention problem and come to understand the longitudinal 
nature of student departure. The longitudinal framework urges researchers to structure the problem not "as a singular process, but [one] marked by distinct stages" over time (Tinto, 1988, p. 453). Seen this way, the problem can be considered from a developmental frame of reference in which we would expect students to experience different reasons for leaving college depending on where they are in the process of persisting toward earning a college degree (Boivin, Fountain, \& Baylis, 2000). Seeing retention as a longitudinal process invites practitioners to look beyond the first year and to consider interventions during the next worst year for college retention - the second year of college.

\section{The Longitudinal Nature of College Student Retention}

For over 30 years, research has described the problem of student departure as being longitudinal in nature; however, institutions continue to apply interventions myopically by intensely focusing on the first year (Amaury et al., 2005) leading to falling retention and graduation rates nationwide. While the literature on retention to the third year is still small (Amaury et al., 2005), there exists a large body of literature on retention in general that identifies students as progressing through developmental stages of transition in their college career with persistence being most likely when a student has achieved academic and social integration and self-efficacy.

The concept of academic and social integration within a longitudinal framework of student departure arose from Tinto's (1975) Interactionalist Theory of Student Departure, which he first proposed in 1975 and subsequently revised in 1988 and 1993. 
In a revision of Tinto's (1975) Interactionalist Theory, Braxton, Hirschy, and McLendon (2011) support the validity of the longitudinal nature of student departure while identifying two factors directly within the institution's control that lead to academic and social integration as well as self-efficacy. Those two factors are student interactions with faculty and staff which 1) increase the student's belief that the institution has integrity and that 2) the institution is concerned for the student's welfare and success.

Tinto's (1993) direction that educational researchers frame inquiry on retaining students as consisting of stages and being essentially developmental in nature provides the rationale for the developmental framework used for this study -- King and Kitchener's $(1994,2002)$ Reflective Judgment Model. The Reflective Judgment Model (King \& Kitchener, 1994, 2002) describes the time period at the end of the traditionally aged freshman year as the beginning of an important epistemic transition from one way of approaching knowledge to a more mature approach suitable to success in the upper divisions of college. Applying the Reflective Judgment Model framework within Tinto's $(1988,1993)$ longitudinal model, this review explores the second year as one of transition in which one would expect problems associated with student departure to be different from other years in college and to require intense faculty and staff assistance during the second year transition to the upper divisions of college through advising and mentoring interventions.

The review concludes by narrowing the intervention focus to one most suitable for the transitional issues second year students' experience. The Student/Institutional Engagement Model theoretical framework (Amaury, 2004) is referred to in this section to 
provide support for the research questions of this study which examine how second year students' attitudes towards and experiences with academic advising and their faculty relationships may differ from other students. Specifically, the research questions ask if there is a difference in attitudes towards and experiences with academic advising between 1) students in their second year of college and students in their first year of college, and 2) students in their second year of college and students at the upper division of college (the junior and senior years of college). In addition the research questions ask if the attitudes towards and experiences with academic advising reported during the second year differ between those students who persist into the junior year of college and those who do not persist.

\section{The Second Year of College}

\section{Definitions and Origins}

American colleges name the second year of college the "sophomore" year. The word sophomore has ancient roots coming from the Greek word "sophos" meaning wise. Most folk etymologies look to the second root of the word as "moros" meaning fool in Greek - thus the common understanding of the sophomore as being a "wise fool." But the roots and conception of the sophomore, the second year student, actually go back to the Greek Sophists who, being educated enough to teach, were nonetheless considered "know-it-alls"; their form of simplistic debate has come to be known as "sophisms." The real teachers, the Greek Philosophers, looked down upon their Sophist brethren. 
The term came to what would become the United States at the establishment of North America's first institution of higher education. Harvard College, the first college in the English colonies, took the language of the colleges from its homeland to describe each year in college based upon student abilities at debate and logic. Freshmen were expected to have very little participation and abilities with respect to debate. The second and third year students were typically able to make points marginally better than the freshmen novices; so their arguments were called Sophisms and they were called junior sophisters and senior sophisters.

By the 18th century American colleges had begun calling the second year students sophomores to distinguish them from the novice freshmen and the upper division mature students who were called juniors and seniors. Sophomores had become and remain to this day the class of transition between the novice students (freshmen) and the students ready to be apprentices to the faculty within the upper divisions of the junior and senior years.

\section{History of the Second Year and Current State of the Research}

While the topic of the second year of college has an increasing body of research, it is still small and only recently has seen growth (Amaury et al., 2005). Two monographs addressing the second year of college were published in 2000 and 2007 respectively. The first, Visible Solutions for Invisible Students: Helping Sophomores Succeed edited by Schreiner and Pattengale (2000) provides a substantial assessment and presentation of the research on the second year experience current to 2000. Schreiner and Pattengale's major 
recommendations have influenced the questions guiding this study. For instance, the authors of the summary and recommendations chapter specifically call on researchers to pay more attention to the second year as a critical transition when "students are making extremely important decisions" (Schreiner \& Pattengale, 2000, p. 91) .

The authors explain that lack of attention to second year students may set up the environment within which second year students experience what has become known in the literature as the "Sophomore Slump" (Schreiner \& Pattengale, 2000, p. 91; Lemons \& Richmond, 1987). According to the Sophomore Slump literature, the Sophomore Slump occurs when the faculty and staff attention a student had grown accustomed to during the first year is withdrawn whereupon the student is set adrift (Gardner, 2000). The characteristics of the drifting and slumping second year student include:

- Prolonged indecisiveness about selecting a major

- Inappropriate decision making about academic course selection and major and minor fields of study

- Low levels of commitment

- Disappointment and frustration with the academic experience

- Increased time-to-degree completion rates, and

- Lack of social and academic integration (Gardner et al., 2000)

The authors of the first monograph (Schreiner \& Pattengale, 2000) found large gaps in the research about second year students which they assert results in a misunderstanding of the potentially unique developmental tasks and needs of students during their second 
year. The core recommendation of this monograph directed university resources to advising since "there was substantial evidence pointing to sophomores' need for meaning and purpose as they made decisions about a major and career" (Tobolowsky \& Cox, 2007, p. v). Tobolowsky and Cox specifically recommended that researchers conduct future studies that collect data to answer the following questions:

a. What are the differences between first- and second-year dropouts?

b. How well are the systems and structures of advising working for second year students compared to other students?

c. What are the satisfaction levels and attitudes of second year students towards faculty availability and advising? (Gardner et al., 2000, pp. 91-92).

Lingering myths about the nature of the second year were identified in the summary and recommendations chapter of the 2000 monograph (Schreiner \& Pattengale, 2000) as well. These myths may inhibit campuses and researchers from adequately studying the phenomenon. Those myths include:

1. that the retention problem in higher education is a first year phenomenon.

2. that if educators focus retention efforts on the first year, the problem will be solved, and,

3. that once a student makes it to the second year, progress to graduation is nearly guaranteed. (Gardner et al., 2000, pp. 91-92).

Schreiner and Pattengale (2000) and Gardner (2000) propose that institutions will see higher retention and graduation rates by dispensing with these myths. 
A companion monograph, Shedding Light on Sophomores: An Exploration of the Second Year, (Tobolowsky \& Cox, 2007) followed Schreiner and Pattengale's (2000) assessment of the second year experience to review any progress made in higher education with respect to their recommendations in 2000. Pattengale and Schreiner note in the forward to the 2007 monograph that while many programs had developed around the nation since the 2000 monograph, several of their recommendations still seemed out of reach for colleges. The authors encouraged educators to make second year interventions more intentional by increasing "the sophomores' academic engagement in order to maintain the momentum of the first year" (Pattengale \& Schreiner, 2007, p. vi).

The 2007 monograph did, however, note important progress made in two of the most important recommendations from 2000. The monograph editors, Tobolowsky and Cox (2007), first confirmed considerable progress being made toward the key recommendation that attention should be given to the advising area for the second year. They found that " 61 percent of the colleges participating in the national survey reported advising programs specifically designed to meet sophomores' needs" where that number was considerably lower in 2000 (Pattengale \& Schreiner, 2007, p. v). The editors also noted progress toward the recommendation in 2000 to collect data about second year transitions and experiences. Most of the monograph is composed of findings from these mostly qualitative studies.

Tobolowsky and Cox (2007) remark in the introduction, however, that though progress in collecting data had transpired since 2000, they had discovered a distinct lack of empirical evidence on the experiences of second year students engaged in programs 
designed with the key recommendations from the 2000 monograph in mind. Their finding in this matter suggests that empirical evidence is still needed to shed light on second year attitudes towards and experiences with advising as well as how those second year attitudes and experiences differ from first year and upper division students.

To summarize, then, the 2007 monograph contains eight chapters, six of which simply describe current (2007) programs at six institutions related to higher education. The descriptions, however, neither provide empirical evidence of their efficiency, nor of second year experiences with advising programs. The final chapter includes recommendations for future second year initiatives, some of which echo the 2000 monograph's recommendations to "target sophomores for educationally purposeful activities" (p. 97). Though the writers increase knowledge about the second year incrementally, their work does point to the need for further research more tightly focused on the second year, especially with respect to advising.

\section{Contemporary Understanding of the Second Year}

The literature suggests that it is easier to define the differences between the first and second year than it is to actually define what a "sophomore" is. This is true for many reasons, according to Gahagan and Hunter (2006), whose research into “the Academy's Middle Child" has recently opened the door to new studies. For instance, a sophomore could be any student who has earned the correct number of credit hours to transition into the sophomore year. Registrar offices tend to define a sophomore this way. Residence hall and student activities systems are more likely to define a sophomore as a student who 
has continued into his or her second year of school, regardless of credit hours.

Sophomores can also be defined based on the number of years out of high school and by age, especially when it comes to special scholarships and programs. Gahagan and Hunter (2006) found that although one agreed upon concrete definition of the second year student did not exist at the time of their work, they would settle on one - "Sophomores were finally defined as 'first-time, full-time students who have persisted into their second year of academic work... and it is more accurate to use 'second year experience' to describe this period" (Gahagan \& Hunter, 2006, p. 18). This study will use Gahagan and Hunter's definition of the second year with the inclusion of a traditional age timeline (1723 ) to correspond with the developmental framework for this study (King \& Kitchener, 1994, 2002). Although this classification will be the operational definition of "sophomore" for this study, the following section describes different conceptions of the second year in the literature.

\section{Middle Children}

Gahagan and Hunter (2006) were among several researchers who refer to second year students as middle children. Juillerat (2000) also uses the family metaphor to suggest that the legitimate needs of the middle child in a family of three is lost among the incessant and pressing survival needs of the newborn and the usually complimentary interest paid by the parents to the oldest child. While the university is not a family, the

division of class years into new (freshmen), middle (sophomore), and oldest (upper division juniors and seniors) allows the Middle Child metaphor to be used for 
illumination on a misunderstood time in college life. Juillerat's (2000) study suggests that the "rest of the family does not care" about the middle child when the college attends to the urgent needs of the new students and invests energy in making sure the soon to be alumni will graduate on time and wish to give back to the university.

Bellani (2007), in his dissertation about second year men, invokes the classic 1970s era family sitcom The Brady Bunch in which the middle sister, Jan, struggles in her role as the middle child. Using this pop culture analogy, Bellani's (2007) study helps the reader see how second year students in college struggle to find their identity during a time when all the former attention of once being the new child disappears while the family fawns over the newest addition to the family. The metaphor is also important to Bellani (2007) whose study establishes the unique nature of the second year in college while setting up the context for findings that support treating second year students differently from the "newborn" first year students and the oldest children in the bunch the juniors and seniors.

\section{The Sophomore Slump}

One of the most frequently used terms for the challenges faced by the second year student is "the Sophomore Slump." Colloquially it has become common knowledge that something happens during that second year of college. When a college student's second year problems come up in conversation, it is common to hear, for instance, “oh he's just going through his sophomore slump" as if it is to be expected and the student will snap out of it eventually. So from a common knowledge point of view it is recognized that 
students in college can experience a "slump" of sorts after the initial first year experience wears off and the student settles into something more serious and less fun.

The earliest found reference to the sophomore slump in the literature is from Freedman's 1956 essay describing the uniqueness of each class year in college. Freedman's (1956) essay - The Passage through College -- is a brief qualitative study based on interviews with college students, administrators, and faculty at an elite, residential, East Coast liberal arts college. The next citation in the second year literature is from Feldman and Newcomb (1969) who spoke to the sophomore slump as a time when students lose their sense of satisfaction with the college, almost as if the first year had worn off and the institution and they themselves had become different after a year.

Besides those two relatively early references, the next major citation for the sophomore slump comes from Richmond's (1985) and Lemons and Richmond's (1987) articles in which the authors reference the concept of a sophomore slump as one in which frustrated sophomores, overwhelmed with real life decisions such as selection of a major, begin to disengage due to lack of support. Richmond's (1985) recommendations call for a special attention on mentoring relationships that focus on personal advising and counseling, noting that "the most important factor in helping students overcome the sophomore slump, regardless of specific causes, is personal attention from a residence hall staff member or other concerned individual" (p. 176). Lemons and Richmond (1987) conceptually frame the sophomore slump as developmental by tying the source of the slump to problems second year students face in negotiating tasks associated with four of 
Chickering's (1969) Vectors of student development - competence, autonomy, purpose, and identity.

\section{Sophomore Year as a Transition}

Transition has been used as a framework for understanding the second year and the challenges associated with it that lead to the sophomore slump. Schaller (2000), for instance, organizes her qualitative research about second year students using a metaphor of transition. Through her literature review about transition she cites several transition researchers to support the assertion that traditional-aged second year students are making a significant evolution from what Levinson (as cited in Schaller, 2000) calls "preadulthood to early adulthood" (p.17) during the ages 17 through 22. Schaller (2000) notes that most transition researchers, including Levinson, describe this transition process as happening in three parts with "endings, neutral zones, and beginnings" (p. 19).

Schaller's (2000) review supports the belief that traditional-aged second year students who are 19-20 years of age are naturally negotiating the middle portion of a transition to the upper divisions of college. This transition concept is compelling for understanding struggling second year students because the middle portion of the transition is characterized by "disidentification, disenchantment, and disorientation" (Schaller, 2000, p. 18). This language sounds similar to the language used by Gardner (2000) who describes the drifting second year student as experiencing disengagement, indecisiveness, and disappointment due to the withdrawal of faculty and staff mentoring the student had come to expect during the first year. 
Tinto (1988), in Stages of Student Departure, expresses similar support for the concept that transition forms the basis of what happens with students who go to college, stating that "it is difficult to envision persistence as not entailing some form of transition, some pattern of incorporation into new forms of social and intellectual association" (p. 449). Tinto (1988) drew on Dutch social anthropologist Arnold Van Gennep's research into how tribal societies negotiate the passage from membership in one aspect of society to another more mature aspect of society. Tinto (1988) included Van Gennep's research because it helped him describe the passage American youth make from high school to college. The stages as described by Tinto (1988) include three parts - separation, transition, and incorporation. Like the middle stage described by Schaller (2000), Van Gennep's (as cited in Tinto, 1988) middle stage is a movement from "associations of the past and hoped for associations with communities of the present" (p. 444) in which students often encounter difficulties they cannot negotiate without assistance from staff and faculty. As with Schaller's (2000) research into transitions in college, Tinto's hypothesis about passages through college resonates with the migration difficulties faced by struggling second year students who drift without assistance from caring college staff and faculty.

In a later conceptual work, Schaller (2005) described students moving into their second year as developing a broader and more mature understanding of what it means to be a student. Yazedjian, Toews, Sevin, and Purswell (2008), in their qualitative exploration of college students' definitions of and strategies for college success, use a similar transition metaphor about how second year students move beyond an infant 
academic stage to a mature academic stage. One of the conclusions in their study was that the second year student's "development of skills that allow the individual to transition into more adult roles" was vital to their success during that transitional year to the upper divisions of college (Yazedjian et al, 2008, p. 147).

That transition includes a preoccupation with more serious matters related to the developmental transition second year students are making. First year students, conversely, often are preoccupied with success in social matters, finding their way around campus, and learning about how college works. In addition, first year students enjoy what Margolis (1976) called "barometers of success." These barometers of success include immediate social feedback in residence hall communities, feedback from Resident Assistants and Student Affairs staff, and one-on-one advising (Margolis, 1976). Second year students, however, do not usually benefit from these barometers of success. Instead, they are left to create their own barometers during a time when crucial decisions are being made in the areas of choice of major and career choices. In addition, although these students enhance their academic success by making use of the social ties they formed during their first year, second year students question the value of those very relationships, especially as those relationships relate to the new developmental and transitional challenges they face (Yazedjian et al., 2008). This confusion about relationships can lead further to feelings of disconnection for second year students who the research suggests need connection just as much as they did in their first year. 


\section{Developmental Literature Regarding the Second Year of College}

\section{Schaller's Four Stage Sophomore Transition Model}

Schaller (2005) said that "institutions that wish to attend to sophomore students in new ways need to ground their programs in an understanding of the challenges of the sophomore year" (p. 18). Using a case-study methodology, Schaller (2000) defines second year students within a framework in terms of their development over time and based loosely on age, much like King and Kitchener $(1994,2002)$ do in their Reflective Judgment Model (discussed below). A summary of her four stage framework follows:

Random exploration. This stage typically defines the first year of college. Some second year students in her study remained in this stage, but most had moved on. This stage is defined by exuberance, social energy, lack of focus, and a lack of reflection.

Focused exploration. Schaller found that students moved slowly into this stage, usually during the summer after the first year and the first part of the second year. Here she found the beginning of second year frustrations over their first year relationships and decisions along with irritation over their academic life. Second year students in this stage begin to feel great pressure to choose a major and to articulate a purpose in life. With great pressure comes "fence sitting" for many and crisis for some.

Tentative choices. Often a time when students admit that the first year was about having fun and making friends, the second year students in Schaller's study describe this time as one of "settling down" and taking academics more like a real student. These are 
choices that often set the course for the rest of college and early adulthood. Schaller notes that students are able to move out of focused exploration by making these choices.

Commitment. Schaller reports that she did not find commitment much among the second year students in her study, but that commitment to academics and other aspects of life came toward the beginning of the junior year.

Schaller (2000) undertook her qualitative study of nineteen traditional-age second year students at a mid-sized, private, Catholic university to "make sense of the sophomore year" (p. 18). Though her sample was small and focused on one school, as a qualitative study it does help researchers with a deeper understanding of the second year experience. The insights provided through interviews and focus groups suggest educators should not treat second year students like first year students because the second year student has different needs, motivations, and often sits at a different developmental place than the first year student. Schaller's findings resonate well with much earlier research by Furr and Gannaway (1982) in which they assert that though second year students may have matured, they are not yet fully equipped to "cope with the multiple alternatives presented by a college community" (p. 340).

\section{Flanagan's Student Life and Retention Model}

Flanagan (2006) posits a Student Life and Retention Model based on Tinto's $(1988,1993)$ social and academic integration model. Flanagan (2006) uses his model to demonstrate, like Tinto $(1988,1993)$, that students who feel connected to the institution 
both academically and socially are more likely to graduate. Flanagan's (2006) model advances Tinto's $(1988,1993)$, however, by including the concept that second year students have developmentally different needs from important academic integration programs such as advising and faculty mentoring compared to first year students. His model carries the student departure theory of Tinto $(1988,1993)$ through the second year, implying that successful second year programs in advising will increase second year retention and bring more students to the upper divisions of college. The model therefore builds importantly on Tinto's $(1988,1993)$ and others' work which focus mainly on first year strategies to increase student success to graduation.

\section{King and Kitchener's Reflective Judgment Model}

King and Kitchener $(1994,2002)$ provide a developmental theory that proves the most useful as a theoretical framework for understanding the distinct developmental needs of the second year student because the stages are sequential and "correlate highly with age, and they are linked to educational attainment” (Tennant \& Pogson, 1995, p. 129). King and Kitchener's (1994, 2002) seven stage longitudinally-tested model chronicles how the learner moves from childhood and adolescence in stage one (prereflective) through young adulthood (quasi-reflective) and onto maturity and the potential for stage seven (reflective judgment). King and Kitchener used the model to test how learners managed "ill-structured" problems - problems such as choice of major and career for which there is not one, concrete solution. 
King and Kitchener $(1994,2002)$ began this research in the early 1980 s as a way to expand upon the theories of human development produced by William Perry. Over the next thirty years they tested the theory that a consistent, predictable "Reflective Judgment" journey exists that begins in the latter part of high school and proceeds through graduate school (for traditionally aged people who choose higher education). During this journey growth occurs from "pre-reflective" learning towards a major advance into "quasi-reflective" learning which King and Kitchener also describe as corresponding well with the "moral and personal" problems college students work through from first to senior year.

King and Kitchener $(1994,2002)$ specifically use their model to explain how humans develop in late adolescence and into adulthood with respect to solving "illstructured problems" that cannot be "solved by the mechanical application of an algorithm" (such as "prescriptive" advising that tells a student what classes to take to satisfy a first year requirement). Ill-structured problems necessitate the addition of a developmental approach to advising because they "require making judgments based on the strength of available evidence and the adequacy of argument in tandem with another person" (p.37).

For example, second year college students are typically faced with the following types of questions: What should my major should be? What should my career be? What kind of adult do I want to be? I'm done with my first year of college games, how do I make the choices to be a mature student?" These are ill-structured problems and questions for which "people hold opposing and contradictory views [where] even the 
most conscientious [people] become perplexed" (King \& Kitchener, 2002, p. 37) about what to do. Second year students face these questions at a time when they are most likely to be in or just moving beyond a "pre-reflective" stage where knowledge (of what to do, for instance) is gained through the word of an authority figure (a first year advisor using prescriptive means, for instance, or a parent). But the questions second year students face do not have answers best handled by the pre-reflective mind and so one would expect to find that second year students not only have different needs than first year and upper division students, but that they have as great a need for assistance from an adult mentor or advisor when compared to other students.

This framework therefore anticipates that second year students' attitudes and experiences toward advising will differ from the first year and upper division students as a result of making a crucial transition toward quasi-reflective reasoning. As a way of examining the problem of retention, this framework suggests that our loss of second year students may occur because of a problem matching our interventions (or even offering interventions) with the second year student's typical developmental needs, which are indicative of this major transition. This framework also anticipates that advisors can help frame their interventions best by devising advising interventions for those second year students institutions might otherwise lose to attrition.

\section{Research Prescriptions for Sophomore Success}

Schaller's (2000) qualitative study and King and Kitchener's (1994, 2002) framework support the recently growing belief that colleges should not treat second year 
students like new students. Other researchers concur, such as Sanchez-Leguelinel (2008) who used an explanatory factor analysis to report that second year students benefitted most when they experienced individualized and one on one attention. SanchezLeguelinel (2008) interpreted his findings to mean that second year students desire a more personalized advising environment. His interpretation included the assumption that second years students express distinctly different needs than first year and other students, since they occupy a different developmental level than the first year student. Since second year students are making a developmental transition and have different needs than first year students, they specifically do not need first year programs simply extended into their second year. Sanchez-Leguelinel (2008) suggests practitioners need to be especially cautious not to place the template of the first year on the second year student; instead practitioners should consider developing programs specific to the unique needs of the second year student.

Furr and Gannaway (1982), in one of the earliest reports on second year students, suggest that though second year students may occupy a different place in the academic procession from other students, they have not developed enough to handle the kinds of issues second year students typically face without some kind of faculty or staff assistance such as one on one advising.

Graunke and Woosley (2005) provide additional support for understanding the ramifications for second year students when they no longer receive special attention from faculty and staff. For instance, Graunke and Woosley (2005) found that faculty interactions were a significant predictor of second year success. In other words, the 
extent to which second year students were satisfied with their opportunities to interact with faculty, and "the extent to which sophomores felt that faculty were concerned with their academic success had an impact on sophomores' academic performance" (Graunke \& Woosley, 2005, p. 6). Their research also showed the importance for second year students to be connected to a major, a developmental task most commonly accomplished through one on one advising and career counseling.

Academic advising puts students in direct contact with faculty and staff (Kuh, 2008). As such, advising has also been cited in the research as a vitally important contributor to second year student success (Frost, 1991; Kramer, 2000; Schaller \& Tetley, in press; Smith, 2002; Steele \& McDonald, 2000; Tobolowsky \& Cox, 2007). The type of advising matters, too. That is, advising should not be done by disinterested faculty or staff (Gahagan \& Hunter, 2006; Nealy, 2005). Nor should it necessarily be either prescriptive advising or developmental advising. Rather advising should combine the two advising approaches and allow the student to communicate his or her needs (Smith \& Allen, 2006) . Moreover, as reviewed earlier, Richmond and Lemons (1985) stated simply that personal attention from a university staff or faculty person is the most important method for helping second year students stay motivated. These suggestions from the research suggest that advising should be one on one and involve interested faculty and staff who strive to make a personal connection rather than simply go through the prescriptive motions of signing paperwork and suggesting classes. 


\section{Why Sophomores Leave and Stay}

Until recently, the interventions and contexts within which second year students make decisions about leaving or staying have not been adequately addressed. In one of the few studies on the topic, Juillerat (2000) used the Student Satisfaction Inventory developed by Schreiner and Juillerat (1993) to assess the levels of expectations and satisfaction of college students in a number of areas related to the college experience. She found second year students who failed to persist complained about advising and faculty relationship noting that:

sophomores are significantly less satisfied than the students in other class levels...[and may] very well be contributing to the sophomore slump...Perhaps most noteworthy is that sophomores are significantly less satisfied than all other students with the approachability and concern of their advisers, issues they have already identified as being critically important to them (Juillerat, 2000, p. 24)

Juillerat (2000) further found interesting differences between private school and public school second year students. She found that although private school second year students share many satisfaction points with first year and upper division students, they did differ from other class years in their satisfaction with developmental aspects of academic advising and faculty such as with relationships and mentoring. Juillerat's (2000) study found, on the other hand, that public school second year students did not share the same level of dissatisfaction over developmental academic advising, instead 
focusing on complaints about prescriptive advising for processes such as registration for classes. Nonetheless, dissatisfaction with advising came up for both public and private college second year students as an obstacle to their success. Juillerat's (2000) study is important because it is the only empirical study to date that attempts to compare second year students with other class years. However, her instrument included over 100 satisfaction variables which created only a very general picture into how students comparatively describe their satisfaction with all aspects of college. Her findings also were not tied to retention specifically but rather conceptually.

Pullins (2011) conducted an empirical study to predict college second year students" retention based on "satisfaction predictor variables" which included academic advising and campus climate. Limitations to her study are important to take into account. The limitations include the correlational design, which limits its predictive value, and the study's reliance on self-reported data. The sample size was large however, $(9,078$ college second year students at 65 institutions) lending power to the probability calculation of the independent variable (satisfaction) on the dependent variable (student persistence).

Pullins (2011), like Juillerat (2000), explored a large number of satisfaction variables in an attempt to show a predictive value for retention through satisfaction. One of those satisfaction variables included second year students' satisfaction with academic advising and faculty relationships. Pullins (2011) found that satisfaction with advising played a significant role for retention to the junior year which suggests looking much more closely at the nuances of second year attitudes and experiences with advising as a means to improve advising interventions toward increased retention to the third year. 
Converse to Juillerat (2000), however, who found satisfaction with advising as more important to private school sophomores, Pullins' findings showed that satisfaction with advising translated into a 14 percent increase in second year retention to the third year for public college students. Taken together, Juillerat's (2000) and Pullins' (2011) research conclusions support findings that Pullins (2011) cites in her literature by Seidman (1991) which links advising with persistence for students at public institutions.

Both Pullins (2011) and Juillerat (2000) assert their findings should be explored in future studies to better understand the association between advising and second year attrition. That they both find that academic advising is a significant factor in second year satisfaction and retention but find different results between private school students and public school students also supports a research design which focuses more deeply on advising by examining the attitudes toward and experiences with advising for second year students from both a private school and public school perspective (Juillerat, 2000; Pattengale, 2000; Pullins, 2011).

\section{Section Summary}

From a developmental perspective, this portion of the literature review provided a framework for understanding the second year college student as beginning a significant cognitive and developmental advance from the first year into the upper divisions of college that occurs during the second year of college (King \& Kitchener, 1994, 2002). Though few dispute decades of research supporting the importance to retention of 
interventions made in the first year, the second year transition to the junior year should be seen as important and oftentimes more difficult (Gahagan \& Hunter, 2006).

The evidence of low retention to the third year can be understood with this framework because the second year college student experiences unique developmental issues that may best be addressed by caring faculty and staff through the academic support environment and coinciding with a time when colleges routinely withdraw advising and assistance by faculty and staff. The important implication for this study is that second year students may need time during the transition to mature through the second year with advising and assistance from faculty and staff at a level, albeit different, from that received during the first year.

\section{The Retention Problem}

\section{Retention and Attrition Statistics}

Though most of what colleges do for retention has focused on helping students to their second year, and though this focus has relied on literature with extensive holes on helping students beyond their first year (Amaury, Barlow, \& Crisp 2005), studies do support the premise that attrition is also a problem during the second year of college. Early research from 1980 to the 1990s, for instance, estimated that nearly 50 percent of college students would not complete higher education (Porter, 1989). Two decades later, Ho Yu, DiGangi, Jannasch-Pennell, and Kaprolet (2010) used a data mining methodology to estimate the proportion of students who begin their second year of college, but do not return for their junior year. The authors acknowledge the copious research and data for 
retention to the sophomore year, but, unlike nearly all retention researchers, they also point out through their work and analysis of American College Testing data that attrition does not magically end when the second year begins. Instead, attrition remains at a high level through the second year so that colleges can expect to lose nearly as many students after the first year as they lost during that first year. The National Center for Public Policy and Higher Education in 2004 more conservatively estimates losses after the first year at 70 percent of first year losses.

Though statistics change from institution to institution, the pattern in the limited post-first year retention literature is generally the same. Given a 50 percent college graduation rate, for instance, 75 percent of college losses will occur before the junior year, with no less than a third or more of that coming between the second and third year. The remaining and comparatively very small attrition occurs during the junior and senior years. Amaury, Barlow, and Crisp (2005) looked at the small body of literature examining retention rates beyond the second year and point to data that confirm that 80 percent of first time college students persist to their second year and only 66 percent to their third year.

First year students who persist into their second year are wrongly assumed to be on the way to nearly assured graduation (Nealy, 2005) when the fact is that universities lose at least half -- and sometimes as many - second year students as they do new students. For instance, the national average second to third year retention rate is 83 percent (Noel-Levitz, 2011) leading to retention rates that have not budged in 30 years and graduation rates which have declined to as low as 51.6 percent in recent years despite 
enormous resources being poured into first year programs designed to increase retention university wide (ACT, 2009; Ho Yu et al., 2010; Pattengale, 2000; Tinto, 1993).

ACT data for 2000 and 2003, also shows that retention rates nationwide have not changed since the 1980s and early 1990s when first year programs had already taken hold nationally and increased first year retention from previous decades (Pascarella \& Terenzini, 2005).

Ho Yu, DiGangi, Jannash-Pennell, and Kaprolet's (2010) evaluation of ACT and NCPPHE data from the previous seven years shows that though first year attrition is high, it is only marginally higher than attrition from second year to third year. Additionally, Pattengale (2000) points out that most institutions lose at least half as many students during the second year as they do students during the first year, whereas students making it to their third year are highly likely to graduate within four or five years. Flanagan $(1991,2006)$ found in his study of selective liberal arts schools that a much larger number of second year students were failing to return for the junior year than expected and that the retention concerns for these universities was more acute than their concerns for students during their first year.

For some reason, however, the lingering belief is that rising to second year status equates to an on time graduation when evidence shows the opposite is true. In other words, once a student makes it past his or her second year, attrition rates drop significantly meaning that if a student successfully rises to the junior year, his or her chances of graduating within five years increase dramatically (Brainard \& Carlin, 1998; Gahagan \& Hunter, 2006). 


\section{Front Loading for Retention}

For decades the focus on increasing retention has understandably been on the first year, after which university support and resources are withdrawn as the institution focuses its finite resources on the next incoming class expecting the now second year students to be fine on their own. As discussed above, colleges routinely believe that after the first year, students will simply progress through the curriculum to graduate in four or five years. But this perception is not accurate, as will be further discussed below.

Much of the support granted to first year students is offered as a vital tool for university retention. This "front loading," as retention researchers have called it (Pascarella \& Terenzini, 2005; Tinto, 1988, 1993), is understandable from a retention point of view as research shows that interaction and developing a sense of belonging in the first year of school is vital to that sense of "fit" that students desire in their new academic and social setting (Walton \& Cohen, 2007). When a university makes the choice to focus on the first year in college, it does so with an eye toward retaining that student to the second year and, presumably to graduation. This choice, of course, potentially preserves the enormous investment Admissions made in getting the student to the college in the first place while focusing equally on the development of an important person - the student. The data, however, shows that to properly preserve the investment in the student, the college should concentrate on significant support through the first two years. To do otherwise is only putting half the effort required to promote the new student into the upper divisions. 
To summarize the above section, then, it seems that the challenge of transitioning to college continues through the second year; and while concerns may be different during the second year when compared to the first, they are no less serious, leading to attrition rates during the second year that sometimes approach losses colleges experience with first year students.

\section{Reasons for Departure}

Though the losses can be similar, the reasons for student departure seem to differ for second year students. For instance, Boivin, Beuthin, and Hauger's (1993) study of the second year noted that the reasons students gave for leaving during their second year were different from those given by students in their first year. Following up this study, Boivin, Fountain, and Bayard (2000) suggest that:

Unless consideration is given to the sophomore year experience, successive cohorts of first-year students will continue to weather the storms of first-year transition, only to bail out of higher education when they face the serious developmental challenges which continue and even intensify in the sophomore year. (p. 2)

Boivin, Fountain, and Bayard (2000) later provided support for reconsidering the second year experience with the finding that when students leave during the second year, they are more likely to report the departure occurred due to problems with the school itself and its inability to "deliver in terms of the students' initial expectations" (p. 1). These initial expectations are built during the first year when universities lavish attention 
on orientation and advising for students new to the college environment. According to the authors, those expectations are not met when the student arrives on campus for his or her second year only to find those resources and attention no longer available.

These studies taken together suggest that paying attention to retention through the second year might pay off dramatically for institutions who invest heavily in retention efforts. As these prior and more recent studies suggest, the second year of college brings with it an unexpectedly high attrition even after more than two decades of showering abundant attention on first year students. It seems that this attention, while warranted and responsible for early retention gains, is not enough to lift schools struggling with the retention problem. And while it is certainly costly when a student leaves after the first year, it is necessarily more so when the departure occurs during the second year or later. It is significant for the student who has invested two years and 60 academic credits by the end of the second year only to quit. A second year departure is also costly to universities who pour enormous resources into first year programs only to see the fruits of those efforts come to failure when the second year student fails to make the transition from second year student to mature upper division student.

\section{The Role of Advising Towards Retention for the Second Year Student}

The transition from brand new student through a period of time when a student is recognized by faculty as mature - as para-professional with them - is interrupted when the student leaves the institution they worked so hard to get to in the first place. Tinto's Model of Student Departure $(1988,1993)$ describes how this transition must include 
academic and social integration to come to fruition. According to Tinto's theory, if the student is not integrated academically or socially, the student himself cannot reach academic maturity, does not fully make the transition to para-professional academic, and will be more likely to drop out of school. This transition to para-professional is heavily influenced by the relationships students make outside of the classroom, especially the relationships students make with faculty and staff outside of the classroom.

Academic and social integration can occur through many avenues, of course, which creates challenges for practitioners wanting to know precisely where to focus their efforts to properly tackle student departure issues. Many of the theories of student retention developed in the last several decades seem to point to some salient commonalities - "hand holds" -- for practitioners to use in developing retention strategies. For instance, Tinto (2005) asserts that these hand holds, broadly understood, include academic preparation, commitments, and involvement. Gordan and Habley (2000) and Tinto and Pusser (2006) use slightly more specific language by suggesting that theories of student retention commonly point to student preparation, advising, and relationships with faculty and staff as institutionally vital components for retention (Gordan \& Habley, 2000; Tinto \& Pusser, 2006; Pascarella \& Terenzini 2005).

Concurrently, a Student/Institutional Engagement Model theoretical framework (Amaury, 2004) is used by Amaury, Barlow, and Crisp (2005) to examine the many factors which shape the student departure equation beyond the first year. These factors include those external to the institution's control such as pre-college abilities and a student's initial commitments to college as well as factors within the institution's control 
such as formal and informal interactions with faculty and staff. The framework lists six aspects within the factor of academic and social experiences, four of which relate directly to a student's experience with advising and faculty relationships. They are:

- Formal and informal interactions with faculty

- Involvement in learning communities outside of the classroom

- Validating experiences including encouragement and support from faculty and staff

- Mentoring experiences with faculty and advising staff

Amaury, Barlow, and Crisp's (2005) report thus provides the researcher with valuable data from a six year longitudinal profile using a database of student characteristics, academic performance, and attrition rates from what they describe as a "highly diverse student population enrolled at a major research university" (p. 130). Though the database is limited to one institution, upon analysis it does indeed provide a large and diverse sample size. The study also follows the prescription for research to consider attrition beyond the first year using longitudinal data. For this reason the authors' preliminary findings should be considered compelling for the research questions posed by this study. Specifically, their framework and preliminary findings lend credence to the recommendations for researchers to gather and examine data on students and their experiences with student support services in academic support environments where students might receive encouragement, validation, and the means to continue into the third year and onto graduation. 


\section{Support Services for Retention}

Though a comprehensive model for student persistence has not been fully developed (Tinto, 2005), the fairly recent congealment of theories in the Student/Institutional Engagement Model (Amaury, 2004) provides support for the many ways that universities employ student academic support programs to increase student persistence beyond the first year.

That support takes many forms and comes from several areas of each university; indeed, most universities utilize a diversity of interventions and efforts toward the goal of high retention. We see student affairs interventions and programs beginning pre-college with summer orientations, move in day at residence halls, orientation programs just prior to the start of school, as well as a host of diversity focused programs designed to orient multicultural, low SES, first generation, disabled, and other students identified as high risk. As the year proceeds, many universities also employ first year programs, first year residence halls, first year experience classrooms, first year faculty and staff mentoring, and special scholar programs all designed to enhance the student experience by bringing together student affairs with academic affairs into a co-curricular and longer term support network.

While these interventions have the potential to increase retention (Pascarella \& Terenzini, 2005), they often focus on only one year in college when the problem of retention should be considered over the entire lifespan of a college student's career. As has been suggested by research presented earlier in this review, interventions for retention to the third year should not be based on the template of support services used 
during the first year (Frost, 1991; Sanchez-Leguelinel, 2008). In other words, when it comes to advising for retention, one-size does not fit all (Smith \& Allen, 2006).

In further support of considering different support service approaches for different students, Smith and Allen (2006), in their study to understand advising at an urban university, identified 12 functions of academic advising that over the last 30 years have been identified in the literature as essential to quality academic advising. They then asked students to rate how important each function was to them and how satisfied they were with the advising they received on each function. Smith and Allen (2006) found that importance and satisfaction ratings varied by student characteristics, including class level. In particular, the authors found that importance ratings of 2 of the 12 functions varied, implying that as students move through college their perceptions of what they need change as they change. Though the study was limited because all participants were selfselected students from one institution, the sample size was large $(2,100)$ and diverse.

Smith and Allen (2006) summarize some of their findings with an assertion echoing previous researchers that the "one size fits all conceptualization of advising is inappropriate" (p. 63). This assertion lends considerable weight to approaching the second year student differently from the new or the upper division student because, from a developmental framework, the second year student is taking on a completely different set of tasks and problems while negotiating a transition into a more mature conceptualization of self, understanding of the nature of knowledge, and relationship with faculty and staff (Boivin et al., 2000; King \& Kitchener, 1994, 2002; SanchezLeguelinel, 2008). The nature of this developmental transition during the second year 
suggests looking to advising as a vital tool in the effort to increase second year student success.

\section{The Importance of Advising}

One of the great limitations in the literature on advising is the dearth of studies that empirically link advising to retention, especially for retention beyond the second year. Though evidence has been described as "spotty" (Bean, 2005), a small but important body of empirical research does exist linking advising to retention from the first year to the second.

Metzner's (1989) study is an early example of where evidence for the advising link to retention is made. Metzner (1989) cites eight studies which described a relationship between a student's perception of the quality of advising and retention. To support what she describes as the "equivocal nature of the research at the time" (p. 423), she also cites eight studies which did not find a relationship between the quality of advising and retention

Using a random and representative sample of 1,033 first year students at a large, public university, Metzner (1989) used ordinary least squares multiple regression to estimate her model. Through her analysis, Metzner found an indirect effect of advising on likelihood to dropout with intervening effects through GPA, intent to leave, utility (how useful the students thought their education would be for future employment), and satisfaction. In the discussion, Metzner states that "the best single strategy for improving retention is to offer good advising to students who would otherwise belong to the no 
advising group...increasing the quality from poor to good advising should also improve retention” (p. 434).

Another early empirical study by Seidman (1991) used an experimental design that showed that advising helped first year students persist to the second year at a much higher rate (up to 20 percent) than those not receiving advising. Additionally, in their extensive review of the retention and advising literature, Pascarella and Terenzini (2005) cite eight later empirical studies establishing a link through advising to persistence to the second year.

Advising interventions place students in direct contact with faculty and staff and are linked to student perceptions of university support leading to student success (Kuh, 2008). As a result, advising practices have recently been identified nationwide as being one of the three top contributors to increasing retention (Habley et al., 2004).

The empirical evidence linking advising to retention from the second to third year, however, is considerably more scarce. One early study (Wilder, 1993) does provide empirical evidence supporting advising as important to retention to the junior year. Wilder (1993) conducted her study to identify factors that contributed to attrition for second year students whose GPAs exhibited at least a 20 percent decline from their first year. Using discriminant analysis, she tested six hypotheses of variables that impact academic performance, four of which were found significant at the $\mathrm{p}<.05$ level. Though the study was limited by its small population of 196 students at one university and for its use of discriminant analysis rather than a regression equation, her statistically significant findings relative to advising are important to the direction of this study. Specifically, 
Wilder (1993) found that contact with faculty and staff, especially in the advising relationship, was a significant variable for the second year population she studied. Based on this finding, Wilder recommended that institutions reconsider their approach to advising second year students to focus on assisting them in managing unique second year tasks such as decision making about majors and careers.

Fairly recent research into advising in the college setting also suggests the importance of advising to how a student perceives the collegiate experience (Gordon, Habley, \& Grites, 2008; Pascarella \& Terenzini, 2005; Pullins, 2011), to the support of second year students in their specific developmental needs, (Anderson \& Schreiner, 2000; Boivin et al., 2000) and as an efficacious tool for increasing retention and student satisfaction (Nealy, 2005).

Earlier conceptual work into the efficacy of advising includes Susan Frost's Academic Advising for Student Success (1991). The work is limited due to its conceptual nature, not being based empirically, and for the time span since its publication. But Frost (1991) does draw upon very early research in the 1980s from the National Institute of Education (1984) and Ernest Boyer (1987) that advocates advising as a "principal tool" in assisting students for academic success. This early work by Frost also establishes important concepts for understanding the relationship of advising to student success.

Frost (1991) suggested that students need advising if for no other reason than to simply figure out which classes to take and where to find things (prescriptive advising). But advising has a great deal more potential toward student development and student 
success than simply pointing the way. For one thing, advising of some sort does occur over the entire span of a student's college career. First year programs on the other hand last through the first year only, if that. Advising also puts college students in direct contact with a professional academician or staff person and such contact has been identified as nearly as important as peer contact for impacting a student's perceptions of his or her experiences (Boivin et al., 2000).

Salient to this study is Frost's (1991) additional call to focus advising efforts on students with special needs (new students and students with disabilities for instance) and students in transition (transfer students and undecided students - the majority of whom are second year students). She states that "perceptive advisers" will encourage all students in transition to focus on exploring developmental tasks now associated specifically with the second year - academic, career, and life goals leading to choice of major and transition to greater self efficacy in the junior year. Second year students, however, are missing from her list because the concept of second year students as being in transition or needing special support had barely been considered by 1991. Now that literature exists to support the concept of second year students as being unique from first year and upper division students as well as being in transition, Frost's recommendation can logically be extended to include the second year student.

Frost (1991) was also an early promoter of the concept that advising can be efficacious for retention and student success by asserting through her literature review and research that faculty-student contact encourages student involvement, student involvement encourages persistence, and advising increases the likelihood of faculty- 
student involvement. With this equation, Frost conceives of advising theoretically, if not empirically, as a key factor towards greater retention and student success.

Indeed, universities all employ some form of advising because the advising process and relationships with faculty have for decades been identified as a key to the support of students from first year to last. Advising at its simplest provides directions and prescriptions for how to do things and find things. At a higher developmental level, advising is itself a form of involvement in line with Astin's theory of involvement (Astin, 1993) because faculty-staff contact is a form of involvement for students through

programs such as advising which are linked to student success and persistence (Anderson \& Schreiner, 2000; Kuh, 2008).

\section{Advising Attitudes and Experiences}

Bean (2005) advances Tinto’s research by shifting the focus of retention away from previous approaches that concentrated on what retention programs are supposed to accomplish towards what attitudes those programs engender in students toward the institution. Bean (2005) offered nine themes of retention. One of his themes focused on how a student interacts with the academic environment. Though Bean (2005) cautions universities to not overestimate the importance of this theme, he explains that students develop attitudes while interacting with faculty and staff in academic environments such as the classroom and through advising that impacts their sense of academic self efficacy and consequently their decision to stay or leave. With this focus in mind, it makes sense to conduct research about the attitudes towards advising experiences between second year 
students who leave with those who become juniors and between second year students and first year and upper division students.

Anderson and Schreiner (2000) are more specific in asserting that the "academic advising relationship holds particular promise as a strategy for supporting sophomores and encouraging their success" (p. 55). According to their observations and review of research, second year students are making important choices regarding career, major, and personal identity at a time when the "advising picture for sophomores is rather bleak" ( $\mathrm{p}$. 55). Anderson and Schreiner (2000) note that while second year students are often randomly assigned to advisors who may or may not care about them as individuals, second year students actually will benefit from an intentional assignment of faculty or staff who understand and care about their unique needs.

Finally important to this study is what Frost (1991) drew from her review of the retention and advising literature with respect to attitudes and experiences. Simply put, she found through her research that attitudes toward advising have an important influence on the decisions students make about staying in college or not. Despite the stated limitations on Frost's early research, her suggestions do correspond well with the research about retention and advising that followed her writing through the late 1990s up until the present day. And her writing foreshadows the focus on second year students' attitudes towards and experiences with advising taken up by this study. 


\section{Summary and Conclusion}

The purpose of this literature review was to expand the understanding of the retention problem beyond the first year of college and to consider advising attitudes and experiences of second year students. King and Kitchener's (1994, 2002) Reflective Judgment Model was further elucidated to provide a framework for conceptualizing the second year as a time of transition as important as the transition to college from high school.

Since one of the lingering problems institutions face is low graduation rates and those low rates seem to be the result of focusing mostly on first year retention efforts, institutions need to look beyond their ubiquitous and longstanding first year retention practices if they have any hope of improving retention. The second year of college has been identified as the time of highest attrition after the first year, and so the second year represents the apparent first place for institutions to focus new, research based retention efforts.

Advising is an important place to look for ways to increase second year retention because faculty and staff are responsible for advising, and the mentoring that occurs is an important by-product of advising. Tinto $(1988,2006)$ asserts that it is the faculty and staff who are keys to an institution's efforts to enhance student retention; and Kuh (2008) points out that advising puts students in direct contact with faculty and staff representing a "precious opportunity of meaningful interaction" (p. 79). Besides the residence halls where staff and faculty live with students, the advising and faculty/staff 
mentoring engagements on campus are the institution's best way to formalize interested adult interactions with students (Lotkowski, Robbins, \& Noethe, 2004).

Habley and McLanahan (2004) further state that advising practices are among the top three most important institutional practices for retention, along with first year programs and learning support. Smith and Allen (in press) additionally showed how students who availed themselves of advising were significantly more likely to score higher on advising learning outcomes the authors identified as consistent with retention.

Furthermore, perceptions, or attitudes, towards advising affect a student's success through college (Kuh, 2008). In order to develop effective advising efforts specific to second year success, educators need to better understand how second year students may differ in their attitudes and experiences - their perceptions - of the advising experience. Knowing how those attitudes and experiences differ for second year students will provide advisors with a better understanding of the academic and social integration transition that students continue through their second year.

As discussed above, the second year transition to upper division student involves honing an academic persona through the last stages of academic and social integration, which involves important and life defining decisions such as settling on a major and choosing a career. The transition is vital to a student becoming a junior, a senior, and then on to graduation and the professional world.

Research concerning the second year of college as it relates to retention has grown but still remains sparse. Most of the literature available for this review includes important descriptive and qualitative research or literature based on conjecture gleaned 
from past literature, program reviews, and professional experiences. . Empirical data about the topic is particularly slight. Most recently, and as discussed above, three empirically based dissertations on the topic of second year students have been produced since 2009 , two of which addressed second year retention specifically.

These recent studies do not, however, examine the untested assumptions that have dominated the second year literature to date that second year students differ from first year and upper division students. To review, Pullins' (2011) dissertation about satisfaction and retention states that satisfaction with advising predicts retention to the upper divisions of college. This is an important finding but it is necessary to delve more deeply into Pullins' (2011) link of advising satisfaction with retention to learn whether second year students actually differ from their first year and upper division peers as well as from their second year peers who leave. This and other prior research also does not take into account how second year students differ in what they identify as important in the advising experience nor how second year students assess themselves differently on what they know, do, or value as a result of involvement in advising experiences.

Further research is, therefore, needed to help practitioners and future researchers better understand the second year transition and the unique needs of second year students as they progress through this transition, as well as how these needs may differ from new and upper division students. Ultimately the questions posed by this study have been formulated because we need to know how second year students might differ in their attitudes towards and experiences with advising and faculty/staff interactions from other students and from second year dropouts in order that future programs might succeed in 
adding another solution to the retention puzzle by increasing the retention of second year students.

In the next chapter, the methodology for this study will be described in detail including information about the correlational research design, participants, data collection and analysis. 


\section{CHAPTER 3}

\section{METHODOLOGY}

The purpose of this chapter is to describe the methods used to address the six research questions posed in this study. Included is an outline of the research design, participant information, measures used, variables, procedures, and data analysis methods.

\section{Research Design}

Creswell (2008) identifies two types of correlational research designs - explanatory and predictive. An explanatory correlational design is used when the objective of the study is to explain the association between or among variables. The predictive design is best suited for research questions which identify variables intended to predict an outcome. This study seeks to explain the relationship between and among variables to consider how they co-vary. The goal is not to create a predictive design. Therefore this study was conducted as an explanatory correlational research design (Creswell 2008). Furthermore, the design uses simultaneous multiple regression to control for covariates in order to identify how variables are uniquely associated.

\section{Data Collection}

This research involved the examination of pre-existing data. This data came from survey responses collected in the spring of 2010 and 2011 from students enrolled in five public universities, two private universities, and two community colleges in Oregon. The 
survey administrators invited all fully admitted students at the universities and all students enrolled in credit-bearing classes at the community colleges to participate in the survey. The data were collected through the cooperation of a research collaborative headed by Dr. Janine Allen and Dr. Cathleen Smith, both faculty at Portland State University. Approval of the research protocol involving human subjects was secured from the institutional review boards at eight of the nine study institutions. Approval of the research protocol for the ninth institution was secured from the institutional review board of Portland State University. For the present study, the survey responses of students enrolled at five of the public universities and the two private universities were used. Community college students in the larger sample were not selected because by definition these institutions only serve lower division students, thus it is not possible for students to advance to their junior year at these institutions. Furthermore, community college students are more likely to be older, be independent of their parents, and express a great diversity of reasons for matriculation (which may not be obtaining a four-year degree) than traditionally aged college students in four year institutions (Horn, Nevill, \& Griffith, 2006).

\section{Participants}

Table 1 provides names, Carnegie classification, and size (fulltime equivalent enrollment), when the survey was administered, number of participants, and response rate of the seven study institutions. 
Table 1

Carnegie Classification and Fulltime Equivalent (fte) Enrollment of Study Institutions, Number of Participants from each Study Institution

\begin{tabular}{|l|l|l|l|l|l|}
\hline Institution & $\begin{array}{l}\text { Carnegie } \\
\text { Classification }\end{array}$ & $\begin{array}{l}\text { Institution } \\
\text { FTE }\end{array}$ & $\begin{array}{l}\text { Number of } \\
\text { participant } \\
\text { s }\end{array}$ & $\begin{array}{l}\text { Survey } \\
\text { Administere } \\
\text { d }\end{array}$ & $\begin{array}{l}\text { Respon } \\
\text { se Rate }\end{array}$ \\
\hline University 1 & $\begin{array}{l}\text { Master's (small } \\
\text { programs) }\end{array}$ & 3721 & 1225 & Spring 2011 & 32.9 \\
\hline University 2 & $\begin{array}{l}\text { Master's (medium } \\
\text { programs) }\end{array}$ & 4875 & 1495 & Spring 2010 & 30.7 \\
\hline University 3 & $\begin{array}{l}\text { Research } \\
\text { University (high } \\
\text { research activity) }\end{array}$ & 21674 & 2748 & Spring 2010 & 12.7 \\
\hline University 4 & $\begin{array}{l}\text { Research } \\
\text { University (very } \\
\text { high research } \\
\text { activity) }\end{array}$ & 18514 & 3647 & Spring 2010 & 19.7 \\
\hline University 5 & $\begin{array}{l}\text { Research } \\
\text { University (very } \\
\text { high research } \\
\text { activity) }\end{array}$ & 19558 & 4003 & Spring 2011 & 20.47 \\
\hline Private 1 & $\begin{array}{l}\text { Master's (larger } \\
\text { programs) }\end{array}$ & 1117 & 437 & Spring 2010 & 39.1 \\
\hline Private 2 & $\begin{array}{l}\text { Master's (larger } \\
\text { programs) }\end{array}$ & 3037 & 1599 & Spring 2010 & 52.7 \\
\hline
\end{tabular}

The survey sample for this study consisted of 15,154 undergraduate students at the seven universities as shown in Table 1 above. From that survey sample of all participants from the seven study institutions, I selected undergraduate students from the overall sample at the seven universities who were under the age of 25 at the time of the survey who enrolled in one of the universities directly from high school (enrolled in their university the fall term after graduating from high school). Using this definition, the overall sample for this research consisted of 8500 students under the age of 25 . 
I selected students under the age of 25 (traditionally aged students) based on the developmental framework of King and Kitchener $(1994,2002)$ who identify a developmental transition from pre-reflective to quasi-reflective reasoning that occurs in the traditional ages of the first, second, and upper divisions of college. According to two decades of longitudinal research by King and Kitchener, these stages are sequential and correlate highly with age (17-22). In addition, the age correlated and sequential stages are linked to traditionally-aged class standing levels of educational attainment (i.e. firsttime, full-time freshman being about aged 18, first-time, full-time sophomores about aged 19-20, and so on).

The demographic data on the sample from each study institution was compared with the demographic profile of the target population from that institution. Table 2 below provides this information. Appendix A provides a demographic table for each institution. In general, survey respondents were more likely to be female, Asian, and Hispanic compared to the general population. African American and Native American students were slightly underrepresented compared to the general population.

Table 2

Comparison of Sample Demographics with Population Demographics

\begin{tabular}{|c|c|c|c|c|}
\hline & Sample & Percent & Population & Percent \\
\hline Sex & & & & \\
\hline Female & 9,667 & $63.9 \%$ & 37,610 & $51.9 \%$ \\
\hline Male & 5,434 & $35.9 \%$ & 34,683 & $47.8 \%$ \\
\hline Unknown & 5 & $0.0 \%$ & 203 & $0.3 \%$ \\
\hline Total & 15,133 & & 72,496 & \\
\hline Race/Ethnicity & & & & \\
\hline Asian American & 1,301 & $8.6 \%$ & 5,544 & $7.6 \%$ \\
\hline African American & 213 & $1.4 \%$ & 1,587 & $2.2 \%$ \\
\hline Hispanic & 884 & $5.8 \%$ & 3,782 & $5.2 \%$ \\
\hline
\end{tabular}




\begin{tabular}{|c|c|c|c|c|} 
Native American & 169 & $1.1 \%$ & 914 & $1.3 \%$ \\
\hline White & 10,955 & $72.4 \%$ & 50,014 & $69.0 \%$ \\
\hline Multiple & 256 & $1.7 \%$ & 500 & $0.7 \%$ \\
\hline $\begin{array}{c}\text { Non-resident } \\
\text { Alien }\end{array}$ & 0 & & & \\
\hline Unknown & 1,355 & $9.0 \%$ & 6,736 & $9.3 \%$ \\
\hline Total & 15,133 & & 72,496 & \\
\hline Class Level & & & & \\
\hline Freshman & 2,024 & $13.4 \%$ & 1,148 & $27.4 \%$ \\
\hline Sophomore & 2,807 & $18.5 \%$ & 970 & $23.1 \%$ \\
\hline Junior & 3,620 & $23.9 \%$ & 957 & $22.8 \%$ \\
\hline Senior & 6,588 & $43.5 \%$ & 1,120 & $26.7 \%$ \\
\hline Missing & 94 & $0.6 \%$ & 0 & \\
\hline Total & 0 & & 0 & \\
\hline Total & 15,133 & & 4,195 & \\
\hline Age & & & & \\
\hline$>18$ & 27 & $0.2 \%$ & 1,394 & $1.9 \%$ \\
\hline $18-24$ & 11,317 & $74.8 \%$ & 54,490 & $75.2 \%$ \\
\hline $25-29$ & 1,484 & $9.8 \%$ & 8,035 & $11.1 \%$ \\
\hline $30-35$ & 895 & $5.9 \%$ & 4,121 & $5.7 \%$ \\
\hline$>35$ & 1,382 & $9.1 \%$ & 4,430 & $6.1 \%$ \\
\hline Unknown & 28 & $0.2 \%$ & 26 & $0.0 \%$ \\
\hline Total & 15,133 & & 72,496 & \\
\hline
\end{tabular}

\section{Measures}

Measures for this study came from the survey instrument developed by Smith and Allen (2006), the Inventory of Academic Advising Functions-Student Version. The survey was adapted slightly for each institution. For instance, the name of the institution was used and response options for questions that asked students where they received their advising were actual places at that institution. The generic version (non institutional specific) of the survey is included in Appendix B. 
The survey asked students about their attitudes toward and experiences with academic advising and other aspects of their education. Students were asked, "Which of the following describes where at name of institution you get your PRIMARY academic advising, that is, the advising you consider most central to your academic progress?" Students chose one option from a list that included general institutional representatives that existed at all study institutions ("faculty advisor in my program of study") as well as advising offices (e.g., "advising center," "student support office”) unique to each institution. The options referred either to an actual person or to an office where a student might interact with faculty or staff advisors. Because most institutions did not have mandatory advising systems, the list also included the following no advising option: "I have not received academic advising from faculty or staff at name of institution."

The survey also asked students to rate the importance of and their satisfaction with 12 advising functions which operationalize five domains that Smith and Allen (2006) found had been consistently identified as essential to the advising role: integration, referral, information, individuation, and shared responsibility. Table 3 below lists each of the 12 advising functions with its corresponding variable name and construct (integration, referral, information, individuation, and shared responsibility). 
Table 3

\begin{tabular}{|c|c|}
\hline Variable Name & Academic Advising Functions and Survey Items \\
\hline & Integration Functions \\
\hline Overall connect & $\begin{array}{l}\text { Advising that helps students connect their academic, career, and } \\
\text { life goals }\end{array}$ \\
\hline Major connect & $\begin{array}{l}\text { Advising that helps students choose among courses in the major } \\
\text { that connect their academic, career, and life goals }\end{array}$ \\
\hline Gen Ed connect & $\begin{array}{l}\text { Advising that assists students with choosing among the various } \\
\text { general education options (e.g., choice of capstone, cluster, } \\
\text { courses within cluster) that connect their academic, career, and life } \\
\text { goals }\end{array}$ \\
\hline Degree connect & $\begin{array}{l}\text { Advising that assists students with deciding what kind of degree to } \\
\text { pursue (bachelor of arts, bachelor of music) to connect their } \\
\text { academic, career, and life goals }\end{array}$ \\
\hline \multirow[t]{2}{*}{$\begin{array}{l}\text { Out-of-class } \\
\text { connect }\end{array}$} & $\begin{array}{l}\text { Advising that assists students with choosing out-of -class } \\
\text { activities (e.g., part-time employment, internships or practicum, } \\
\text { participation in clubs or organizations) that connect their } \\
\text { academic, career, and life goals }\end{array}$ \\
\hline & Referral Functions \\
\hline Referral academic & $\begin{array}{l}\text { When students need it, referral to campus resources that address } \\
\text { academic problems (e.g., math or science tutoring, writing, } \\
\text { disability accommodations, testing anxiety) }\end{array}$ \\
\hline \multirow[t]{2}{*}{$\begin{array}{l}\text { Referral non- } \\
\text { academic }\end{array}$} & $\begin{array}{l}\text { When students need it, referral to campus resources that address } \\
\text { non-academic problems (e.g., child care, financial, physical, and } \\
\text { mental health) }\end{array}$ \\
\hline & Information Functions \\
\hline How things work & $\begin{array}{l}\text { Assisting students with understanding how things work at this } \\
\text { university (understanding time lines, policies, and procedures with } \\
\text { regard to registration, financial aid, grading, graduation, petition, } \\
\text { and appeal, etc.) }\end{array}$ \\
\hline \multirow[t]{2}{*}{$\begin{array}{l}\text { Accurate } \\
\text { information }\end{array}$} & $\begin{array}{l}\text { Ability to give students accurate information about degree } \\
\text { requirements }\end{array}$ \\
\hline & Individuation Functions \\
\hline $\begin{array}{l}\text { Skills abilities } \\
\text { interests }\end{array}$ & $\begin{array}{l}\text { Taking into account students' skills, abilities, and interests in } \\
\text { helping them choose courses }\end{array}$ \\
\hline \multirow[t]{2}{*}{$\begin{array}{l}\text { Know as } \\
\text { individual }\end{array}$} & Knowing the student as an individual \\
\hline & Shared Responsibility Function \\
\hline $\begin{array}{l}\text { Shared } \\
\text { responsibility }\end{array}$ & $\begin{array}{l}\text { Encouraging students to assume responsibility for their education } \\
\text { by helping them develop planning, problem-solving, and decision- } \\
\text { making skills }\end{array}$ \\
\hline
\end{tabular}


For each function, participants were asked, "How important is this advising function to you?" and rated the importance using a 6 point Likert-type scale, where scale point $1=$ Not Important and scale point $6=$ Very Important. Students were also asked about their satisfaction with the advising they receive on each function, "How satisfied are you with the advising you receive on this function?" and rated their satisfaction using a 6 point Likert-type scale, where scale point $1=$ Not Satisfied and scale point $6=$ Very Satisfied. Students who indicated when asked where at the institution they received their primary advising that they had not receive advising from anyone at the institution were not asked the satisfaction questions.

The survey also included seven advising learning outcome statements. Smith and Allen (2006) describe these advising learning outcomes as statements that represent what we would expect students to know, do, or value as a result of participation in academic advising. Table 4 lists each of the learning outcomes and its corresponding variable names. Students were asked to rate their level of agreement with each learning outcome using a 6 point Likert-type scale, where scale point $1=$ Strongly Disagree and scale point $6=$ Strongly Agree 
Table 4

Advising Learning Outcomes
\begin{tabular}{|l|l|}
\hline \multicolumn{1}{|c|}{ Variable Name } & \multicolumn{1}{c|}{ Advising Learning Outcome } \\
\hline Knows Requirements & $\begin{array}{l}\text { I know what requirements (e.g., major, general } \\
\text { education, other university requirements) I must } \\
\text { fulfill in order to earn my degree }\end{array}$ \\
\hline Knows Resources & $\begin{array}{l}\text { When I have a problem, I know where I can go to } \\
\text { get help }\end{array}$ \\
\hline Understands How Things Work & $\begin{array}{l}\text { I understand how things work (timelines, policies, } \\
\text { and procedures with regard to registration, financial } \\
\text { aid, grading, graduation, petition and appeals, etc. }\end{array}$ \\
\hline Understands Connections & $\begin{array}{l}\text { I understand how my academic choices connect to } \\
\text { my career and life goals }\end{array}$ \\
\hline Has Educational Plan & I have a plan to achieve my educational goals \\
\hline Has Significant Relationship & $\begin{array}{l}\text { I have had at least one relationship with a faculty or } \\
\text { staff member that has had a significant and positive } \\
\text { influence on me }\end{array}$ \\
\hline $\begin{array}{l}\text { Values Advisor-Advisee } \\
\text { Relationship }\end{array}$ & $\begin{array}{l}\text { It is important to develop an advisor-advisee } \\
\text { relationship with someone on campus }\end{array}$ \\
\hline
\end{tabular}

\section{Procedures}

Using a secure data transfer protocol, the institutional research office at each of the seven institutions uploaded to a secure server at Portland State University a file containing the names and email addresses of students who met the criteria - for universities, fully admitted undergraduate students enrolled during the term in which the survey was administered. Each student record was assigned a unique data reference number by the institutional research personnel from the respective institution. The survey was administered using Qualtrics Online Survey Software licensed to Portland State University.

Students were sent an email from a senior administrator at their institution inviting them to participate in the web-based survey through an embedded link. The 
elements of informed consent were included in the email message. The purpose of the survey was described to the students, and they were advised that their response would be kept confidential, their participation was voluntary, and whether or not they participated in the survey would not affect their relationship with the university. Two weeks after the initial email, a follow-up email was sent to the students who had not yet taken the survey; two weeks later a second follow-up email was sent to the students who had not taken the survey. As an incentive, students at six of the seven institutions were offered a chance to be randomly selected to receive one of four $\$ 50$ gift certificates to the institution's bookstore. Students at the seventh institution were not offered the incentive because institutional policy at that institution prohibited the use of incentives for students to participate in research; however, this institution's response rate $(20.5 \%)$ was comparable to or higher than the other research universities. See Appendix $C$ for an example email sent to students.

Once the survey was closed, survey responses from those who participated were transferred to SPSS and the students' names and email addresses were deleted. Only the data reference number was paired with the students' survey responses. In addition, the original files provided by the institutional research offices which contained the names and email addresses of students invited to participate were destroyed.

The data reference numbers were sent to institutional research personnel at each institution who used them to provide demographic and enrollment data on the students who participated in the survey. See Appendix A for a list of demographic data provided. Each year since the survey was administered, institutional research personnel at each 
institution use the data reference number to provide information about retention for that number.

Because the data used was secondary data, I submitted a request to Portland State University's Human Subjects Research Review Committee (HSRRC) to determine that a human subjects review is not required (see Appendix D for the HSRRC request and approval). The HSRRC subsequently determined that a review was not required, whereupon my advisor provided me with a file containing data on the participants who met the criteria specified above -- traditionally-aged students who enrolled in one of the seven universities directly from high school. The file contained no identifying information that could link data back to individual participants.

\section{Data Analysis}

Six questions were posed in this study. The first three questions were posed to consider whether second year students differed from first year students and/or upper division students in their attitudes about and experiences with academic advising. These questions were:

1. Do second year students differ from first year and upper division students in the importance they ascribe to any of the twelve advising functions?

2. Do second year students differ from first year and upper division students in their satisfaction with any of the twelve advising functions? 
3. Do second year students differ from first year and upper division students in their level of agreement with statements that reflect what students know, do, or value as a result of receiving academic advising (Learning Outcomes)?

Simultaneous regression analyses were conducted to address these three research questions. Simultaneous regression allows us to control for confounding variables that might influence the continuous outcome variable - in this case student advising importance and satisfaction ratings as well as learning outcome scores. A separate regression analysis was conducted for each importance (12) satisfaction (12), and learning outcome (7) variable. Independent variables entered into each regression included dummy coding which was used to create two variables for year in school. For the first dummy variable (represented in Figure 1 as dummy variable 1), second year students were coded as 0 and first year students were coded as 1 . For the second dummy variable (Dummy variable 2 in Figure 1 below), second year students were coded as 0 and upper division students as 1. Other independent variables (listed below, which represented factors that have been conceptually or empirically associated with the outcome variables, were entered into the model to determine if year in college was uniquely associated with the students' importance and satisfaction ratings and their scores on the learning outcomes. These variables were Gender, Financial Need, First Generation College Student, African American, Asian American, Hispanic, Multiple Ethnicities, Native American, and Private Institution for importance and satisfaction ratings and Size 
of Institution and Institutional GPA at Time of Survey for learning outcomes (Smith \& Allen, 2006, 2008).

The second set of questions, which were posed to consider whether second year students who are retained differ from second year students who are not retained in their attitudes about and experiences with academic advising, compared two groups and required a logistic regression model. These questions were:

4. Do retained second year students differ from not retained second year students in the importance they ascribe to any of the twelve advising functions?

5. Do retained second year students differ from not retained second year students in their satisfaction with any of the twelve advising functions?

6. Do retained second year students differ from not retained second year students in their level of agreement with statements that reflect what students know, do, or value as a result of receiving academic advising (Learning Outcomes)?

I created a binary logistic regression model to examine differences in questions four through six between groups formed by retained and not retained second year students. Logistic regression allows us to control for confounding variables that might influence the continuous outcome variable - in this case student advising importance and satisfaction ratings as well as learning outcome scores. A separate regression analysis was conducted for each importance (12) satisfaction (12), and learning outcome (7) variable. Independent variables entered into each regression included dummy coding which was used to create two variables for retained and not retained second year students. 
For the first dummy variable (represented in Figure 1 as dummy variable "retained"), retained second year students were coded as 0 and not retained second year students were coded as 1. Other independent variables, which represented factors that have been conceptually or empirically associated with the outcome variables, were entered into the model to determine if second year retention status in college was uniquely associated with the students' importance and satisfaction ratings and their scores on the learning outcomes.

As reported in Table 2 and referred to earlier in this chapter, the sample contained an underrepresentation of men (who are less likely to respond to surveys), African American, and Native American students. Women, Asian American, and Hispanic students were overrepresented. Student characteristics such as those included in the sample are associated with attitudes toward and experiences with academic advising (Smith \& Allen, 2006) . Also, GPA has been identified as having an influence on retention. For these reasons, my data analysis included Logistic Regression analysis to consider confounding variables that might influence my results (Field, 2009).

\section{Regression Models}

Data was entered into SPSS 18.0 for Windows, a statistical software program, and one regression model was created for each question.

Ordinarily, a method to control for Type I error across the multiple tests of statistical significance would be warranted. But considering the absence of research that compares perspectives on advising of second year students with those of first year 
students and upper division students, I also was concerned with failing to detect differences that actually may exist. Thus, rather than use a conservative procedure such as the Bonferroni procedure, I considered all findings that were at the $\mathrm{p}<.05$ significance level.

I included several statistics for evaluating the strength of the logistic regression model. The log likelihood statistic (-2LL) for each logistic regression test is the goodness of fit model included to assess the improvement of the model after a predictive variable is included. A lower -2LL after the predictor variable is included indicates the model has been improved by the addition of the variable. The Hosmer and Lemeshow statistic is also reported as a part of the goodness of fit test. When the Hosmer and Lemeshow statistic is insignificant it indicates the appropriateness of the model to the data (Field, 2009).

The Chi-square statistic and its significance were reported as a means to determine if the overall model is significant. The value given in the "sig" column is the probability of obtaining the Chi-square statistic if there is no effect of the independent variables on the dependent variable.

The $\beta$ value is included and reported along with the Standard Error on $\beta$ (SE). The $\beta$ is an expression of the weight for the value of each predictor variable. These values indicate the increase or decrease of the effect on the outcome variable by the independent variables and are reported in log odds values. The $\beta$ is also reported in a log odds ratio called the $\operatorname{Exp}(\beta)$ statistic. This study reports effect size using the Nagelkerke $\mathrm{R}^{2}$ and the Cox and Snell $\mathrm{R}^{2}$. 
Figure 1

Dummy Coded Variables

\begin{tabular}{|c|c|c|c|c|}
\hline $\begin{array}{c}\text { Research } \\
\text { Question 1-3 }\end{array}$ & $\begin{array}{c}\text { Dummy } \\
\text { Variable 1 }\end{array}$ & $\begin{array}{c}\text { Dummy } \\
\text { Variable 2 }\end{array}$ & $\begin{array}{c}\text { Research } \\
\text { Question 4-6 }\end{array}$ & $\begin{array}{c}\text { Dummy } \\
\text { Variable } \\
\text { Retained }\end{array}$ \\
\hline Second Year & 0 & 0 & Retained & 0 \\
\hline First Year & 1 & 0 & Not Retained & 1 \\
\hline Upper Division & 0 & 1 & & \\
\hline
\end{tabular}

\section{Summary}

The purpose of this chapter was to outline the research design for this study along with information about the study's participants, instrument, data collection procedures, and the techniques to be used for analyzing the data in consideration of the two sets of research questions. 


\section{CHAPTER 4}

\section{RESULTS}

In this chapter I present the results of data analysis conducted to address the six research questions posed in the study. Those research questions are:

1. Do second year students differ from first year and upper division students in the importance they ascribe to any of the twelve importance ratings?

2. Do second year students differ from first year and upper division students in their satisfaction with advising?

3. Do second year students differ from first year and upper division students in their level of agreement with statements that reflect what students know, do, or value as a result of receiving academic advising (Learning Outcomes)?

4. Do retained second year students differ from not retained second year students in the importance they ascribe to any of the twelve importance ratings?

5. Do retained second year students differ from not retained second year students in their satisfaction with advising?

6. Do retained second year students differ from not retained second year students in their level of agreement with statements that reflect what students know, do, or value as a result of receiving academic advising (Learning Outcomes)?

Due to the large number of individual data tables required to report the results, I have included a summary of significant results for each research question in table in the text. The tables that present the results of all analyses are in Appendix E. 


\section{Differences between Second Year Students and First Year Students and Upper \\ Division Students}

\section{Importance Ratings}

To answer the first research question, which asked whether second year students differ from first year students and/or upper division students in the importance they ascribe to any of the twelve importance ratings, I conducted 12 simultaneous regression analyses - one for the importance ratings of each advising function. To determine if year of enrollment was uniquely associated with importance ratings, I entered into the regression analyses student characteristics found in previous research to be associated with importance ratings. Thus, in addition to the dummy variable used to compare second year students with first year students and the dummy variable used to compare second year students with upper division students, I included the following control variables in the regression analyses: Gender, Financial Need, First Generation College Student, African American, Asian American, Hispanic, Multiple Ethnicities, Native American, and Private Institution.

Results of the 12 simultaneous regression analyses are found in Tables 20-31 located in Appendix E. Table 5, found below, provides the n, mean, and standard deviation of importance rating of each advising function for first year students, second year students, and upper division students. All importance ratings for all three groups were on the importance end of the scale - above scale point 4 on the 6-point scale. For all three groups, Accurate Information was the function rated highest in importance with the 
lowest standard deviation. For all three groups, Referral Non-Academic was rated lowest in importance with the highest standard deviation.

Table 5 also provides a summary of the results of the regression analyses examining differences between first year students and second year students and between second year students and upper division students when relevant student characteristics were controlled. Table 6 provides only the statistically significant results of the 12 regression analyses.

Table 5

Numbers, Means, and Standard Deviations of Importance Ratings of First Year, Second Year, and Upper Division Students and Summary of Results of Simultaneous Regression Analyses Comparing Importance Ratings of Second Year Students with First Year Students and Upper Division Students

\begin{tabular}{|c|c|c|c|c|c|}
\hline & & $n$ & Mean & $s d$ & Sig. \\
\hline \multirow[t]{3}{*}{ Overall Connect } & First Year & 2471 & 4.85 & 1.09 & \\
\hline & Second Year & 1973 & 4.89 & 1.06 & \\
\hline & $\begin{array}{l}\text { Upper } \\
\text { Division }\end{array}$ & 3746 & 4.91 & 1.13 & \\
\hline \multirow[t]{3}{*}{ Major Connect } & First Year & 2467 & 5.07 & 1.00 & \\
\hline & Second Year & 1966 & 5.03 & 1.02 & \\
\hline & $\begin{array}{l}\text { Upper } \\
\text { Division }\end{array}$ & 3732 & 5.01 & 1.06 & \\
\hline \multirow[t]{3}{*}{ Gen Ed Connect } & First Year & 2449 & $4.67^{1}$ & 1.18 & $* *$ \\
\hline & Second Year & 1948 & 4.56 & 1.24 & \\
\hline & $\begin{array}{l}\text { Upper } \\
\text { Division }\end{array}$ & 3705 & $4.44^{4}$ & 1.34 & $* *$ \\
\hline \multirow[t]{3}{*}{ Degree Connect } & First Year & 2439 & $4.70^{1}$ & 1.29 & $* *$ \\
\hline & Second Year & 1951 & 4.57 & 1.37 & \\
\hline & $\begin{array}{l}\text { Upper } \\
\text { Division }\end{array}$ & 3689 & 4.49 & 1.46 & \\
\hline \multirow[t]{3}{*}{ Out-of-Class Connect } & First Year & 2427 & 4.50 & 1.30 & \\
\hline & Second Year & 1943 & 4.50 & 1.36 & \\
\hline & $\begin{array}{l}\text { Upper } \\
\text { Division }\end{array}$ & 3669 & 4.52 & 1.41 & \\
\hline \multirow[t]{3}{*}{ Referral Academic } & First Year & 2426 & $4.58^{1}$ & 1.32 & * \\
\hline & Second Year & 1931 & 4.47 & 1.34 & \\
\hline & Upper & 3644 & $4.37^{4}$ & 1.45 & * \\
\hline
\end{tabular}




\begin{tabular}{|c|c|c|c|c|c|}
\hline & Division & & & & \\
\hline \multirow[t]{3}{*}{ Refer Non-Academic } & First Year & 2408 & $4.27^{1}$ & 1.45 & $* *$ \\
\hline & Second Year & 1923 & 4.12 & 1.55 & \\
\hline & $\begin{array}{l}\text { Upper } \\
\text { Division }\end{array}$ & 3629 & 4.09 & 1.58 & \\
\hline \multirow[t]{3}{*}{ How Things Work } & First Year & 2408 & 4.87 & 1.16 & \\
\hline & Second Year & 1914 & 4.81 & 1.19 & \\
\hline & $\begin{array}{l}\text { Upper } \\
\text { Division }\end{array}$ & 3634 & 4.82 & 1.27 & \\
\hline \multirow[t]{3}{*}{ Accurate Information } & First Year & 2409 & 5.45 & .86 & \\
\hline & Second Year & 1920 & 5.48 & .82 & \\
\hline & $\begin{array}{l}\text { Upper } \\
\text { Division }\end{array}$ & 3647 & $5.54^{3}$ & .83 & $* *$ \\
\hline \multirow{3}{*}{$\begin{array}{l}\text { Skills Abilities } \\
\text { Interests }\end{array}$} & First Year & 2409 & 5.03 & 1.06 & \\
\hline & Second Year & 1909 & 4.97 & 1.08 & \\
\hline & $\begin{array}{l}\text { Upper } \\
\text { Division }\end{array}$ & 3617 & 4.92 & 1.15 & \\
\hline \multirow[t]{3}{*}{ Know as Individual } & First Year & 2408 & $4.93^{2}$ & 1.19 & $* *$ \\
\hline & Second Year & 1916 & 5.00 & 1.15 & \\
\hline & $\begin{array}{l}\text { Upper } \\
\text { Division }\end{array}$ & 3625 & 4.96 & 1.20 & \\
\hline \multirow[t]{3}{*}{ Shared Responsibility } & First Year & 2396 & 4.81 & 1.21 & \\
\hline & Second Year & 1906 & 4.78 & 1.22 & \\
\hline & $\begin{array}{l}\text { Upper } \\
\text { Division }\end{array}$ & 3603 & 4.75 & 1.26 & \\
\hline
\end{tabular}

Note: For mean importance ratings, $1=$ not important and $6=$ very important.

$*=<.05 * *=<.01 * * *=<.001$

${ }^{1}$ Importance ratings of second year students lower than those of first year students

${ }^{2}$ Importance ratings of second year students higher than those of first year students

${ }^{3}$ Importance ratings of second year students lower than those of upper division students

${ }^{4}$ Importance ratings of second year students higher than those of upper division students

Table 6

Significant Results of Regression Analyses Comparing Importance Ratings of Second Year Students with those of First Year Students and Upper Division Students

\begin{tabular}{|c|c|c|c|c|c|c|}
\hline Name & $\begin{array}{c}\text { Comparison } \\
\text { Year }\end{array}$ & $B$ & $S E B$ & $\beta$ & Sig. & Model Summary \\
\hline $\begin{array}{c}\text { Gen Ed } \\
\text { Connect }\end{array}$ & First Year & 0.12 & 0.04 & 0.04 & 0.00 & $\begin{array}{c}R^{2=} .025, F(11,8087)= \\
30.370, p<.001\end{array}$ \\
\hline $\begin{array}{c}\text { Degree } \\
\text { Connect }\end{array}$ & First Year & 0.13 & 0.04 & 0.04 & 0.00 & $\begin{array}{c}R^{2=} .025, F(11,8064)= \\
35.490, p<.001\end{array}$ \\
\hline
\end{tabular}




\begin{tabular}{|c|c|c|c|c|c|c|}
\hline $\begin{array}{l}\text { Referral } \\
\text { Academic }\end{array}$ & First Year & 0.09 & 0.04 & 0.03 & 0.03 & $\begin{array}{c}R^{2=} .032, F(11,7986)= \\
44.485, p<.001\end{array}$ \\
\hline $\begin{array}{c}\text { Referral } \\
\text { Non- } \\
\text { Academic }\end{array}$ & First Year & 0.13 & 0.05 & 0.04 & 0.01 & $\begin{array}{c}R^{2=} .038, F(11,7945)= \\
65.353, p<.001\end{array}$ \\
\hline $\begin{array}{c}\text { Know as } \\
\text { Individua } \\
1\end{array}$ & First Year & -0.07 & 0.04 & -0.03 & 0.04 & $\begin{array}{c}R^{2=} .036, F(11,7934)= \\
36.470, p<.001\end{array}$ \\
\hline $\begin{array}{l}\text { Gen Ed } \\
\text { Connect }\end{array}$ & $\begin{array}{c}\text { Upper } \\
\text { Division }\end{array}$ & -0.11 & 0.04 & -0.04 & 0.00 & $\begin{array}{c}R^{2=} .025, F(11,8087)= \\
30.370, p<.001\end{array}$ \\
\hline $\begin{array}{c}\text { Referral } \\
\text { Academic } \\
\end{array}$ & $\begin{array}{c}\text { Upper } \\
\text { Division } \\
\end{array}$ & -0.10 & 0.04 & -0.04 & 0.01 & $\begin{array}{c}R^{2=} .032, F(11,7986)= \\
44.485, p<.001\end{array}$ \\
\hline $\begin{array}{l}\text { Accurate } \\
\text { Informati } \\
\text { on }\end{array}$ & $\begin{array}{l}\text { Upper } \\
\text { Division }\end{array}$ & 0.07 & 0.02 & 0.04 & 0.00 & $\begin{array}{c}R^{2=} .024, F(11,7961)= \\
12.476, p<.001\end{array}$ \\
\hline
\end{tabular}

\section{Comparison of second year and first year students' importance ratings. As}

noted in Table 5 above, statistically significant differences were observed between the importance ratings of first and second year students on 5 of the 12 advising functions. Second year students rated four functions, Gen Ed Connect, Degree Connect, Referral Academic, and Referral Non-Academic, as less important than did first year students. Second year students rated one function, Know as Individual, as more important than did first year students.

\section{Comparison of second year and upper division students' importance ratings.}

As noted in Table 5, statistically significant differences were observed between the importance ratings of second year and upper division students on 3 of the 12 advising functions. Second year students rated two functions, Gen Ed Connect and Referral Academic, as more important than did upper division students. Second year students rated one function, Accurate Information as less important than did upper division students. 


\section{Satisfaction Ratings}

To answer the second research question, which asked whether second year students differ from first year students and/or upper division students in the satisfaction they ascribe to any of the twelve advising functions, I conducted 12 simultaneous regression analyses - one for the satisfaction ratings of each advising function. To determine if year of enrollment was uniquely associated with satisfaction ratings, I entered into the regression analyses student characteristics found in previous research to be associated with satisfaction ratings. Thus, in addition to the dummy variable used to compare second year students with first year students and the dummy variable used to compare second year students with upper division students, I included the following control variables in the regression analyses: Gender, Financial Need, First Generation College Student, African American, Asian American, Hispanic, Multiple Ethnicities, Native American, and Private Institution.

Results of the 12 simultaneous regression analyses are found in Tables 32-43 located in Appendix E. Table 7, found below, provides the n, mean, and standard deviation of satisfaction ratings for first year students, second year students, and upper division students. Satisfaction ratings for all three groups ranged from the middle of the satisfaction scale ( 3 on the 6 point scale) with the majority on the satisfied end of the scale - above point 3.5 on the 6-point scale. For all three groups, Accurate Information was the function rated highest in satisfaction. For all three groups, Out-of-Class Connect was rated lowest in importance. Standard deviations were similar among all advising functions. 
Table 7 also provides a summary of the results of the regression analyses examining differences between first year students and second year students and between second year students and upper division students when relevant student characteristics were controlled. Table 8 provides the statistically significant results of the 12 regression analyses.

Table 7 Satisfaction Ratings

Numbers, Means and Standard Deviations of Satisfaction Ratings of First Year, Second Year, and Upper Division Students and Summary of Results of Simultaneous Regression Analyses Comparing Satisfaction Ratings of Second Year Students with First Year Students and Upper Division Students

\begin{tabular}{|c|c|c|c|c|c|}
\hline Advising Function & & $n$ & Mean & $s d$ & Sig. \\
\hline \multirow[t]{3}{*}{ Overall Connect } & First Year & 2229 & $4.24^{1}$ & 1.27 & $* * *$ \\
\hline & Second Year & 1872 & 4.08 & 1.35 & \\
\hline & $\begin{array}{l}\text { Upper } \\
\text { Division }\end{array}$ & 3565 & 4.01 & 1.42 & \\
\hline \multirow[t]{3}{*}{ Major Connect } & First Year & 2225 & $4.28^{1}$ & 1.25 & $* *$ \\
\hline & Second Year & 1866 & 4.15 & 1.34 & \\
\hline & $\begin{array}{l}\text { Upper } \\
\text { Division }\end{array}$ & 3554 & $4.02^{4}$ & 1.41 & $* * *$ \\
\hline \multirow[t]{3}{*}{ Gen Ed Connect } & First Year & 2191 & $4.14^{1}$ & 1.33 & $* * *$ \\
\hline & Second Year & 1846 & 3.96 & 1.40 & \\
\hline & $\begin{array}{l}\text { Upper } \\
\text { Division }\end{array}$ & 3496 & $3.82^{4}$ & 1.46 & $* * *$ \\
\hline \multirow[t]{3}{*}{ Degree Connect } & First Year & 2204 & $4.19^{1}$ & 1.28 & $* * *$ \\
\hline & Second Year & 1841 & 4.00 & 1.36 & \\
\hline & $\begin{array}{l}\text { Upper } \\
\text { Division }\end{array}$ & 3520 & $3.80^{4}$ & 1.41 & $* * *$ \\
\hline \multirow[t]{3}{*}{ Out-of-Class Connect } & First Year & 2183 & $3.60^{1}$ & 1.38 & $* *$ \\
\hline & Second Year & 1831 & 3.45 & 1.46 & \\
\hline & $\begin{array}{l}\text { Upper } \\
\text { Division }\end{array}$ & 3484 & $3.35^{4}$ & 1.50 & * \\
\hline \multirow[t]{3}{*}{ Referral Academic } & First Year & 2171 & $4.18^{1}$ & 1.29 & $* * *$ \\
\hline & Second Year & 1819 & 4.00 & 1.34 & \\
\hline & $\begin{array}{l}\text { Upper } \\
\text { Division }\end{array}$ & 3443 & $3.88^{4}$ & 1.39 & $* *$ \\
\hline Referral Non- & First Year & 2142 & $3.98^{1}$ & 1.29 & $* * *$ \\
\hline
\end{tabular}




\begin{tabular}{|c|c|c|c|c|c|}
\hline \multicolumn{6}{|l|}{ Academic } \\
\hline & Second Year & 1798 & 3.80 & 1.38 & \\
\hline & $\begin{array}{l}\text { Upper } \\
\text { Division }\end{array}$ & 3395 & 3.74 & 1.38 & \\
\hline \multirow[t]{3}{*}{ How Things Work } & First Year & 2160 & $4.05^{1}$ & 1.31 & $* * *$ \\
\hline & Second Year & 1805 & 3.88 & 1.41 & \\
\hline & $\begin{array}{l}\text { Upper } \\
\text { Division }\end{array}$ & 3448 & $3.71^{4}$ & 1.46 & $* * *$ \\
\hline \multirow[t]{3}{*}{ Accurate Information } & First Year & 2177 & $4.47^{1}$ & 1.27 & $* *$ \\
\hline & Second Year & 1818 & 4.35 & 1.35 & \\
\hline & $\begin{array}{l}\text { Upper } \\
\text { Division }\end{array}$ & 3471 & $4.19^{4}$ & 1.49 & $* * *$ \\
\hline \multirow{3}{*}{$\begin{array}{l}\text { Skills Abilities } \\
\text { Interests }\end{array}$} & First Year & 2163 & $4.07^{1}$ & 1.32 & $* *$ \\
\hline & Second Year & 1801 & 3.94 & 1.40 & \\
\hline & $\begin{array}{l}\text { Upper } \\
\text { Division }\end{array}$ & 3436 & $3.83^{4}$ & 1.43 & $* *$ \\
\hline \multirow[t]{3}{*}{ Know as Individual } & First Year & 2164 & $3.86^{1}$ & 1.47 & $*$ \\
\hline & Second Year & 1812 & 3.74 & 1.57 & \\
\hline & $\begin{array}{l}\text { Upper } \\
\text { Division }\end{array}$ & 3444 & $3.83^{3}$ & 1.63 & $*^{5}$ \\
\hline \multirow[t]{3}{*}{ Shared Responsibility } & First Year & 2151 & $4.16^{1}$ & 1.27 & $* *$ \\
\hline & Second Year & 1797 & 4.03 & 1.32 & \\
\hline & $\begin{array}{l}\text { Upper } \\
\text { Division }\end{array}$ & 3412 & $3.94^{4}$ & 1.39 & * \\
\hline
\end{tabular}

Note: For mean satisfaction ratings, $1=$ not satisfied and $6=$ very satisfied.

$*=<.05 * *=<.01 * * *=<.001$

${ }^{1}$ Satisfaction ratings of second year students lower than those of first year students

${ }^{2}$ Satisfaction ratings of second year students higher than those of first year students

${ }^{3}$ Satisfaction ratings of second year students lower than those of upper division students

${ }^{4}$ Satisfaction ratings of second year students higher than those of upper division students

${ }^{3}$ Approaching statistical significance $(\mathrm{p}=.054)$

Table 8

Significant Results of Regression Analyses Comparing Satisfaction Ratings of Second Year Students with those of First Year Students and Upper Division Students

\begin{tabular}{|c|c|c|c|c|c|c|}
\hline $\begin{array}{c}\text { Variable } \\
\text { Name }\end{array}$ & $\begin{array}{c}\text { Compariso } \\
\text { n Year }\end{array}$ & $B$ & $S E B$ & $\beta$ & Sig. & \multicolumn{1}{c|}{ Model Summary } \\
\hline $\begin{array}{c}\text { Overall } \\
\text { Connect }\end{array}$ & First Year & 0.15 & 0.04 & 0.05 & $<.001$ & $\begin{array}{l}R^{2=} .014, F(11,7651)= \\
18.098, p<.001\end{array}$ \\
\hline $\begin{array}{c}\text { Major } \\
\text { Connect }\end{array}$ & First Year & 0.12 & 0.04 & 0.04 & .004 & $\begin{array}{l}R^{2=} .015, F(11,7630)= \\
19.295, p<.001\end{array}$ \\
\hline
\end{tabular}


Retention Reconsidered

\begin{tabular}{|c|c|c|c|c|c|c|}
\hline $\begin{array}{l}\text { Gen Ed } \\
\text { Connect }\end{array}$ & First Year & 0.18 & 0.04 & 0.06 & $<.001$ & $\begin{array}{l}R^{2=} .029, F(11,7550)= \\
36.907, p<.001\end{array}$ \\
\hline $\begin{array}{l}\text { Degree } \\
\text { Connect }\end{array}$ & First Year & 0.17 & 0.04 & 0.06 & $<.001$ & $\begin{array}{l}R^{2=} .019, F(11,7518)= \\
25.336, p<.001\end{array}$ \\
\hline $\begin{array}{l}\text { Out-of- } \\
\text { Class } \\
\text { Connect }\end{array}$ & First Year & 0.14 & 0.05 & \begin{tabular}{|l|}
0.04 \\
\end{tabular} & .002 & $\begin{array}{l}R^{2=} .013, F(11,7483)= \\
19.107, p<.001\end{array}$ \\
\hline $\begin{array}{c}\text { Referral } \\
\text { Academic }\end{array}$ & First Year & 0.17 & 0.04 & 0.06 & $<.001$ & $\begin{array}{l}R^{2=} .018, F(11,7418)= \\
22.418, p<.001\end{array}$ \\
\hline $\begin{array}{c}\text { Referral } \\
\text { Non- } \\
\text { Academic }\end{array}$ & First Year & 0.17 & 0.04 & 0.06 & $<.001$ & $\begin{array}{l}R^{2=} .012, F(11,7320)= \\
14.783, p<.001\end{array}$ \\
\hline $\begin{array}{l}\text { How } \\
\text { Things } \\
\text { Work }\end{array}$ & First Year & 0.16 & 0.05 & 0.05 & $<.001$ & $\begin{array}{l}R^{2=} .019, F(11,7398)= \\
25.025, p<.001\end{array}$ \\
\hline $\begin{array}{l}\text { Accurate } \\
\text { Information }\end{array}$ & First Year & 0.12 & 0.04 & \begin{tabular}{|l|l|}
0.04 \\
\end{tabular} & .007 & $\begin{array}{l}R^{2=} .017, F(11,7451)= \\
22.790, p<.001\end{array}$ \\
\hline $\begin{array}{c}\text { Skills } \\
\text { Abilities } \\
\text { Interest }\end{array}$ & First Year & 0.11 & 0.04 & 0.04 & .01 & $\begin{array}{l}R^{2=} .012, F(11,7385)= \\
15.227, p<.001\end{array}$ \\
\hline $\begin{array}{l}\text { Know as } \\
\text { Individual }\end{array}$ & First Year & 0.10 & 0.05 & 0.03 & .041 & $\begin{array}{l}R^{2=} .020, F(11,7405)= \\
33.148, p<.001\end{array}$ \\
\hline $\begin{array}{c}\text { Shared } \\
\text { Responsibil } \\
\text { ity }\end{array}$ & First Year & 0.11 & 0.04 & 0.04 & .008 & $\begin{array}{l}R^{2=} .016, F(11,7345)= \\
18.971, p<.001\end{array}$ \\
\hline $\begin{array}{l}\text { Major } \\
\text { Connect }\end{array}$ & $\begin{array}{l}\text { Upper } \\
\text { Division }\end{array}$ & $-\overline{12}$ & 0.04 & -0.05 & .001 & $\begin{array}{l}R^{2=} .015, F(11,7630)= \\
19.295, p<.001\end{array}$ \\
\hline $\begin{array}{l}\text { Gen Ed } \\
\text { Connect }\end{array}$ & $\begin{array}{c}\text { Upper } \\
\text { Division }\end{array}$ & $\begin{array}{c}- \\
0.19\end{array}$ & 0.04 & -0.07 & $<.001$ & $\begin{array}{l}R^{2=} .029, F(11,7550)= \\
36.907, p<.001\end{array}$ \\
\hline $\begin{array}{l}\text { Degree } \\
\text { Connect }\end{array}$ & $\begin{array}{l}\text { Upper } \\
\text { Division }\end{array}$ & 0.14 & 0.04 & -0.05 & .001 & $\begin{array}{l}R^{2=} .019, F(11,7518)= \\
25.336, p<.001\end{array}$ \\
\hline $\begin{array}{l}\text { Out-of- } \\
\text { Class } \\
\text { Connect }\end{array}$ & $\begin{array}{l}\text { Upper } \\
\text { Division }\end{array}$ & $\begin{array}{c}- \\
0.10\end{array}$ & 0.04 & -0.04 & .014 & $\begin{array}{l}R^{2=} .013, F(11,7483)= \\
19.107, p<.001\end{array}$ \\
\hline $\begin{array}{c}\text { Referral } \\
\text { Academic }\end{array}$ & $\begin{array}{l}\text { Upper } \\
\text { Division }\end{array}$ & $-\overline{12}$ & 0.04 & -0.04 & .002 & $\begin{array}{l}R^{2=} .018, F(11,7418)= \\
22.418, p<.001\end{array}$ \\
\hline $\begin{array}{c}\text { How } \\
\text { Things } \\
\text { Work }\end{array}$ & $\begin{array}{l}\text { Upper } \\
\text { Division }\end{array}$ & 0.17 & 0.04 & -0.06 & $<.001$ & $\begin{array}{l}R^{2=} .019, F(11,7398)= \\
25.025, p<.001\end{array}$ \\
\hline $\begin{array}{l}\text { Accurate } \\
\text { Information }\end{array}$ & $\begin{array}{c}\text { Upper } \\
\text { Division }\end{array}$ & $-\overline{15}$ & 0.04 & -0.06 & $<.001$ & $\begin{array}{l}R^{2=} .017, F(11,7451)= \\
22.790, p<.001\end{array}$ \\
\hline $\begin{array}{c}\text { Skills } \\
\text { Abilities } \\
\text { Interest }\end{array}$ & $\begin{array}{l}\text { Upper } \\
\text { Division }\end{array}$ & $\begin{array}{c}- \\
0.11\end{array}$ & 0.04 & -0.04 & .008 & $\begin{array}{l}R^{2=} .012, F(11,7385)= \\
15.227, p<.001\end{array}$ \\
\hline
\end{tabular}




\begin{tabular}{|c|c|c|c|c|c|l|}
\hline $\begin{array}{c}\text { Shared } \\
\begin{array}{c}\text { Responsibil } \\
\text { ity }\end{array}\end{array}$ & $\begin{array}{c}\text { Upper } \\
\text { Division }\end{array}$ & -0.09 & 0.04 & -0.03 & .024 & $\begin{array}{l}R^{2=} .016, F(11,7345)= \\
18.971, p<.001\end{array}$ \\
\hline $\begin{array}{c}\text { Know as } \\
\text { Individual }\end{array}$ & $\begin{array}{c}\text { Upper } \\
\text { Division }\end{array}$ & .09 & .04 & .03 & .054 & $\begin{array}{l}R^{2=} .020, F(11,7405)= \\
33.148, p<.001\end{array}$ \\
\hline
\end{tabular}

Comparison of second year and first satisfaction ratings. As noted in Table 7

above, statistically significant differences were observed between the satisfaction ratings of first and second year students on all 12 of the advising functions. Second year students rated their satisfaction on every advising function lower than did first year students.

Comparison of second year and upper division satisfaction ratings. As noted in Table 7 above, statistically significant differences were observed between the satisfaction ratings of second year and upper division students on 9 of the 12 advising functions. Second year students rated their satisfaction on all 9 functions, Major Connect, Gen Ed Connect, Degree Connect, Out-of-Class Connect, Referral Academic, How Things Work, Accurate Information, Skills Abilities Interests, and Shared Responsibility as more satisfied than did upper division students. The function Know as Individual approached significance $(\mathrm{p}=.054)$ with upper division scoring higher in satisfaction compared to second year students.

\section{Learning Outcomes}

To answer the third research question, which asked whether second year students differ from first year students and/or upper division students in their level of agreement with statements that reflect what students know, do, or value as a result of receiving academic advising (learning outcomes), I conducted 7 simultaneous regression analyses - 
one for each learning outcome. To determine if year of enrollment was uniquely associated with learning outcome ratings, I entered into the regression analyses student characteristics found in previous research to be associated with learning outcome ratings. Thus, in addition to the dummy variable used to compare second year students with first year students and the dummy variable used to compare second year students with upper division students, I included the following control variables in the regression analyses: Size of Institution and Institutional GPA at Time of Survey.

Results of the 7 simultaneous regression analyses are found in Tables 44-50 located in Appendix E. Table 9, found below, provides the n, mean, and standard deviation of learning outcome ratings for first year students, second year students, and upper division students. All learning outcome ratings for all three groups were on the importance end of the scale - above scale point 4 on the 6-point scale. For all three groups, Has Educational Plan was the learning outcome rated highest with the lowest standard deviation. For all three groups, Has Significant Relationship was the learning outcome rated lowest with the highest standard deviation.

Table 9 also provides a summary of the results of the regression analyses examining differences between first year students and second year students and between second year students and upper division students when relevant student characteristics were controlled. Table 10 provides the statistically significant results of the regression analyses. 
Table 9

Numbers, Means, and Standard Deviations of Satisfaction Ratings of First Year, Second Year, and Upper Division Students and Summary of Results of Simultaneous Regression Analyses Comparing Learning Outcome Ratings of Second Year Students with First Year Students and Upper Division Students

\begin{tabular}{|l|l|c|c|c|c|}
\hline & & $n$ & Mean & sd & Sig. \\
\hline Knows Requirements & First Year & 2387 & $4.67^{2}$ & 1.21 & $* * *$ \\
\hline & Second Year & 1898 & 5.00 & 1.12 & \\
\hline & Upper Division & 3608 & $5.30^{3}$ & 0.95 & $* * *$ \\
\hline Knows Resources & First Year & 2387 & 4.27 & 1.33 & \\
\hline & Second Year & 1889 & 4.34 & 1.35 & \\
\hline & Upper Division & 3601 & 4.37 & 1.36 & \\
\hline Understands How Things Work & First Year & 2388 & $4.23^{2}$ & 1.20 & $* * *$ \\
\hline & Second Year & 1894 & 4.42 & 1.24 & \\
\hline & Upper Division & 3605 & $4.59^{3}$ & 1.23 & $* * *$ \\
\hline Understands Connections & First Year & 2372 & $4.81^{2}$ & 1.12 & $*$ \\
\hline & Second Year & 1894 & 4.87 & 1.09 & \\
\hline Has Educational Plan & Upper Division & 3597 & 4.91 & 1.11 & \\
\hline & First Year & 2479 & $5.28^{2}$ & 0.96 & $* *$ \\
\hline & Second Year & 1979 & 5.35 & 0.91 & \\
\hline Has Significant Relationship & Upper Division & 3765 & $5.41^{3}$ & 0.87 & $* *$ \\
\hline & First Year & 2482 & $4.07^{2}$ & 1.50 & $* * *$ \\
\hline & Second Year & 1981 & 4.32 & 1.50 & \\
\hline Values Advisor-Advisee & Upper Division & 3757 & $4.69^{3}$ & 1.44 & $* * *$ \\
\hline Relationship & First Year & 2395 & $5.04^{2}$ & 1.05 & $*$ \\
\hline & & & & & \\
\hline & Second Year & 1895 & 5.10 & 0.99 & \\
\hline & Upper Division & 3608 & 5.06 & 1.09 & \\
\hline
\end{tabular}

Note: For mean Learning Outcome ratings, $1=$ lowest and $6=$ highest.

$*=<.05 * *=<.01 * * *=<.001$

${ }^{1}$ Learning Outcome ratings of second year students lower than those of first year students

${ }^{2}$ Learning Outcome ratings of second year students higher than those of first year students

${ }^{3}$ Learning Outcome ratings of second year students lower than those of upper division students

${ }^{4}$ Learning Outcome ratings of second year students higher than those of upper division students 
Table 10

Significant Results of Regression Analyses Comparing Learning Outcome Ratings of Second Year Students with those of First Year Students and Upper Division Students

\begin{tabular}{|c|c|c|c|c|c|c|}
\hline Variable Name & $\begin{array}{c}\text { Comparison } \\
\text { Year }\end{array}$ & $B$ & $S E B$ & $\beta$ & Sig. & Model Summary \\
\hline $\begin{array}{l}\text { Knows } \\
\text { Requirements }\end{array}$ & First Year & -0.34 & 0.03 & -0.14 & $<.001$ & $\begin{array}{l}R 2=.070, F(4,7868) \\
=170.138, p<.001\end{array}$ \\
\hline $\begin{array}{l}\text { Understands } \\
\text { How Things } \\
\text { Work }\end{array}$ & First Year & -0.20 & 0.04 & -0.07 & $<.001$ & $\begin{array}{l}R 2=.024, F(4,7862) \\
=73.001, p<.001\end{array}$ \\
\hline $\begin{array}{l}\text { Understands } \\
\text { Connections }\end{array}$ & First Year & -0.07 & 0.03 & -0.03 & .042 & $\begin{array}{c}R 2=.015, F(4,7838) \\
=35.007, p<.001\end{array}$ \\
\hline $\begin{array}{l}\text { Has } \\
\text { Educational } \\
\text { Plan }\end{array}$ & First Year & -0.07 & 0.03 & -0.04 & .01 & $\begin{array}{l}R 2=.013, F(5,8175) \\
\quad=17.245, p<.001\end{array}$ \\
\hline $\begin{array}{l}\text { Has Significant } \\
\text { Relationship }\end{array}$ & First Year & -0.26 & 0.04 & -0.08 & $<.001$ & $\begin{array}{l}R 2=.075, F(4,8194) \\
=344.196, p<.001\end{array}$ \\
\hline $\begin{array}{l}\text { Values } \\
\text { Advisor- } \\
\text { Advisee } \\
\text { Relationship }\end{array}$ & First Year & -0.06 & 0.03 & -0.03 & .047 & $\begin{array}{l}R 2=.014, F(4,7873) \\
\quad=31.351, p<.001\end{array}$ \\
\hline $\begin{array}{l}\text { Knows } \\
\text { Requirements }\end{array}$ & $\begin{array}{c}\text { Upper } \\
\text { Division }\end{array}$ & 0.28 & 0.03 & 0.13 & $<.001$ & $\begin{array}{l}R 2=.070, F(4,7868) \\
=170.138, p<.001\end{array}$ \\
\hline $\begin{array}{l}\text { Understands } \\
\text { How Things } \\
\text { Work }\end{array}$ & $\begin{array}{c}\text { Upper } \\
\text { Division }\end{array}$ & 0.16 & 0.04 & 0.07 & $<.001$ & $\begin{array}{l}R 2=.024, F(4,7862) \\
\quad=73.001, p<.001\end{array}$ \\
\hline $\begin{array}{l}\text { Has } \\
\text { Educational } \\
\text { Plan }\end{array}$ & $\begin{array}{c}\text { Upper } \\
\text { Division }\end{array}$ & 0.05 & 0.03 & 0.03 & .004 & $\begin{array}{l}R 2=.013, F(5,8175) \\
\quad=17.245, p<.001\end{array}$ \\
\hline $\begin{array}{l}\text { Has Significant } \\
\text { Relationship }\end{array}$ & $\begin{array}{c}\text { Upper } \\
\text { Division }\end{array}$ & 0.36 & 0.04 & 0.12 & $<.001$ & $\begin{array}{l}R 2=.075, F(4,8194) \\
=344.196, p<.001\end{array}$ \\
\hline
\end{tabular}

Comparison of second year and first year learning outcome ratings. As noted

in Table 10, statistically significant differences were observed between the advising learning outcome ratings of first and second year students on 6 of the 7 learning outcomes. Second year students were more likely to agree with statements reflecting the learning outcomes on Knows Requirements, Understands How Things Work, 
Understands Connections, Values Advisor-Advisee Relationship, Has Educational Plan, and Has Significant Relationship.

\section{Comparison of second year and upper division learning outcome ratings. As}

noted in Table 10, statistically significant differences were observed between the advising learning outcome ratings of second year and upper division students on 4 of the 7 learning outcomes. Second year students were less likely to agree with statements reflecting the learning outcomes on Knows Requirements, Understands How Things Work, Has Educational Plan, and Has Significant Relationship.

\section{Differences between Retained Second Year Students and Not Retained Second Year \\ Students}

\section{Importance Ratings}

To answer the fourth research question which asked whether retained second year students differ from not retained second year students in the importance they ascribe to any of the twelve importance ratings, I conducted 12 logistic regression analyses - one for the importance ratings of each advising function. To determine if retention status was uniquely associated with importance ratings, I entered into the regression analyses student characteristics found in previous research to be associated with importance ratings. Thus, in addition to the dummy variable used to compare students with respect to retention status, I included the following control variables in the regression analyses: Gender, Financial Need, First Generation College Student, African American, Asian American, Hispanic, Multiple Ethnicities, Native American, and Private Institution. 
Results of the 12 logistic regression analyses are found in Tables 51-62 located in Appendix E. Table 11, found below, provides the n, mean, and standard deviation of importance ratings for retained second year students and not retained second year students for each advising function. All importance ratings for both groups were on the importance end of the scale - above scale point 4 on the 6-point scale. For both groups, Accurate Information was the function rated highest in importance with the lowest standard deviation. For both groups, Referral Non-Academic was rated lowest in importance with the highest standard deviation.

Table 11 also provides a summary of the results of the regression analyses examining differences between retained second year students and not retained second year students when relevant student characteristics were controlled. Tables 12 and 13 provide only the statistically significant results and model tests of the regression analyses.

Table 11

Results of Logistic Regressions with Results for $n$, Means, Standard Deviations, and Significance of Importance Ratings of Retained and Not Retained Second Year Students and Comparison of Both Groups

\begin{tabular}{|c|c|c|c|c|c|c|c|}
\hline Variable & \multicolumn{6}{|c|}{ Retained } & \multirow[t]{3}{*}{ Sig. } \\
\hline & \multicolumn{3}{|c|}{ Yes } & \multicolumn{3}{|c|}{ No } & \\
\hline & $\mathrm{n}$ & Mean & $\mathrm{sd}$ & $\mathrm{n}$ & Mean & $\mathrm{sd}$ & \\
\hline Overall Connect & 7691 & 4.89 & 1.10 & 480 & 4.78 & 1.16 & \\
\hline Major Connect & 7666 & 5.04 & 1.03 & 480 & 4.90 & 1.09 & $* 1$ \\
\hline Gen Ed Connect & 7609 & 4.54 & 1.27 & 474 & 4.48 & 1.35 & \\
\hline Degree Connect & 7583 & 4.57 & 1.39 & 477 & 4.58 & 1.39 & \\
\hline $\begin{array}{l}\text { Out-of-Class } \\
\text { Connect }\end{array}$ & 7548 & 4.52 & 1.36 & 473 & 4.40 & 1.42 & \\
\hline $\begin{array}{l}\text { Referral } \\
\text { Academic }\end{array}$ & 7509 & 4.45 & 1.39 & 473 & 4.53 & 1.36 & \\
\hline $\begin{array}{l}\text { Referral Non- } \\
\text { Academic }\end{array}$ & 7470 & 4.14 & 1.54 & 471 & 4.28 & 1.49 & $*^{2}$ \\
\hline $\begin{array}{l}\text { How Things } \\
\text { Work }\end{array}$ & 7471 & 4.84 & 1.21 & 466 & 4.68 & 1.27 & $* * * 1$ \\
\hline
\end{tabular}


Retention Reconsidered 100

\begin{tabular}{|l|c|c|c|c|c|c|c|}
\hline $\begin{array}{l}\text { Accurate } \\
\text { Information }\end{array}$ & 7495 & 5.50 & 0.84 & 462 & 5.46 & 0.85 & \\
\hline $\begin{array}{l}\text { Skills Abilities } \\
\text { Interests }\end{array}$ & 7455 & 4.97 & 1.11 & 461 & 4.91 & 1.11 & \\
\hline $\begin{array}{l}\text { Know as } \\
\text { Individual }\end{array}$ & 7469 & 4.96 & 1.18 & 461 & 4.83 & 1.29 & \\
\hline $\begin{array}{l}\text { Shared } \\
\text { Responsibility }\end{array}$ & 7424 & 4.78 & 1.23 & 462 & 4.73 & 1.29 & \\
\hline
\end{tabular}

$*=<.05 \quad * *=<.01 \quad * * *=<.001$

${ }^{1}$ Retained significantly higher than not retained

${ }^{2}$ Retained significantly lower than not retained

Table 12

Summary of Significant Values for Importance Ratings

\begin{tabular}{|c|c|c|c|c|}
\hline Name & $\mathrm{B}(S E)$ & Wald's $\chi^{2}(d f)$ & $p$ & $e^{\beta}$ \\
\hline Major Connect & $-.10(.04)$ & $5.63(1)$ & 0.018 & 0.90 \\
\hline $\begin{array}{c}\text { Referral Non- } \\
\text { Academic }\end{array}$ & $.07(.03)$ & $4.74(1)$ & 0.03 & 1.07 \\
\hline How Things Work & $-.10(.04)$ & $7.05(1)$ & 0.008 & 0.90 \\
\hline
\end{tabular}

Table 13

Model Tests for Variables with Significant Values for Importance Ratings Comparing Retained Second Year Students with Not Retained Second Year Students

\begin{tabular}{|c|c|c|c|c|c|c|}
\hline Name & $\begin{array}{c}\text { Overall model } \\
\text { evaluation } \\
\text { likelihood ratio } \\
\text { test } \chi^{2}(d f)\end{array}$ & $p$ & $\begin{array}{c}\text { Homer \& } \\
\text { Lemeshow } \chi^{2} \\
(d f)\end{array}$ & $p$ & $\begin{array}{c}\text { Cox } \\
\text { and } \\
\text { Snell } \\
R^{2}\end{array}$ & $\begin{array}{c}\text { Nagelke } \\
\text { rke } \\
R^{2}\end{array}$ \\
\hline $\begin{array}{c}\text { Major } \\
\text { Connect }\end{array}$ & $115.37(10)$ & $<.001$ & $14.36(8)$ & .073 & 0.01 & 0.04 \\
\hline $\begin{array}{c}\text { Referral } \\
\text { Non- } \\
\text { Academic }\end{array}$ & $113.57(10)$ & $<.001$ & $9.82(8)$ & $\begin{array}{c}0.27 \\
8\end{array}$ & 0.01 & 0.04 \\
\hline $\begin{array}{c}\text { How Things } \\
\text { Work }\end{array}$ & $115.69(10)$ & $<.001$ & $13.43(8)$ & $\begin{array}{c}0.09 \\
8\end{array}$ & 0.01 & 0.04 \\
\hline
\end{tabular}

\section{Comparison of retained and not retained second year importance ratings. As}

noted in Table 12, statistically significant differences were observed between the 
importance ratings of retained and not retained second year students on 3 of the 12 advising functions. Retained second year students rated two functions, Major Connect and How Things Work as more important than did not retained second year students. Retained second year students rated one function, Referral Non-Academic, as less important than did not retained second year students.

\section{Satisfaction Ratings}

To answer the fifth research question which asked whether retained second year students differ from not retained second year students in the satisfaction they ascribe to any of the twelve advising functions, I conducted 12 logistic regression analyses - one for the satisfaction ratings of each advising function. To determine if retention status was uniquely associated with satisfaction ratings, I entered into the regression analyses student characteristics found in previous research to be associated with satisfaction ratings. Thus, in addition to the dummy variable used to compare students with respect to retention status, I included the following control variables in the regression analyses: Gender, Financial Need, First Generation College Student, African American, Asian American, Hispanic, Multiple Ethnicities, Native American, and Private Institution.

Results of the 12 simultaneous regression analyses are found in Tables 63-74 located in Appendix E. Table 14, found below, provides the n, mean, and standard deviation of satisfaction ratings for retained second year students and not retained second year students. Five of the satisfaction ratings for the retained group were on the satisfied end of the scale ( 4 on the 6 point scale) while two of the satisfaction ratings were on the 
satisfied end of the scale for not retained students. The rest of the satisfaction ratings were in the middle of the scale, between scale point 3 and 4 of the 6 point scale. For both groups, Accurate Information was the function rated highest in satisfaction. For both groups, Out-of-Class Connect was rated lowest in satisfaction. Standard deviations were consistently above 1.3 for all advising functions for both groups.

Table 14 also provides a summary of the results of the regression analyses examining differences between retained second year students and not retained second year students. Tables 15 and 16 provide only the statistically significant results and model tests of the regression analyses.

Table 14

Results of Logistic Regressions with Results for $n$, Means, Standard Deviations, and Significance of Satisfaction Ratings of Retained and Not Retained Second Year Students and Comparison of Both Groups

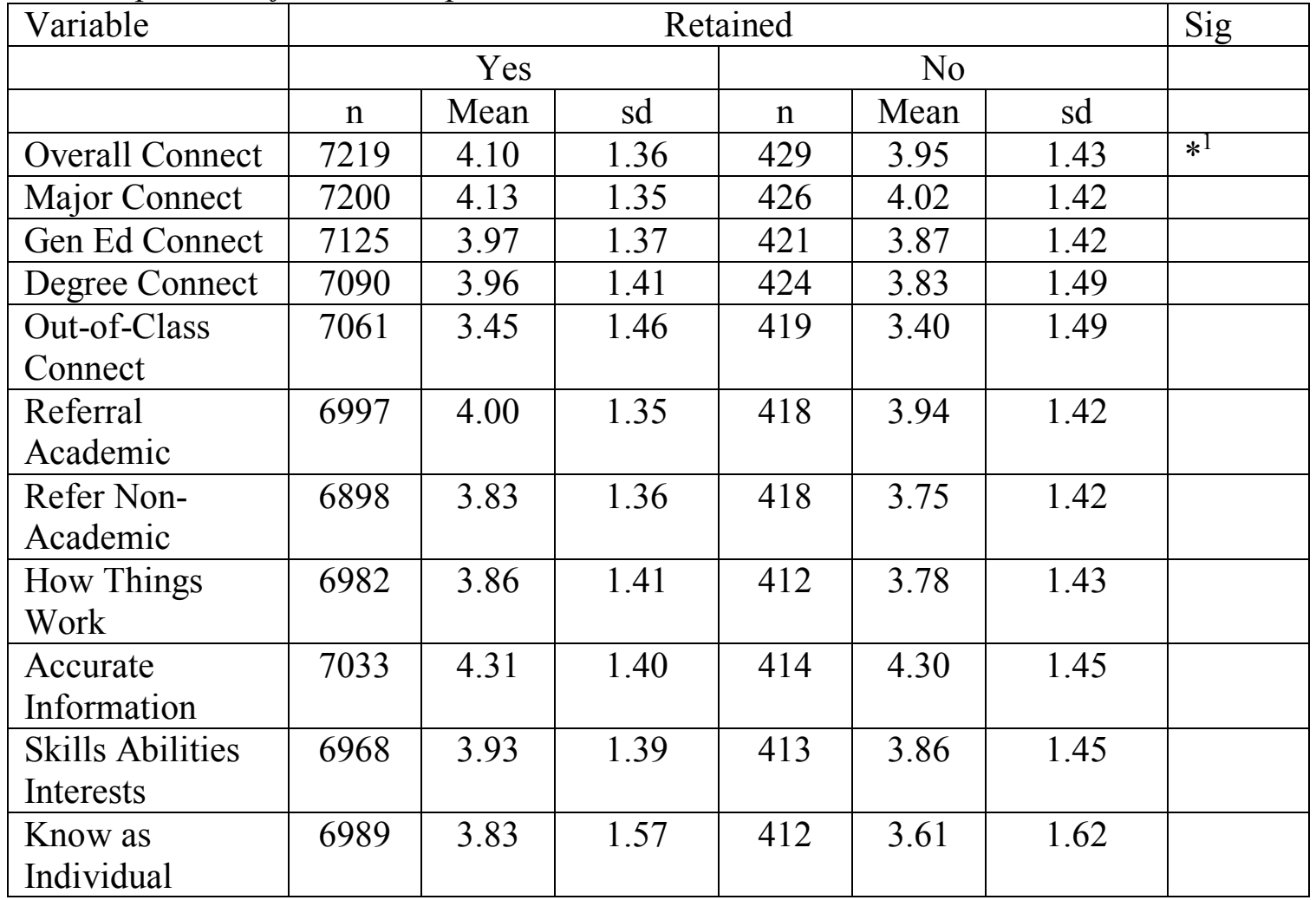




\begin{tabular}{|l|l|l|l|l|l|l|l|}
\hline $\begin{array}{l}\text { Shared } \\
\text { Responsibility }\end{array}$ & 6931 & 4.04 & 1.33 & 410 & 3.85 & 1.41 & $* 1$ \\
\hline
\end{tabular}

$*=<.05 * *=<.01 * * *=<.001$

${ }^{1}$ Retained significantly higher than not retained

${ }^{2}$ Retained significantly lower than not retained

Table 15

Summary of Significant Values for Satisfaction Ratings

\begin{tabular}{|c|c|c|c|c|}
\hline Name & $\mathrm{B}(S E)$ & Wald's $\chi^{2}(d f)$ & $p$ & $e^{\beta}$ \\
\hline Overall Connect & $-.07(.04)$ & $3.87(1)$ & -.05 & 0.93 \\
\hline $\begin{array}{c}\text { Shared } \\
\text { Responsibility }\end{array}$ & $-.08(.04)$ & $4.13(1)$ & 0.04 & 0.93 \\
\hline
\end{tabular}

Table 16

Model Tests for Variables with Significant Values for Satisfaction Ratings

\begin{tabular}{|c|c|c|c|c|c|c|}
\hline Name & $\begin{array}{c}\text { Overall } \\
\text { model } \\
\text { evaluation } \\
\text { likelihood } \\
\text { ratio test } \chi^{2} \\
(d f)\end{array}$ & $p$ & $\begin{array}{c}\text { Homer \& } \\
\text { Lemesho } \\
\mathrm{w} \chi^{2}(d f)\end{array}$ & $p$ & $\begin{array}{c}\text { Cox and } \\
\text { Snell }\end{array}$ & Nagelkerke \\
\hline $\begin{array}{c}\text { Overall } \\
\text { Connect }\end{array}$ & $100.64(10)$ & $<.001$ & $3.63(8)$ & .89 & 0.01 & 0.04 \\
\hline $\begin{array}{c}\text { Shared } \\
\text { Responsibility }\end{array}$ & $99.41(10)$ & $<.001$ & $13.07(8)$ & .11 & 0.01 & 0.04 \\
\hline
\end{tabular}

\section{Comparison of retained and not retained second year satisfaction ratings. As}

noted in Table 15, statistically significant differences were observed between the satisfaction ratings of retained and not retained second year students on 2 of the 12 advising functions. Retained second year students rated two functions, Overall Connect and Shared Responsibility with higher satisfaction ratings compared to not retained second year students. 


\section{Learning Outcomes}

To answer the sixth research question which asked whether retained second year students differ from not retained second year students in their level of agreement with statements that reflect what students know, do, or value as a result of receiving academic advising (learning outcomes), I conducted 7 logistic regression analyses - one for each learning outcome. To determine if retention status was uniquely associated with learning outcomes ratings, I entered into the regression analyses student characteristics found in previous research to be associated with learning outcomes. Thus, in addition to the dummy variable used to compare students with respect to retention status, I included the following control variables in the regression analyses: Size of Institution and Institutional GPA at Time of Survey.

Results of the 7 simultaneous regression analyses are found in Tables 75-81 located in Appendix E. Table 17, found below, provides the n, mean, and standard deviation of learning outcomes ratings for retained second year students and not retained second year students. All learning outcomes ratings for both groups were on the high end of the scale - above scale point 4 on the 6-point scale. For both groups, Has Educational Plan was the learning outcome rated highest with the lowest standard deviation. For retained second year students, Knows Resources was rated lowest with the second highest standard deviation. For not retained second year students, Has Significant Relationship was the learning outcome rated lowest with the highest standard deviation.

Table 17 also provides a summary of the results of the regression analyses examining differences between retained second year students and not retained second year students. 
Tables 18 and 19 provide the statistically significant results and model tests of the regression analyses.

Table 17

Results of Logistic Regressions with Results for $n$, Mean, Standard Deviation, and Significance of Learning Outcomes of Retained and Not Retained Second Year Students and Comparison of Both Groups

\begin{tabular}{|c|c|c|c|c|c|c|c|}
\hline \multirow[t]{3}{*}{ Variable } & \multicolumn{6}{|c|}{ Retained } & \multirow[t]{3}{*}{ Sig. } \\
\hline & \multicolumn{3}{|c|}{ Yes } & \multicolumn{3}{|c|}{ No } & \\
\hline & $n$ & Mean & $s d$ & $n$ & Mean & $s d$ & \\
\hline $\begin{array}{l}\text { Knows } \\
\text { Requirements }\end{array}$ & 7413 & 5.05 & 1.10 & 461 & 4.78 & $\begin{array}{c}1.1 \\
8\end{array}$ & $* * * 1$ \\
\hline Knows Resources & 7398 & 4.35 & 1.35 & 460 & 4.12 & $\begin{array}{c}1.4 \\
0\end{array}$ & $* * * 1$ \\
\hline $\begin{array}{l}\text { Understands How } \\
\text { Things Work }\end{array}$ & 7410 & 4.45 & 1.23 & 458 & 4.24 & $\begin{array}{c}1.2 \\
7\end{array}$ & $* * * 1$ \\
\hline $\begin{array}{l}\text { Understands } \\
\text { Connections }\end{array}$ & 7383 & 4.88 & 1.10 & 461 & 4.71 & $\begin{array}{c}1.1 \\
9\end{array}$ & $*^{1}$ \\
\hline $\begin{array}{l}\text { Has Educational } \\
\text { Plan }\end{array}$ & 7717 & 5.37 & 0.91 & 488 & 5.23 & $\begin{array}{c}0.9 \\
6\end{array}$ & \\
\hline $\begin{array}{l}\text { Has Significant } \\
\text { Relationship }\end{array}$ & 7716 & 4.43 & 1.49 & 485 & 4.07 & $\begin{array}{c}1.6 \\
0\end{array}$ & $* * * 1$ \\
\hline $\begin{array}{l}\text { Values Advisor- } \\
\text { Advisee } \\
\text { Relationship }\end{array}$ & 7418 & 5.07 & 1.05 & 461 & 4.95 & $\begin{array}{c}1.1 \\
5\end{array}$ & \\
\hline
\end{tabular}

$*=<.05 * *=<.01 * * *=<.001$

${ }^{1}$ Retained significantly higher than not retained

${ }^{2}$ Retained significantly lower than not retained

Table 18

Summary of Significant Values for Learning Outcomes

\begin{tabular}{|c|c|c|c|c|}
\hline Name & $\mathrm{B}(S E)$ & Wald's $\chi^{2}(d f)$ & $p$ & $e^{\beta}$ \\
\hline Know Requirements & $-.13(.04)$ & $10.34(1)$ & 0.001 & 0.88 \\
\hline Knows Resources & $-.10(.04)$ & $8.41(1)$ & 0.004 & 0.90 \\
\hline $\begin{array}{c}\text { Understands How } \\
\text { Things Work }\end{array}$ & $-.11(.04)$ & $7.71(1)$ & 0.005 & 0.90 \\
\hline $\begin{array}{c}\text { Understands } \\
\text { Connections }\end{array}$ & $-.09(.04)$ & $4.74(1)$ & 0.03 & 0.91 \\
\hline $\begin{array}{c}\text { Has Significant } \\
\text { Relationship }\end{array}$ & $-.10(.03)$ & $10.56(1)$ & 0.001 & 0.90 \\
\hline
\end{tabular}


Table 19

Model Tests for Variables with Significant Values for Learning Outcomes

\begin{tabular}{|c|c|c|c|c|c|c|}
\hline Name & $\begin{array}{c}\text { Overall model } \\
\text { evaluation } \\
\text { likelihood ratio } \\
\text { test } \chi^{2}(d f)\end{array}$ & $p$ & $\begin{array}{c}\text { Homer \& } \\
\text { Lemeshow } \\
\chi^{2}(d f)\end{array}$ & $p$ & $\begin{array}{c}\text { Cox } \\
\text { and } \\
\text { Snell }\end{array}$ & Nagelkerke \\
\hline $\begin{array}{c}\text { Know } \\
\text { Requirements }\end{array}$ & $289.49(3)$ & 0 & $23.28(8)$ & 0.003 & 0.04 & 0.10 \\
\hline $\begin{array}{c}\text { Knows } \\
\text { Resources }\end{array}$ & $282.76(3)$ & 0 & $19.70(8)$ & 0.012 & 0.04 & 0.1 \\
\hline $\begin{array}{c}\text { Understands } \\
\text { How Things } \\
\text { Work }\end{array}$ & $284.148(3)$ & 0 & $34.58(8)$ & 0 & 0.04 & 0.1 \\
\hline $\begin{array}{c}\text { Understands } \\
\text { Connections }\end{array}$ & $283.965(3)$ & 0 & $22.74(8)$ & 0.004 & 0.04 & 0.1 \\
\hline $\begin{array}{c}\text { Has } \\
\text { Significant } \\
\text { Relationship }\end{array}$ & $287.489(4)$ & 0 & $17.64(8)$ & 0.024 & & \\
\hline
\end{tabular}

\section{Comparison of retained and not retained second year learning outcome}

ratings. As noted in Table 18, statistically significant differences were observed between the learning outcomes ratings of retained and not retained second year students on 5 of the 7 learning outcomes. Retained second year students rated Knows Requirements, Knows Resources, Understands How Things Work, Understands Connections, and Has Significant Relationship higher compared to not retained second year students.

\section{Conclusion}

This study was designed to examine six research questions addressing differences in attitudes and experiences with college academic advising. The first three questions examined differences between student groups formed by class year with respect to 
advising importance ratings, satisfaction ratings, and learning outcomes. The last three questions examined differences between second year student groups formed by retention status with respect to advising importance ratings, satisfaction ratings, and learning outcomes.

The first three research questions were examined using a simultaneous regression model while the last three research questions used a logistic regression model. Both models controlled for demographic and other variables found in previous research (and reported in Chapter Three) to have an effect on the model being examined.

In general for the first three questions, significant differences were identified between first and second year. Results for research questions four through six also indicate significant differences in the attitudes and experiences of retained second year students compared to not retained second year students.

Standard deviations were above 1.2 for most measures except for Accurate Information in which the standard deviation was well below 1.0 for importance rating. The standard deviation of the Satisfaction Rating for Accurate Information, however, came closer to the standard deviations on all other measures.

Chapter Five will provide an analysis of these findings, address their implications in relation to existing knowledge, and provide suggestions and implications for future research on the topic of advising interventions for second year retention. 


\section{CHAPTER 5}

\section{SUMMARY AND DISCUSSION}

\section{Introduction}

One of the lingering problems institutions of higher education face is low retention rates. Although first year retention did improve with the advent in the 1980 s of "front loading" practices with their emphasis on supporting first year students, retention rates have stagnated since then (Seidman, 2005). Retention literature suggests that stubbornly low retention seems to result from devoting nearly all institutional retention resources to first year programs rather than regarding retention as a longitudinal phenomenon occurring at any stage of the student's educational experience (Tinto, 1988, 1993). The common practice of abruptly curtailing support to second year students exacerbates the problem (Amaury et al., 2005). Institutions may wish, therefore, to look beyond the ubiquitous and longstanding front loading practices if they hope to improve retention. The second year of college has been identified as a time of high attrition secondly to the first year -- and so the second year represents the apparent first place for institutions to focus new, research based retention efforts.

Unfortunately, the second year literature base consists mostly of expository and conceptual works which, though useful for understanding the second year from a descriptive point of view, offer little empirical research to guide practitioners. Except for one study (Juillerat, 2000), what empirical research that does exist about the second year of college does not examine untested assumptions that differences exist between second 
year students and their first year and upper division student peers. These assumptions form the foundation of the second year literature. Although the more conceptual work, on the whole, suggests that institutions should treat second year students differently, to date this literature provides little to help us understand if, and in what ways, the attitudes and experiences of second year students differ from those of the first and upper division peers.

The present study was undertaken to fill these gaps in the second year student retention literature. Because of the influence academic advising is thought to exert on retention, the study examined students' attitudes and experiences with academic advising. The research had two overall purposes. The first purpose was to examine whether and how second year students' attitudes and experiences with academic advising differ from those of first year and upper division students. Specifically, the following research questions were posed:

1. Do second year students differ from first year and upper division students in the importance they ascribe to any of the twelve advising functions?

2. Do second year students differ from first year and upper division students in their satisfaction with any of the twelve advising functions?

3. Do second year students differ from first year and upper division students in their level of agreement with statements that reflect what students know, do, or value as a result of receiving academic advising (learning outcomes)? 
The second purpose of the research was to examine if, and in what ways, advising attitudes and experiences of second year students who are retained and enroll in their third year of college differ from those second year students who are not retained. The specific research questions posed were:

4. Do retained second year students differ from not retained second year students in the importance they ascribe to any of the twelve advising functions?

5. Do retained second year students differ from not retained second year students in their satisfaction with any of the twelve advising functions?

6. Do retained second year students differ from not retained second year students in their level of agreement with statements that reflect what students know, do, or value as a result of receiving academic advising (learning outcomes)?

I provide in this chapter a discussion of the implications and importance of the results presented in Chapter Four. The chapter is organized to first review the methodology and to provide a brief summary of the results. Following this information, I provide discussion on the results of comparisons of second year students with first year and upper division students and a discussion of the results of the comparisons between second year student who were retained and those who were not retained. In the discussion, I consider the results in relation to past research. I conclude the chapter with a discussion concerning the implications of the results for future practice and research. 


\section{Review of the Methodology}

This study used a correlational design to examine secondary data collected from five public and two private four-year institutions of higher education in the Pacific Northwest of the United States of America. The data was gathered from 15,133 college students during the spring of 2010 and 2011 using the Inventory of Advising Functions -

Student Version (C 2006 By Cathleen L. Smith and Janine M. Allen). Demographic information and retention data were provided by each participating institution. A subset of this sample consisting of 8,500 undergraduate students 25 years old or younger who had remained in continuous enrollment since entering their institution as first time freshmen was chosen for the study.

Two sets of three questions each were posed for this study. For the first set of questions, which asks if second year students differ from first year and upper division students in their attitudes about and experiences with academic advising, simultaneous regression was used for the analysis. The second set of questions, having to do with whether second year students who are retained differ from second year students who are not retained in their attitudes about and experiences with academic advising, was analyzed using logistic regression.

\section{The Importance of Difference}

This study was undertaken because previous research about the second year student experience implies that a difference exists in that class year compared to other class years, but no empirical study has provided evidence of this purported difference. 
Additionally, many educators speculate that advising interventions for second year students will find greater success if advisors understand whether differences do exist and, if so, where the differences lie so as to pinpoint appropriate advising interventions. The results of this study provide statistically significant evidence that differences do exist between class years with respect to advising attitudes and experiences.

Empirical knowledge of the second year student's experiences with advising and how those experiences differ from other students is important for several reasons. First, higher education research since the early 1980s has suggested that the second year experience is different from the first year (Boivin et al., 1993; Furr \& Gannaway, 1982; Gahagan \& Hunter, 2006; Lemons \& Richmond, 1987; Schaller, 2000, 2005). In addition, the research also proposes that the second year student experiences something like what the middle child in a family of three experiences. That is, the second year student comes back to campus in the fall after his or her first year to find that the support he or she had grown to appreciate no longer exists (Gahagan \& Hunter, 2006). Also retention statistics show that second year students represent the most at-risk population for leaving college after the first year (ACT, 2009; Ho Yu et al., 2010; Pattengale, 2000; Tinto, 1993). This low second year retention rate is costly to the university, the student, the student's family, and of course to society as a whole.

Previous research similarly implies that differences may exist in the experiences of second year students compared to their upper division peers. And so it is additionally important to determine if differences do exist and to understand those differences if they do. Using the middle child metaphor again, the second year student feels ignored 
compared to both the first year student and the upper division student (Gahagan \& Hunter, 2006). But this information is not sufficient to plan for the second year student's actual needs. Without knowing whether and what differences exist, well meaning advisers may simply be "shooting in the dark" to devise programs they hope will meet the needs of the second year student. Knowing how second year students differ from first year and upper division students will help advising programs more accurately address second year student needs.

Knowing how second year students differ from their peers in their advising attitudes and experiences may also provide insight into the historical prescriptive versus developmental dichotomy in advising (Smith \& Allen, 2006). Smith and Allen (2006) describe this dichotomous approach as problematic because it "does not allow students to tell the researcher that both kinds of advising are important to them" (p. 56). In keeping with Tinto's $(1988,1993)$ longitudinal concept for retention, it is also reasonable to take Smith and Allen's (2006) admonition further by understanding that advising needs change as the student progresses from first year to second and from second year to the upper divisions. Finally, our advising intervention efforts will not be wasted on initiatives that may not matter to the targeted student. It is therefore as important to simply know what first year and upper division students find important as it is to understand how the second year students differ from them.

\section{Differences Exist between Second Year and First Year and Upper Division Students}




\section{Importance Ratings}

The first set of research questions was posed to ask whether differences exist between second year students and first year and upper division students. It should first be noted that although statistically significant differences were found between first year and second year students, as well as between upper division and second year students, all students found all the advising functions important (above scale point 4 on the 6 point scale). The most important function for all students was the ability to give students accurate information about degree requirements.

Advising is, therefore, important to all three groups of students. However, second year students' mean importance ratings differed from those of first year and upper division students on only some functions. Not all of them were found to show difference between class years.

Second year students differed from first year students in the importance they ascribed to two of the integration functions and one of the referral functions. Second year students regarded the integration function having to do with choosing general education options that connect the student's academic, career, and life goals as less important than first year students. Second year students also regarded advising that helps students with deciding what kind of degree to pursue in order to connect their academic, career, and life goals as less important. Second year students furthermore regarded both referral functions having to do with referring students to campus resources which address academic and non-academic problems as less important than first year students. Second year students considered only one function as more important than first year students. 
That was the individuation function that has to do with knowing the student as an individual.

Second year students differed from upper division students on the importance they ascribed to three advising functions. The integration function concerning advising that helps students with choosing among the various general education options that connect their academic, career, and life goals was more important for second year students than it was for upper division students. The referral function that involves advising that connects students with campus resources which address academic problems was also more important for second year students than it was for upper division students. Conversely upper division students reported that the ability to give students accurate information about degree requirements held greater importance for them than it did for second year students.

\section{Discussion}

Developmental pattern. These findings of difference reveal an important developmental pattern that has implications for practice. To illustrate, first year students begin college with little knowledge about what classes to take and only rudimentary academic, career, and life goals. First year students understandably, therefore, need advising about general education requirements and about what type of degree to pursue to link the new student to his or her early academic, career, and life goals. Because the integration functions involve connecting student goals to a particular academic task, the advisor necessarily must get to know the student well enough to help the student 
accomplish the task. While the integration functions require a holistic and developmental approach, the type of information needed to accomplish the task during the first year is usually rather prescribed by the university meaning the advisor should be comfortable both with learning the rudiments of the student's goals while also knowing how to prescribe the proper initial course through the curriculum.

Second year students, on the other hand, do not need to know what courses to enroll in to satisfy general requirements or to pursue the general aspects of a degree BA, BS, B of Music, and so on. This is likely because second year students are approaching their decision about majors while the general education requirements dominate the first year curriculum. Furthermore the decision about the kind of degree to pursue needs to be made before the second year because of the sequential nature of courses taken to meet degree requirements such as language requirements and science and math classes.

Second year students identified the referral functions as less important than the first year students. This difference likely appeared for two reasons. First, from a retention standpoint, the referral functions deal with issues that might hinder retention such that a student who did not resolve those issues as a first year student likely would not return for the second year to even need referral. Secondly, first year students are making the most significant lifestyle adjustment of their lives when they arrive at college. The entire concept of "front-loading" for retention is based on this college reality. The adjustments necessary to succeed in one's first year involve not only academic issues, but also interpersonal adjustments involving finding a sense of belonging, adjusting to new 
friends, living on campus, and working through key issues of identity (Kuh, 1969). All of these adjustments can foment significant crises well beyond the scope of the advising relationship requiring referral to campus resources designed to assist the student through these transitional crises. Second year students, on the other hand, have usually adjusted to all of the initial college changes and have come to focus on more advanced life defining transitions and decisions which will provide the shape of the rest of their lives.

Overall, these findings of difference suggest a pattern of development is taking place, as we would expect based on the Reflective Judgment Model (King \& Kitchener, 1994, 2002), in which what is defined as important changes significantly during the second year. Advisors may wish to cater their interventions to first year students and second year students with these difference needs in mind.

A unique need to be unique. Although second year students rated all the functions on the important end of the scale, being known as an individual was significantly more important to them than it was for first year students. In general, the individuation functions speak directly to the relational role that advisors can play. When an advisor focuses on knowing a student as a unique person that advisor necessarily makes a commitment to a relationship with that student and to a more developmental approach to advising. While the integration functions also require a holistic and developmental approach, the second year student seems to be looking for a deeper, more mentoring relationship in addition to advising that links his or her curricular choices to his or her goals, especially as he or she comes back to campus realizing the attention received during the first year is no longer being offered. This necessary relational 
redefinition has significant implications for practice as advisors seek to provide appropriate interventions for the second year student.

For instance, though second year students still find the integration and referral functions important, they frequently feel ignored, left out, and asking for a deeper and more mature relationship. This finding corresponds directly with assertions made by earlier researchers that a deeper relationship is missing in the second year and that such relationships should form the backbone of advising interventions for the second year student (Gahagan \& Hunter, 2006; Graunke \& Woosley, 2005; Juillerat, 2000).

The importance second year students place on being known as an individual may also reflect the developmental changes they experience as they transition from the first year of college to the upper divisions. Schaller (2005) describes this important transition as being composed of four stages in which second year students migrate from Random Exploration through Focused Exploration and into Tentative Choices. In a later article, Schaller and Tetley (in press) link this transitional process directly to academic advising within which they stress the importance of tying learning outcomes typical of each stage of second year development with advising practices that most likely will help the student to achieve those learning outcomes and succeed to the junior year.

A pattern of transition. According to Schaller (2005), the second year student has moved from the first year of Random Exploration into a college life in which "students... begin to feel the pressure to be prepared for adulthood" (Schaller \& Tetley, in press, p. 12) and in which students begin a distinct stage of "discernment" (Schaller \& Tetley, in press, p. 13). Discernment is a dynamic process in which the student strives to 
learn about him or herself more deeply and then make decisions and choices which match this vision of who he or she wishes to become. Being dynamic and reflective, this process necessarily requires a relationship with an interested adult willing to offer more than prescriptive advising practices such as listing out the choices of classes which can be made. This dynamic process requires a relationship in which the advisor takes the time to know the student well enough to assist in the work of making choices that connect the student to his or her academic, career, and life goals. Such a relationship may require a retooling in faculty and advisor attitudes towards the advising relationship as current research suggests that faculty find the individuation functions as less important than students do (Allen \& Smith, 2008).

Upon examination of these results, therefore, a developmental pattern appears in which students change in what they find important over time. First year students report higher importance ratings for advising that helps connect their very first classes to their early academic, career, and life goals. Such advising requires a holistic and developmental advising approach because the advisor must first understand the student's goals. But the first year curriculum is usually rigid and prescribed meaning the advisor necessarily must also be somewhat prescriptive in his or her approach with the mechanics of this advising function.

Second year students define importance for functions differently from upper division students much like first year students define importance ratings differently from second year students. This pattern also indicates a growth pattern over time which is supported in the second year retention literature as well as by the developmental 
framework informing this study (King \& Kitchener, 1994, 2002). Throughout this developmental progression of advising needs, second year students identify being known as an individual as uniquely more important between all three groups indicating that as they progress towards the upper divisions, they are looking for a more mature relationship with the advisor. Again, according to Schaller (2005), the second year student negotiates an important transition between the first year and the upper divisions of college. This transitional year corresponds also with the vital cognitive transition as described by King and Kitchener (1994, 2002) with the Reflective Judgment Model.

The upper division student, however, has already made this progression and has become firmly ensconced in the work of his or her major, internships, and co-curricular activities all of which converge on a valuable and meaningful degree at the end of the senior year. By the time the upper division student has begun participation in the upper division work of college, it is also conceivable that he or she may be as likely to seek mentor assistance from a favorite professor or an internship supervisor as from an academic advisor.

Second year students regarded advising that assists students with choosing among the various general education requirements that connect them with their goals as well as advising that refers them to academic support with greater importance compared to the upper division students. This is likely because second year students are making final preparations for important second year tasks such as choice of major. They need to make sure their general education requirements line up properly with their academic, career, and life goals. This preparation through general education connection lays the 
groundwork for the appropriate choice of major and choice of suitable classes within the major that occurs in the second year. Second year students also must prepare for the important decisions of that year by shoring up weaknesses in their academic skills which may explain why they find advising that refers them to academic support services as more important than upper division students. A student who rises to second year status with poor study skills and a lower than hoped for GPA, for instance, may feel great anxiety as he or she anticipates the academic choices he or she must make in the second year. Some of these choices involve meeting GPA and course requirements for admittance to professional programs. The upper division student who has already made those decisions will not find referral to academic resources as important as the second year student, as this study suggests. Again, this finding should help advisors to hone their interventions properly for the second year.

Finally, while accurate information is important to all students, according to this study, it is more so for the upper division student whom we can presume wishes to graduate and graduate on time. Accurate information becomes ever more important as the window of opportunity in college narrows. An information mistake, for instance, in the spring of one's senior year will negatively affect that student's goal of an on time graduation more than a course choice mistake made in the second year. Dispensing accurate information implies a shift back to prescriptive advising techniques suggesting further that the "one-size-fits-all" (Smith \& Allen, 2006, p. 63) approach to advising may not be appropriate as a student progresses through the college life span. 


\section{Satisfaction}

Satisfaction ratings scores for all students fell in the mid to high range (above scale point 3.5 through 5.0 on the 6 point scale). While all students reported some level of satisfaction for all the advising functions, more differences were detected between second year students and first year students and upper division students on satisfaction ratings than on importance ratings.

Second year students differed from first year students, reporting greater satisfaction on all 12 advising functions. Conversely second year students differed from upper division students reporting greater satisfaction with nine of the 12 functions, also spanning all five of the functional areas. While not statistically significant at the alpha level $(p<.05)$ established for this study, differences between the mean satisfaction ratings of second year students and upper division students on the function having to do with being known as an individual was approaching significance $-p=.054$.

\section{Discussion}

Students in general are consistently dissatisfied with the academic advising they receive (Allen \& Smith, 2008); and second year students have been found to be more dissatisfied with academic advising and associated advising such as career counseling than other students (Astin, 1987; Juillerat, 2000; Pullins, 2011). Pullins (2011) states in her study on satisfaction and retention for second year students that dissatisfaction with academic advising is a predictor of attrition. Research concurrently points to academic advising as a key tool for retention throughout the college student life span (Habley et al., 
2004; Pascarella \& Terenzini, 2005; Tinto, 1988, 1993). Though prior research suggests that students are dissatisfied with advising and that advising is linked to student success and retention, knowledge of the differences in satisfaction between class years may prove useful to academic advisors. As with discerning class year differences in importance ratings, information about satisfaction is necessary to more accurately target improvements in advising delivery methods for second year students who suffer from stubbornly low retention rates.

Retention researchers also have found that students become less satisfied with the college over time so that seniors are more likely to be dissatisfied compared to first year and second year students (Liu \& Jung, 1980; Smith \& Allen, 2006). And so we would expect to see the same change in satisfaction levels over time in this study. There are a few notable anomalies in this pattern from the findings in this study worthy of discussion.

First year students, for example, reported greater satisfaction than second year students on all of the twelve advising functions while the upper division students were more dissatisfied than second year students on eight of the functions. Given the general pattern of satisfaction dropping over time with age and class year (Liu \& Jung, 1980;), the pattern should maintain itself such that upper division students are dissatisfied on all 12 of the advising functions compared to second year students. But the results of this study show that, contrary to the expected pattern, second year students are more dissatisfied than first year students while satisfaction improves for upper division students. This pattern reversal supports the "middle child" metaphor (Gahagan \& Hunter, 
2006) in which the second year student is caught between the two classes feeling ignored and dissatisfied.

That second year students reported significantly lower satisfaction than the first year students on every function possibly reflects a significant change in perspective and attitude may be taking place as the second year student moves into this "middle child" status. The second year students' dissatisfaction compared to first year students comes during a time when persistence is in jeopardy and when university resources are being withdrawn. Given Pullin's (2011) findings about the predictive validity of satisfaction to the retention of second year students, this finding suggests that advising practices may need to pinpoint second year satisfaction more aggressively to reduce the high number of statistically significant differences in satisfaction ratings compared to first year students.

Finally, another important aspect of these findings is that both first year and upper division students reported being more satisfied on the one advising function that second year students found to be most important - being known as an individual. Juillerat (2000) similarly found in her study on second year satisfaction that second year students reported significantly lower levels of satisfaction than other students with the "approachability and concern of their advisors, issues they have already identified as being critically important to them" (p. 24). Pullins (2011) also discovered a similar dissatisfaction such that second year students reported dissatisfaction with the advising relationship and being known as an individual during a time when they also say they need it most. 
It must be noted again that for upperclass students the significance level for advising which helps the student feel known as an individual fell .004 higher than the set significance level for the study. However the significance level is so close to the established alpha and in such congruence with previous research that it deserves attention in this exploratory study. It deserves attention because it breaks the pattern of satisfaction levels dropping over time while the classes on either side of the second year student in this study report greater satisfaction on the one thing second year students identify as more important compared to their peers in the first year and upper divisions of college.

\section{Learning Outcomes}

Statistically significant differences were found between second year students and first year and upper division students on 6 of the 7 learning outcomes. Specifically, second year students differed from first year students in their tendency to agree that they had an educational plan, knew how things worked at their college with regard to policies and procedures, knew the requirements of the college, had a significant relationship with some university official, understood how their academic choices connect to their academic, career, and life goals, and valued the advisor-advisee relationship. Second year students differed from upper division students in that upper division students were more likely to agree that they had an educational plan, knew how things worked, knew the requirements, and had a significant relationship with some university official compared to second students. 


\section{Discussion}

These findings can be seen as "good news" for the most part. For instance, learning outcome achievement appears to improve with second year students reporting progress on nearly all of the learning outcomes compared to the first year students. Interestingly as well, second year students agreed that they experienced a significant relationship with a university official more than first year students. Although these findings provide reason for some optimism about advising interventions, they also point to some key ways that colleges might improve their advising efforts for second year students.

For instance, the learning outcome difference in which second year students are more likely to agree that they experienced a significant relationship does not mean that the second year student experienced this significant relationship in the advising context. A relationship could arise from anywhere in the college. Indeed, and logically, the longer a student remains at a college, the more likely significant relationships will develop with anyone on the faculty or staff.

In light of not knowing if the significant relationship occurred in the advising setting, it is particularly notable that second year students also report they value the advisor-advisee relationship significantly more than the first year students do. Taken with the importance second year students place on being known as an individual as well as the finding of lower satisfaction with being known as an individual, this finding is cogent. Second year students find this advisor-advisee relationship important, they value it more than the first year students do, and yet they are more dissatisfied than first year 
students or upper division students indicating advising interventions specifically tuned to second year needs and learning outcomes may be warranted.

\section{Differences Exist between Retained and Not Retained Second Year Students}

The second set of research questions were posed to discover whether retained second year students differed from not retained second year students on the importance ratings, satisfaction ratings, and advising learning outcomes. As noted in Chapter Two, the issue of retention is longitudinal according to the retention framework informing this study (Tinto, 1988, 1993). As a longitudinal process, retention should be considered a potential problem beyond the first year when most retention programs are applied by colleges. Prior retention research provides evidence that colleges see attrition levels from second to junior year approach attrition levels found during the first year (Flanagan, 1991; Ho Yu et al., 2010; Pattengale, 2000). Since retention has not changed in 30 years, it makes sense to apply retention specific interventions beyond the first year. Due to such low retention rates for second year students, then, this study also focused on how retained second year students differ from not retained second year students to discern clues to help advisors create or fine-tune programs that address the needs of second year students who would leave otherwise. Results indicated that differences do exist between retained second year students and not retained second year students. 


\section{Importance Ratings and Discussion}

Retained second year students differed from not retained second year students in the importance they ascribed to advising that provides information about how things work at the university and that connects choices about their major to their academic, career, and life goals. Conversely, not retained second year students differed from retained second year students in the importance they ascribed to advising which provides non-academic referral support. There were no other statistically significant findings for importance levels, a finding that can be as instructive as knowing how the two groups differed significantly.

For instance, findings for the first set of questions suggest that second year students seek a one on one mentoring relationship compared to the first year and upper division students. But when comparing retained with not retained second year students, no statistically significant difference was found. This lack of significance does not imply that second year students do not value this advising function - the importance of being well known as an individual in a relationship with an adult; rather this finding suggests that advisors who wish to fine-tune their approaches to assist those most likely to leave in their second year should also realize what to do with the knowledge gained from close personal advising relationships.

For example, those second year students who leave indicated a greater attribution of importance in the area of non-academic referrals. Non-academic issues such as roommate conflicts, emotional issues, alcohol and drug problems, family problems and the "who am I and what is life all about," issues can derail educational plans and goals. 
Advisors cannot make informed non-academic referrals for these types of problems without first seeking this kind of information through their advising role by establishing a close and trusting relationship. Advisors, and those who train advisors, should consider this implication in light of previous advising research findings that show that faculty believe advising functions involving knowing students as individuals is less important compared to all students, second year or not (Allen \& Smith, 2008).

While knowing what retained and not retained second year students did not consider important is instructive, advisors should also reflect on the statistically significant differences between the importance ratings for these two groups. Retained second years students differed from not retained second year students in the importance they ascribed to advising that provides information about how things work and advising that connects them to a major. This finding is consistent with Anderson and Schreiner's (2000) research that states the three most important second year tasks are "dealing with an intensified curriculum," (p. 56) declaring a major, and selecting a career path. Second year students faced with an intensified curriculum will still need to know how things work. In this case the "things" may not necessarily consist of first year pertinent information such as "where is my class" and "how do I put more points on my meal card." Instead the second year student who faces an increasingly difficult curriculum will need help negotiating class requirements, understanding a more advanced syllabus, and how to begin a professional student relationship with a professor. The significant differences for the "how things work" advising function between retained and not retained second year students suggest that advisors should not assume they can simply 
apply the "template" from their first year advising strategies to the second year students and expect positive results (Sanchez-Leguelinel, 2008). Instead practitioners should consider developing programs specific to the unique information needs of the second year student, especially since delivery of accurate information is valued by all students.

In addition to the more difficult curriculum, the second year student will feel great pressure to pick a major if they have not already done so (Schaller, 2005). He or she also may recognize that the major should connect to their academic, career, and life goals (Anderson \& Schreiner, 2000), a task that usually requires assistance from an advisor. This kind of information, of course, does not come from an advising relationship shaped only of the prescriptive advising approach. This kind of information comes forth through a relationship that has been forged from a holistic and developmental perspective with shared responsibility.

\section{Satisfaction Ratings and Discussion}

Interestingly for the above findings, while all second year students, retained and not retained, found shared responsibility in the advising relationship to be very important, retained second year students and not retained second year students did not differ in the importance they ascribed to the shared responsibility function. In looking at the Satisfaction Ratings, however, retained second year students differed from not retained second year students in their satisfaction in the area of shared responsibility. So, while all of these students found the shared responsibility function important, those who left were significantly less satisfied, which further indicates that something went missing in 
the relationship the student had (or did not have) with the advisor. For instance, lack of help from the advisor in developing an educational plan and in decision making could affect retention by the student not having the required skills to make informed educational decisions and choices.

Retained second year students also differed from not retained second year students in their satisfaction with advising that connects their academic, career, and life goals. This finding is consistent with the above finding regarding satisfaction with shared responsibility in that advising that connects students to their goals requires a two way communication, which establishes a shared decision making approach. When sharing is absent in the advising relationship the advisor cannot have the information necessary to connect the student to his or her goals. A disconnected student is one who cannot become socially or academically integrated (Tinto, 1993) and who is a candidate for the classic signs of the Sophomore Slump -- prolonged indecisiveness about selecting a major and inappropriate decision making about academic course selection and major and minor fields of study (Gardner 2000).

Finally for the advising functions, it is important to note that though no statistical difference between the two groups was found with respect to satisfaction with nonacademic referral, both groups rated their satisfaction with this function on the low end of the six point scale. Non-academic referral is important to students struggling in areas not usually handled in the advising relationship. Second year students who leave college may benefit from improvements in advising specifically targeted to providing better 
referral to non-academic resources such as college counseling centers and residence hall staff. Advisors could benefit from specific helping and listening skills training, for instance, from health and counseling center staff to shore up the skills necessary to recognize issues requiring non-academic referrals.

\section{Learning Outcomes and Discussion}

Significant differences were found between retained and not retained second year students on 5 of the 7 learning outcomes. These differences complement the above findings about importance and satisfaction. For instance, retained second year students differed from not retained second year students in their agreement with statements that indicated they know the requirements for a degree at the institution, they had a significant relationship with an adult at the college, they know where to get help, they feel connected to their career and life goals, and they value the advisor-advisee relationship. While we should expect that students who leave would not agree with these statements, examining them more closely sheds some light on important nuances in these differences.

Good advising helps students integrate academically and socially by connecting them to knowledge of how to get a degree, teaching them to navigate campus personnel for help, linking them to their own personal goals, and providing mentoring relationships with faculty or staff. Academic and Social integration is a key to retention (Tinto, 1993) and interaction with faculty and staff through advising is thought also to improve retention. The second year student who manages to avoid the slump seems to be able to do so when his or her experiences with advising provide these tools for persistence. The 
second year student who slumps and does not receive these tools should be sought out before he or she drops out.

The most important of these distinctions is that second year students who leave do not value the advisor-advisee relationship as much as the second year students who are retained. A student who does not value this kind of relationship probably will feel no motivation to seek it out. And yet prior research suggests that a maturing relationship with an adult at the college, especially in the advising setting, will help the second year student make the important transition from quasi-reflective judgment to reflective judgment between the first and junior year (Gahagan \& Hunter, 2006; Graunke \& Woosley, 2005; Juillerat, 2000; King \& Kitchener, 1994, 2002). This finding implies that college advising professionals may need to "invite" students who do not naturally find this kind of relationship valuable. This kind of stance with the student may appear more "parental" than some advisors may feel comfortable with; but without taking that extra step of inviting students who do not value the relationship, the students may, as Gardner (2000) predicts, drift about with no direction and no guidance, failing to make connections and decisions and finally leaving the institution bewildered at what happened. 


\section{Relationship of the Current Study to Previous Research}

\section{The Longitudinal Nature of Retention}

Tinto's (1993) longitudinal theory of retention informed this study of advising attitudes and experiences for two reasons. First, the theory expands the two most important aspects of retention, academic and social integration, through the entire college lifespan. While Tinto's conceptualization is supported through many years of research and studies, colleges still tend to focus only on the first year of college for their retention efforts (Amaury et al., 2005; Seidman, 2005). And while the focus on the first year did bring a boost to retention when these efforts began and through the $1990 \mathrm{~s}$, retention has stagnated as a result of ignoring the longitudinal nature of college retention. This study expands our understanding of the longitudinal nature of retention to include the second year, a practice increasingly called for in the last ten years of research (Pattengale, 2000; Tobolowsky \& Cox, 2007).

Tinto's (1993) longitudinal model informed this study also because it implies that students change over time in their development and consequently in their needs. This implication means, for instance, that practitioners should not simply assume that a second year student can be treated as they were treated in their first year (Flanagan, 2006; Sanchez-Leguelinel, 2008). 
King and Kitchener's (1994, 2002) Reflective Judgment Model provided the developmental frame of reference to further support the longitudinal conception of the college life span. The Reflective Judgment Model (King \& Kitchener, 1994, 2002) describes the time period at the end of the first year as the beginning of an important epistemic transition from one way of approaching knowledge to a more mature approach suitable to success in the upper divisions of college. Their framework was useful for this study into traditional-aged college students because the stages are sequential, "correlate highly with age, and they are linked to educational attainment” (Tennant \& Pogson, 1995, p. 129).

Specifically for this study, King and Kitchener $(1994,2002)$ found that students using pre-reflective judgment are often in the last two years of high school and in the first year of college. This stage is characterized by a recognition that a truth may exist but that it may not always be accessible. Those using pre-reflective judgment look for fully concrete evidence and in its absence look solely to "what feels right at the moment."

Students often achieve stage four - quasi-reflective judgment - according to the model, during the second year and into the end of college. This stage is characterized by the student acknowledging an uncertainty in knowing the "truth," a certain skepticism about how one should relate to authorities (such as professors and advisors), and a "growing distinction between well-structured problems that can be solved with certainty, and ill-structured problems" (Tennant \& Pogson 1995, p. 128). Again, this part of the model corresponds with findings in this study which suggest that second year students are 
searching for the right kind of relationship with an authority, the advisor, who they perceive differently in the transition from second year to the upper divisions of college.

\section{The Role of Advising}

Advising formed the focus of this study for several reasons. First, the longitudinal and developmental frameworks used for this study offer institutional support personnel a wider picture of the college journey from matriculation to graduation. One of the support practices present over the entire college life span is advising. Other practices, such as first year orientation and residence hall programs, affect the student at early points in the college career. Internships, practica, research projects, and collaboration with faculty occur at later points in the college career.

Secondly, advising has been called for in much of the research conducted about supporting second year students over the last ten years. In addition, advising has been identified as one of the most important methods for putting students into a mentoring relationship with college staff and faculty, a practice with strong ties to retention (Habley et al., 2004; Kuh, 2008). These are the relationships where a college staff or professor can "bring students alongside him or her and model for the student the pursuit of a profession" (Boivin et al., 2000, p. 8) which corresponds with previous research assertions that second year students benefit from an advising relationship that assists them in making career and personal decisions matching their academic, career, and life goals. 


\section{Prescriptive or Developmental Advising}

In addition to considering how to broaden the university approach to retention, this study was also undertaken to investigate the many assertions in the research of the past ten years that 1) something is different with second year students and that 2)

understanding those differences, if they exist, might help educators improve advising interventions with greater precision. In other words, it is not simply enough to find out that something is different; we need to know how they are different.

Smith and Allen (2006), who developed the instrument used by this study, assert that this kind of knowledge can also mediate the ever present "prescriptive versus developmental" debate that tends to distract rather than inform the advising and student success community. Smith and Allen (2006) describe the prescriptive-developmental advising dichotomy as "problematic" because it does not take into account that a student might benefit from both types of advising. Many of the results of this study support this assertion with findings that show that second year students are indeed different in their advising attitudes and experiences compared to first year and upper division students. From a practical viewpoint, this information also supports Smith and Allen's (2006, 2008) suggestion that institutions should provide the kind of training that will help advisors, especially faculty advisors, know that advising means more than simply giving out the most accurate information possible. Though all students value accurate information above all else, second year students, in particular, seek the beginnings of a mentoring relationship with a professional academic who can model for them what it means to be a student on the path to post-college success. Appropriate training for 
university advisors should therefore focus on the reality that a "one-size-fits-all" (Smith \& Allen, 2006, p.63) advising mentality does not fit the statistically significant findings of difference found in this study.

\section{Schaller's Stages of Second Year Development}

This study also supports Schaller's (2005) qualitative study about second year student experiences in which she formulated a model for understanding the development second year students experience as they transition to the upper divisions of college. Institutions using Schaller's (2005) model alongside the findings of difference provided by this study should be able to more effectively pinpoint interventions during the second year to coincide with second year developmental patterns and tasks.

\section{Second Year Specific Learning Outcomes}

Schaller and Tetley (in press) suggest that advising systems tied to uniquely tailored learning outcomes may help increase second year student engagement and, therefore, retention to the upper divisions of college. Schaller and Tetley (in press) tie a learning outcomes prescription to Schaller's (2005) four stage model of second year development. As students progress through the second year, according to Schaller and Tetley (in press), advisors should expect that second year students will revise their first year educational plan. The findings in this study support the concept of developmental transition for the second year student who may have a different conception of the educational plan compared to first year students and upper division students. 
Schaller and Tetley (in press) also propose that advisors should expect the transitional journey second year student's experience to involve a complex and dynamic "discernment" process involving the "whole person, a rich exploration process, and sophisticated selection" (p. 14). This discernment process requires a more refined and developmental advising relationship than the second year student may have wanted his or her first year but which this study suggests the second year student seeks after leaving that first year behind. This discernment process also requires a relationship that faculty do not find as important as students do, which has implications for faculty training (Smith \&Allen, 2008).

\section{Implications for Practice}

Universities should consider the findings in this study as a means of providing a coherent and assessable framework for institutional efforts in advising through the development of advising practices specific to the second year student. Information from this study suggests those advising practices can be devised by looking at the differences between what is important and how satisfied second year students are in comparison to their first year and upper division peers. This suggestion also implies looking very closely at how retained second year students differ from their second year peers who did not make it to the upper divisions. A close examination of these differences may help advising teams discover answers to questions such as "what seems to have been missing in not retained second year students' experiences with the advising program compared to second year students who transitioned to the upper divisions?" Advising practices 
designed with this information may be useful not only because their creation necessarily motivates advisors to focus intentionally on that notoriously ignored second year of college, but they also provide measures for high quality and meaningful assessment of advising programs as they relate to student learning, engagement and, ultimately, retention.

\section{Advising Learning Outcomes for Second Year Students}

Smith and Allen (2013) "propose that the learning that transpires in students as a result of participation in academic advising is one mechanism through which advising exerts its influence on retention" (p. 5). One of the implications of this study in light of their proposal is that learning occurs over time through the advising relationship. For instance, first year students reported support for a certain set of developmental tasks associated with advising that links them to general educational requirements that match their academic, career, and life goals. Second year students identified different developmental needs such as connection to a major as important. But the second year students also identified the need for an advising relationship that helps them feel unique as an individual more so than first year or upper division students.

Upper division students' needs also changed from the second year students. They were more interested in informational advising needs such as accurate information about degree requirements. In keeping with this pattern of developmental change over time, second year students identified needs more like what first year students asked for such as connection to general education requirements and referral to academic resources. 
One implication from this study, then, is that learning outcomes change over time as developmental needs change from first year to second year and then into the upper divisions. As Smith and Allen (in press) find in their recent study, advising increases learning outcomes scores for students who avail themselves of that advising. And learning outcomes are key links to retention. Schaller and Tetley (in press) provide the theoretical framework discussed earlier for composing second year specific learning outcomes as a means to address the second year specific needs that this study identifies. Universities should consider the findings from this study about second year differences in light of Schaller and Tetley's (in press) framework and Smith and Allen's (in press) research to devise second year specific learning outcomes as a means to increase second year retention.

\section{Dispense with the Dichotomy}

The above implication about advising needs changing over time suggests, as well, that the prescriptive-developmental dichotomy should be reconsidered in light of research assertions by Smith and Allen (2006) who describe the dichotomy as "problematic" (p. 56). The problem can be seen through the findings from this study that students change over time but that advising often is applied with an either/or option that does not give the student the opportunity to tell the advisor what he or she needs. The findings provided by this study, and in light of Smith and Allen's research (2006, in press), suggest advisors should consider each student's needs longitudinally by providing intervention approaches appropriately based on where the student is on the academic and developmental timeline. 
Perhaps a first year student, for instance, does not need a mentoring style relationship with an advisor such as the second year students seem to be asking for. They still need a developmental relationship with the advisor in order to connect the advising encounter with their academic, career, and life goals. But much of the work done in the first year is prescribed somewhat rigidly once a basic decision about type of degree is made. First year students, furthermore, usually have not made the more advanced decisions about major and career direction and so may simply need a direction on what classes to take, how to negotiate student accounts, and how to find their classes in a way that links them to their very early academic, career, and life goals - goals that may change significantly by the time they progress into the second year. As the student naturally matures and gains mastery of these simpler aspects of the college world through the first year, his or her advising relationship needs will grow as well to require a more mature adult relationship with the advisor that can be described more accurately as mentoring.

\section{Consider a Dual Advisor Structure}

One implication for practice, as well, is to consider a two advisor structure. For instance a student might receive advising from both a faculty and residence hall staff person or a faculty and professional advisor - one to address academic information functions and the other to address more developmental functions. Given the duration with which professional residence life staff members spend time with resident students, and the increasing practice of requiring second year students to live on campus, the 
residence hall professional staff are particularly well positioned to embark on relationships with second year students that will help the student feel known as an individual. Residence hall systems should consider developing in-hall advising programs in partnership with already existing academic advising programs as a means to provide advising which helps the student feel known as an individual.

\section{Dispense with Front Loading}

Since retention has stagnated over much time and the second year currently is the best place to apply new retention approaches, the front loading paradigm should change to include advising support through the second year. Front loading brought results for universities and students for some time that shows evidence of the success of these kinds of interventions. Providing support like this over a longer period is suggested by this study such that front loading disappears in favor of a more constant and longitudinal delivery of advising services.

\section{Training for Advisors}

Finally, advisors must be made aware of the differences between second year students and the other students they serve. Advising is a complicated enough job as it is simply keeping up with the more prescriptive needs of the advising relationship such as graduation requirements and core curriculum requirements. The results of this study suggest that advisors need to know even more about their students to provide the kind of advising that might play a role in greater retention. Specifically advisors should know 
that differences do exist between first year and second year students, that knowing a second year student as an individual should be a priority for them despite their inclinations otherwise, that advising cannot be either prescriptive or developmental, and that applying the first year advising template onto the second year student will not produce the results they hope for.

\section{Limitations}

This study was conducted as a means to explore untested assumptions about differences in the second year of college compared to the first year and the upper divisions. A correlational design was used because of its recognized utility as a method for expressing the relationship between variables, a key method for exploratory research such as this study (Field, 2009). Due to the correlational design of the study, however, the results can have no predictive possibilities. Since the design is not experimental this means that cause and effect cannot be established.

The second limitation on the design is that the data relied upon student selfreported data on a survey instrument. Self-reported data may not reflect the student's actual experiences or learning.

The third limitation is that although the study had a longitudinal perspective in that the survey included responses of students who were retained along with those of students who were not, it was not entirely longitudinal in nature. The data used to address the first three research questions, having to do with whether second year students differ from first year and upper division students, were cross-sectional. Thus we cannot 
be certain that responses of the first year students are what the responses of the second year students in the study would have been when they were new students. Similarly, we cannot be certain the responses of the upper division students would be the same for the second year students in this study when they arrive at the upper division level.

Finally, the sample is not random since the students self-selected to participate in the survey. It is plausible that those who participated did so for reasons (e.g., either they were very happy or very unhappy with the advising they received), which would be reflected in their survey responses, but not be representative of the population.

\section{Suggestions for Additional Research}

The results of this study provide possibilities for important future research to explore second year student success towards improving retention. This study also provides affirmation for previous research conjectures that important differences exist between second year students and other students. This statistical confirmation of

difference is an important next step in the research about second year students because it provides an empirical foundation for assumptions that can guide research to further pinpoint areas of concern for second year students with respect to advising and student support with the goal of increasing second year student success and retention. Below are some suggestions for future research. 


\section{Longitudinal Study}

This study was not longitudinal in design which presents a major limitation. An obvious difficulty of the longitudinal design is the length of time and the complexity of the design required to complete it properly. Those two research requirements precluded the use of such a design for this study. However, what is missing from this study's design is knowledge about how the same student may change over time with respect to advising attitudes and experiences. Knowing how a large sample of students changes over time from first year to the upper divisions will provide keener insight into the unique nature of the second year that this study affirms. It is recommended that a future study replicate the basis of this one using Smith and Allen's (2006) Inventory of Advising Functions in conjunction with a longitudinal design framework.

\section{Private/Public Differences}

Two previous studies provide results about the second year experience that show differences between private school second year students and public school second year students (Juillerat, 2000; Pullins, 2011). For instance, Juillerat (2000) found that private school second year students complained more about developmental advising issues while public school students complained more about issues with respect to prescriptive advising. Pullins' (2011) study on second year satisfaction, on the other hand, found some contrasting differences from Juillerat (2000) between private school and public school second year students. Studies should look more closely at these differences to 
provide advisors within each type of institution the information necessary to tailor advising interventions more carefully to the needs of students at their type of institution.

\section{Identify At-Risk Second Year Students}

Some of the retention data included in this study's database, but not analyzed for the research questions, suggest an at-risk category for second year students that should be explored in more detail. Retention data from Private University 2 showed, for instance, that students who had progressed to the second year without enough credits to qualify academically as a "sophomore" had a retention rate below 70 percent while the retention rate for second year students with enough credits to qualify academically as a sophomore was over 90 percent. While research of this type has implications for first year advising it should not be discounted among the second year literature given the longitudinal approach to retention that this study supports. Also as Schaller posits (2005) the path through to the upper divisions of college within the second year begins at the end of the first year as a student moves from Random Exploration to Focused Exploration.

\section{Differences within the Second Year}

The results of this study offer an analysis which supports longstanding assumptions that second year students are different from first year and upper division students. This study also examined the differences within the second year by comparing second year students who persist with those who do not. However, more research into differences among students within the second year itself should follow. Pullins (2011) 
notes, for instance, that her study did not take into account among her population participation in first year programs. This study did not take that participation into account either. Such participation signifies an important difference to examine among second year students themselves because a first year program represents an important pre-second year intervention. Should differences be found between those groups, the findings could support not only the importance of first year experience programs for their intended audience, but also for helping prepare the second year student to handle the important transition to the upper divisions of college.

\section{Conclusion}

The goal of this study was to provide more information on whether differences exist and, if so, where differences exist in the areas of advising importance ratings, satisfaction, and advising learning outcomes for second year students. This information may help institutions break out of the retention rut by developing advising programs more appropriately based on the specific needs of the second year student identified by this study so that practitioners neither waste their time on programs that do not match second year needs nor miss interventions that second year students require.

The second year of college, then, is when institutions should increase advising and student success support efforts. Second year students are different from first year and upper division students. In many instances, the second year student will not need the same advising information or relationship as the first year or upper division student will. The second year student does need a grown up academic or staff person he or she can 
look up to, who will invite, who will get to know him or her, and who will provide motivation to develop an educational plan and a pathway to the mature academic upper divisions of college - a place where students almost always graduate on time. 


\section{REFERENCES}

ACT. (2009). National collegiate retention and persistence to degree rates. Retrieved June 18th, 2012, from http://www.act.org/research/policymakers/pdf/retain_2009.pdf

Allen, J., \&Smith, C., . (2008). Faculty and student perspectives on advising: Implications for student satisfaction. Journal of College Student Development, 49(6), 397-411.

Allen, J., \&Smith, C., (2013). Does contact with advisors predict judgments and attitudes consistent with success? A multi-institutional study. Unpublished manuscript.

Allen, J., Robbins, S. B., Casillas, A., \& Oh, I.S. (2008). Third-year college retention and transfer: Effects of academic performance, motivation, and social connectedness. Research in Higher Education, 49(7), 647-664.

Amaury, N. (2004). The role of habitus and cultural capital in choosing a college, transitioning from high school to higher education, and persisting in college among minority and non-minorty students. Journal of Hispanic Higher Education, 3(2), 180-208.

Amaury, N., Barlow, E., \& Crisp, G. (2005). Student persistence and degree attainment beyond the first year in college: The need for research. In A. Seidman (Ed.), College student retention: Formula for student success (pp. 129-154). Westport, CT: Praeger Publishers.

Anderson, E., \& Schreiner, L. A. (2000). Advising for sophomore success. In L. A. Schreiner \& J. Pattengale (Eds.), Visible solutions for invisible students: Helping 
sophomores succeed (Monograph No. 31) (pp. 55-65). Columbia, SC: University of South Carolina, National Resource Center for The First-Year Experience and Students in Transition.

Astin, A. W. (1987). Retaining and satisfying students. Educational Record, 68(1), 3642.

Astin, A. W. (1993). What matters in college: Four critical years revisited. San Francisco: Jossey-Bass.

Baum, S., Ma, J., \& Payea, J. (2010). Education pays: the benefits of higher education for individuals and society. Trends in higher education.

Bean, J. P. (2005). Nine themes of college student retention. In A. Seidman (Ed.), College student retention: Formula for student success (pp. 215-243). Westport, CT: Praeger Publishers.

Bellani, R. (2007). Sophomore men: Their growth, relationships and search for life direction at Colgate University. (Ed.D. Dissertation), University of Pennsylvania, United States -- Pennsylvania. Dissertations \& Theses: Full Text database. (Publication No. AAT 3255859).

Boivin, M., Beuthin, T. M., \& Hauger, G. (1993). Why Christian students leave Christian colleges: Evaluating the dynamics of adjustment in a Christian community. The Journal of the First Year Experience, 5, 93-125.

Boivin, M., Fountain, G. A., \& Baylis, B. (2000). Meeting the challenges of the sophomore year. In L. A. Schreiner \& J. Pattengale (Eds.), Visible solutions for invisible students: Helping sophomores succeed (Monograph No. 31) (pp. 19-30). 
Columbia, SC: University of South Carolina, National Resource Center for The First-Year Experience and Students in Transition.

Brainard, S. G., \& Carlin, L. (1998). A six-year longitudinal study of undergraduate women in engineering and science. Journal of Engineering Education, October (1998).

Braxton, J. M., Hirschy, A. S., \& McClendon, S. A. (2011). Understanding and Reducing College Student Departure: Ashe-Eric Higher Education Report: John Wiley \& Sons.

Braxton, J. M., \& Lee, S. D. (2005). Toward reliable knowledge about college student departure. In A. Seidman (Ed.), College student retention : formula for student success (pp. 107-128). Westport, CT: Praeger Publishers.

Chickering, A. (1969). Education and identity. San Francisco: Jossey-Bass.

Coll, J. E., \& Draves, P. (2009). Traditional age students: Worldviews and satisfaction with advising. College Student Affairs Journal, 27(2), 215-223.

Creswell, J. W. (2008). Educational research: Planning, conducting, and evaluating quantitative and qualitative research. Upper Saddle River, NJ: Pearson Education, Inc.

Dewitz, J., Woolsey, L., \& Walsh, W. B. (2009). College student retention: an exploration of the relationship between self-efficacy, beliefs, and purpose in life among college students. Journal of College Student Development, 50(1), 19-34.

Feldman, K., \& Newcomb, T. (1969). The impact of colleges on their students. San Francisco: Jossey-Bass. 
Field, A. P. (2009). Discovering statistics using SPSS : (and sex and drugs and rock ' $n$ ' roll). Los Angeles: SAGE Publications.

Flanagan, W. J. (1991). Sophomore retention: The missing strategy in small college retention efforts: University of Wisconsin-Madison.

Flanagan, W. J. (2006). The future of the small college dean: Challenges and opportunities. New Directions for Student Services, 2006(116), 67-83.

Freedman, M. B. (1956). The Passage Through College. Journal of Social Issues, 12(4), pp. 13-28.

Frost, S. H. (1991). Academic advising for student success: a system of shared responsibility. Washington, D.C.: School of Education and Human Development, the George Washington University.

Furr, S. R., \& Gannaway, L. (1982). Easing the sophomore slump: A student development approach. Journal of College Student Personnel, 23(4), 340-341.

Gahagan, J., \& Hunter, M. S. (2006). The second-year experience: Turning attention to the academy's middle children. About Campus, 11(3), 17-22.

Gardner, J., Pattengale, J., \& Schreiner, L. (2000). The sophomore year: Summary and recommendations. In L. A. Schreiner \& J. Pattengale (Eds.), Visible solultions for invisible students: Helping sophomores succeed (Monograph No. 31) (pp. 89-94). Columbia, SC: University of South Carolina, National Resource Center for The First-Year Experience and Students in Transition.

Gardner, J. N. (2000). From drift to engagement: Finding purpose and making career connections in the Sophomore year. In L. A. Schreiner \& J. Pattengale (Eds.), 
Visible solutions for invisible students: Helping sophomores succeed (Monograph No. 31) (pp. 19-29). Columbia, SC: University of South Carolina, National Resource Center for The First-Year Experience and Students in Transition.

Gordon, V., \& Habley, W. (2000). Academic advising a comprehensive handbook (1st ed.). San Francisco: Jossey-Bass.

Gordon, V., Habley, W., \& Grites, T. (2008). Academic advising: a comprehensive handbook. San Francisco, CA: Jossey-Bass.

Graunke, S. S., \& Woosley, S. A. (2005). An exploration of the factors that affect the academic success of college sophomores. College Student Journal, 39(2), 367376.

Habley, W. R., \& McClanahan, R. (2004). What works in student retention? All Survey Colleges: ACT, Inc.

Harris, R. E. (2012). The role of E-mentoring in helping college sophomores persist and stay enrolled. (Order No. 3528920, Northcentral University). ProQuest Dissertations and Theses, , 189. Retrieved from http://search.proquest.com/docview/1052391191?accountid=13265. (prod.academic_MSTAR_1052391191).

Ho Yu, C., DiGangi, S., Jannash-Pennell, A., \& Kaprolet, C. (2010). A data-mining approach for identifying predictors of student retention from sophomore to junior year. Journal of Data Science, 8(2010), 307-325.

Horn, L., Nevill, S., Griffith, J., MPR Associates, B. A., \& National Center for Education Statistics (ED), W. C. (2006). Profile of Undergraduates in U.S. Postsecondary 
Education Institutions, 2003-04: With a Special Analysis of Community College Students. Statistical Analysis Report. NCES 2006-184. National Center For Education Statistics.

Juillerat, S. (2000). Assessing the expectations and satisfaction of sophomores. In L. A. Schreiner \& J. Pattengale (Eds.), Visible solutions for invisible students: Helping sophomores succeed (Monograph No. 31) (pp. 19-29). Columbia, SC: University of South Carolina, National Resource Center for The First-Year Experience and Students in Transition.

Kawczynski, K. A. (2009). The college sophomore student experience: A phenomenological study of a second year program. (Ph.D. dissertation), University of Hawai'i at Manoa, United States -- Hawaii. Dissertations \& Theses: Full Text database. (Publication No. AAT 3378310).

Kezar, A. (2004). Obtaining integrity?: reviewing and examining the charter between higher education and society. The Review of Higher Education, 27(4), 429-459.

King, P. M., \& Kitchener, K. S. (1994). Developing reflective judgment: Understanding and promoting intellectual growth and critical thinking in adolescents and adults. San Francisco: Jossey-Bass.

King, P. M., \& Kitchener, K. S. (2002). The reflective judgment model: Twenty years of research on epistemic cognition. In B. K. Hofer \& P. R. Pintrich (Eds.), Personal epistemology: The psychology of beliefs about knowledge and knowing (pp. 3761). Mahwah, NJ: Lawrence Erlbaum Associates. 
Kramer, G. L. (2000). Advising students at different educational levels. In V. N. Gordon, W. R. Habley \& Associates (Eds.), Academic Advising: A comprehensive handbook (pp. 84-104). San Francisco: Jossey-Bass.

Kuh, G. D. (2008). Advising for student success. In V. N. Gordon, W. R. Habley \& T. J. Grites (Eds.), Academic advising: A comprehensive handbook (2nd ed.). Manhattan, KS: Jossey-Bass.

Kuh, G. D., Kinzie, J., Cruce, T., Shoup, R., \& Gonyea, R. (2006). Connecting the dots: Multifaceted analyses of the relationships between student engagement results from the NSSE, and the institutional policies and conditions that foster student success. Bloomington: Center for Postsecondary Research, Indiana University.

Lemons, J. L., \& Richmond, D. R. (1987). A Developmental Perspective of Sophomore Slump. NASPA Journal, 24(3), 15-19.

Liu, R., \& Jung, L. (1980). The commuter student and student satisfaction. Research in Higher Education, 12(3), 215-226.

Lotkowski, V. A., Robbins, S. B., \& Noeth, R. J. (2004). The role of academic and nonacademic factors in improving college retention. ACT Policy Report, 1.

Margolis, G. (1976). Unslumping our sophomores: Some clinical observations and strategies. The Journal of the American College Health Association, 25(2), 133135.

Metzner, B. S. (1989). Perceived quality of academic advising: The effect on freshman attrition. American Educational Research Journal, 26(3), 422-442.

Morgan, G. (2006). Images of organization. Beverly Hills, CA: Sage Publications. 
Nealy, M. (2005). Key to student retention - strong advising. Diverse Issues in Higher Education, 22(14), 12.

Noel-Levitz, I. (2011). Student Retention Practices at Four-Year and Two-Year Institutions, 2011. Noel-Levitz Report on Undergraduate Trends in Enrollment Management. Noel-Levitz, Inc. Retrieved from http://stats.lib.pdx.edu/proxy.php?url=http://search.ebscohost.com/login.aspx?dire $\mathrm{ct}=$ true $\& \mathrm{db}=$ eric $\& A N=$ ED536417\& site $=$ ehost-live

Pascarella, E. T., \& Terenzini, P. T. (2005). How college affects students: A third decade of research (Vol. 2). San Francisco: Jossey-Bass.

Pattengale, J. (2000). Policies and practices to enhance sophomore success. In L. A. Schreiner \& J. Pattengale (Eds.), Visibile solutions for invisible students: Helping sophomores succeed (Monograph No. 31) (pp. 31-46). Columbia, SC: University of South Carolina, National Resource Center for The First-Year Experience and Students in Transition.

Pattengale, J., \& Schreiner, L. A. (2007). The advancement of sophomore initiatives. In B. F. Tobolowsky \& B. E. Cox (Eds.), Shedding light on sophomores: An exploration of the second college year (Monograph No. 47) (pp. v-vii). Columbia, SC: University of South Carolina, National Resource Center for The First-Year Experience \& Students in Transition.

Institute for Higher Education Policy, W. (1998). Reaping the Benefits: Defining the Public and Private Value of Going to College. The New Millennium Project on Higher Education Costs, Pricing, and Productivity. Retrieved from 
http://stats.lib.pdx.edu/proxy.php?url=http://search.ebscohost.com/login.aspx?dire ct $=$ true $\& \mathrm{db}=$ eric $\& A N=$ ED420256\& site $=$ ehost-live

Porter, O. F., \& National Inst. of Independent Colleges and Universities, W. (1989). Undergraduate Completion and Persistence at Four-Year Colleges and Universities: Completers, Persisters, Stopouts, and Dropouts. Retrieved from http://stats.lib.pdx.edu/proxy.php?url=http://search.ebscohost.com/login.aspx?dire $\mathrm{ct}=$ true $\& \mathrm{db}=$ eric $\& A N=\mathrm{ED} 319343 \&$ site $=$ ehost-live .

Pullins, T. L. (2011). Predicting the retention of college sophomores: The importance of satisfaction (Ph.D.). Azusa Pacific University, Ann Arbor. Retrieved from ProQuest Dissertations \& Theses Full Text. prod.academic_MSTAR_910560877)

Richmond, D. R., \& Lemons, J. L. (1985). Sophomore slump: An individual approach to recognition and response. Journal of College Student Personnel, 26(2), 176-177.

Robbins, R. (2009). Evaluation and assessment in career advising. In K. Hughey, D. Burton Nelson, J. Damminger, and E. McCalla-Wriggins (eds.). Handbook of Career Advising. San Francisco, CA: Jossey-Bass.

Sanchez-Leguelinel, C. (2008). Supporting 'slumping' sophomores: Programmatic peer initiatives designed to enhance retention in the crucial second year of college. College Student Journal, 42(2), 637-646.

Schaller, M. A. (2000). A phenomenological study of the traditional-aged college sophomore experience at a four-year, residential university. (Order No. 9996422, Ohio University). ProQuest Dissertations and Theses, , 247-247 p. Retrieved 
from http://search.proquest.com/docview/304611269?accountid=13265.

(prod.academic_MSTAR_304611269).

Schaller, M. A. (2005). Wandering and wondering: Traversing the uneven terrain of the second college year. About Campus, 10(3), 17-24.

Schaller, M. A., \& Tetley, J. (in press). Academic advising in the sophomore year: A student learning outcomes approach. NACADA Journal.

Schreiner, L. A., \& Juillerat, S. L. (1994). Student satisfaction inventory. Iowa City, IA: Noel-Levitz.

Schreiner, L. A., \& Pattengale, J. (Eds.). (2000). Visible solutions for invisible students: helping sophomores succeed (Monograph No. 31). Columbia, SC: University of South Carolina, National Resource Center for the First-Year Experience \& Students in Transition.

Schuh, J. H. (2005). Finances and retention: trends and potential implications. In A. Seidman (Ed.), College student retention: formula for student success (pp. 277294). Westport, CT: Praeger Publishers.

Seidman, A. (1991). Managing Enrollment for Student Satisfaction: An Integrated Admissions and Counseling Process.

Seidman, A. (2005). College student retention : Formula for student success. Westport, CT: Praeger Publishers.

Siegel, M. J. (2011). Reimagining the retention problem: Moving our thinking from endproduct to by-product. About Campus, 15(6), 8-18. 
Smith, C., \& Allen, J. (2006). Essential functions of academic advising: What students want and get. NACADA Journal, 26(1), 56-66.

Smith, J. S. (2002). First-year student perceptions of academic advisement: A qualitative study and reality check. NACADA Journal, 22(2), 39-49.

Steele, G. E., \& McDonald, M. L. (2000). Moving through college. In V. Gordon, W. R. Habley \& T. J. Grites (Eds.), Academic advising: A comprehensive handbook (2nd ed., pp. 142-156). San Francisco: Jossey-Bass.

Tennant, M., \& Pogson, P. (1995). Learning and change in the adult years : A developmental perspective. San Francisco, CA: Jossey-Bass.

Tinto, V. (1975). Dropout from higher education: A theoretical synthesis of recent research. Review of Educational Research, 45, 89-125.

Tinto, V. (1988). Stages of student departure: Reflections on the longitudinal character of student leaving. The Journal of Higher Education, 59(4), 438-455.

Tinto, V. (1993). Leaving college: rethinking the causes and cures of student attrition (2nd ed.). Chicago, IL: The University of Chicago Press.

Tinto, V. (2005). Foreward. In A. Seidman (Ed.), College student retention: Formula for student success (pp. ix-x). Westport, CT: Praeger Publishers.

Tinto, V. (2006). Research and practice of student retention: What next? Journal of College Student Retention, 8(1), 1-19.

Tinto, V., \& Pusser, B. (2006). Moving from theory to action: Building a model of institutional action for student success. National Postsecondary Education Cooperative, 1-51. 
Tobolowsky, B. F., \& Cox, B. E. (2007). Shedding light on sophomores: An exploration of the second college year (Monograph No. 47). Columbia, SC: University of South Carolina, National Resource Center for The First-Year Experience \& Students in Transition.

Walton, G. M., \& Cohen, G. L. (2007). A question of belonging: Race, social fit, and achievement. Journal of Personality and Social Psychology, 92(1), 82-96.

Wilder, J. S. (1993). The sophomore slump: A complex developmental period that contributes to attrition. College Student Affairs Journal, 12(2), 18-27.

Yazedjian, A., Toews, M., Sevin, T., \& Purswell, K. (2008). It's a whole new world: A qualitative exploration of college students' definitions of and strategies for college success. Journal of College Student Development, 49(2), 141-153. 
APPENDIX A Demographics

University 1

\begin{tabular}{|c|c|c|c|c|}
\hline & \multicolumn{2}{|c|}{ Sample } & \multicolumn{2}{|c|}{ Population } \\
\hline & $\mathrm{N}$ & Percent & $\mathrm{N}$ & Percent \\
\hline \multicolumn{5}{|l|}{ Gender } \\
\hline Female & 871 & 72.2 & 2,270 & 61.0 \\
\hline Male & 335 & 27.8 & 1,451 & 39.0 \\
\hline Unknown & & & & \\
\hline Total & 1206 & 100.0 & 3,721 & 100.0 \\
\hline \multicolumn{5}{|l|}{ Race/Ethnicity } \\
\hline Asian American & 51 & 4.2 & 126 & 3.4 \\
\hline African American & 20 & 1.7 & 74 & 2.0 \\
\hline Hispanic & 58 & 4.8 & 197 & 5.3 \\
\hline Native American & 30 & 2.5 & 75 & 2.0 \\
\hline White & 998 & 82.8 & 2,968 & 79.8 \\
\hline Multiple & & & 18 & .5 \\
\hline Non-resident Alien & & & 42 & 1.1 \\
\hline Unknown & 49 & 4.1 & 221 & 5.9 \\
\hline Total & 1206 & 100.0 & 3,721 & 100 \\
\hline \multicolumn{5}{|l|}{ Class Level } \\
\hline Freshman & 172 & 14.3 & & \\
\hline Sophomore & 208 & 17.2 & & \\
\hline Junior & 307 & 25.5 & & \\
\hline Senior & 519 & 43.0 & & \\
\hline Missing & & & & \\
\hline \multicolumn{5}{|l|}{ Total } \\
\hline Total & 1206 & 100.0 & & \\
\hline \multicolumn{5}{|l|}{ Age } \\
\hline$>18$ & 0 & 0.0 & 79 & 2.0 \\
\hline $18-24$ & 473 & 39.2 & 1,767 & 47.0 \\
\hline $25-29$ & 150 & 12.4 & 513 & 14.0 \\
\hline $30-35$ & 166 & 13.8 & 482 & 13.0 \\
\hline$>35$ & 417 & 34.6 & 877 & 24.0 \\
\hline Unknown & & & 3 & 0.0 \\
\hline Total & 1206 & 100.0 & 3,721 & 100.0 \\
\hline
\end{tabular}


University 2

\begin{tabular}{|c|c|c|c|c|}
\hline & \multicolumn{2}{|c|}{ Sample } & \multicolumn{2}{|c|}{ Population } \\
\hline & $\mathrm{N}$ & Percent & $\mathrm{N}$ & Percent \\
\hline Gender & & & & \\
\hline $\begin{array}{l}\text { Female } \\
\text { Male } \\
\text { Unknown } \\
\text { Total }\end{array}$ & $\begin{array}{l}1066 \\
429 \\
\\
1495\end{array}$ & $\begin{array}{l}71.3 \\
28.7 \\
100.0\end{array}$ & $\begin{array}{l}2,799 \\
2,076 \\
\\
4,875\end{array}$ & $\begin{array}{l}57.4 \\
42.6 \\
\\
100.0\end{array}$ \\
\hline Race/Ethnicity & & & & \\
\hline $\begin{array}{l}\text { Asian American } \\
\text { African American } \\
\text { Hispanic } \\
\text { Native American } \\
\text { White } \\
\text { Multiple } \\
\text { Non-resident Alien } \\
\text { Unknown } \\
\text { Total }\end{array}$ & $\begin{array}{c}93 \\
17 \\
141 \\
25 \\
1157 \\
46 \\
\\
16 \\
1495 \\
\end{array}$ & $\begin{array}{c}6.2 \\
1.1 \\
9.4 \\
1.7 \\
77.4 \\
3.1 \\
\\
1.1 \\
100.0 \\
\end{array}$ & $\begin{array}{c}188 \\
129 \\
415 \\
86 \\
3,559 \\
\\
267 \\
231 \\
4,875 \\
\end{array}$ & $\begin{array}{c}3.9 \\
2.6 \\
8.5 \\
1.8 \\
73.0 \\
\\
5.5 \\
4.7 \\
100 \\
\end{array}$ \\
\hline Class Level & & & & \\
\hline $\begin{array}{l}\text { Freshman } \\
\text { Sophomore } \\
\text { Junior } \\
\text { Senior } \\
\text { Missing }\end{array}$ & $\begin{array}{c}132 \\
301 \\
358 \\
703 \\
1\end{array}$ & $\begin{array}{c}8.8 \\
20.1 \\
23.9 \\
47.0 \\
.1\end{array}$ & & \\
\hline Total & 1494 & 99.9 & & \\
\hline Total & 1495 & 100.0 & & \\
\hline Age & & & & \\
\hline $\begin{array}{l}>18 \\
18-24 \\
25-29 \\
30-35 \\
>35 \\
\text { Unknown } \\
\text { Total }\end{array}$ & $\begin{array}{c}2 \\
1230 \\
135 \\
46 \\
82\end{array}$ & $\begin{array}{c}.1 \\
82.3 \\
9.0 \\
3.1 \\
5.5\end{array}$ & $\begin{array}{c}26 \\
4,048 \\
427 \\
164 \\
207 \\
3 \\
4,875\end{array}$ & $\begin{array}{c}1.0 \\
83.0 \\
9.0 \\
3.0 \\
4.0 \\
0 \\
100.0\end{array}$ \\
\hline
\end{tabular}


University 3

\begin{tabular}{|c|c|c|c|c|}
\hline & \multicolumn{2}{|c|}{ Sample } & \multicolumn{2}{|c|}{ Population } \\
\hline & $\mathrm{N}$ & Percent & $\mathrm{N}$ & Percent \\
\hline Gender & & & & \\
\hline $\begin{array}{l}\text { Female } \\
\text { Male } \\
\text { Unknown } \\
\text { Total }\end{array}$ & $\begin{array}{c}1710 \\
1006 \\
3 \\
2746 \\
\end{array}$ & $\begin{array}{c}62.3 \\
36.6 \\
.1 \\
100.0\end{array}$ & $\begin{array}{c}11,433 \\
10,054 \\
187 \\
21,674\end{array}$ & $\begin{array}{c}52.7 \\
46.4 \\
0.9 \\
100.0\end{array}$ \\
\hline Race/Ethnicity & & & & \\
\hline $\begin{array}{l}\text { Asian } \\
\text { American } \\
\text { African } \\
\text { American } \\
\text { Hispanic } \\
\text { Native } \\
\text { American } \\
\text { White } \\
\text { Multiple } \\
\text { Non-resident } \\
\text { Alien } \\
\text { Unknown } \\
\text { Total }\end{array}$ & $\begin{array}{c}215 \\
22 \\
\\
1899 \\
136\end{array}$ & $\begin{array}{c}7.8 \\
.8 \\
\\
69.2 \\
5.0\end{array}$ & $\begin{array}{c}1,117 \\
299 \\
13,487 \\
1,173 \\
\\
2,910 \\
21,674\end{array}$ & $\begin{array}{l}9.4 \\
3.0 \\
\\
5.2 \\
1.4 \\
62.2 \\
5.4 \\
\\
13.4 \\
100\end{array}$ \\
\hline Class Level & & & & \\
\hline $\begin{array}{l}\text { Freshman } \\
\text { Sophomore } \\
\text { Junior } \\
\text { Senior } \\
\text { Missing }\end{array}$ & $\begin{array}{c}263 \\
404 \\
755 \\
1266 \\
58\end{array}$ & $\begin{array}{c}9.6 \\
14.7 \\
27.5 \\
46.1 \\
2.1\end{array}$ & & \\
\hline Total & 2688 & 97.9 & & \\
\hline Total & 2746 & 100.0 & & \\
\hline Age & & & & \\
\hline $\begin{array}{l}>18 \\
18-24 \\
25-29 \\
30-35 \\
>35 \\
\text { Unknown } \\
\text { Total }\end{array}$ & $\begin{array}{c}6 \\
1387 \\
587 \\
324 \\
415 \\
27 \\
2746 \\
\end{array}$ & $\begin{array}{c}.2 \\
50.5 \\
21.4 \\
11.8 \\
15.1 \\
1.0 \\
100.0\end{array}$ & $\begin{array}{c}903 \\
12,001 \\
4,496 \\
2,237 \\
2,029 \\
8 \\
21,674\end{array}$ & $\begin{array}{c}4.0 \\
55.0 \\
21.0 \\
10.0 \\
9.0 \\
0 \\
100\end{array}$ \\
\hline
\end{tabular}


University 4

\begin{tabular}{|c|c|c|c|c|}
\hline & \multicolumn{2}{|c|}{ Sample } & \multicolumn{2}{|c|}{ Population } \\
\hline & $\mathrm{N}$ & Percent & $\mathrm{N}$ & Percent \\
\hline Gender & & & & \\
\hline $\begin{array}{l}\text { Female } \\
\text { Male } \\
\text { Unknown } \\
\text { Total }\end{array}$ & $\begin{array}{c}2313 \\
1334 \\
0 \\
3647\end{array}$ & $\begin{array}{c}63.4 \\
36.6 \\
0 \\
100.0\end{array}$ & $\begin{array}{c}9344 \\
9165 \\
5\end{array}$ & $\begin{array}{c}49.5 \\
50.5 \\
0.0 \\
100.0\end{array}$ \\
\hline Race/Ethnicity & & & & \\
\hline $\begin{array}{l}\text { Asian } \\
\text { American } \\
\text { African } \\
\text { American } \\
\text { Hispanic } \\
\text { Native } \\
\text { American } \\
\text { White } \\
\text { Non-resident } \\
\text { Alien } \\
\text { Unknown } \\
\text { Total }\end{array}$ & $\begin{array}{c}362 \\
45 \\
\\
150 \\
29 \\
\\
2671 \\
0 \\
\\
\\
390 \\
3647\end{array}$ & $\begin{array}{c}4.1 \\
.8 \\
\\
73.2 \\
0 \\
\\
\\
10.7 \\
100\end{array}$ & $\begin{array}{c}1191 \\
339 \\
722 \\
195 \\
\\
13598 \\
1047 \\
\\
1422 \\
18514\end{array}$ & $\begin{array}{c}6.4 \\
1.8 \\
\\
3.9 \\
1.1 \\
\\
73.4 \\
5.7 \\
\\
7.7 \\
100\end{array}$ \\
\hline Class Level & & & & \\
\hline $\begin{array}{l}\text { Freshman } \\
\text { Sophomore } \\
\text { Junior } \\
\text { Senior } \\
\text { Missing }\end{array}$ & $\begin{array}{c}494 \\
791 \\
873 \\
1454 \\
35 \\
\end{array}$ & $\begin{array}{c}13.5 \\
21.7 \\
23.9 \\
39.9 \\
1.0\end{array}$ & & \\
\hline Total & 3612 & 99.0 & & \\
\hline Total & 3647 & & & \\
\hline Age & & & & \\
\hline $\begin{array}{l}>18 \\
18-24 \\
25-29 \\
30-35 \\
>35 \\
\text { Unknown } \\
\text { Total }\end{array}$ & $\begin{array}{c}9 \\
3237 \\
191 \\
93 \\
117 \\
0 \\
3647\end{array}$ & $\begin{array}{c}.2 \\
88.8 \\
5.2 \\
2.6 \\
3.2 \\
0 \\
100\end{array}$ & $\begin{array}{c}188 \\
16639 \\
955 \\
359 \\
372 \\
1 \\
18514\end{array}$ & $\begin{array}{c}1 \\
90 \\
5 \\
2 \\
2 \\
0 \\
100\end{array}$ \\
\hline
\end{tabular}


University 5

\begin{tabular}{|c|c|c|c|c|}
\hline & \multicolumn{2}{|c|}{ Sample } & \multicolumn{2}{|c|}{ Population } \\
\hline & $\mathrm{N}$ & Percent & $\mathrm{N}$ & Percent \\
\hline \multicolumn{5}{|l|}{ Gender } \\
\hline Female & 2293 & 57.3 & 9,206 & 47.1 \\
\hline Male & 1708 & 42.7 & 10,341 & 52.9 \\
\hline Unknown & 2 & .0 & 11 & 0.1 \\
\hline Total & 4003 & 100.0 & 19,558 & 100.0 \\
\hline \multicolumn{5}{|l|}{ Race/Ethnicity } \\
\hline Asian American & 308 & 7.7 & 1585 & 8.1 \\
\hline African American & 31 & .8 & 267 & 1.4 \\
\hline Hispanic & 214 & 5.3 & 1,110 & 5.7 \\
\hline Native American & 43 & 1.1 & 216 & 1.1 \\
\hline White & 2828 & 70.6 & 13,656 & 69.8 \\
\hline Multiple & 74 & 1.8 & 391 & 2.0 \\
\hline Non-resident Alien & & & 810 & 4.1 \\
\hline Unknown & 505 & 12.6 & 1,523 & 7.8 \\
\hline Total & 4003 & 100.0 & 19,558 & 100 \\
\hline \multicolumn{5}{|l|}{ Class Level } \\
\hline Freshman & 494 & 12.3 & & \\
\hline Sophomore & 704 & 17.6 & & \\
\hline Junior & 891 & 22.3 & & \\
\hline Senior & 1914 & 47.8 & & \\
\hline Missing & & & & \\
\hline \multicolumn{5}{|l|}{ Total } \\
\hline Total & 4003 & 100.0 & & \\
\hline \multicolumn{5}{|l|}{ Age } \\
\hline$>18$ & 8 & .2 & 157 & 1.0 \\
\hline $18-24$ & 3164 & 79.0 & 16,313 & 83.0 \\
\hline $25-29$ & 341 & 8.5 & 1,493 & 8.0 \\
\hline $30-35$ & 213 & 5.3 & 785 & 4.0 \\
\hline$>35$ & 277 & 6.9 & 810 & 4.0 \\
\hline Unknown & & & & \\
\hline Total & 4003 & 100.0 & 19558 & 100.0 \\
\hline
\end{tabular}


Private 1

\begin{tabular}{|c|c|c|c|c|}
\hline & \multicolumn{2}{|c|}{ Sample } & \multicolumn{2}{|c|}{ Population } \\
\hline & $\mathrm{N}$ & Percent & $\mathrm{N}$ & Percent \\
\hline Gender & & & & \\
\hline $\begin{array}{l}\text { Female } \\
\text { Male } \\
\text { Unknown } \\
\text { Total }\end{array}$ & $\begin{array}{l}316 \\
121 \\
\\
437 \\
\end{array}$ & $\begin{array}{r}72.3 \\
27.7 \\
100.0\end{array}$ & $\begin{array}{r}702 \\
415 \\
1117\end{array}$ & $\begin{array}{r}62.8 \\
37.2 \\
100.0\end{array}$ \\
\hline Race/Ethnicity & & & & \\
\hline $\begin{array}{l}\text { Asian American } \\
\text { African American } \\
\text { Hispanic } \\
\text { Native American } \\
\text { White } \\
\text { Multiple } \\
\text { Non-resident Alien } \\
\text { Unknown } \\
\text { Total }\end{array}$ & $\begin{array}{c}29 \\
25 \\
26 \\
4 \\
302\end{array}$ & $\begin{array}{c}6.6 \\
5.7 \\
5.9 \\
.9 \\
69.1\end{array}$ & $\begin{array}{c}70 \\
77 \\
60 \\
12 \\
711 \\
7 \\
180 \\
1117 \\
\end{array}$ & $\begin{array}{c}6.3 \\
6.9 \\
5.4 \\
1.0 \\
63.7 \\
\\
.6 \\
16.1 \\
100.0\end{array}$ \\
\hline Class Level & & & & \\
\hline $\begin{array}{l}\text { Freshman } \\
\text { Sophomore } \\
\text { Junior } \\
\text { Senior } \\
\text { Missing }\end{array}$ & $\begin{array}{c}48 \\
67 \\
87 \\
235\end{array}$ & $\begin{array}{l}11.0 \\
15.3 \\
19.9 \\
53.8\end{array}$ & $\begin{array}{l}332 \\
182 \\
229 \\
374\end{array}$ & $\begin{array}{l}29.7 \\
16.3 \\
20.5 \\
33.5\end{array}$ \\
\hline $\begin{array}{l}\text { Total } \\
\text { Total }\end{array}$ & 437 & 100.0 & 1117 & 100.0 \\
\hline Age & & & & \\
\hline $\begin{array}{l}>18 \\
18-24 \\
25-29 \\
30-35 \\
>35 \\
\text { Unknown } \\
\text { Total }\end{array}$ & $\begin{array}{c}306 \\
44 \\
29 \\
57 \\
1 \\
437\end{array}$ & $\begin{array}{c}70.0 \\
10.1 \\
6.6 \\
13.0 \\
.2 \\
100.0\end{array}$ & $\begin{array}{c}38 \\
785 \\
99 \\
70 \\
114 \\
11 \\
1117\end{array}$ & $\begin{array}{c}3.4 \\
70.3 \\
8.9 \\
6.3 \\
10.2 \\
.9 \\
100.0\end{array}$ \\
\hline
\end{tabular}


Private 2

\begin{tabular}{|c|c|c|c|c|}
\hline & \multicolumn{2}{|c|}{ Sample } & \multicolumn{2}{|c|}{ Population } \\
\hline & $\mathrm{N}$ & Percent & $\mathrm{N}$ & Percent \\
\hline \multicolumn{5}{|l|}{ Gender } \\
\hline Female & 1098 & 68.7 & 1856 & 61.1 \\
\hline Male & 501 & 31.3 & 1181 & 38.9 \\
\hline \multicolumn{5}{|l|}{ Unknown } \\
\hline Total & 1599 & 100.0 & 3037 & 100 \\
\hline \multicolumn{5}{|l|}{ Race/Ethnicity } \\
\hline Asian American & 188 & 11.8 & 354 & 11.7 \\
\hline African American & 21 & 1.3 & 43 & 1.4 \\
\hline Hispanic & 80 & 5.0 & 161 & 5.3 \\
\hline Native American & 16 & 1.0 & 31 & 1.0 \\
\hline White & 1100 & 68.8 & 2035 & 67.0 \\
\hline Multiple & & & 91 & 3.0 \\
\hline Non-resident Alien & & & 73 & 2.4 \\
\hline Unknown & 194 & 12.1 & 249 & 8.2 \\
\hline Total & 1599 & 100.0 & 3037 & \\
\hline \multicolumn{5}{|l|}{ Class Level } \\
\hline Freshman & 421 & 26.3 & 816 & 26.5 \\
\hline Sophomore & 332 & 20.8 & 788 & 25.6 \\
\hline Junior & 349 & 21.8 & 728 & 23.7 \\
\hline Senior & 497 & 31.1 & 746 & 24.2 \\
\hline Missing & & & & \\
\hline \multicolumn{5}{|l|}{ Total } \\
\hline Total & 1599 & 100.0 & 3078 & 100.0 \\
\hline \multicolumn{5}{|l|}{ Age } \\
\hline$>18$ & 2 & .1 & 3 & .1 \\
\hline $18-24$ & 1520 & 95.1 & 2937 & 96.7 \\
\hline $25-29$ & 36 & 2.3 & 52 & 1.7 \\
\hline $30-35$ & 24 & 1.5 & 24 & .8 \\
\hline$>35$ & 17 & 1.1 & 21 & .7 \\
\hline \multicolumn{5}{|l|}{ Unknown } \\
\hline Total & 1599 & 100.0 & 3037 & 100.0 \\
\hline
\end{tabular}


APPENDIX B Survey

\title{
Inventory of Academic Advising Function Student Version
}

Instructions: Please answer the following questions according to your experiences at Name of Institution.

\author{
(C) Cathleen L. Smith and Janine M. Allen
}

\author{
What is your main reason for attending Name of Institution? (community college \\ students only) \\ To earn credit toward a bachelor's (four-year) degree \\ Learn English \\ Take a ABE/GED class \\ Complete a certificate or career technical program at Name of Institution \\ $\square$ Take a course for personal interest \\ $\square$ Explore educational opportunities at Name of Institution \\ $\square$ Take a class for high school credit \\ $\square$ Improve writing, reading, or math skills \\ Learn skills to get or keep a job \\ Explore a new career area
}


Which of the following best describes where at Name of Institution you get your PRIMARY academic advising, i.e., the advising you consider most central to your academic progress? (Choose one)

$\square$ I have not received academic advice from faculty or staff at Name of Institution

$\square$ Adviser in my major department

$\square$ List include places at the institution where students might receive advising $\square$ Other (please specify)

If you selected other, please specify

On average, how often do you get advice from your primary source of advising, i.e., the advising you consider most central to your academic progress?

$\square$ I'm not currently getting academic advice from faculty or staff at Name of Institution

$\square$ At least once per term

$\square$ At least twice per year

$\square$ At least once per year 
How do you access your primary source of advising, i.e., the advising you consider most central to your academic progress?
$\square$ Phone
$\square$ Email
$\square$ In person
$\square \operatorname{Fax}$

Please select the circle that best describes where you get most of your information about classes to take to meet requirements.

$\square$ Adviser/Professor in my major department

$\square$ List include places at the institution where students might receive advising I

$\square$ Bulletin (University Catalog)

$\square$ Undergraduate Advising Website

$\square$ Departmental Website

$\square$ Friend(s)/Other Student(s)

$\square$ Family Member(s)

Overall, I am satisfied with the academic advising I receive at Name of Institution.

$\square 1$ Strongly Disagree 
$\square 5$

$\square 6$ Strongly Agree

It is important for me to graduate from college.

$\square 1$ Strongly Disagree

$\square 2$

$\square 3$

$\square 4$

5

$\square 6$ Strongly Agree

I am confident that I made the right decision in choosing to attend Name of Institution.

$\square 1$ Strongly Disagree

$\square 2$

3

$\square 4$

5

$\square 6$ Strongly Agree

I have a plan to achieve my educational goals.

$\square 1$ Strongly Disagree 


$\square 2$
$\square 3$
$\square 4$
$\square 5$
$\square 6$ Strongly Agree

I have had at least one relationship with a faculty or staff member at Name of Institution that has had a significant and positive influence on me.

$\square 1$ Strongly Disagree

$\square 2$

3

$\square 4$

$\square 5$

$\square 6$ Strongly Agree

I plan to graduate from Name of Institution.

$\square 1$ Strongly Disagree

$\square 2$

3

$\square 4$

$\square 5$

$\square 6$ Strongly Agree 
Overall, I am satisfied with my educational experience at Name of Institution.

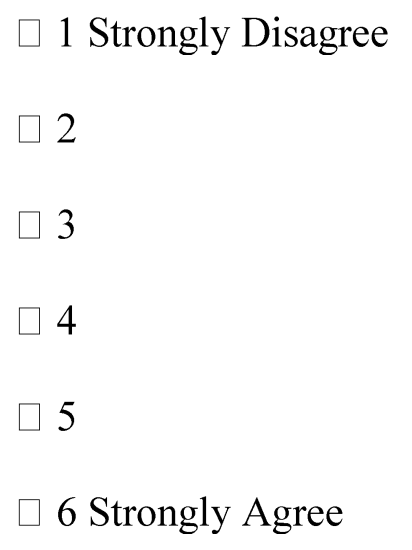

\section{Highest educational level of your parent(s)/guardian(s)}

\section{Parent Number One}

$\square$ High School degree or less, no college

$\square$ Some college, no degree

$\square$ Associate (2 year) degree

$\square$ Baccalaureate (e.g., BS or BA) degree or above

\section{Parent Number Two}

$\square$ Not applicable, I have only one parent

$\square$ High school degree or less, no college

$\square$ Some college, no degree

$\square$ Associate (2 year) degree

$\square$ Baccalaureate (e.g., BS or BA) degree or above 
Does your family use a language other than English at home?
$\square$ No
$\square$ Yes

In the space provided, please indicate the name(s) of the language(s), other than English, used in your home.

Have you ever been a foster child?
$\square$ No
$\square$ Yes

The following questions refer to various kinds of help that academic advisers might provide to students. Given your experience with your PRIMARY source of academic advising at Name of Institution, i.e., the advising you consider most central 
to your academic progress, make two ratings for each advising function.
a. its importance to you
b. your satisfaction with the advising you receive

Advising that helps students connect their academic, career, and life goals.

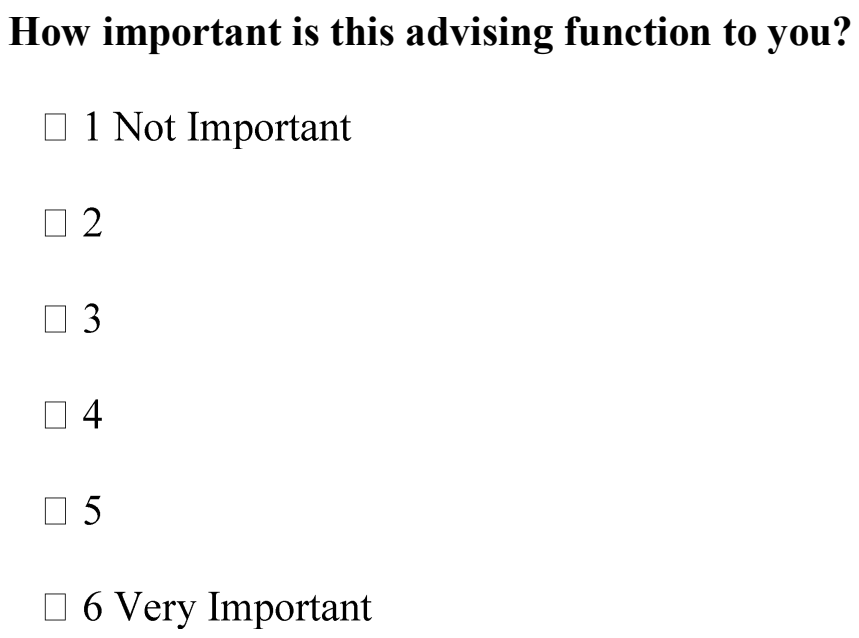

How satisfied are you with the advising you receive on this function?

$\square 1$ Not Satisfied

$\square 6$ Very Satisfied 
Advising that helps students choose among courses in their major that connect their academic, career, and life goals.

How important is this advising function to you?

$\square 1$ Not Important

$\square 2$

$\square 3$

4

5

$\square 6$ Very Important

How satisfied are you with the advising you receive on this function?

$\square$ 1 Not Satisfied

$\square 2$

3

4

5

$\square 6$ Very Satisfied

Advising that assists students with choosing among the various General Education options (e.g., examples unique to each institution) that connect their academic, 
career, and life goals.

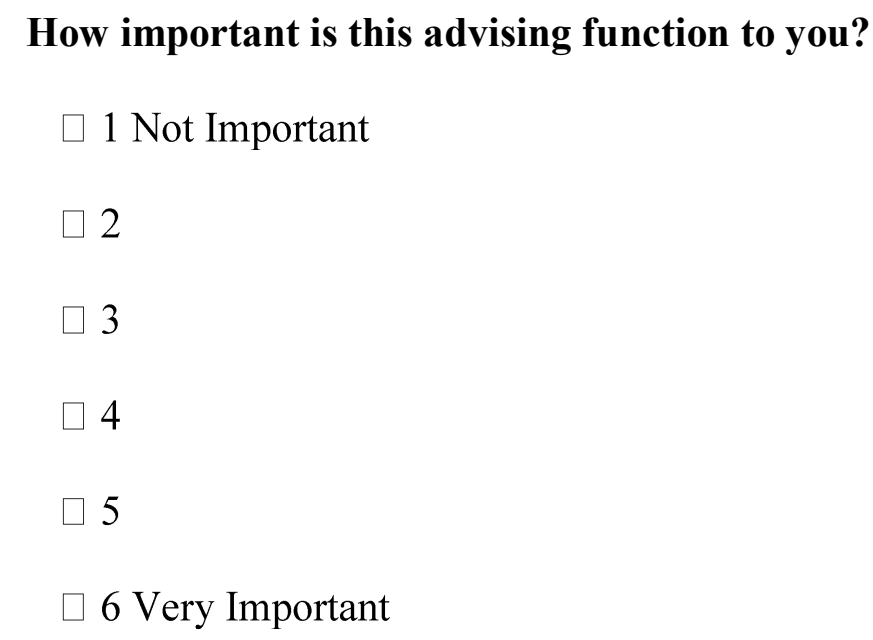

How satisfied are you with the advising you receive on this function?

$\square 1$ Not Satisfied

$\square 2$

3

$\square 4$

5

$\square 6$ Very Satisfied

Advising that assists students with deciding what kind of degree to pursue (Examples for Universities include: Bachelor of Science, Bachelor of Arts, Bachelor of Music. Examples for community colleges include: transfer degree, career technical degree, certificate) in order to connect their academic, career, and life goals. 
How important is this advising function to you?

$\square 1$ Not Important

$\square 2$

3

$\square 4$

5

$\square 6$ Very Important

How satisfied are you with the advising you receive on this function?

$\square 1$ Not Satisfied

$\square 2$

3

$\square 4$

5

$\square 6$ Very Satisfied

Advising that assists students with choosing out-of-class activities (e.g., part-time or summer employment, internships or practicum, participation in clubs or organizations) that connect their academic, career, and life goals. 
How important is this advising function to you?

$\square 1$ Not Important

$\square 2$

3

$\square 4$

5

$\square 6$ Very Important

How satisfied are you with the advising you receive on this function?

$\square 1$ Not Satisfied

$\square 2$

3

$\square 4$

5

$\square 6$ Very Satisfied

When students need it, referral to campus resources that address academic problems (e.g., math or science tutoring, writing, disability accommodation, test anxiety). 
How important is this advising function to you?

$\square 1$ Not Important

$\square 2$

3

$\square 4$

5

$\square 6$ Very Important

How satisfied are you with the advising you receive on this function?
$\square 1$ Not Satisfied
2
3
$\square 4$
5
$\square 6$ Very Satisfied

When students need it, referral to campus resources that address non-academic problems (e.g., child-care, financial, physical and mental health).

How important is this advising function to you?

$\square 1$ Not Important

$\square 2$ 
$\square 3$

4

5

6 Very Important

How satisfied are you with the advising you receive on this function?

$\square 1$ Not Satisfied

$\square 2$

3

4

5

$\square 6$ Very Satisfied

Assisting students with understanding how things work at Name of Institution (understanding timelines, policies, and procedures with regard to registration, financial aid, grading, graduation, petitions and appeals, etc.).

How important is this advising function to you?

$\square 1$ Not Important

3 
$\square 6$ Very Important

How satisfied are you with the advising you receive on this function?

$\square 1$ Not Satisfied

3

$\square 4$

5

$\square 6$ Very Satisfied

Ability to give students accurate information about degree requirements.

How important is this advising function to you?

$\square 1$ Not Important

2

3

$\square 4$

$\square 5$

$\square 6$ Very Important 
How satisfied are you with the advising you receive on this function?

$\square 1$ Not Satisfied

$\square 2$

3

$\square$

5

$\square 6$ Very Satisfied

Taking into account students' skills, abilities, and interests in helping them choose courses.

How important is this advising function to you?

$\square 1$ Not Important

2

3

4

5

$\square 6$ Very Important

How satisfied are you with the advising you receive on this function?

$\square 1$ Not Satisfied 
$\square 3$

$\square 4$

$\square 5$

$\square$ Very Satisfied

Knowing the student as an individual.

How important is this advising function to you?

$\square 1$ Not Important

$\square 2$

3

$\square 4$

$\square 5$

$\square 6$ Very Important

How satisfied are you with the advising you receive on this function?

$\square 1$ Not Satisfied

$\square 2$

3

$\square 4$ 
$\square 6$ Very Satisfied

Encouraging students to assume responsibility for their education by helping them develop planning, problem-solving, and decision-making skills.

How important is this advising function to you?

$\square 1$ Not Important

$\square 2$

3

4

5

$\square 6$ Very Important

How satisfied are you with the advising you receive on this function?

$\square 1$ Not Satisfied

2

3

$\square 4$

$\square 5$

$\square 6$ Very Satisfied 
For the next series of questions, indicate your level of agreement.

It is important to develop an adviser/advisee relationship with someone on campus.
$\square 1$ Strongly Disagree
$\square 2$
$\square 3$
4
5
$\square 6$ Strongly Agree

There should be mandatory academic advising for students.
$\square 1$ Strongly Disagree
$\square 2$
3
4
5
$\square 6$ Strongly Agree

43) I know what requirements (e.g., major, general education, other university requirements) I must fulfill in order to earn my degree. 


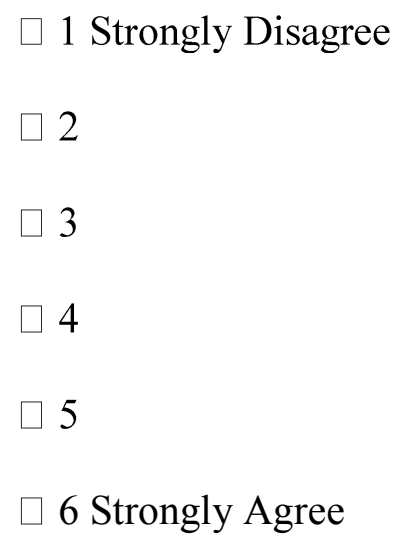

I understand how things work at Name of Institution (timelines, policies, and procedures with regard to registration, financial aid, grading, graduation, petition and appeals, etc.)

$\square 1$ Strongly Disagree

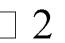

$\square 3$

$\square 4$

5

$\square 6$ Strongly Agree

I understand how my academic choices at Name of Institution connect to my career and life goals.

$\square 1$ Strongly Disagree

$\square 2$ 
$\square 6$ Strongly Agree

When I have a problem, I know where at Name of Institution I can go to get help.
$\square 1$ Strongly Disagree
$\square 2$
$\square 3$
4
5
$\square 6$ Strongly Agree

I have used the Degree Audit Reporting System (DARS). If applicable.
$\square$ No
$\square$ Yes

DARS is helpful in understanding academic requirements at Name of Institution and tracking progress toward my degree.

$\square 1$ Strongly Disagree 
6 Strongly Agree

I believe I have been accurately advised by faculty or staff at Name of Institution.

$\square$ Yes

$\square$ No

If no, what consequences resulted from the advising inaccuracy? (check all that apply)

$\square$ I have had to delay my graduation in order to take one or more additional classes.

$\square$ I have petitioned for an exception to an academic requirement.

$\square$ I have had to take one or more classes that I later discovered I didn't need (for universities students "to Graduate" was added).

$\square \square$ I took a course that did not transfer as I expected. (An option for community college students)

$\square$ I was placed in a course for which I was unprepared.

Other (please specify)

If you selected other, please specify 
51) Please use the space below to comment about any aspect of advising at Name of institution:

When you click the "next page" button, your survey will be submitted. 
APPENDIX C Sample Student Invitation Email

Subject: Academic Advising- We Need Your Input

Dear Student:

Academic advising is important to students, and I want to hear about your experiences with advising at the University. I am asking you to complete a survey that will tell us what you think about academic advising at the University. Your answers to these questions are crucial to our continued efforts to improve student experiences at the University, and I hope you will take the 12 minutes required to complete the survey. As an incentive, I am offering the chance to win 1 of 4 GIFT CERTIFICATES from the University Bookstore, each worth $\mathbf{\$ 5 0}$, to be randomly awarded to participants who complete the survey by the closing date. This is my way of letting you know how much I appreciate your time and input. You can take the survey now by clicking here. (Insert Link to URL)

Please be assured that your answers are completely confidential. Any information that is obtained in connection with this study that can be linked to you or identify you will be confidential. The answers you provide will be summarized along with the responses of other students so that your individual responses will never be identified in any report. 
Although your participation is entirely voluntary, I hope you will complete the survey. Your willingness or unwillingness to participate will not affect decisions involving course grades or other evaluations of your coursework, or your employment or relationship with the University. You may choose not to participate and can withdraw at any time, but if you do not complete and submit the survey you will not be eligible for the gift certificate drawings.

If you have concerns about your participation in this study, please contact the Office for Protection of Human Subjects. If you have questions about the study itself, please contact (name omitted)

Thank you for telling us what we are doing well with academic advising and where we need to improve. You can take the survey now by clicking here. (Insert Link to URL).

Sincerely, 
APPENDIX D Summary of Significant Results for Each Research Question

Simultaneous Regression Tables

Importance Ratings

Table 20

Results of Simultaneous Regression Analysis Predicting Importance Ratings of Overall Connect

\begin{tabular}{|l|c|c|c|c|}
\hline & $B$ & $S E B$ & $\beta$ & Sig. \\
\hline (Constant) & 4.673 & .032 & & \\
\hline Gender & .247 & .026 & .106 & .000 \\
\hline Financial Need & .044 & .029 & .018 & .133 \\
\hline First Generation College & -.006 & .027 & -.003 & .823 \\
Student & & & & \\
\hline African American & .192 & .116 & .018 & .097 \\
\hline Asian American & .052 & .040 & .015 & .191 \\
\hline Hispanic & .193 & .051 & .042 & .000 \\
\hline Multiple Ethnicities & .055 & .118 & -.005 & .643 \\
\hline Native American & .157 & .131 & .013 & .233 \\
\hline Private Institution & -.045 & .031 & .045 & .000 \\
\hline First Year Student & .025 & .033 & -.019 & .179 \\
\hline Third or More Year Student & $R^{2} .017, F(11,8175)=15.39, p<.001$ & .011 & .419 \\
\hline
\end{tabular}

Not for Table 1-12. Gender coded as $1=$ female, $0=$ male; ethnicity coded as $1=$

member of specific ethnic group, $0=$ White; first generation college student coded as $1=$ neither parent had baccalaureate degree, $0=$ at least one parent had baccalaureate degree; financial need coded as $1=$ Pell Grant Recipient, $0=$ not Pell Grant Recipient; Private Institution coded as $1=$ private, $0=$ public; first year student was coded as $1=$ first year enrollment, 0 = second year of enrollment; and third or more year student was coded as 1 $=$ third or more year of enrollment, $0=$ second year of enrollment. 
Table 21

Results of Simultaneous Regression Analysis Predicting Importance Ratings of Major Connect

\begin{tabular}{|c|c|c|c|c|}
\hline & $B$ & $S E B$ & $\beta$ & Sig. \\
\hline (Constant) & 4.847 & .030 & & \\
\hline Gender & .226 & .024 & .103 & .000 \\
\hline Financial Need & .023 & .027 & .010 & .396 \\
\hline $\begin{array}{l}\text { First Generation College } \\
\text { Student }\end{array}$ & -.029 & .026 & -.013 & .256 \\
\hline African American & .149 & .108 & .015 & .167 \\
\hline Asian American & -.033 & .038 & -.010 & .375 \\
\hline Hispanic & .191 & .048 & .045 & .000 \\
\hline Multiple Ethnicities & -.077 & .111 & -.008 & .485 \\
\hline Native American & .033 & .124 & .003 & .791 \\
\hline Private Institution & .114 & .029 & .044 & .000 \\
\hline First Year Student & .040 & .031 & .018 & .199 \\
\hline Third or More Year Student & -.011 & .029 & -.005 & .710 \\
\hline
\end{tabular}

Table 22

Results of Simultaneous Regression Analysis Predicting Importance Ratings of Gen Ed Connect

\begin{tabular}{|c|c|c|c|c|}
\hline & $B$ & $S E B$ & $\beta$ & Sig. \\
\hline (Constant) & 4.286 & .037 & & \\
\hline Gender & .294 & .030 & .109 & .000 \\
\hline Financial Need & .013 & .034 & .004 & .705 \\
\hline $\begin{array}{l}\text { First Generation College } \\
\text { Student }\end{array}$ & .015 & .031 & .006 & .640 \\
\hline African American & .245 & .132 & .020 & .064 \\
\hline Asian American & .139 & .046 & .034 & .003 \\
\hline Hispanic & .298 & .059 & .057 & .000 \\
\hline Multiple Ethnicities & -.172 & .136 & -.014 & .208 \\
\hline Native American & .374 & .153 & .027 & .015 \\
\hline Private Institution & .122 & .035 & .038 & .001 \\
\hline First Year Student & .115 & .038 & .042 & .003 \\
\hline Third or More Year Student & -.107 & .035 & -.042 & .002 \\
\hline
\end{tabular}


Table 23

Results of Simultaneous Regression Analysis Predicting Importance Ratings of Degree Connect

\begin{tabular}{|l|c|c|c|c|}
\hline & $B$ & $S E B$ & $\beta$ & Sig. \\
\hline (Constant) & 4.260 & .041 & & \\
\hline Gender & .331 & .033 & .113 & .000 \\
\hline Financial Need & .036 & .037 & .012 & .328 \\
\hline $\begin{array}{l}\text { First Generation College } \\
\text { Student }\end{array}$ & .028 & .034 & .010 & .416 \\
\hline African American & .482 & .482 & .036 & .001 \\
\hline Asian American & .157 & .051 & .035 & .002 \\
\hline Hispanic & .341 & .065 & .060 & .000 \\
\hline Multiple Ethnicities & -.051 & .149 & -.004 & .732 \\
\hline Native American & .212 & .168 & .014 & .205 \\
\hline Private Institution & .107 & .039 & .031 & .005 \\
\hline First Year Student & .131 & .042 & .043 & .002 \\
\hline Third or More Year Student & -.074 & .039 & -.026 & .056 \\
\hline \multicolumn{2}{|l|}{$R^{2} .025, F(11,8064)=35.490, p<.001$} & & \\
\hline
\end{tabular}

Table 24

Results of Simultaneous Regression Analysis Predicting Importance Ratings of Out-ofClass Connect

\begin{tabular}{|l|c|c|c|c|}
\hline & $B$ & $S E B$ & $\beta$ & Sig. \\
\hline (Constant) & 4.288 & .040 & & \\
\hline Gender & .223 & .032 & .077 & .000 \\
\hline Financial Need & .023 & .037 & .008 & .526 \\
\hline $\begin{array}{l}\text { First Generation College } \\
\text { Student }\end{array}$ & -.003 & .034 & -.001 & .936 \\
\hline African American & .267 & .145 & .020 & .066 \\
\hline Asian American & .196 & .050 & .044 & .000 \\
\hline Hispanic & .267 & .065 & .047 & .000 \\
\hline Multiple Ethnicities & .085 & .148 & .006 & .565 \\
\hline Native American & .169 & .166 & .011 & .307 \\
\hline Private Institution & .073 & .038 & .021 & .056 \\
\hline First Year Student & -.006 & .042 & -.002 & .890 \\
\hline Third or More Year Student & .031 & .038 & .011 & .417 \\
\hline \multicolumn{2}{|l|}{$R^{2} .011, F(11,8024)=14.976, p<.001$} & & \\
\hline
\end{tabular}


Table 25

Results of Simultaneous Regression Analysis Predicting Importance Ratings of Referral Academic

\begin{tabular}{|l|c|c|c|c|}
\hline & $B$ & $S E B$ & $\beta$ & Sig. \\
\hline (Constant) & 4.101 & .041 & & \\
\hline Gender & .362 & .032 & .123 & .000 \\
\hline Financial Need & .045 & .037 & .014 & .221 \\
\hline $\begin{array}{l}\text { First Generation College } \\
\text { Student }\end{array}$ & .173 & .034 & .060 & .000 \\
\hline African American & .370 & .145 & .028 & .011 \\
\hline Asian American & .102 & .051 & .022 & .044 \\
\hline Hispanic & .325 & .065 & .056 & .000 \\
\hline Multiple Ethnicities & .198 & .148 & .015 & .015 \\
\hline Native American & .130 & .165 & .009 & .434 \\
\hline Private Institution & .093 & .038 & .027 & .016 \\
\hline First Year Student & .093 & .042 & .031 & .027 \\
\hline Third or More Year Student & -.098 & .038 & -.035 & .011 \\
\hline \multicolumn{2}{|l|}{$R^{2} .032, F(11,7986)=44.485, p<.001$} & & \\
\hline
\end{tabular}

Table 26

Results of Simultaneous Regression Analysis Predicting Importance Ratings of Referral Non-Academic

\begin{tabular}{|l|c|c|c|c|}
\hline & $B$ & $S E B$ & $\beta$ & Sig. \\
\hline (Constant) & 3.667 & .045 & & \\
\hline Gender & .410 & .036 & .126 & .000 \\
\hline Financial Need & .264 & .041 & .076 & .000 \\
\hline $\begin{array}{l}\text { First Generation College } \\
\text { Student }\end{array}$ & .088 & .038 & .027 & .021 \\
\hline African American & .226 & .161 & .016 & .159 \\
\hline Asian American & .092 & .056 & .018 & .101 \\
\hline Hispanic & .450 & .072 & .071 & .000 \\
\hline Multiple Ethnicities & .128 & .164 & .009 & .434 \\
\hline Native American & .346 & .183 & .021 & .059 \\
\hline Private Institution & .188 & .043 & .049 & .000 \\
\hline First Year Student & .129 & .046 & .039 & .005 \\
\hline Third or More Year Student & -.025 & .043 & -.008 & .557 \\
\hline \multicolumn{2}{|l|}{$R^{2}$} \\
\hline
\end{tabular}


Table 27

Results of Simultaneous Regression Analysis Predicting Importance Ratings of How Things Work

\begin{tabular}{|c|c|c|c|c|}
\hline & $B$ & $S E B$ & $\beta$ & Sig. \\
\hline (Constant) & 4.546 & .036 & & \\
\hline Gender & .300 & .029 & .117 & .000 \\
\hline Financial Need & .078 & .033 & .028 & .018 \\
\hline $\begin{array}{l}\text { First Generation College } \\
\text { Student }\end{array}$ & .027 & .030 & .011 & .374 \\
\hline African American & .229 & .129 & .020 & .076 \\
\hline Asian American & .004 & .045 & .001 & .924 \\
\hline Hispanic & .224 & .058 & .044 & .000 \\
\hline Multiple Ethnicities & -.038 & .131 & -.003 & .771 \\
\hline Native American & .186 & .147 & .014 & .205 \\
\hline Private Institution & .090 & .034 & .029 & .009 \\
\hline First Year Student & .051 & .037 & .019 & .172 \\
\hline Third or More Year Student & .014 & .034 & .006 & .681 \\
\hline
\end{tabular}

Table 28

Results of Simultaneous Regression Analysis Predicting Importance Ratings of Accurate Information

\begin{tabular}{|l|c|c|c|c|}
\hline & $B$ & $S E B$ & $\beta$ & Sig. \\
\hline (Constant) & 5.336 & .025 & & \\
\hline Gender & .224 & .020 & .126 & .000 \\
\hline Financial Need & -.005 & .022 & -.003 & .833 \\
\hline $\begin{array}{l}\text { First Generation College } \\
\text { Student }\end{array}$ & -.025 & .021 & -.014 & .236 \\
\hline African American & & & & \\
\hline Asian American & -.029 & .088 & -.004 & .746 \\
\hline Hispanic & -.149 & .031 & -.054 & .000 \\
\hline Multiple Ethnicities & .017 & .040 & .005 & .666 \\
\hline Native American & -.112 & .090 & -.014 & .214 \\
\hline Private Institution & .087 & .101 & .010 & .390 \\
\hline First Year Student & .089 & .023 & .042 & .000 \\
\hline Third or More Year Student &. .026 & .069 & -.014 & .310 \\
\hline \multicolumn{2}{|l|}{$R^{2}$} \\
\hline
\end{tabular}


Table 29

Results of Simultaneous Regression Analysis Predicting Importance Ratings of Skills Abilities Interests

\begin{tabular}{|l|c|c|c|c|}
\hline & $B$ & $S E B$ & $\beta$ & Sig. \\
\hline (Constant) & 4.753 & .033 & & \\
\hline Gender & .256 & .026 & .109 & .000 \\
\hline Financial Need & .005 & .030 & .002 & .854 \\
\hline $\begin{array}{l}\text { First Generation College } \\
\text { Student }\end{array}$ & .040 & .028 & .017 & .153 \\
\hline African American & .115 & .117 & .011 & .326 \\
\hline Asian American & -.041 & .041 & -.011 & .319 \\
\hline Hispanic & .203 & .053 & .044 & .000 \\
\hline Multiple Ethnicities & -.054 & .119 & -.005 & .648 \\
\hline Native American & .097 & .134 & .008 & .468 \\
\hline Private Institution & .112 & .031 & .041 & .000 \\
\hline First Year Student & .052 & .034 & .022 & .123 \\
\hline Third or More Year Student & -.052 & .031 & -.023 & .093 \\
\hline \multicolumn{2}{|l|}{$R^{2}$} \\
\hline
\end{tabular}

Table 30

Results of Simultaneous Regression Analysis Predicting Importance Ratings of Know as Individual

\begin{tabular}{|c|c|c|c|c|}
\hline & $B$ & $S E B$ & $\beta$ & Sig. \\
\hline (Constant) & 4.661 & .035 & & \\
\hline Gender & .337 & .028 & .134 & .000 \\
\hline Financial Need & .040 & .032 & .015 & .210 \\
\hline $\begin{array}{l}\text { First Generation College } \\
\text { Student }\end{array}$ & .051 & .029 & .021 & .082 \\
\hline African American & .084 & .125 & .007 & .502 \\
\hline Asian American & -.007 & .043 & -.002 & .872 \\
\hline Hispanic & .258 & .056 & .052 & .000 \\
\hline Multiple Ethnicities & -.050 & .127 & -.004 & .695 \\
\hline Native American & .304 & .142 & .024 & .033 \\
\hline Private Institution & .320 & .033 & .108 & .000 \\
\hline First Year Student & -.074 & .036 & -.029 & .040 \\
\hline Third or More Year Student & -.034 & .033 & -.014 & .297 \\
\hline
\end{tabular}


Table 31

Results of Simultaneous Regression Analysis Predicting Importance Ratings of Shared Responsibility

\begin{tabular}{|c|c|c|c|c|}
\hline & $B$ & $S E B$ & $\beta$ & Sig. \\
\hline (Constant) & 4.513 & .037 & & \\
\hline Gender & .197 & .029 & .075 & .000 \\
\hline Financial Need & .042 & .033 & .015 & .206 \\
\hline $\begin{array}{l}\text { First Generation College } \\
\text { Student }\end{array}$ & .119 & .031 & .046 & .000 \\
\hline African American & .219 & .131 & .019 & .093 \\
\hline Asian American & .152 & .045 & .038 & .001 \\
\hline Hispanic & .301 & .059 & .059 & .000 \\
\hline Multiple Ethnicities & .085 & .133 & .007 & .526 \\
\hline Native American & .271 & .149 & .020 & .069 \\
\hline Private Institution & .204 & .035 & .066 & .000 \\
\hline First Year Student & .016 & .038 & .006 & .670 \\
\hline Third or More Year Student & -.025 & .035 & -.010 & .463 \\
\hline \multicolumn{5}{|c|}{$R^{2=} .020, F(11,7890)=14.767, p<.001$} \\
\hline
\end{tabular}


Satisfaction Ratings

Table 32

Results of Simultaneous Regression Analysis Predicting Satisfaction Ratings of Overall Connect

\begin{tabular}{|c|c|c|c|c|}
\hline & $B$ & $S E B$ & $\beta$ & Sig. \\
\hline (Constant) & 3.991 & .041 & & .000 \\
\hline Gender & -.043 & .033 & -.015 & .190 \\
\hline Financial Need & .137 & .037 & .045 & .000 \\
\hline $\begin{array}{l}\text { First Generation College } \\
\text { Student }\end{array}$ & .064 & .035 & .023 & .065 \\
\hline African American & -.027 & .146 & -.002 & .855 \\
\hline Asian American & .193 & .051 & .043 & .000 \\
\hline Hispanic & .075 & .066 & .013 & .258 \\
\hline Multiple Ethnicities & .051 & .152 & .004 & .736 \\
\hline Native American & -.210 & .165 & -.014 & .204 \\
\hline Private Institution & .187 & .039 & .055 & .000 \\
\hline First Year Student & .149 & .043 & .050 & .000 \\
\hline Third or More Year Student & -.070 & .039 & -.026 & .069 \\
\hline & \multicolumn{4}{|c|}{$R^{2}=.014, F(11,7651)=18.098, p<.001$} \\
\hline
\end{tabular}

Note for Tables 17-28. Gender coded as $1=$ female, $0=$ male; ethnicity coded as $1=$ member of specific ethnic group, $0=$ White; first generation college student coded as $1=$ neither parent had baccalaureate degree, $0=$ at least one parent had baccalaureate degree; financial need coded as $1=$ Pell Grant Recipient, $0=$ not Pell Grant Recipient; Private Institution coded as $1=$ private, $0=$ public; first year student was coded as $1=$ first year enrollment, 0 = second year of enrollment; and third or more year student was coded as 1 $=$ third or more year of enrollment, $0=$ second year of enrollment.

$* p<.05 ; \quad * * p<.01 ; * * * p<.001$. 
Table 33

Results of Simultaneous Regression Analysis Predicting Satisfaction Ratings of Major Connect

\begin{tabular}{|c|c|c|c|c|}
\hline & $B$ & $S E B$ & $\beta$ & Sig. \\
\hline (Constant) & 4.038 & .041 & & .000 \\
\hline Gender & -.014 & .033 & -.005 & .661 \\
\hline Financial Need & .111 & .037 & .036 & .003 \\
\hline $\begin{array}{l}\text { First Generation College } \\
\text { Student }\end{array}$ & .047 & .035 & .017 & .174 \\
\hline African American & .122 & .144 & .010 & .396 \\
\hline Asian American & .162 & .051 & .037 & .001 \\
\hline Hispanic & .115 & .065 & .021 & .077 \\
\hline Multiple Ethnicities & .024 & .150 & .002 & .875 \\
\hline Native American & -.097 & .165 & -.007 & .556 \\
\hline Private Institution & .230 & .038 & .069 & .000 \\
\hline First Year Student & .121 & .042 & .041 & .004 \\
\hline Third or More Year Student & -.123 & .038 & -.045 & .001 \\
\hline & \multicolumn{4}{|c|}{$R^{2=} .015, F(11,7630)=19.295, p<.001$} \\
\hline
\end{tabular}

Table 34

Results of Simultaneous Regression Analysis Predicting Satisfaction Ratings of Gen Ed Connect

\begin{tabular}{|l|c|c|c|c|}
\hline & $B$ & $S E B$ & $\beta$ & Sig. \\
\hline (Constant) & 3.829 & .041 & & .000 \\
\hline Gender & .022 & .033 & .008 & .504 \\
\hline Financial Need & .128 & .037 & .042 & .001 \\
\hline $\begin{array}{l}\text { First Generation College } \\
\text { Student }\end{array}$ & .080 & .035 & .028 & .023 \\
\hline African American & .203 & .144 & .016 & .160 \\
\hline Asian American & .175 & .051 & .039 & .001 \\
\hline Hispanic & .093 & .066 & .016 & .161 \\
\hline Multiple Ethnicities & .032 & .152 & .002 & .834 \\
\hline Native American & -.025 & .166 & -.002 & .880 \\
\hline Private Institution & .321 & .039 & .095 & .000 \\
\hline First Year Student & .177 & .043 & .059 & .000 \\
\hline Third or More Year Student & -.190 & .039 & -.069 & .000 \\
\hline \multicolumn{2}{|l|}{$R^{2} .029, F(11,7550)=36.907, p<.001$} \\
\hline
\end{tabular}


Table 35

Results of Simultaneous Regression Analysis Predicting Satisfaction Ratings of Degree Connect

\begin{tabular}{|l|c|c|c|c|}
\hline & $B$ & $S E B$ & $\beta$ & Sig. \\
\hline (Constant) & 3.866 & .043 & & .000 \\
\hline Gender & -.041 & .034 & -.014 & .231 \\
\hline Financial Need & .045 & .039 & .014 & .247 \\
\hline $\begin{array}{l}\text { First Generation College } \\
\text { Student }\end{array}$ & .100 & .036 & .034 & .006 \\
\hline African American & .073 & .153 & .005 & .633 \\
\hline Asian American & .182 & .053 & .040 & .001 \\
\hline Hispanic & .057 & .069 & .010 & .403 \\
\hline Multiple Ethnicities & -.009 & .159 & -.001 & .957 \\
\hline Native American & -.035 & .174 & -.002 & .840 \\
\hline Private Institution & .272 & .040 & .078 & .000 \\
\hline First Year Student & .170 & .044 & .055 & .000 \\
\hline Third or More Year Student & -.137 & .040 & -.048 & .001 \\
\hline \multicolumn{2}{|c|}{$R^{2=} .019, F(11,7518)=25.336, p<.001$} \\
\hline
\end{tabular}

Table 36

Results of Simultaneous Regression Analysis Predicting Satisfaction Ratings of Out-ofClass Connect

\begin{tabular}{|l|c|c|c|c|}
\hline & $B$ & $S E B$ & $\beta$ & Sig. \\
\hline (Constant) & 3.414 & .045 & & .000 \\
\hline Gender & -.099 & .036 & -.032 & .006 \\
\hline Financial Need & .077 & .041 & .023 & .058 \\
\hline $\begin{array}{l}\text { First Generation College } \\
\text { Student }\end{array}$ & .060 & .038 & .020 & .110 \\
\hline African American & .096 & .158 & .007 & .543 \\
\hline Asian American & .262 & .055 & .055 & .000 \\
\hline Hispanic & .201 & .072 & .033 & .005 \\
\hline Multiple Ethnicities & .113 & .163 & .008 & .489 \\
\hline Native American & -.080 & .180 & -.005 & .656 \\
\hline Private Institution & .113 & .042 & .031 & .007 \\
\hline First Year Student & .140 & .046 & .044 & .002 \\
\hline Third or More Year Student & -.104 & .042 & -.035 & .014 \\
\hline \multicolumn{2}{|l|}{} \\
\hline
\end{tabular}


Table 37

Results of Simultaneous Regression Analysis Predicting Satisfaction Ratings of Referral Academic

\begin{tabular}{|l|c|c|c|c|}
\hline & $B$ & $S E B$ & $\beta$ & Sig. \\
\hline (Constant) & 3.904 & .042 & & .000 \\
\hline Gender & -.037 & .033 & -.013 & .264 \\
\hline Financial Need & .108 & .038 & .035 & .004 \\
\hline $\begin{array}{l}\text { First Generation College } \\
\text { Student }\end{array}$ & .095 & .035 & .034 & .007 \\
\hline African American & & & & \\
\hline Asian American & -.115 & .145 & -.009 & .430 \\
\hline Hispanic & .071 & .051 & .016 & .165 \\
\hline Multiple Ethnicities & .192 & .066 & .034 & .004 \\
\hline Native American & .260 & .151 & .020 & .085 \\
\hline Private Institution & -.238 & .165 & -.017 & .150 \\
\hline First Year Student & .197 & .039 & .059 & .000 \\
\hline Third or More Year Student & .167 & .043 & .056 & .000 \\
\hline \multicolumn{2}{|c|}{$R^{2=} .018, F(11,7418)=22.418, p<.001$} \\
\hline
\end{tabular}

Table 38

Results of Simultaneous Regression Analysis Predicting Satisfaction Ratings of Referral Non-Academic

\begin{tabular}{|l|c|c|c|c|}
\hline & $B$ & $S E B$ & $\beta$ & Sig. \\
\hline (Constant) & 3.769 & .042 & & .000 \\
\hline Gender & -.060 & .034 & -.021 & .073 \\
\hline Financial Need & .126 & .038 & .041 & .001 \\
\hline $\begin{array}{l}\text { First Generation College } \\
\text { Student }\end{array}$ & .003 & .036 & .001 & .932 \\
\hline African American & -.276 & .146 & -.022 & .059 \\
\hline Asian American & .050 & .052 & .011 & .333 \\
\hline Hispanic & .198 & .067 & .035 & .003 \\
\hline Multiple Ethnicities & .025 & .153 & .002 & .873 \\
\hline Native American & -.417 & .168 & -.029 & .013 \\
\hline Private Institution & .116 & .039 & .035 & .003 \\
\hline First Year Student & .174 & .043 & .058 & .000 \\
\hline Third or More Year Student & -.061 & .039 & -.022 & .125 \\
\hline & $R^{2=} .012, F(11,7320)=14.783, p<.001$ \\
\hline
\end{tabular}


Table 39

Results of Simultaneous Regression Analysis Predicting Satisfaction Ratings of How Things Work

\begin{tabular}{|c|c|c|c|c|}
\hline & $B$ & $S E B$ & $\beta$ & Sig. \\
\hline (Constant) & 3.800 & .043 & & .000 \\
\hline Gender & -.061 & .035 & -.020 & .079 \\
\hline Financial Need & .095 & .039 & .030 & .015 \\
\hline $\begin{array}{l}\text { First Generation College } \\
\text { Student }\end{array}$ & .090 & .037 & .031 & .014 \\
\hline African American & .106 & .152 & .008 & .484 \\
\hline Asian American & .141 & .053 & .031 & .008 \\
\hline Hispanic & .072 & .069 & .012 & .298 \\
\hline Multiple Ethnicities & -.112 & .158 & -.008 & .477 \\
\hline Native American & -.283 & .174 & -.019 & .105 \\
\hline Private Institution & .224 & .040 & .065 & .000 \\
\hline First Year Student & .161 & .045 & .052 & .000 \\
\hline Third or More Year Student & -.165 & .041 & -.058 & .000 \\
\hline & \multicolumn{4}{|c|}{$R^{2=} .019, F(11,7398)=25.025, p<.001$} \\
\hline
\end{tabular}

Table 40

Results of Simultaneous Regression Analysis Predicting Satisfaction Ratings of Accurate Information

\begin{tabular}{|l|c|c|c|c|}
\hline & $B$ & $S E B$ & $\beta$ & Sig. \\
\hline (Constant) & 4.332 & .043 & & .000 \\
\hline Gender & -.107 & .034 & -.036 & .002 \\
\hline Financial Need & .056 & .039 & .018 & .150 \\
\hline $\begin{array}{l}\text { First Generation College } \\
\text { Student }\end{array}$ & -.004 & .036 & -.001 & .905 \\
\hline African American & & & & \\
\hline Asian American & .045 & .151 & .003 & .764 \\
\hline Hispanic & .097 & .053 & .021 & .068 \\
\hline Multiple Ethnicities & .062 & .069 & .011 & .366 \\
\hline Native American & -.012 & .156 & -.001 & .941 \\
\hline Private Institution & -.265 & .173 & -.018 & .126 \\
\hline First Year Student & .299 & .040 & .087 & .000 \\
\hline Third or More Year Student & .119 & .044 & .039 & .007 \\
\hline \multicolumn{2}{|l|}{} \\
\hline
\end{tabular}


Table 41

Results of Simultaneous Regression Analysis Predicting Satisfaction Ratings of Skills Abilities Interests

\begin{tabular}{|c|c|c|c|c|}
\hline & $B$ & $S E B$ & $\beta$ & Sig. \\
\hline (Constant) & 3.859 & .043 & & .000 \\
\hline Gender & -.027 & .034 & -.009 & .429 \\
\hline Financial Need & .065 & .039 & .021 & .094 \\
\hline $\begin{array}{l}\text { First Generation College } \\
\text { Student }\end{array}$ & .054 & .036 & .018 & .140 \\
\hline African American & .091 & .151 & .007 & .547 \\
\hline Asian American & .097 & .053 & .021 & .067 \\
\hline Hispanic & .115 & .069 & .020 & .095 \\
\hline Multiple Ethnicities & .033 & .157 & .002 & .832 \\
\hline Native American & .084 & .173 & .006 & .628 \\
\hline Private Institution & .238 & .040 & .069 & .000 \\
\hline First Year Student & .114 & .044 & .037 & .010 \\
\hline Third or More Year Student & -.108 & .040 & -.039 & .008 \\
\hline & \multicolumn{4}{|c|}{$R^{2=} .012, F(11,7385)=15.227, p<.001$} \\
\hline
\end{tabular}

Table 42

Results of Simultaneous Regression Analysis Predicting Satisfaction Ratings of Know as Individual

\begin{tabular}{|c|c|c|c|c|}
\hline & $B$ & $S E B$ & $\beta$ & Sig. \\
\hline (Constant) & 3.638 & .048 & & .000 \\
\hline Gender & -.118 & .039 & -.035 & .002 \\
\hline Financial Need & .107 & .044 & .030 & .014 \\
\hline $\begin{array}{l}\text { First Generation College } \\
\text { Student }\end{array}$ & .096 & .041 & .029 & .018 \\
\hline African American & .044 & .168 & .003 & .796 \\
\hline Asian American & .089 & .060 & .017 & .135 \\
\hline Hispanic & .154 & .077 & .024 & .046 \\
\hline Multiple Ethnicities & .012 & .175 & .001 & .947 \\
\hline Native American & .098 & .193 & .006 & .610 \\
\hline Private Institution & .487 & .045 & .126 & .000 \\
\hline First Year Student & .102 & .050 & .029 & .041 \\
\hline Third or More Year Student & .087 & .045 & .028 & .054 \\
\hline & \multicolumn{4}{|c|}{$R^{2=} .020, F(11,7405)=33.148, p<.001$} \\
\hline
\end{tabular}


Table 43

Results of Simultaneous Regression Analysis Predicting Satisfaction Ratings of Shared Responsibility

\begin{tabular}{|l|c|c|c|c|}
\hline & $B$ & $S E B$ & $\beta$ & Sig. \\
\hline (Constant) & 3.957 & .041 & & .000 \\
\hline Gender & -.062 & .033 & -.022 & .060 \\
\hline Financial Need & .066 & .037 & .022 & .078 \\
\hline $\begin{array}{l}\text { First Generation College } \\
\text { Student }\end{array}$ & .064 & .035 & .023 & .067 \\
\hline African American & -.102 & .145 & -.008 & .482 \\
\hline Asian American & .072 & .051 & .016 & .160 \\
\hline Hispanic & .126 & .066 & .023 & .058 \\
\hline Multiple Ethnicities & .063 & .151 & .005 & .674 \\
\hline Native American & -.052 & .165 & -.004 & .754 \\
\hline Private Institution & .315 & .038 & .096 & .000 \\
\hline First Year Student & .113 & .043 & .038 & .008 \\
\hline Third or More Year Student & -.088 & .039 & -.033 & .024 \\
\hline \multicolumn{4}{|l|}{$R^{2=} .016, F(11,7345)=18.971, p<.001$} & \\
\hline
\end{tabular}


Learning Outcomes

Table 44

Results of Simultaneous Regression Analysis Predicting Learning Outcomes Dependent Variable: Knows Requirements

\begin{tabular}{|l|c|c|c|c|}
\hline & $B$ & $S E B$ & $\beta$ & Sig. \\
\hline (Constant) & 4.569 & .080 & & \\
\hline Size of Institution & $-7.417 \mathrm{E}-6$ & .000 & -.058 & .000 \\
\hline Ins GPA at time of Survey & .174 & .022 & .085 & .000 \\
\hline D_First_Yr & -.338 & .033 & -.140 & .000 \\
\hline D_Third_Yr & .283 & .030 & .127 & .000 \\
\hline \multicolumn{4}{|l|}{$R 2=.070, F(4,7868)=170.138, p<.001$} \\
\hline
\end{tabular}

Note for tables 31-37. Gender coded as $1=$ female, $0=$ male; ethnicity coded as $1=$

member of specific ethnic group, $0=$ White; first generation college student coded as $1=$ neither parent had baccalaureate degree, $0=$ at least one parent had baccalaureate degree; financial need coded as $1=$ Pell Grant Recipient, $0=$ not Pell Grant Recipient; Private Institution coded as $1=$ private, $0=$ public; first year student was coded as $1=$ first year enrollment, 0 = second year of enrollment; and third or more year student was coded as 1 $=$ third or more year of enrollment, $0=$ second year of enrollment.

Table 45

Results of Simultaneous Regression Analysis Predicting Learning Outcomes Dependent Variable: Knows Resources

\begin{tabular}{|l|c|c|c|c|}
\hline & $B$ & $S E B$ & $\beta$ & Sig. \\
\hline (Constant) & 4.424 & .100 & & \\
\hline Size of Institution & $-1.910 \mathrm{E}-5$ & .000 & -.122 & .000 \\
\hline Ins GPA at time of Survey & .069 & .028 & .028 & .014 \\
\hline D_First_Yr & -.077 & .041 & -.026 & .063 \\
\hline D_Third_Yr & .028 & .038 & .010 & .456 \\
\hline & \multicolumn{2}{|c|}{$R 2=.017, F(4,7852)=61.718, p<.001$} \\
\hline
\end{tabular}


Table 46

Results of Simultaneous Regression Analysis Predicting Learning Outcomes

Dependent Variable: Understands How Things Work

\begin{tabular}{|l|r|r|r|r|}
\hline & \multicolumn{1}{|c|}{ B } & \multicolumn{1}{|c|}{ SE B } & \multicolumn{1}{c|}{ Sig. } \\
\hline (Constant) & 4.397 & .091 & & \\
\hline Size of Institution & $-1.252 \mathrm{E}-5$ & .000 & -.088 & .000 \\
\hline Ins GPA at time of Survey & .070 & .025 & .031 & .006 \\
\hline D_First_Yr & -.198 & .038 & -.074 & .000 \\
\hline D_Third_Yr & .161 & .035 & .065 & .000 \\
\hline & $R 2=.024, F(4,7862)=73.001, p<.001$ \\
\hline
\end{tabular}

Table 47

Results of Simultaneous Regression Analysis Predicting Learning Outcomes Dependent Variable: Understands Connections

\begin{tabular}{|l|c|c|c|c|}
\hline & $B$ & $S E B$ & $\beta$ & Sig. \\
\hline (Constant) & 4.786 & .082 & & \\
\hline Size of Institution & $-1.308 \mathrm{E}-5$ & .000 & -.102 & .000 \\
\hline Ins GPA at time of Survey & .091 & .023 & .045 & .000 \\
\hline D_First_Yr & -.069 & .034 & -.029 & .042 \\
\hline D_Third_Yr & .031 & .031 & .014 & .315 \\
\hline \multicolumn{4}{|r|}{$R 2=.015, F(4,7838)=35.007, p<.001$} \\
\hline
\end{tabular}

Table 48

Results of Simultaneous Regression Analysis Predicting Learning Outcomes Dependent Variable: Has Educational Plan

\begin{tabular}{|l|c|c|c|c|}
\hline & $B$ & $S E B$ & $\beta$ & Sig. \\
\hline (Constant) & 4.845 & .064 & & \\
\hline Ins GPA at time of Survey & .157 & .018 & .094 & .121 \\
\hline First_Gen_No_BA & .027 & .022 & .014 & -.016 \\
\hline D_Fin_Need & .008 & .024 & .004 & -.039 \\
\hline D_First_Yr & -.071 & .027 & -.036 & -.124 \\
\hline D_Third_Yr & .053 & .025 & .029 & .004 \\
\hline & \multicolumn{2}{|c|}{$R 2=.013, F(5,8175)=17.245, p<.001$} \\
\hline
\end{tabular}


Table 49

Results of Simultaneous Regression Analysis Predicting Learning Outcomes Dependent Variable: Has Significant Relationship

\begin{tabular}{|l|c|c|c|c|}
\hline & $B$ & $S E B$ & $\beta$ & Sig. \\
\hline (Constant) & 4.092 & .105 & & \\
\hline Size of Institution & $-3.184 \mathrm{E}-5$ & .000 & -.184 & .000 \\
\hline Ins GPA at time of Survey & .229 & .029 & .083 & .000 \\
\hline D_First_Yr & -.261 & .043 & -.080 & .000 \\
\hline D_Third_Yr & .358 & .040 & .119 & .000 \\
\hline & \multicolumn{2}{|l}{} \\
\hline
\end{tabular}

Table 50

Results of Simultaneous Regression Analysis Predicting Learning Outcomes Dependent Variable: Values Advisor-Advisee Relationship

\begin{tabular}{|l|c|c|c|c|}
\hline & $B$ & $S E B$ & $\beta$ & Sig. \\
\hline (Constant) & 5.182 & .078 & & \\
\hline Size of Institution & $-1.393 \mathrm{E}-5$ & .000 & -.114 & .000 \\
\hline Ins GPA at time of Survey & .042 & .022 & .022 & .053 \\
\hline D_First_Yr & -.064 & .032 & -.028 & .047 \\
\hline D_Third_Yr & -.035 & .030 & -.016 & .245 \\
\hline \multicolumn{4}{|r|}{$R 2=.014, F(4,7873)=31.351, p<.001$} \\
\hline
\end{tabular}


Logistic Regression Tables

Importance Ratings

Table 51

Results of Logistic Regression Analysis Examining the Relationship between Scores on Overall Connect and Student Retention from Second to Third Year

\begin{tabular}{|c|c|c|c|c|c|c|}
\hline Predictor & B & $\mathrm{SE}$ & Wald's $\chi^{2}$ & $\mathrm{df}$ & $p$ & $e^{\beta}$ \\
\hline Constant & -2.315 & .212 & 119.828 & 1 & .000 & .099 \\
\hline Overall Connect & -.079 & .042 & 3.566 & 1 & .059 & .924 \\
\hline African American & -.077 & .467 & .027 & 1 & .870 & .926 \\
\hline Asian American & .090 & .151 & .355 & 1 & .551 & 1.094 \\
\hline Hispanic & -.232 & .211 & 1.207 & 1 & .272 & .793 \\
\hline Multiple Ethnic & -.820 & .591 & 1.926 & 1 & .165 & .441 \\
\hline Native American & -.811 & .722 & 1.264 & 1 & .261 & .444 \\
\hline Financial Need & .146 & .110 & 1.775 & 1 & .183 & 1.158 \\
\hline Gender & .059 & .101 & .343 & 1 & .558 & 1.061 \\
\hline Private & -1.715 & .225 & 57.841 & 1 & .000 & .180 \\
\hline First Gen No BA & .106 & .104 & 1.038 & 1 & .308 & 1.112 \\
\hline \multirow{2}{*}{$\begin{array}{l}\text { Test } \\
\text { Overall model } \\
\text { evaluation }\end{array}$} & & & $\chi^{2}(d f)$ & & $p$ & \\
\hline & & & & & & \\
\hline Likelihood ratio test & & & $113.057(10)$ & & .000 & \\
\hline \multicolumn{7}{|l|}{ Goodness-of-fit } \\
\hline Homer \& Lemeshow & & & $9.627(8)$ & & .292 & \\
\hline
\end{tabular}

Note. Cox and Snell $R^{2}=.014$. Nagelkerke $R^{2}=.038$

\section{Classification Table ${ }^{a}$}

\begin{tabular}{|c|c|c|c|c|}
\hline & \multirow[b]{3}{*}{ Observed } & \multicolumn{3}{|c|}{ Predicted } \\
\hline & & \multicolumn{2}{|c|}{$\begin{array}{l}\text { Retained or Grad as of fall } \mathrm{Yr} \\
2\end{array}$} & \multirow{2}{*}{$\begin{array}{c}\text { Percentage } \\
\text { Correct } \\
\end{array}$} \\
\hline & & yes & no & \\
\hline \multirow[t]{3}{*}{ Step 1} & Retained or Grad as of fall yes & 7688 & 0 & 100.0 \\
\hline & no & 480 & 0 & .0 \\
\hline & Overall Percentage & & & 94.1 \\
\hline
\end{tabular}

a. The cut value is .500 
Table 52

Results of Logistic Regression Analysis Examining the Relationship between Scores on Major Connect and Student Retention from Second to Third Year

\begin{tabular}{|c|c|c|c|c|c|c|}
\hline Predictor & B & $\mathrm{SE}$ & Wald's $\chi^{2}$ & df & $p$ & $e^{\beta}$ \\
\hline Constant & -2.178 & .227 & 92.049 & 1 & .000 & .113 \\
\hline Major Connect & -.104 & .044 & 5.629 & 1 & .018 & .901 \\
\hline African American & -.091 & .467 & .038 & 1 & .846 & .913 \\
\hline Asian American & .085 & .151 & .312 & 1 & .577 & 1.088 \\
\hline Hispanic & -.232 & .211 & 1.213 & 1 & .271 & .793 \\
\hline Multiple Ethnic & -.824 & .591 & 1.945 & 1 & .163 & .439 \\
\hline Native American & -.805 & .722 & 1.243 & 1 & .265 & .447 \\
\hline Financial Need & .145 & .110 & 1.728 & 1 & .189 & 1.156 \\
\hline Gender & .065 & .101 & .408 & 1 & .523 & 1.067 \\
\hline Private & -1.714 & .225 & 57.795 & 1 & .000 & .180 \\
\hline First Gen No BA & .105 & .104 & 1.010 & 1 & .315 & 1.110 \\
\hline Test & & & $\chi^{2}(d f)$ & & $p$ & \\
\hline $\begin{array}{l}\text { Overall model } \\
\text { evaluation }\end{array}$ & & & & & & \\
\hline Likelihood ratio test & & & $113.057(10)$ & & .000 & \\
\hline Goodness-of-fit & & & & & & \\
\hline Homer \& Lemeshow & & & $9.627(8)$ & & .292 & \\
\hline
\end{tabular}

Note. Cox and Snell $R^{2}=.014$. Nagelkerke $R^{2}=.038$

\section{Classification Table ${ }^{a}$}

\begin{tabular}{|c|c|c|c|c|}
\hline & & \multicolumn{3}{|c|}{ Predicted } \\
\hline & & \multicolumn{2}{|c|}{$\begin{array}{l}\text { Retained or Grad as of fall } \mathrm{Yr} \\
2\end{array}$} & \multirow{2}{*}{$\begin{array}{c}\text { Percentage } \\
\text { Correct } \\
\end{array}$} \\
\hline & Observed & yes & no & \\
\hline \multirow[t]{3}{*}{ Step 1} & Retained or Grad as of fall yes & 7688 & 0 & 100.0 \\
\hline & Yr 2 & 480 & 0 & .0 \\
\hline & Overall Percentage & & & 94.1 \\
\hline
\end{tabular}

a. The cut value is .500 
Table 53

Results of Logistic Regression Analysis Examining the Relationship between Scores on Gen Ed Connect and Student Retention from Second to Third Year

\begin{tabular}{|c|c|c|c|c|c|c|}
\hline Predictor & B & $\mathrm{SE}$ & Wald's $\chi^{2}$ & df & $p$ & $e^{\beta}$ \\
\hline Constant & -2.559 & .181 & 199.662 & 1 & .000 & .077 \\
\hline Gen Ed Connect & -.026 & .037 & .500 & 1 & .480 & .974 \\
\hline African American & -.099 & .467 & .045 & 1 & .832 & .906 \\
\hline Asian American & .080 & .153 & .276 & 1 & .599 & 1.084 \\
\hline Hispanic & -.231 & .211 & 1.197 & 1 & .274 & .794 \\
\hline Multiple Ethnic & -.801 & .591 & 1.840 & 1 & .175 & .449 \\
\hline Native American & -.791 & .722 & 1.202 & 1 & .273 & .453 \\
\hline Financial Need & .138 & .111 & 1.550 & 1 & .213 & 1.148 \\
\hline Gender & .038 & .102 & .136 & 1 & .712 & 1.038 \\
\hline Private & -1.717 & .226 & 57.957 & 1 & .000 & .180 \\
\hline First Gen No BA & .104 & .105 & .977 & 1 & .323 & 1.109 \\
\hline Test & & & $\chi^{2}(d f)$ & & $p$ & \\
\hline $\begin{array}{l}\text { Overall model } \\
\text { evaluation }\end{array}$ & & & & & & \\
\hline Likelihood ratio test & & & $113.057(10)$ & & .000 & \\
\hline Goodness-of-fit & & & & & & \\
\hline Homer \& Lemeshow & & & $9.627(8)$ & & .292 & \\
\hline
\end{tabular}

Note. Cox and Snell $R^{2}=.014$. Nagelkerke $R^{2}=.038$

\section{Classification Table ${ }^{a}$}

\begin{tabular}{|c|c|c|c|c|}
\hline & & \multicolumn{3}{|c|}{ Predicted } \\
\hline & & \multicolumn{2}{|c|}{$\begin{array}{l}\text { Retained or Grad as of fall } \mathrm{Yr} \\
2\end{array}$} & \multirow{2}{*}{$\begin{array}{c}\text { Percentage } \\
\text { Correct } \\
\end{array}$} \\
\hline & Observed & yes & no & \\
\hline \multirow[t]{3}{*}{ Step 1} & Retained or Grad as of fall yes & 7688 & 0 & 100.0 \\
\hline & Yr 2 & 480 & 0 & .0 \\
\hline & Overall Percentage & & & 94.1 \\
\hline
\end{tabular}

a. The cut value is .500 
Table 54

Results of Logistic Regression Analysis Examining the Relationship between Scores on Degree Connect and Student Retention from Second to Third Year

\begin{tabular}{|c|c|c|c|c|c|c|}
\hline Predictor & B & $\mathrm{SE}$ & Wald's $\chi^{2}$ & df & $p$ & $e^{\beta}$ \\
\hline Constant & -2.717 & .175 & 240.434 & 1 & .000 & .066 \\
\hline Degree Connect & .012 & .035 & .117 & 1 & .732 & 1.012 \\
\hline African American & -.107 & .467 & .052 & 1 & .819 & .899 \\
\hline Asian American & .051 & .154 & .112 & 1 & .738 & 1.053 \\
\hline Hispanic & -.255 & .211 & 1.456 & 1 & .228 & .775 \\
\hline Multiple Ethnic & -.814 & .591 & 1.901 & 1 & .168 & .443 \\
\hline Native American & -.803 & .722 & 1.237 & 1 & .266 & .448 \\
\hline Financial Need & .144 & .110 & 1.699 & 1 & .192 & 1.155 \\
\hline Gender & .036 & .102 & .127 & 1 & .722 & 1.037 \\
\hline Private & -1.727 & .225 & 58.636 & 1 & .000 & .178 \\
\hline First Gen No BA & .105 & .105 & 1.008 & 1 & .315 & 1.111 \\
\hline Test & & & $\chi^{2}(d f)$ & & $p$ & \\
\hline $\begin{array}{l}\text { Overall model } \\
\text { evaluation }\end{array}$ & & & & & & \\
\hline Likelihood ratio test & & & $113.057(10)$ & & .000 & \\
\hline Goodness-of-fit & & & & & & \\
\hline Homer \& Lemeshow & & & $9.627(8)$ & & .292 & \\
\hline
\end{tabular}

Note. Cox and Snell $R^{2}=.014$. Nagelkerke $R^{2}=.038$

Classification Table ${ }^{a}$

\begin{tabular}{|c|c|c|c|c|}
\hline & & \multicolumn{3}{|c|}{ Predicted } \\
\hline & & \multicolumn{2}{|c|}{$\begin{array}{l}\text { Retained or Grad as of fall } \mathrm{Yr} \\
2\end{array}$} & \multirow{2}{*}{$\begin{array}{c}\text { Percentage } \\
\text { Correct } \\
\end{array}$} \\
\hline & Observed & yes & no & \\
\hline \multirow[t]{3}{*}{ Step 1} & Retained or Grad as of fall yes & 7688 & 0 & 100.0 \\
\hline & Yr 2 & 480 & 0 & .0 \\
\hline & Overall Percentage & & & 94.1 \\
\hline
\end{tabular}

a. The cut value is .500 
Table 55

Results of Logistic Regression Analysis Examining the Relationship between Scores on Out-of-Class Connect and Student Retention from Second to Third Year

\begin{tabular}{|c|c|c|c|c|c|c|}
\hline Predictor & B & $\mathrm{SE}$ & Wald's $\chi^{2}$ & df & $p$ & $e^{\beta}$ \\
\hline Constant & -2.413 & .171 & 199.369 & 1 & .000 & .090 \\
\hline Out-of-Class Connect & -.057 & .034 & 2.806 & 1 & .094 & .944 \\
\hline African American & -.085 & .467 & .033 & 1 & .855 & .918 \\
\hline Asian American & .068 & .154 & .198 & 1 & .657 & 1.071 \\
\hline Hispanic & -.252 & .215 & 1.381 & 1 & .240 & .777 \\
\hline Multiple Ethnic & -.807 & .591 & 1.864 & 1 & .172 & .446 \\
\hline Native American & -.795 & .722 & 1.213 & 1 & .271 & .451 \\
\hline Financial Need & .158 & .111 & 2.040 & 1 & .153 & 1.171 \\
\hline Gender & .030 & .101 & .090 & 1 & .765 & 1.031 \\
\hline Private & -1.717 & .226 & 57.990 & 1 & .000 & .180 \\
\hline First Gen No BA & .104 & .105 & .983 & 1 & .321 & 1.110 \\
\hline Test & & & $\chi^{2}(d f)$ & & $p$ & \\
\hline $\begin{array}{l}\text { Overall model } \\
\text { evaluation }\end{array}$ & & & & & & \\
\hline Likelihood ratio test & & & $113.057(10)$ & & .000 & \\
\hline Goodness-of-fit & & & & & & \\
\hline Homer \& Lemeshow & & & $9.627(8)$ & & .292 & \\
\hline
\end{tabular}

Note. Cox and Snell $R^{2}=.014$. Nagelkerke $R^{2}=.038$

Classification Table ${ }^{a}$

\begin{tabular}{|c|c|c|c|c|}
\hline & & \multicolumn{3}{|c|}{ Predicted } \\
\hline & & \multicolumn{2}{|c|}{$\begin{array}{l}\text { Retained or Grad as of fall } \mathrm{Yr} \\
2\end{array}$} & \multirow{2}{*}{$\begin{array}{c}\text { Percentage } \\
\text { Correct } \\
\end{array}$} \\
\hline & Observed & yes & no & \\
\hline \multirow[t]{3}{*}{ Step 1} & Retained or Grad as of fall yes & 7688 & 0 & 100.0 \\
\hline & Yr 2 & 480 & 0 & .0 \\
\hline & Overall Percentage & & & 94.1 \\
\hline
\end{tabular}

a. The cut value is .500 
Table 56

Results of Logistic Regression Analysis Examining the Relationship between Scores on Referral Academic and Student Retention from Second to Third Year

\begin{tabular}{|c|c|c|c|c|c|c|}
\hline Predictor & B & SE & Wald's $\chi^{2}$ & df & $p$ & $e^{\beta}$ \\
\hline Constant & -2.866 & .175 & 267.413 & 1 & .000 & .057 \\
\hline Referral Academic & .050 & .036 & 1.945 & 1 & .163 & 1.051 \\
\hline African American & -.139 & .467 & .089 & 1 & .766 & .870 \\
\hline Asian American & .077 & .153 & .256 & 1 & .613 & 1.080 \\
\hline Hispanic & -.330 & .218 & 2.279 & 1 & .131 & .719 \\
\hline Multiple Ethnic & -.831 & .591 & 1.976 & 1 & .160 & .436 \\
\hline Native American & -.827 & .722 & 1.312 & 1 & .252 & .438 \\
\hline Financial Need & .166 & .111 & 2.262 & 1 & .133 & 1.181 \\
\hline Gender & .018 & .102 & .030 & 1 & .863 & 1.018 \\
\hline Private & -1.728 & .226 & 58.717 & 1 & .000 & .178 \\
\hline First Gen No BA & .079 & .105 & .568 & 1 & .451 & 1.083 \\
\hline Test & & & $\chi^{2}(d f)$ & & $p$ & \\
\hline $\begin{array}{l}\text { Overall model } \\
\text { evaluation }\end{array}$ & & & & & & \\
\hline Likelihood ratio test & & & $113.057(10)$ & & .000 & \\
\hline Goodness-of-fit & & & & & & \\
\hline Homer \& Lemeshow & & & $9.627(8)$ & & .292 & \\
\hline
\end{tabular}

Note. Cox and Snell $R^{2}=.014$. Nagelkerke $R^{2}=.038$

\section{Classification Table ${ }^{a}$}

\begin{tabular}{|c|c|c|c|c|}
\hline & & \multicolumn{3}{|c|}{ Predicted } \\
\hline & & \multicolumn{2}{|c|}{$\begin{array}{l}\text { Retained or Grad as of fall } \mathrm{Yr} \\
2\end{array}$} & \multirow{2}{*}{$\begin{array}{c}\text { Percentage } \\
\text { Correct } \\
\end{array}$} \\
\hline & Observed & yes & no & \\
\hline \multirow[t]{3}{*}{ Step 1} & Retained or Grad as of fall yes & 7688 & 0 & 100.0 \\
\hline & Yr 2 & 480 & 0 & .0 \\
\hline & Overall Percentage & & & 94.1 \\
\hline
\end{tabular}

a. The cut value is .500 
Table 57

Results of Logistic Regression Analysis Examining the Relationship between Scores on Referral Non-Academic and Student Retention from Second to Third Year

\begin{tabular}{|c|c|c|c|c|c|c|}
\hline Predictor & B & SE & Wald's $\chi^{2}$ & df & $p$ & $e^{\beta}$ \\
\hline Constant & -2.912 & .155 & 350.627 & 1 & .000 & .054 \\
\hline $\begin{array}{l}\text { Referral Non- } \\
\text { Academic }\end{array}$ & .070 & .032 & 4.737 & 1 & .030 & 1.073 \\
\hline African American & -.142 & .467 & .092 & 1 & .762 & .868 \\
\hline Asian American & .055 & .154 & .129 & 1 & .719 & 1.057 \\
\hline Hispanic & -.294 & .215 & 1.875 & 1 & .171 & .745 \\
\hline Multiple Ethnic & -.828 & .591 & 1.965 & 1 & .161 & .437 \\
\hline Native American & -.843 & .722 & 1.363 & 1 & .243 & .430 \\
\hline Financial Need & .133 & .111 & 1.425 & 1 & .233 & 1.142 \\
\hline Gender & -.010 & .102 & .010 & 1 & .920 & .990 \\
\hline Private & -1.736 & .226 & 59.162 & 1 & .000 & .176 \\
\hline First Gen No BA & .090 & .105 & .733 & 1 & .392 & 1.094 \\
\hline \multirow{2}{*}{$\begin{array}{l}\text { Test } \\
\text { Overall model } \\
\text { evaluation }\end{array}$} & & & $\chi^{2}(d f)$ & & $p$ & \\
\hline & & & & & & \\
\hline Likelihood ratio test & & & $113.057(10)$ & & .000 & \\
\hline \multicolumn{7}{|l|}{ Goodness-of-fit } \\
\hline Homer \& Lemeshow & & & $9.627(8)$ & & .292 & \\
\hline
\end{tabular}

Note. Cox and Snell $R^{2}=.014$. Nagelkerke $R^{2}=.038$

\section{Classification Table ${ }^{a}$}

\begin{tabular}{|c|c|c|c|c|}
\hline & & \multicolumn{3}{|c|}{ Predicted } \\
\hline \multirow{2}{*}{\multicolumn{2}{|c|}{ Observed }} & \multicolumn{2}{|c|}{$\begin{array}{l}\text { Retained or Grad as of fall } \mathrm{Yr} \\
2\end{array}$} & \multirow{2}{*}{$\begin{array}{c}\text { Percentage } \\
\text { Correct }\end{array}$} \\
\hline & & yes & no & \\
\hline \multirow[t]{3}{*}{ Step 1} & Retained or Grad as of fall yes & 7688 & 0 & 100.0 \\
\hline & Yr 2 & 480 & 0 & .0 \\
\hline & Overall Percentage & & & 94.1 \\
\hline
\end{tabular}

a. The cut value is .500 
Table 58

Results of Logistic Regression Analysis Examining the Relationship between Scores on How Things Work- and Student Retention from Second to Third Year

\begin{tabular}{|c|c|c|c|c|c|c|}
\hline Predictor & B & $\mathrm{SE}$ & Wald's $\chi^{2}$ & $\mathrm{df}$ & $p$ & $e^{\beta}$ \\
\hline Constant & -2.214 & .191 & 134.281 & 1 & .000 & .109 \\
\hline How Things Work & -.101 & .038 & 7.045 & 1 & .008 & .904 \\
\hline African American & -.070 & .467 & .022 & 1 & .882 & .933 \\
\hline Asian American & .093 & .153 & .374 & 1 & .541 & 1.098 \\
\hline Hispanic & -.216 & .215 & 1.006 & 1 & .316 & .806 \\
\hline Multiple Ethnic & -.802 & .591 & 1.842 & 1 & .175 & .448 \\
\hline Native American & -1.482 & 1.010 & 2.152 & 1 & .142 & .227 \\
\hline Financial Need & .158 & .112 & 1.994 & 1 & .158 & 1.171 \\
\hline Gender & .056 & .103 & .296 & 1 & .586 & 1.057 \\
\hline Private & -1.702 & .226 & 56.920 & 1 & .000 & .182 \\
\hline First Gen No BA & .103 & .106 & .942 & 1 & .332 & 1.108 \\
\hline \multirow{2}{*}{$\begin{array}{l}\text { Test } \\
\text { Overall model } \\
\text { evaluation }\end{array}$} & & & $\chi^{2}(d f)$ & & $p$ & \\
\hline & & & & & & \\
\hline Likelihood ratio test & & & $113.057(10)$ & & .000 & \\
\hline \multicolumn{7}{|l|}{ Goodness-of-fit } \\
\hline Homer \& Lemeshow & & & $9.627(8)$ & & .292 & \\
\hline
\end{tabular}

Note. Cox and Snell $R^{2}=.014$. Nagelkerke $R^{2}=.038$

\section{Classification Table ${ }^{a}$}

\begin{tabular}{|c|c|c|c|c|}
\hline & & \multicolumn{3}{|c|}{ Predicted } \\
\hline & & \multicolumn{2}{|c|}{$\begin{array}{l}\text { Retained or Grad as of fall } \mathrm{Yr} \\
2\end{array}$} & \multirow{2}{*}{$\begin{array}{c}\text { Percentage } \\
\text { Correct } \\
\end{array}$} \\
\hline & Observed & yes & no & \\
\hline \multirow[t]{3}{*}{ Step 1} & Retained or Grad as of fall yes & 7688 & 0 & 100.0 \\
\hline & Yr 2 & 480 & 0 & .0 \\
\hline & Overall Percentage & & & 94.1 \\
\hline
\end{tabular}

a. The cut value is .500 
Table 59

Results of Logistic Regression Analysis Examining the Relationship between Scores on Accurate Information and Student Retention from Second to Third Year

\begin{tabular}{|c|c|c|c|c|c|c|}
\hline Predictor & B & $\mathrm{SE}$ & Wald's $\chi^{2}$ & $\mathrm{df}$ & $p$ & $e^{\beta}$ \\
\hline Constant & -2.501 & .311 & 64.674 & 1 & .000 & .082 \\
\hline Accurate Information & -.033 & .056 & .355 & 1 & .551 & .967 \\
\hline African American & -.101 & .467 & .047 & 1 & .828 & .904 \\
\hline Asian American & .077 & .154 & .248 & 1 & .619 & 1.080 \\
\hline Hispanic & -.286 & .218 & 1.712 & 1 & .191 & .752 \\
\hline Multiple Ethnic & -.798 & .591 & 1.823 & 1 & .177 & .450 \\
\hline Native American & -1.486 & 1.010 & 2.163 & 1 & .141 & .226 \\
\hline Financial Need & .150 & .112 & 1.803 & 1 & .179 & 1.162 \\
\hline Gender & .038 & .103 & .136 & 1 & .712 & 1.039 \\
\hline Private & -1.699 & .226 & 56.629 & 1 & .000 & .183 \\
\hline First Gen No BA & .099 & .106 & .874 & 1 & .350 & 1.104 \\
\hline Test & & & $\chi^{2}(d f)$ & & $p$ & \\
\hline $\begin{array}{l}\text { Overall model } \\
\text { evaluation }\end{array}$ & & & & & & \\
\hline Likelihood ratio test & & & $113.057(10)$ & & .000 & \\
\hline Goodness-of-fit & & & & & & \\
\hline Homer \& Lemeshow & & & $9.627(8)$ & & .292 & \\
\hline
\end{tabular}

Note. Cox and Snell $R^{2}=.014$. Nagelkerke $R^{2}=.038$

Classification Table ${ }^{a}$

\begin{tabular}{|c|c|c|c|c|}
\hline & & \multicolumn{3}{|c|}{ Predicted } \\
\hline & & \multicolumn{2}{|c|}{$\begin{array}{l}\text { Retained or Grad as of fall } \mathrm{Yr} \\
2\end{array}$} & \multirow{2}{*}{$\begin{array}{c}\text { Percentage } \\
\text { Correct } \\
\end{array}$} \\
\hline & Observed & yes & no & \\
\hline \multirow[t]{3}{*}{ Step 1} & Retained or Grad as of fall yes & 7688 & 0 & 100.0 \\
\hline & Yr 2 & 480 & 0 & .0 \\
\hline & Overall Percentage & & & 94.1 \\
\hline
\end{tabular}

a. The cut value is .500 
Table 60

Results of Logistic Regression Analysis Examining the Relationship between Scores on Skills Abilities Interests and Student Retention from Second to Third Year

\begin{tabular}{|c|c|c|c|c|c|c|}
\hline Predictor & $\mathrm{B}$ & SE & Wald's $\chi^{2}$ & $\mathrm{df}$ & $p$ & $e^{\beta}$ \\
\hline Constant & -2.517 & .223 & 127.488 & 1 & .000 & .081 \\
\hline $\begin{array}{l}\text { Skills Abilities } \\
\text { Interests }\end{array}$ & -.034 & .043 & .612 & 1 & .434 & .967 \\
\hline African American & -.095 & .467 & .041 & 1 & .839 & .910 \\
\hline Asian American & .090 & .154 & .339 & 1 & .560 & 1.094 \\
\hline Hispanic & -.264 & .219 & 1.464 & 1 & .226 & .768 \\
\hline Multiple Ethnic & -.795 & .591 & 1.812 & 1 & .178 & .451 \\
\hline Native American & -1.486 & 1.010 & 2.164 & 1 & .141 & .226 \\
\hline Financial Need & .149 & .112 & 1.764 & 1 & .184 & 1.161 \\
\hline Gender & .043 & .103 & .174 & 1 & .676 & 1.044 \\
\hline Private & -1.698 & .226 & 56.565 & 1 & .000 & .183 \\
\hline First Gen No BA & .093 & .106 & .769 & 1 & .381 & 1.098 \\
\hline \multirow{2}{*}{$\begin{array}{l}\text { Test } \\
\text { Overall model } \\
\text { evaluation }\end{array}$} & & & $\chi^{2}(d f)$ & & $p$ & \\
\hline & & & & & & \\
\hline Likelihood ratio test & & & $113.057(10)$ & & .000 & \\
\hline \multicolumn{7}{|l|}{ Goodness-of-fit } \\
\hline Homer \& Lemeshow & & & $9.627(8)$ & & .292 & \\
\hline
\end{tabular}

Note. Cox and Snell $R^{2}=.014$. Nagelkerke $R^{2}=.038$

\section{Classification Table ${ }^{a}$}

\begin{tabular}{|c|c|c|c|c|}
\hline & & \multicolumn{3}{|c|}{ Predicted } \\
\hline \multirow{2}{*}{\multicolumn{2}{|c|}{ Observed }} & \multicolumn{2}{|c|}{$\begin{array}{l}\text { Retained or Grad as of fall } \mathrm{Yr} \\
2\end{array}$} & \multirow{2}{*}{$\begin{array}{l}\text { Percentage } \\
\text { Correct }\end{array}$} \\
\hline & & yes & no & \\
\hline \multirow[t]{3}{*}{ Step 1} & Retained or Grad as of fall yes & 7688 & 0 & 100.0 \\
\hline & no & 480 & 0 & .0 \\
\hline & Overall Percentage & & & 94.1 \\
\hline
\end{tabular}

a. The cut value is .500 
Table 61

Results of Logistic Regression Analysis Examining the Relationship between Scores on Know as Individual and Student Retention from Second to Third Year

\begin{tabular}{|c|c|c|c|c|c|c|}
\hline Predictor & B & $\mathrm{SE}$ & Wald's $\chi^{2}$ & $\mathrm{df}$ & $p$ & $e^{\beta}$ \\
\hline Constant & -2.417 & .200 & 145.686 & 1 & .000 & .089 \\
\hline Know as Individual & -.060 & .039 & 2.373 & 1 & .123 & .941 \\
\hline African American & -.088 & .467 & .036 & 1 & .850 & .916 \\
\hline Asian American & .087 & .154 & .318 & 1 & .573 & 1.091 \\
\hline Hispanic & -.265 & .219 & 1.466 & 1 & .226 & .767 \\
\hline Multiple Ethnic & -.804 & .591 & 1.851 & 1 & .174 & .448 \\
\hline Native American & -1.472 & 1.011 & 2.121 & 1 & .145 & .230 \\
\hline Financial Need & .166 & .112 & 2.212 & 1 & .137 & 1.181 \\
\hline Gender & .074 & .104 & .506 & 1 & .477 & 1.077 \\
\hline Private & -1.732 & .231 & 56.071 & 1 & .000 & .177 \\
\hline First Gen No BA & .099 & .106 & .864 & 1 & .353 & 1.104 \\
\hline Test & & & $\chi^{2}(d f)$ & & $p$ & \\
\hline $\begin{array}{l}\text { Overall model } \\
\text { evaluation }\end{array}$ & & & & & & \\
\hline Likelihood ratio test & & & $113.057(10)$ & & .000 & \\
\hline Goodness-of-fit & & & & & & \\
\hline Homer \& Lemeshow & & & $9.627(8)$ & & .292 & \\
\hline
\end{tabular}

Note. Cox and Snell $R^{2}=.014$. Nagelkerke $R^{2}=.038$

\section{Classification Table ${ }^{a}$}

\begin{tabular}{|c|c|c|c|c|}
\hline & & \multicolumn{3}{|c|}{ Predicted } \\
\hline & & \multicolumn{2}{|c|}{$\begin{array}{l}\text { Retained or Grad as of fall } \mathrm{Yr} \\
2\end{array}$} & \multirow{2}{*}{$\begin{array}{c}\text { Percentage } \\
\text { Correct } \\
\end{array}$} \\
\hline & Observed & yes & no & \\
\hline \multirow[t]{3}{*}{ Step 1} & Retained or Grad as of fall yes & 7688 & 0 & 100.0 \\
\hline & Yr 2 & 480 & 0 & .0 \\
\hline & Overall Percentage & & & 94.1 \\
\hline
\end{tabular}

a. The cut value is .500 
Table 62

Results of Logistic Regression Analysis Examining the Relationship between Scores on Shared Responsibility and Student Retention from Second to Third Year

\begin{tabular}{|c|c|c|c|c|c|c|}
\hline Predictor & B & $\mathrm{SE}$ & Wald's $\chi^{2}$ & $\mathrm{df}$ & $p$ & $e^{\beta}$ \\
\hline Constant & -2.619 & .197 & 176.260 & 1 & .000 & .073 \\
\hline Shared Responsibility & -.014 & .039 & .124 & 1 & .725 & .986 \\
\hline African American & -.096 & .467 & .042 & 1 & .837 & .908 \\
\hline Asian American & .078 & .154 & .255 & 1 & .614 & 1.081 \\
\hline Hispanic & -.319 & .223 & 2.060 & 1 & .151 & .727 \\
\hline Multiple Ethnic & -.799 & .591 & 1.829 & 1 & .176 & .450 \\
\hline Native American & -1.500 & 1.010 & 2.204 & 1 & .138 & .223 \\
\hline Financial Need & .170 & .112 & 2.310 & 1 & .129 & 1.185 \\
\hline Gender & .049 & .103 & .229 & 1 & .632 & 1.051 \\
\hline Private & -1.704 & .226 & 56.968 & 1 & .000 & .182 \\
\hline First Gen No BA & .097 & .106 & .831 & 1 & .362 & 1.102 \\
\hline Test & & & $\chi^{2}(d f)$ & & $p$ & \\
\hline $\begin{array}{l}\text { Overall model } \\
\text { evaluation }\end{array}$ & & & & & & \\
\hline Likelihood ratio test & & & $113.057(10)$ & & .000 & \\
\hline Goodness-of-fit & & & & & & \\
\hline Homer \& Lemeshow & & & $9.627(8)$ & & .292 & \\
\hline
\end{tabular}

Note. Cox and Snell $R^{2}=.014$. Nagelkerke $R^{2}=.038$

\section{Classification Table ${ }^{a}$}

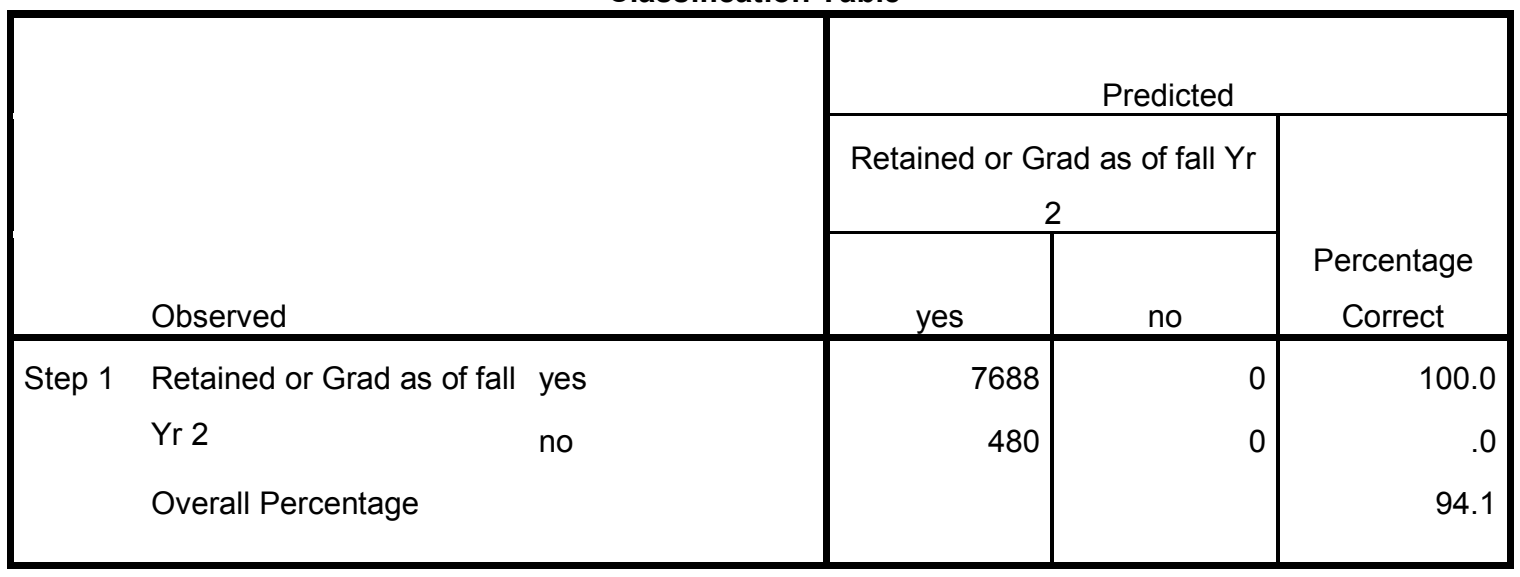

a. The cut value is .500 
Satisfaction Ratings

Table 63

Results of Logistic Regression Analysis Examining the Relationship between Scores on Overall Connect and Student Retention from Second to Third Year

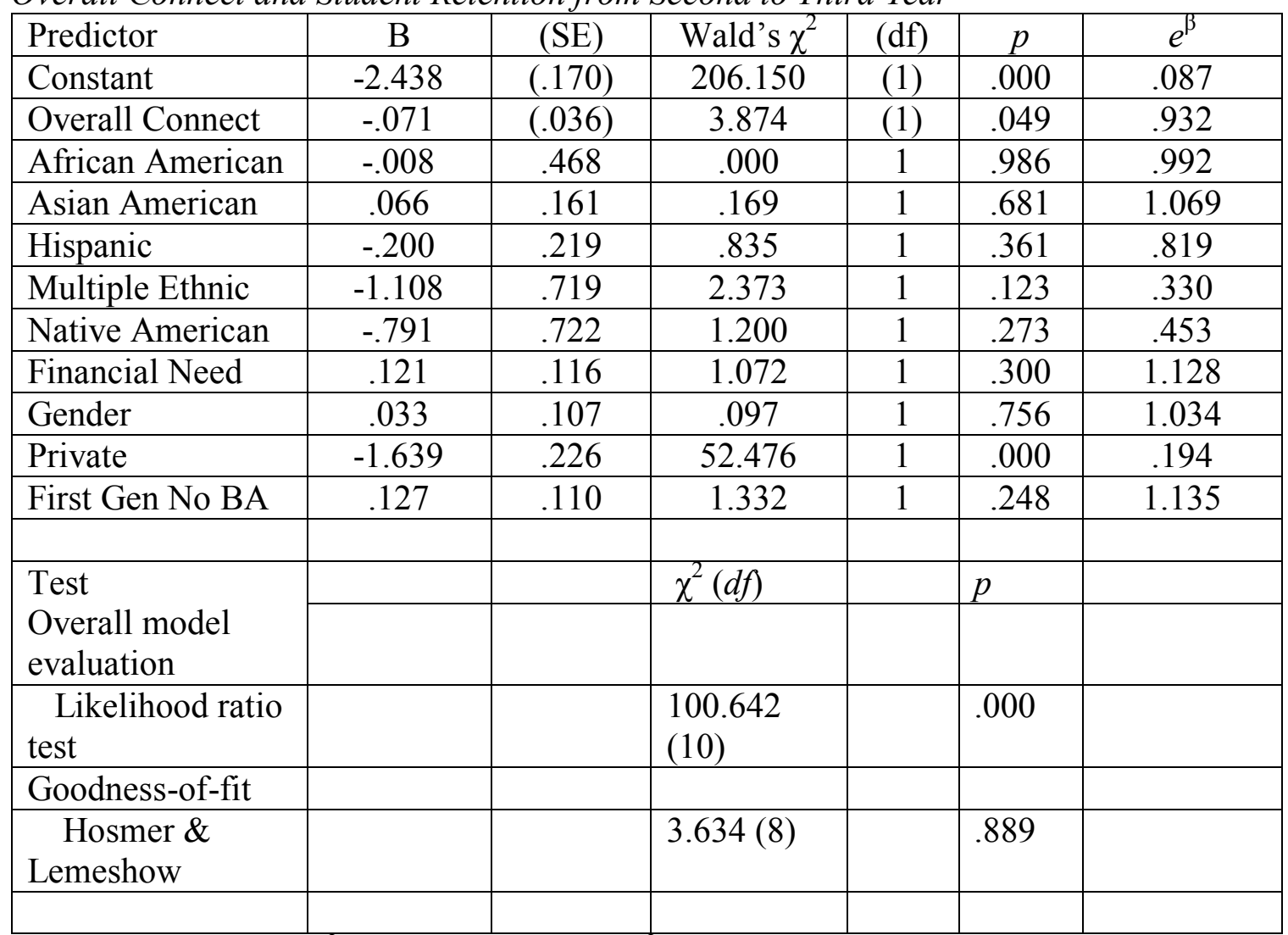

Note. Cox and Snell $R^{2}=.013$. Nagelkerke $R^{2}=.037$

\section{Classification Table ${ }^{\mathrm{a}}$}

\begin{tabular}{|c|c|c|c|c|}
\hline & & \multicolumn{3}{|c|}{ Predicted } \\
\hline & & \multicolumn{2}{|c|}{$\begin{array}{l}\text { Retained or Grad as of fall } \mathrm{Yr} \\
2 \\
\end{array}$} & \multirow{2}{*}{$\begin{array}{l}\text { Percentage } \\
\text { Correct }\end{array}$} \\
\hline & Observed & yes & no & \\
\hline \multirow[t]{3}{*}{ Step 1} & Retained or Grad as of fall yes & 7216 & 0 & 100.0 \\
\hline & Yr 2 & 429 & 0 & .0 \\
\hline & Overall Percentage & & & 94.4 \\
\hline
\end{tabular}

a. The cut value is .500 
Table 64

Results of Logistic Regression Analysis Examining the Relationship between Scores on Major Connect and Student Retention from Second to Third Year

\begin{tabular}{|c|c|c|c|c|c|c|}
\hline Predictor & $\mathrm{B}$ & (SE) & Wald's $\chi^{2}$ & (df) & $p$ & $e^{\beta}$ \\
\hline Constant & -2.554 & .174 & 215.257 & 1 & .000 & .078 \\
\hline Major Connect & -.043 & .037 & 1.369 & 1 & .242 & .958 \\
\hline African American & -.012 & .468 & .001 & 1 & .979 & .988 \\
\hline Asian American & .064 & .161 & .158 & 1 & .691 & 1.066 \\
\hline Hispanic & -.204 & .219 & .864 & 1 & .353 & .816 \\
\hline Multiple Ethnic & -1.109 & .719 & 2.380 & 1 & .123 & .330 \\
\hline Native American & -.760 & .722 & 1.109 & 1 & .292 & .467 \\
\hline Financial Need & .108 & .117 & .855 & 1 & .355 & 1.114 \\
\hline Gender & .034 & .107 & .103 & 1 & .748 & 1.035 \\
\hline Private & -1.635 & .226 & 52.208 & 1 & .000 & .195 \\
\hline First Gen No BA & .138 & .110 & 1.578 & 1 & .209 & 1.149 \\
\hline \multirow{2}{*}{$\begin{array}{l}\text { Test } \\
\text { Overall model } \\
\text { evaluation }\end{array}$} & & & $\chi^{2}(d f)$ & & $p$ & \\
\hline & & & & & & \\
\hline $\begin{array}{l}\text { Likelihood ratio } \\
\text { test }\end{array}$ & & & $97.480(10)$ & & .000 & \\
\hline \multicolumn{7}{|l|}{ Goodness-of-fit } \\
\hline $\begin{array}{l}\text { Hosmer \& } \\
\text { Lemeshow }\end{array}$ & & & $8.762(8)$ & & .363 & \\
\hline & & & & & & \\
\hline
\end{tabular}

Note. Cox and Snell $R^{2}=.013$. Nagelkerke $R^{2}=.036$.

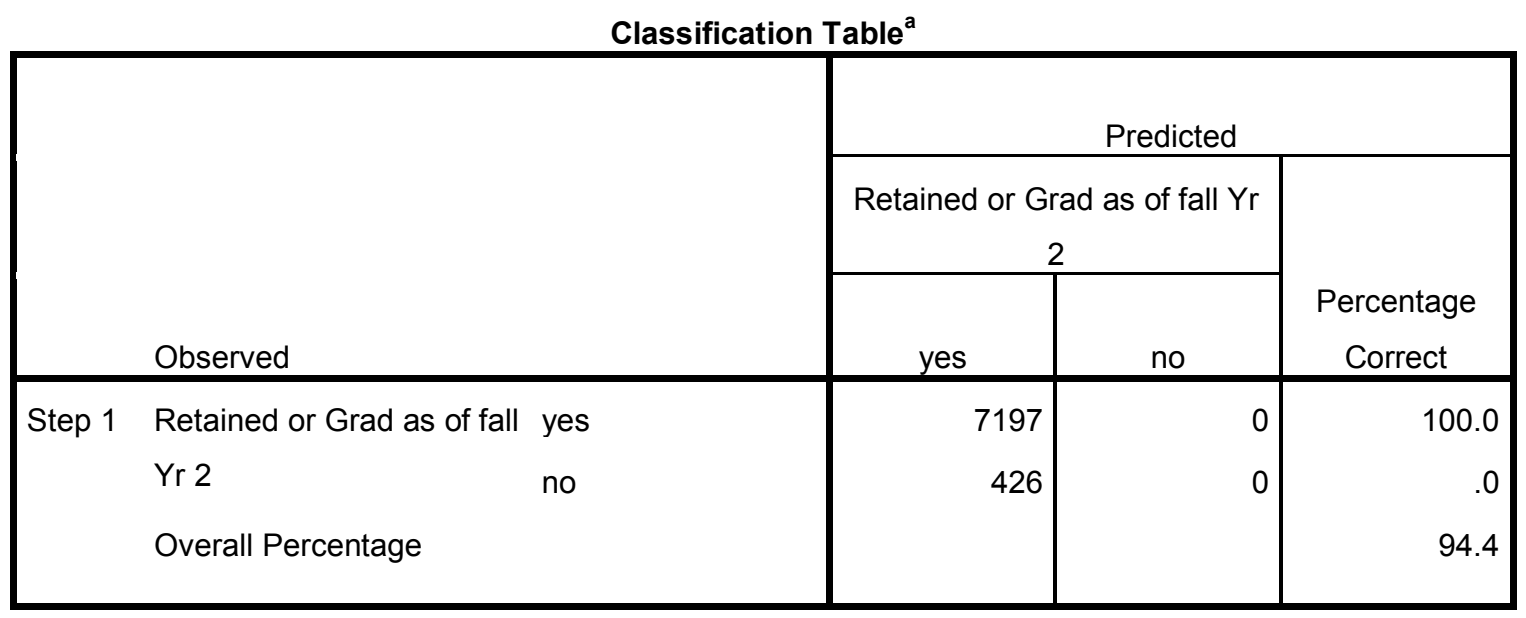

a. The cut value is .500 
Table 65

Results of Logistic Regression Analysis Examining the Relationship between Satisfaction Scores on Gen Ed Connect and Student Retention from Second to Third Year

\begin{tabular}{|c|c|c|c|c|c|c|}
\hline Predictor & $\mathrm{B}$ & $(\mathrm{SE})$ & Wald's $\chi^{2}$ & (df) & $p$ & $e^{\beta}$ \\
\hline Constant & -2.596 & .168 & 240.011 & 1 & .000 & .075 \\
\hline Gen Ed Connect & -.030 & .036 & .685 & 1 & .408 & .970 \\
\hline African American & -.010 & .468 & .000 & 1 & .983 & .990 \\
\hline Asian American & .047 & .163 & .083 & 1 & .773 & 1.048 \\
\hline Hispanic & -.184 & .219 & .707 & 1 & .401 & .832 \\
\hline Multiple Ethnic & -1.091 & .719 & 2.302 & 1 & .129 & .336 \\
\hline Native American & -.753 & .722 & 1.087 & 1 & .297 & .471 \\
\hline Financial Need & .108 & .118 & .838 & 1 & .360 & 1.114 \\
\hline Gender & .027 & .107 & .065 & 1 & .799 & 1.028 \\
\hline Private & -1.634 & .227 & 51.998 & 1 & .000 & .195 \\
\hline First Gen No BA & 118 & .111 & 1.133 & 1 & .287 & 1.126 \\
\hline \multirow{2}{*}{$\begin{array}{l}\text { Test } \\
\text { Overall model } \\
\text { evaluation }\end{array}$} & & & $\chi^{2}(d f)$ & & $p$ & \\
\hline & & & & & & \\
\hline $\begin{array}{l}\text { Likelihood ratio } \\
\text { test }\end{array}$ & & & $95.344(10)$ & & .000 & \\
\hline \multicolumn{7}{|l|}{ Goodness-of-fit } \\
\hline $\begin{array}{l}\text { Hosmer \& } \\
\text { Lemeshow }\end{array}$ & & & $13.592(8)$ & & .083 & \\
\hline & & & & & & \\
\hline
\end{tabular}

Note. Cox and Snell $R^{2}=.013$. Nagelkerke $R^{2}=.036$.

\section{Classification Table ${ }^{a}$}

\begin{tabular}{|c|c|c|c|c|}
\hline & & \multicolumn{3}{|c|}{ Predicted } \\
\hline \multirow{2}{*}{\multicolumn{2}{|c|}{ Observed }} & \multicolumn{2}{|c|}{$\begin{array}{l}\text { Retained or Grad as of fall } \mathrm{Yr} \\
2\end{array}$} & \multirow{2}{*}{$\begin{array}{l}\text { Percentage } \\
\text { Correct }\end{array}$} \\
\hline & & yes & no & \\
\hline Step 1 & Retained or Grad as of fall yes & 7122 & 0 & 100.0 \\
\hline & Yr 2 & 421 & 0 & .0 \\
\hline & Overall Percentage & & & 94.4 \\
\hline
\end{tabular}

a. The cut value is .500 
Table 66

Results of Logistic Regression Analysis Examining the Relationship between Satisfaction Scores on Degree Connect and Student Retention from Second to Third Year

\begin{tabular}{|c|c|c|c|c|c|c|}
\hline Predictor & $\mathrm{B}$ & (SE) & Wald's $\chi^{2}$ & $(\mathrm{df})$ & $p$ & $e^{\beta}$ \\
\hline Constant & -2.554 & .165 & 238.505 & 1 & .000 & .078 \\
\hline Degree Connect & -.042 & .035 & 1.418 & 1 & .234 & .959 \\
\hline African American & -.013 & .468 & .001 & 1 & .978 & .987 \\
\hline Asian American & .017 & .164 & .010 & 1 & .920 & 1.017 \\
\hline Hispanic & -.210 & .219 & .919 & 1 & .338 & .810 \\
\hline Multiple Ethnic & -1.102 & .719 & 2.348 & 1 & .125 & .332 \\
\hline Native American & -.753 & .722 & 1.087 & 1 & .297 & .471 \\
\hline Financial Need & .121 & .117 & 1.066 & 1 & .302 & 1.129 \\
\hline Gender & .046 & .107 & .180 & 1 & .671 & 1.047 \\
\hline Private & -1.637 & .226 & 52.253 & 1 & .000 & .195 \\
\hline First Gen No BA & .128 & .111 & 1.343 & 1 & .246 & 1.137 \\
\hline \multirow{2}{*}{$\begin{array}{l}\text { Test } \\
\text { Overall model } \\
\text { evaluation }\end{array}$} & & & $\chi^{2}(d f)$ & & $p$ & \\
\hline & & & & & & \\
\hline $\begin{array}{l}\text { Likelihood ratio } \\
\text { test }\end{array}$ & & & $97.526(10)$ & & .000 & \\
\hline \multicolumn{7}{|l|}{ Goodness-of-fit } \\
\hline $\begin{array}{l}\text { Hosmer \& } \\
\text { Lemeshow }\end{array}$ & & & $13.929(8)$ & & .084 & \\
\hline & & & & & & \\
\hline
\end{tabular}

Note. Cox and Snell $R^{2}=.013$. Nagelkerke $R^{2}=.037$.

Classification Table ${ }^{a}$

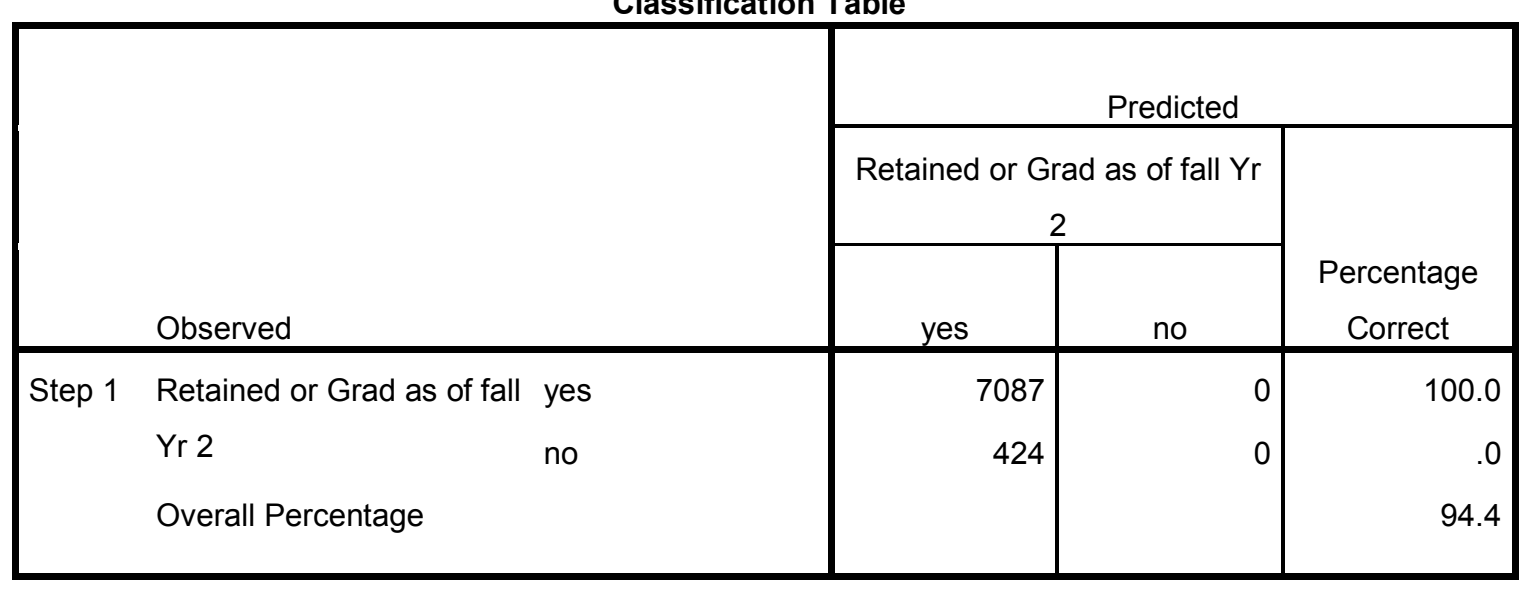

a. The cut value is .500 
Table 67

Results of Logistic Regression Analysis Examining the Relationship between Satisfaction Scores on Out-of-Class Connect and Student Retention from Second to Third Year

\begin{tabular}{|c|c|c|c|c|c|c|}
\hline Predictor & $\mathrm{B}$ & (SE) & Wald's $\chi^{2}$ & (df) & $p$ & $e^{\beta}$ \\
\hline Constant & -2.636 & .152 & 299.527 & 1 & .000 & .072 \\
\hline $\begin{array}{l}\text { Out-of-Class } \\
\text { Connect }\end{array}$ & -.019 & .035 & .305 & 1 & .581 & .981 \\
\hline African American & -.014 & .468 & .001 & 1 & .976 & .986 \\
\hline Asian American & .024 & .165 & .021 & 1 & .886 & 1.024 \\
\hline Hispanic & -.226 & .223 & 1.026 & 1 & .311 & .797 \\
\hline Multiple Ethnic & -1.106 & .719 & 2.364 & 1 & .124 & .331 \\
\hline Native American & -.753 & .722 & 1.088 & 1 & .297 & .471 \\
\hline Financial Need & .124 & .118 & 1.104 & 1 & .293 & 1.131 \\
\hline Gender & .009 & .107 & .007 & 1 & .934 & 1.009 \\
\hline Private & -1.640 & .226 & 52.532 & 1 & .000 & .194 \\
\hline First Gen No BA & .136 & .111 & 1.485 & 1 & .223 & 1.145 \\
\hline \multirow{2}{*}{$\begin{array}{l}\text { Test } \\
\text { Overall model } \\
\text { evaluation }\end{array}$} & & & $\chi^{2}(d f)$ & & $p$ & \\
\hline & & & & & & \\
\hline $\begin{array}{l}\text { Likelihood ratio } \\
\text { test }\end{array}$ & & & $96.128(10)$ & & .000 & \\
\hline \multicolumn{7}{|l|}{ Goodness-of-fit } \\
\hline $\begin{array}{l}\text { Hosmer \& } \\
\text { Lemeshow }\end{array}$ & & & $4.213(8)$ & & .837 & \\
\hline & & & & & & \\
\hline
\end{tabular}

Note. Cox and Snell $R^{2}=.013$. Nagelkerke $R^{2}=.036$.

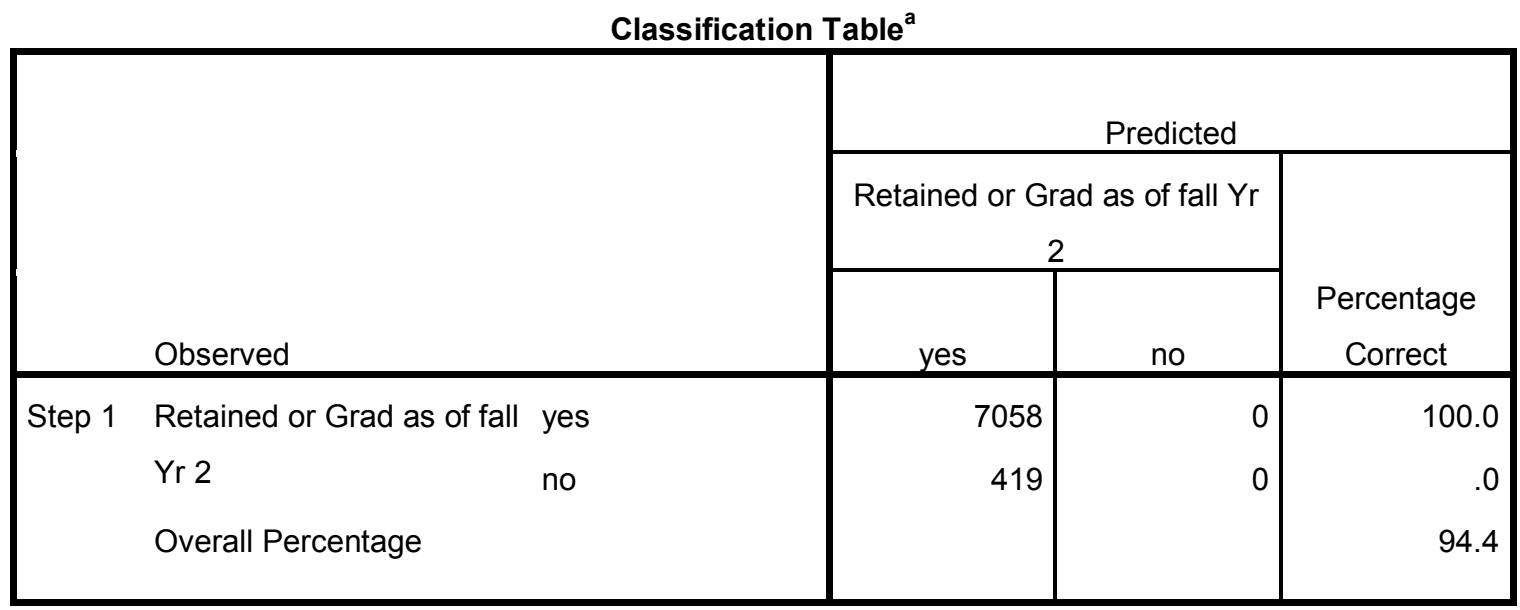

a. The cut value is .500 
Table 68

Results of Logistic Regression Analysis Examining the Relationship between Satisfaction Scores on Referral Academic and Student Retention from Second to Third Year

\begin{tabular}{|c|c|c|c|c|c|c|}
\hline Predictor & $\mathrm{B}$ & (SE) & Wald's $\chi^{2}$ & (df) & $p$ & $e^{\beta}$ \\
\hline Constant & -2.616 & .174 & 225.592 & 1 & .000 & .073 \\
\hline $\begin{array}{l}\text { Referral } \\
\text { Academic } \\
\text { Connect }\end{array}$ & -.020 & .037 & .280 & 1 & .597 & .980 \\
\hline African American & -.036 & .468 & .006 & 1 & .938 & .964 \\
\hline Asian American & .047 & .163 & .083 & 1 & .773 & 1.048 \\
\hline Hispanic & -.267 & .228 & 1.372 & 1 & .241 & .766 \\
\hline Multiple Ethnic & -1.106 & .719 & 2.364 & 1 & .124 & .331 \\
\hline Native American & -.773 & .722 & 1.145 & 1 & .285 & .462 \\
\hline Financial Need & .124 & .118 & 1.097 & 1 & .295 & 1.131 \\
\hline Gender & .024 & .108 & .051 & 1 & .822 & 1.025 \\
\hline Private & -1.642 & .226 & 52.550 & 1 & .000 & .194 \\
\hline First Gen No BA & .109 & .112 & .953 & 1 & .329 & 1.115 \\
\hline \multirow{2}{*}{$\begin{array}{l}\text { Test } \\
\text { Overall model } \\
\text { evaluation }\end{array}$} & & & $\chi^{2}(d f)$ & & $p$ & \\
\hline & & & & & & \\
\hline $\begin{array}{l}\text { Likelihood ratio } \\
\text { test }\end{array}$ & & & $95.830(10)$ & & .000 & \\
\hline \multicolumn{7}{|l|}{ Goodness-of-fit } \\
\hline $\begin{array}{l}\text { Hosmer \& } \\
\text { Lemeshow }\end{array}$ & & & $13.778(8)$ & & .088 & \\
\hline & & & & & & \\
\hline
\end{tabular}

Note. Cox and Snell $R^{2}=.013$. Nagelkerke $R^{2}=.036$.

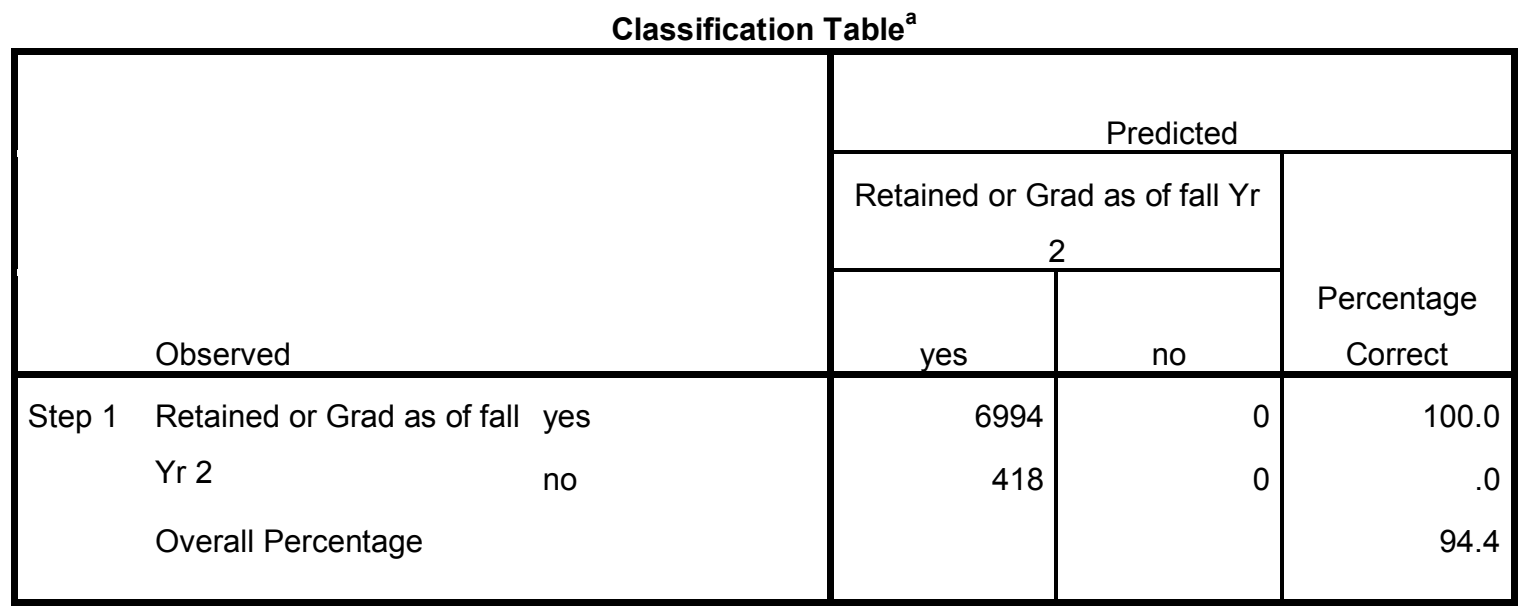

a. The cut value is .500 
Table 69

Results of Logistic Regression Analysis Examining the Relationship between Satisfaction Scores on Referral Non-Academic and Student Retention from Second to Third Year

\begin{tabular}{|c|c|c|c|c|c|c|}
\hline Predictor & B & (SE) & Wald's $\chi^{2}$ & (df) & $p$ & $e^{\beta}$ \\
\hline Constant & -2.537 & .170 & 222.111 & 1 & .000 & .079 \\
\hline $\begin{array}{l}\text { Referral Non- } \\
\text { Academic }\end{array}$ & -.036 & .037 & .918 & 1 & .338 & .965 \\
\hline African American & -.058 & .468 & .015 & 1 & .901 & .944 \\
\hline Asian American & .034 & .163 & .045 & 1 & .833 & 1.035 \\
\hline Hispanic & -.217 & .224 & .938 & 1 & .333 & .805 \\
\hline Multiple Ethnic & -1.111 & .719 & 2.386 & 1 & .122 & .329 \\
\hline Native American & -.782 & .722 & 1.172 & 1 & .279 & .458 \\
\hline Financial Need & .116 & .118 & .970 & 1 & .325 & 1.123 \\
\hline Gender & .006 & .108 & .004 & 1 & .953 & 1.006 \\
\hline Private & -1.644 & .226 & 52.725 & 1 & .000 & .193 \\
\hline First Gen No BA & .121 & .112 & 1.181 & 1 & .277 & 1.129 \\
\hline \multirow{2}{*}{$\begin{array}{l}\text { Test } \\
\text { Overall model } \\
\text { evaluation }\end{array}$} & & & $\chi^{2}(d f)$ & & $p$ & \\
\hline & & & & & & \\
\hline $\begin{array}{l}\text { Likelihood ratio } \\
\text { test }\end{array}$ & & & $96.702(10)$ & & .000 & \\
\hline \multicolumn{7}{|l|}{ Goodness-of-fit } \\
\hline $\begin{array}{l}\text { Hosmer \& } \\
\text { Lemeshow }\end{array}$ & & & $5.689(8)$ & & .682 & \\
\hline & & & & & & \\
\hline
\end{tabular}

Note. Cox and Snell $R^{2}=.013$. Nagelkerke $R^{2}=.037$.

Classification Table ${ }^{a}$

\begin{tabular}{|c|c|c|c|c|}
\hline & & \multicolumn{3}{|c|}{ Predicted } \\
\hline \multirow{2}{*}{\multicolumn{2}{|c|}{ Observed }} & \multicolumn{2}{|c|}{$\begin{array}{l}\text { Retained or Grad as of fall } \mathrm{Yr} \\
22 \\
\end{array}$} & \multirow{2}{*}{$\begin{array}{l}\text { Percentage } \\
\text { Correct }\end{array}$} \\
\hline & & yes & no & \\
\hline \multirow[t]{3}{*}{ Step 1} & Retained or Grad as of fall yes & 6895 & 0 & 100.0 \\
\hline & Yr 2 no & 418 & 0 & .0 \\
\hline & Overall Percentage & & & 94.3 \\
\hline
\end{tabular}


Table 70

Results of Logistic Regression Analysis Examining the Relationship between Satisfaction Scores on How Things Work Connect and Student Retention from Second to Third Year

\begin{tabular}{|c|c|c|c|c|c|c|}
\hline Predictor & $\mathrm{B}$ & $(\mathrm{SE})$ & Wald's $\chi^{2}$ & (df) & $p$ & $e^{\beta}$ \\
\hline Constant & -2.622 & .166 & 247.912 & 1 & .000 & .073 \\
\hline $\begin{array}{l}\text { How Things Work } \\
\text { Connect }\end{array}$ & -.023 & .036 & .409 & 1 & .522 & .977 \\
\hline African American & -.001 & .468 & .000 & 1 & .998 & .999 \\
\hline Asian American & .062 & .163 & .145 & 1 & .703 & 1.064 \\
\hline Hispanic & -.199 & .224 & .793 & 1 & .373 & .819 \\
\hline Multiple Ethnic & -1.086 & .719 & 2.280 & 1 & .131 & .338 \\
\hline Native American & -1.438 & 1.011 & 2.025 & 1 & .155 & .237 \\
\hline Financial Need & .109 & .119 & .840 & 1 & .359 & 1.115 \\
\hline Gender & .014 & .108 & .016 & 1 & .899 & 1.014 \\
\hline Private & -1.624 & .227 & 51.366 & 1 & .000 & .197 \\
\hline First Gen No BA & .132 & .112 & 1.382 & 1 & .240 & 1.141 \\
\hline \multirow{2}{*}{$\begin{array}{l}\text { Test } \\
\text { Overall model } \\
\text { evaluation }\end{array}$} & & & $\chi^{2}(d f)$ & & $p$ & \\
\hline & & & & & & \\
\hline $\begin{array}{l}\text { Likelihood ratio } \\
\text { test }\end{array}$ & & & $95.325(10)$ & & .000 & \\
\hline \multicolumn{7}{|l|}{ Goodness-of-fit } \\
\hline $\begin{array}{l}\text { Hosmer \& } \\
\text { Lemeshow }\end{array}$ & & & $3.871(8)$ & & .869 & \\
\hline & & & & & & \\
\hline
\end{tabular}

Note. Cox and Snell $R^{2}=.013$. Nagelkerke $R^{2}=.037$.

\section{Classification Table ${ }^{a}$}

\begin{tabular}{|c|c|c|c|c|}
\hline & & \multicolumn{3}{|c|}{ Predicted } \\
\hline \multirow{2}{*}{\multicolumn{2}{|c|}{ Observed }} & \multicolumn{2}{|c|}{$\begin{array}{l}\text { Retained or Grad as of fall } \mathrm{Yr} \\
22\end{array}$} & \multirow{2}{*}{$\begin{array}{l}\text { Percentage } \\
\text { Correct }\end{array}$} \\
\hline & & yes & no & \\
\hline \multirow[t]{3}{*}{ Step 1} & Retained or Grad as of fall yes & 6979 & 0 & 100.0 \\
\hline & Yr 2 & 412 & 0 & .0 \\
\hline & Overall Percentage & & & 94.4 \\
\hline
\end{tabular}

a. The cut value is .500 
Table 71

Results of Logistic Regression Analysis Examining the Relationship between Satisfaction Scores on Accurate Information and Student Retention from Second to Third Year

\begin{tabular}{|c|c|c|c|c|c|c|}
\hline Predictor & $\mathrm{B}$ & $(\mathrm{SE})$ & Wald's $\chi^{2}$ & $(\mathrm{df})$ & $p$ & $e^{\beta}$ \\
\hline Constant & -2.798 & .186 & 226.263 & 1 & .000 & .061 \\
\hline Accurate Info & .019 & .036 & .277 & 1 & .598 & 1.019 \\
\hline African American & -.010 & .468 & .000 & 1 & .983 & .990 \\
\hline Asian American & .069 & .163 & .179 & 1 & .672 & 1.071 \\
\hline Hispanic & -.210 & .224 & .882 & 1 & .348 & .811 \\
\hline Multiple Ethnic & -1.094 & .719 & 2.316 & 1 & .128 & .335 \\
\hline Native American & -1.418 & 1.011 & 1.968 & 1 & .161 & .242 \\
\hline Financial Need & .115 & .118 & .939 & 1 & .333 & 1.122 \\
\hline Gender & .028 & .108 & .069 & 1 & .793 & 1.029 \\
\hline Private & -1.640 & .227 & 52.330 & 1 & .000 & .194 \\
\hline First Gen No BA & .115 & .112 & 1.048 & 1 & .306 & 1.122 \\
\hline \multirow{2}{*}{$\begin{array}{l}\text { Test } \\
\text { Overall model } \\
\text { evaluation }\end{array}$} & & & $\chi^{2}(d f)$ & & $p$ & \\
\hline & & & & & & \\
\hline $\begin{array}{l}\text { Likelihood ratio } \\
\text { test }\end{array}$ & & & $95.712(10)$ & & .000 & \\
\hline \multicolumn{7}{|l|}{ Goodness-of-fit } \\
\hline $\begin{array}{l}\text { Hosmer \& } \\
\text { Lemeshow }\end{array}$ & & & $8.365(8)$ & & .399 & \\
\hline
\end{tabular}

Note. Cox and Snell $R^{2}=.013$. Nagelkerke $R^{2}=.037$.

Classification Table ${ }^{\mathrm{a}}$

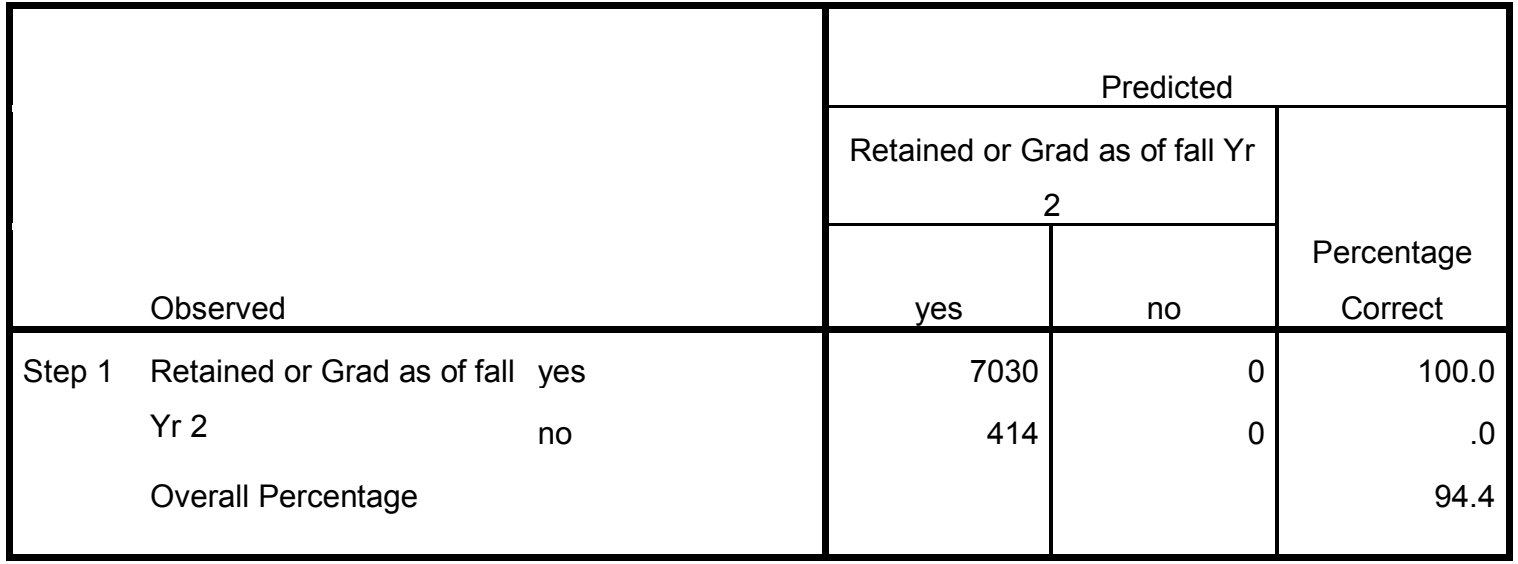

a. The cut value is .500 
Table 72

Results of Logistic Regression Analysis Examining the Relationship between Satisfaction Scores on Skills Abilities Interests and Student Retention from Second to Third Year

\begin{tabular}{|l|c|c|c|c|c|c|}
\hline Predictor & $\mathrm{B}$ & $(\mathrm{SE})$ & Wald's $\chi^{2}$ & $(\mathrm{df})$ & $p$ & $e^{\beta}$ \\
\hline Constant & -2.632 & .170 & 239.449 & 1 & .000 & .072 \\
\hline $\begin{array}{l}\text { Skills Abilities } \\
\text { Interests }\end{array}$ & -.018 & .036 & .254 & 1 & .614 & .982 \\
\hline African American & -.016 & .468 & .001 & 1 & .973 & .984 \\
\hline Asian American & .065 & .163 & .158 & 1 & .691 & 1.067 \\
\hline Hispanic & -.198 & .224 & .783 & 1 & .376 & .820 \\
\hline Multiple Ethnic & -1.086 & .719 & 2.282 & 1 & .131 & .337 \\
\hline Native American & -1.432 & 1.011 & 2.006 & 1 & .157 & .239 \\
\hline Financial Need & .107 & .119 & .811 & 1 & .368 & 1.113 \\
\hline Gender & .016 & .108 & .022 & 1 & .881 & 1.016 \\
\hline Private & -1.627 & .227 & 51.577 & 1 & .000 & .196 \\
\hline First Gen No BA & .124 & .112 & 1.220 & 1 & .269 & 1.132 \\
\hline $\begin{array}{l}\text { Test } \\
\text { Overall model } \\
\text { evaluation }\end{array}$ & & & $\chi^{2}(d f)$ & & $p$ & \\
\hline $\begin{array}{c}\text { Likelihood ratio } \\
\text { test }\end{array}$ & & & $95.308(10)$ & & .000 & \\
\hline Goodness-of-fit & & & $6.506(8)$ & & .591 & \\
\hline $\begin{array}{l}\text { Hosmer \& } \\
\text { Lemeshow }\end{array}$ & & & & & & \\
\hline
\end{tabular}

Note. Cox and Snell $R^{2}=.013$. Nagelkerke $R^{2}=.037$.

\section{Classification Table ${ }^{a}$}

\begin{tabular}{|c|c|c|c|c|}
\hline & & \multicolumn{3}{|c|}{ Predicted } \\
\hline \multirow{2}{*}{\multicolumn{2}{|c|}{ Observed }} & \multicolumn{2}{|c|}{$\begin{array}{l}\text { Retained or Grad as of fall } \mathrm{Yr} \\
22\end{array}$} & \multirow{2}{*}{$\begin{array}{l}\text { Percentage } \\
\text { Correct }\end{array}$} \\
\hline & & yes & no & \\
\hline Step 1 & Retained or Grad as of fall yes & 6965 & 0 & 100.0 \\
\hline & Yr 2 & 413 & 0 & .0 \\
\hline & Overall Percentage & & & 94.4 \\
\hline
\end{tabular}

a. The cut value is .500 
Table 73

Results of Logistic Regression Analysis Examining the Relationship between Satisfaction Scores on Know as Individual and Student Retention from Second to Third Year

\begin{tabular}{|c|c|c|c|c|c|c|}
\hline Predictor & $\mathrm{B}$ & (SE) & Wald's $\chi^{2}$ & (df) & $p$ & $e^{\beta}$ \\
\hline Constant & -2.502 & .153 & 267.997 & 1 & .000 & .082 \\
\hline $\begin{array}{l}\text { Know as } \\
\text { Individual }\end{array}$ & -.059 & .032 & 3.347 & 1 & .067 & .943 \\
\hline African American & -.014 & .468 & .001 & 1 & .976 & .986 \\
\hline Asian American & .082 & .163 & .252 & 1 & .615 & 1.085 \\
\hline Hispanic & -.194 & .224 & .754 & 1 & .385 & .823 \\
\hline Multiple Ethnic & -1.097 & .719 & 2.326 & 1 & .127 & .334 \\
\hline Native American & -1.441 & 1.011 & 2.032 & 1 & .154 & .237 \\
\hline Financial Need & .126 & .119 & 1.123 & 1 & .289 & 1.134 \\
\hline Gender & .025 & .109 & .054 & 1 & .817 & 1.025 \\
\hline Private & -1.658 & .232 & 51.013 & 1 & .000 & .191 \\
\hline First Gen No BA & .126 & .112 & 1.264 & 1 & .261 & 1.135 \\
\hline \multirow{2}{*}{$\begin{array}{l}\text { Test } \\
\text { Overall model } \\
\text { evaluation }\end{array}$} & & & $\chi^{2}(d f)$ & & $p$ & \\
\hline & & & & & & \\
\hline $\begin{array}{l}\text { Likelihood ratio } \\
\text { test }\end{array}$ & & & $\begin{array}{l}102.427 \\
(10)\end{array}$ & & .000 & \\
\hline \multicolumn{7}{|l|}{ Goodness-of-fit } \\
\hline $\begin{array}{l}\text { Hosmer \& } \\
\text { Lemeshow }\end{array}$ & & & $16.753(8)$ & & .033 & \\
\hline & & & & & & \\
\hline
\end{tabular}

Note. Cox and Snell $R^{2}=.014$. Nagelkerke $R^{2}=.039$.

\section{Classification Table ${ }^{\mathrm{a}}$}

\begin{tabular}{|c|c|c|c|c|}
\hline & & \multicolumn{3}{|c|}{ Predicted } \\
\hline \multirow{2}{*}{\multicolumn{2}{|c|}{ Observed }} & \multicolumn{2}{|c|}{$\begin{array}{l}\text { Retained or Grad as of fall } \mathrm{Yr} \\
22\end{array}$} & \multirow{2}{*}{$\begin{array}{l}\text { Percentage } \\
\text { Correct }\end{array}$} \\
\hline & & yes & no & \\
\hline Step 1 & Retained or Grad as of fall yes & 6986 & 0 & 100.0 \\
\hline & Yr 2 & 412 & 0 & .0 \\
\hline & Overall Percentage & & & 94.4 \\
\hline
\end{tabular}

a. The cut value is .500 
Table 74

Results of Logistic Regression Analysis Examining the Relationship between Satisfaction Scores on Shared Responsibility and Student Retention from Second to Third Year

\begin{tabular}{|c|c|c|c|c|c|c|}
\hline Predictor & B & (SE) & Wald's $\chi^{2}$ & (df) & $p$ & $e^{\beta}$ \\
\hline Constant & -2.420 & .174 & 192.303 & 1 & .000 & .089 \\
\hline $\begin{array}{l}\text { Shared } \\
\text { Responsibility }\end{array}$ & -.076 & .037 & 4.131 & 1 & .042 & .927 \\
\hline African American & -.012 & .468 & .001 & 1 & .979 & .988 \\
\hline Asian American & .068 & .163 & .176 & 1 & .675 & 1.071 \\
\hline Hispanic & -.225 & .228 & .974 & 1 & .324 & .799 \\
\hline Multiple Ethnic & -1.083 & .719 & 2.268 & 1 & .132 & .339 \\
\hline Native American & -1.451 & 1.011 & 2.062 & 1 & .151 & .234 \\
\hline Financial Need & .128 & .119 & 1.154 & 1 & .283 & 1.136 \\
\hline Gender & .036 & .109 & .110 & 1 & .740 & 1.037 \\
\hline Private & -1.610 & .227 & 50.376 & 1 & .000 & .200 \\
\hline First Gen No BA & .112 & .113 & .996 & 1 & .318 & 1.119 \\
\hline \multirow{2}{*}{$\begin{array}{l}\text { Test } \\
\text { Overall model } \\
\text { evaluation }\end{array}$} & & & $\chi^{2}(d f)$ & & $p$ & \\
\hline & & & & & & \\
\hline $\begin{array}{l}\text { Likelihood ratio } \\
\text { test }\end{array}$ & & & $\begin{array}{l}99.407 \\
(10)\end{array}$ & & .000 & \\
\hline \multicolumn{7}{|l|}{ Goodness-of-fit } \\
\hline $\begin{array}{l}\text { Hosmer \& } \\
\text { Lemeshow }\end{array}$ & & & $13.070(8)$ & & .109 & \\
\hline & & & & & & \\
\hline
\end{tabular}

Note. Cox and Snell $R^{2}=.013$. Nagelkerke $R^{2}=.038$.

\section{Classification Table ${ }^{\mathrm{a}}$}

\begin{tabular}{|c|c|c|c|c|}
\hline & & \multicolumn{3}{|c|}{ Predicted } \\
\hline \multirow{2}{*}{\multicolumn{2}{|c|}{ Observed }} & \multicolumn{2}{|c|}{$\begin{array}{c}\text { Retained or Grad as of fall } \mathrm{Yr} \\
2\end{array}$} & \multirow{2}{*}{$\begin{array}{c}\text { Percentage } \\
\text { Correct }\end{array}$} \\
\hline & & yes & no & \\
\hline \multirow[t]{3}{*}{ Step 1} & Retained or Grad as of fall yes & 6928 & 0 & 100.0 \\
\hline & Yr 2 & 410 & 0 & .0 \\
\hline & Overall Percentage & & & 94.4 \\
\hline
\end{tabular}

a. The cut value is .500 
Learning Outcomes

Table 75

Results of Logistic Regression Analysis Examining the Relationship between Learning Outcome Knows Requirements and Student Retention from Second to Third Year

\begin{tabular}{|c|c|c|c|c|c|c|}
\hline Predictor & B & (SE) & Wald's $\chi^{2}$ & (df) & $p$ & $e^{\beta}$ \\
\hline Constant & 1.561 & .313 & 24.842 & 1 & .000 & 4.764 \\
\hline $\begin{array}{l}\text { Knows } \\
\text { Requirements }\end{array}$ & -.133 & .041 & 10.342 & 1 & .001 & .876 \\
\hline GPA Ins & -1.296 & .081 & 256.964 & 1 & .000 & .274 \\
\hline Size & .000 & .000 & 3.497 & 1 & .061 & 1.000 \\
\hline \multirow{2}{*}{$\begin{array}{l}\text { Test } \\
\text { Overall model } \\
\text { evaluation }\end{array}$} & & & $\chi^{2}(d f)$ & & $p$ & \\
\hline & & & & & & \\
\hline $\begin{array}{l}\text { Likelihood ratio } \\
\text { test }\end{array}$ & & & $\begin{array}{l}289.494 \\
(3)\end{array}$ & & .000 & \\
\hline \multicolumn{7}{|l|}{ Goodness-of-fit } \\
\hline $\begin{array}{l}\text { Hosmer \& } \\
\text { Lemeshow }\end{array}$ & & & $23.277(8)$ & & .003 & \\
\hline
\end{tabular}

Note. Cox and Snell $R^{2}=.036$. Nagelkerke $R^{2}=.102$.

\section{Classification Table ${ }^{\mathrm{a}}$}

\begin{tabular}{|c|c|c|c|c|}
\hline & & \multicolumn{3}{|c|}{ Predicted } \\
\hline \multirow{2}{*}{\multicolumn{2}{|c|}{ Observed }} & \multicolumn{2}{|c|}{$\begin{array}{l}\text { Retained or Grad as of fall } \mathrm{Yr} \\
2 \\
\end{array}$} & \multirow{2}{*}{$\begin{array}{l}\text { Percentage } \\
\text { Correct }\end{array}$} \\
\hline & & yes & no & \\
\hline Step 1 & Retained or Grad as of fall yes & 7401 & 4 & 99.9 \\
\hline & Yr 2 & 442 & 8 & 1.8 \\
\hline & Overall Percentage & & & 94.3 \\
\hline
\end{tabular}

a. The cut value is .500 
Table 76

Results of Logistic Regression Analysis Examining the Relationship between Learning Outcome Knows Resources and Student Retention from Second to Third Year

\begin{tabular}{|c|c|c|c|c|c|c|}
\hline Predictor & $\mathrm{B}$ & (SE) & Wald's $\chi^{2}$ & (df) & $p$ & $e^{\beta}$ \\
\hline Constant & 1.408 & .303 & 21.517 & 1 & .000 & 4.087 \\
\hline Knows Resources & -.103 & .036 & 8.412 & 1 & .004 & .902 \\
\hline GPA Ins & -1.311 & .081 & 263.694 & 1 & .000 & .270 \\
\hline Size & .000 & .000 & 2.940 & 1 & .086 & 1.000 \\
\hline \multirow{2}{*}{$\begin{array}{l}\text { Test } \\
\text { Overall model } \\
\text { evaluation }\end{array}$} & & & $\chi^{2}(d f)$ & & $p$ & \\
\hline & & & & & & \\
\hline $\begin{array}{l}\text { Likelihood ratio } \\
\text { test }\end{array}$ & & & $282.763(3)$ & & .000 & \\
\hline \multicolumn{7}{|l|}{ Goodness-of-fit } \\
\hline $\begin{array}{l}\text { Hosmer \& } \\
\text { Lemeshow }\end{array}$ & & & $19.699(8)$ & & .012 & \\
\hline & & & & & & \\
\hline
\end{tabular}

Note. Cox and Snell $R^{2}=.035$. Nagelkerke $R^{2}=.100$.

Classification Table ${ }^{a}$

\begin{tabular}{|c|c|c|c|c|}
\hline & & \multicolumn{3}{|c|}{ Predicted } \\
\hline \multirow{2}{*}{\multicolumn{2}{|c|}{ Observed }} & \multicolumn{2}{|c|}{$\begin{array}{l}\text { Retained or Grad as of fall } \mathrm{Yr} \\
2\end{array}$} & \multirow{2}{*}{$\begin{array}{c}\text { Percentage } \\
\text { Correct }\end{array}$} \\
\hline & & yes & no & \\
\hline \multirow[t]{3}{*}{ Step 1} & Retained or Grad as of fall yes & 7386 & 4 & 99.9 \\
\hline & Yr 2 & 443 & 6 & 1.3 \\
\hline & Overall Percentage & & & 94.3 \\
\hline
\end{tabular}

a. The cut value is .500 
Table 77

Results of Logistic Regression Analysis Examining the Relationship between Learning Outcome Understands How Things Work and Student Retention from Second to Third Year

\begin{tabular}{|c|c|c|c|c|c|c|}
\hline Predictor & B & (SE) & Wald's $\chi^{2}$ & (df) & $p$ & $e^{\beta}$ \\
\hline Constant & 1.414 & .310 & 20.791 & 1 & .000 & 4.114 \\
\hline $\begin{array}{l}\text { Understands How } \\
\text { Things Work }\end{array}$ & -.109 & .039 & 7.713 & 1 & .005 & .897 \\
\hline GPA Ins & -1.311 & .081 & 263.060 & 1 & .000 & .269 \\
\hline Size & .000 & .000 & 3.697 & 1 & .055 & 1.000 \\
\hline \multirow{2}{*}{$\begin{array}{l}\text { Test } \\
\text { Overall model } \\
\text { evaluation }\end{array}$} & & & $\chi^{2}(d f)$ & & $p$ & \\
\hline & & & & & & \\
\hline $\begin{array}{l}\text { Likelihood ratio } \\
\text { test }\end{array}$ & & & $284.148(3)$ & & .000 & \\
\hline \multicolumn{7}{|l|}{ Goodness-of-fit } \\
\hline $\begin{array}{l}\text { Hosmer \& } \\
\text { Lemeshow }\end{array}$ & & & $34.583(8)$ & & .000 & \\
\hline & & & & & & \\
\hline
\end{tabular}

Note. Cox and Snell $R^{2}=.036$. Nagelkerke $R^{2}=.100$.

\begin{tabular}{|c|c|c|c|c|}
\hline \multicolumn{5}{|c|}{ Classification Table ${ }^{a}$} \\
\hline \multirow{3}{*}{\multicolumn{2}{|c|}{ Observed }} & \multicolumn{3}{|c|}{ Predicted } \\
\hline & & \multicolumn{2}{|c|}{$\begin{array}{c}\text { Retained or Grad as of fall } \mathrm{Yr} \\
2 \\
\end{array}$} & \multirow{2}{*}{$\begin{array}{c}\text { Percentage } \\
\text { Correct }\end{array}$} \\
\hline & & yes & no & \\
\hline \multirow[t]{3}{*}{ Step 1} & Retained or Grad as of fall yes & 7397 & 5 & 99.9 \\
\hline & Yr 2 & 441 & 6 & 1.3 \\
\hline & Overall Percentage & & & 94.3 \\
\hline
\end{tabular}

a. The cut value is .500 
Table 78

Results of Logistic Regression Analysis Examining the Relationship between Learning Outcome Understands Connections and Student Retention from Second to Third Year

\begin{tabular}{|c|c|c|c|c|c|c|}
\hline Predictor & B & (SE) & Wald's $\chi^{2}$ & (df) & $p$ & $e^{\beta}$ \\
\hline Constant & 1.420 & .326 & 19.038 & 1 & .000 & 4.139 \\
\hline $\begin{array}{l}\text { Understands } \\
\text { Connections }\end{array}$ & -.093 & .043 & 4.738 & 1 & .030 & .911 \\
\hline GPA Ins & -1.314 & .081 & 265.810 & 1 & .000 & .269 \\
\hline Size & .000 & .000 & 3.134 & 1 & .077 & 1.000 \\
\hline \multirow{2}{*}{$\begin{array}{l}\text { Test } \\
\text { Overall model } \\
\text { evaluation }\end{array}$} & & & $\chi^{2}(d f)$ & & $p$ & \\
\hline & & & & & & \\
\hline $\begin{array}{l}\text { Likelihood ratio } \\
\text { test }\end{array}$ & & & $283.965(3)$ & & .000 & \\
\hline \multicolumn{7}{|l|}{ Goodness-of-fit } \\
\hline $\begin{array}{l}\text { Hosmer \& } \\
\text { Lemeshow }\end{array}$ & & & $22.740(8)$ & & .004 & \\
\hline & & & & & & \\
\hline
\end{tabular}

Note. Cox and Snell $R^{2}=.036$. Nagelkerke $R^{2}=.100$.

Classification Table ${ }^{a}$

\begin{tabular}{|c|c|c|c|c|}
\hline & & \multicolumn{3}{|c|}{ Predicted } \\
\hline & & \multicolumn{2}{|c|}{$\begin{array}{l}\text { Retained or Grad as of fall } \mathrm{Yr} \\
2 \\
\end{array}$} & \multirow{2}{*}{$\begin{array}{c}\text { Percentage } \\
\text { Correct }\end{array}$} \\
\hline & Observed & yes & no & \\
\hline \multirow[t]{3}{*}{ Step 1} & Retained or Grad as of fall yes & 7370 & 5 & 99.9 \\
\hline & no & 444 & 6 & 1.3 \\
\hline & Overall Percentage & & & 94.3 \\
\hline
\end{tabular}

a. The cut value is .500 
Table 79

Results of Logistic Regression Analysis Examining the Relationship between Learning Outcome Has Educational Plan and Student Retention from Second to Third Year

\begin{tabular}{|c|c|c|c|c|c|c|}
\hline Predictor & $\mathrm{B}$ & (SE) & Wald's $\chi^{2}$ & (df) & $p$ & $e^{\beta}$ \\
\hline Constant & 1.292 & .349 & 13.672 & 1 & .000 & 3.640 \\
\hline $\begin{array}{l}\text { Has Educational } \\
\text { Plan }\end{array}$ & -.064 & .050 & 1.646 & 1 & .199 & .938 \\
\hline GPA Ins & -1.298 & .078 & 275.149 & 1 & .000 & .273 \\
\hline Size & .000 & .000 & 2.691 & 1 & .101 & 1.000 \\
\hline \multirow{2}{*}{$\begin{array}{l}\text { Test } \\
\text { Overall model } \\
\text { evaluation }\end{array}$} & & & $\chi^{2}(d f)$ & & $p$ & \\
\hline & & & & & & \\
\hline $\begin{array}{l}\text { Likelihood ratio } \\
\text { test }\end{array}$ & & & $290.624(3)$ & & .000 & \\
\hline \multicolumn{7}{|l|}{ Goodness-of-fit } \\
\hline $\begin{array}{l}\text { Hosmer \& } \\
\text { Lemeshow }\end{array}$ & & & $29.382(8)$ & & .000 & \\
\hline & & & & & & \\
\hline
\end{tabular}

Note. Cox and Snell $R^{2}=.035$. Nagelkerke $R^{2}=.097$.

Classification Table ${ }^{a}$

\begin{tabular}{|c|c|c|c|c|}
\hline & & \multicolumn{3}{|c|}{ Predicted } \\
\hline \multirow{2}{*}{\multicolumn{2}{|c|}{ Observed }} & \multicolumn{2}{|c|}{$\begin{array}{l}\text { Retained or Grad as of fall } \mathrm{Yr} \\
2\end{array}$} & \multirow{2}{*}{$\begin{array}{c}\text { Percentage } \\
\text { Correct }\end{array}$} \\
\hline & & yes & no & \\
\hline \multirow[t]{3}{*}{ Step 1} & Retained or Grad as of fall yes & 7704 & 4 & 99.9 \\
\hline & Yr 2 & 470 & 7 & 1.5 \\
\hline & Overall Percentage & & & 94.2 \\
\hline
\end{tabular}

a. The cut value is .500 
Table 80

Results of Logistic Regression Analysis Examining the Relationship between Learning Outcome Has Significant Relationship and Student Retention from Second to Third Year

\begin{tabular}{|c|c|c|c|c|c|c|}
\hline Predictor & B & (SE) & Wald's $\chi^{2}$ & (df) & $p$ & $e^{\beta}$ \\
\hline Constant & 1.291 & .279 & 21.413 & 1 & .000 & 3.635 \\
\hline $\begin{array}{l}\text { Has Significant } \\
\text { Relationship }\end{array}$ & -.094 & .031 & 8.992 & 1 & .003 & .910 \\
\hline GPA Ins & -1.269 & .079 & 261.166 & 1 & .000 & .281 \\
\hline Size & .000 & .000 & 1.839 & 1 & .175 & 1.000 \\
\hline \multirow{2}{*}{$\begin{array}{l}\text { Test } \\
\text { Overall model } \\
\text { evaluation }\end{array}$} & & & $\chi^{2}(d f)$ & & $p$ & \\
\hline & & & & & & \\
\hline $\begin{array}{l}\text { Likelihood ratio } \\
\text { test }\end{array}$ & & & $289.382(3)$ & & .000 & \\
\hline \multicolumn{7}{|l|}{ Goodness-of-fit } \\
\hline $\begin{array}{l}\text { Hosmer \& } \\
\text { Lemeshow }\end{array}$ & & & $20.478(8)$ & & .009 & \\
\hline & & & & & & \\
\hline
\end{tabular}

Note. Cox and Snell $R^{2}=.035$. Nagelkerke $R^{2}=.097$.

Classification Table ${ }^{a}$

\begin{tabular}{|c|c|c|c|c|}
\hline & & \multicolumn{3}{|c|}{ Predicted } \\
\hline & & \multicolumn{2}{|c|}{$\begin{array}{l}\text { Retained or Grad as of fall } \mathrm{Yr} \\
2\end{array}$} & \multirow{2}{*}{$\begin{array}{l}\text { Percentage } \\
\text { Correct }\end{array}$} \\
\hline & Observed & yes & no & \\
\hline \multirow[t]{3}{*}{ Step 1} & Retained or Grad as of fall yes & 7704 & 3 & 100.0 \\
\hline & no & 467 & 7 & 1.5 \\
\hline & Overall Percentage & & & 94.3 \\
\hline
\end{tabular}

a. The cut value is .500 
Table 81

Results of Logistic Regression Analysis Examining the Relationship between Learning Outcome Values Advisor-Advisee Relationship and Student Retention from Second to Third Year

\begin{tabular}{|c|c|c|c|c|c|c|}
\hline Predictor & $\mathrm{B}$ & (SE) & Wald's $\chi^{2}$ & (df) & $p$ & $e^{\beta}$ \\
\hline Constant & 1.440 & .346 & 17.353 & 1 & .000 & 4.220 \\
\hline $\begin{array}{l}\text { Values Advisor- } \\
\text { Advisee } \\
\text { Relationship }\end{array}$ & -.088 & .045 & 3.819 & 1 & .051 & .916 \\
\hline GPA Ins & -1.321 & .081 & 269.084 & 1 & .000 & .267 \\
\hline Size & .000 & .000 & 2.846 & 1 & .092 & 1.000 \\
\hline Test & & & $\chi^{2}(d f)$ & & $p$ & \\
\hline $\begin{array}{l}\text { Overall model } \\
\text { evaluation }\end{array}$ & & & & & & \\
\hline $\begin{array}{l}\text { Likelihood ratio } \\
\text { test }\end{array}$ & & & $283.905(3)$ & & .000 & \\
\hline Goodness-of-fit & & & & & & \\
\hline $\begin{array}{l}\text { Hosmer \& } \\
\text { Lemeshow }\end{array}$ & & & $20.116(8)$ & & .010 & \\
\hline
\end{tabular}

Note. Cox and Snell $R^{2}=.035$. Nagelkerke $R^{2}=.100$.

Classification Table ${ }^{a}$

\begin{tabular}{|c|c|c|c|c|}
\hline & & \multicolumn{3}{|c|}{ Predicted } \\
\hline & & \multicolumn{2}{|c|}{$\begin{array}{l}\text { Retained or Grad as of fall } \mathrm{Yr} \\
2\end{array}$} & \multirow{2}{*}{$\begin{array}{l}\text { Percentage } \\
\text { Correct }\end{array}$} \\
\hline & Observed & yes & no & \\
\hline \multirow[t]{3}{*}{ Step 1} & Retained or Grad as of fall yes & 7406 & 4 & 99.9 \\
\hline & no & 444 & 6 & 1.3 \\
\hline & Overall Percentage & & & 94.3 \\
\hline
\end{tabular}

a. The cut value is .500 